\title{
ESSAYS ON MONETARY ECONOMICS
}

\section{BY DEMET TUNALI}

\author{
A dissertation submitted to the \\ Graduate School-New Brunswick \\ Rutgers, The State University of New Jersey \\ in partial fulfillment of the requirements \\ for the degree of \\ Doctor of Philosophy \\ Graduate Program in Economics \\ Written under the direction of \\ Roberto Chang and Norman Rasmus Swanson \\ and approved by
}

New Brunswick, New Jersey

January, 2012 
(c) 2012

Demet Tunali

\section{ALL RIGHTS RESERVED}




\section{ABSTRACT OF THE DISSERTATION}

\section{Essays on Monetary Economics}

\section{by Demet Tunali \\ Dissertation Director: Roberto Chang and Norman Rasmus Swanson}

In my dissertation, I attempt to shed new light on the impact of central bank behavior. The first chapter proposes indexes of monetary policy design characteristics in line with inflation targeting (IT). Indexes aim to provide a useful classification of central banks and to examine whether IT intensity matters for sacrifice ratio and inflation persistence. Results show that U.S. and Japan are ranked close to early targeters. Armenian central bank is detected to perform remarkably well as opposed to the literature's descriptions. Noteworthy structural changes are noticed in Mexico and Peru. Higher index level significantly reduces OECD countries' inflation persistence through increased transparency. Higher intensity among targeters does not deliver significantly lower sacrifice ratio or inflation persistence. Announcing official targets does not provide additional benefits. Low degree of central bank discretion and limited financing of the government significantly decrease the sacrifice ratio among OECD countries and in the full crosssectional sample respectively. Institutional design features need to be mature enough in order to benefit from inflation targeting. The second chapter examines the usefulness of monetary aggregates. A number of dynamic stochastic general equilibrium models (DSGE) and econometric time series models are jointly specified; including vector autoregressive (VAR), random walk (RW), and various autoregressive (AR) and AR with exogenous variable type models (ARX). Model performance is evaluated via novel testing methods developed for assessing predictive and simulation accuracy. Money is found to matter for inflation simulation purposes in simple econometric models, such as ARX models. With regard to predictive point and density analysis, when complex models are examined, M2 enters into the forecast-best VAR-type inflation models. Model selection is found to be sensitive to researchers objective function, to target 
variable and forecast horizon. Particularly, when the objective is policy analysis, the examination of multivariate models show that DSGE-type models often outperform at longer horizons and mainly for output forecasts. In contrast, VAR-type models win for simulation purposes and short-horizon inflation forecasts. However, univariate models without money generally dominate theoretical and atheoretical multivariate models both with and without money from both forecasting and simulation standpoint. 


\section{Acknowledgements}

I gratefully and sincerely thank my co-advisors, Roberto Chang and Norman R. Swanson, and my committee members, John Landon-Lane and Filippo Occhino. I am highly indebted to my co-advisors for their dedicated guidance. Their encouragements and understanding helped me overcome many crisis situations. I wouldn't also be able to appreciate the excitement of an research career without their support to meet researchers in my field at World Bank, IMF and at various conferences. My committee members have always been there to listen and give advice. Their insights proved so valuable for the progress of my research.

I would also like to express my gratitude to Professor Klein and Dr. Lee for the long discussions that helped me sort out technical problems of my work. I am particularly thankful for those yellow notebook papers on which Professor Klein patiently and very neatly wrote down every detail of his answers to my econometric questions.

I can't thank enough Dorothy Rinaldi for her presence and graceful help from the very first day I walked in the NJ Hall.

I am also happy to have my friends Noha, Oylum and Sumianetra to share my stressful but enriching graduate experience at Rutgers.

Finally, I would like to thank my husband for sacrificing his weekends and holidays. To my parents and my sister, thank you for your endless support. 


\section{Dedication}

I dedicate this dissertation to my understanding and patient husband, Haluk, for his unconditional support during these many years of research and to our precious son, Arda, for the joy he brought to our life. I am also grateful to my dearest Mother, Gulcin, dearest Father, Huseyin, and dearest Sister, Serap, for their love, guidance and encouragement. I must also thank my in-laws who have helped so much with baby-sitting and have given me their fullest support. 


\section{Table of Contents}

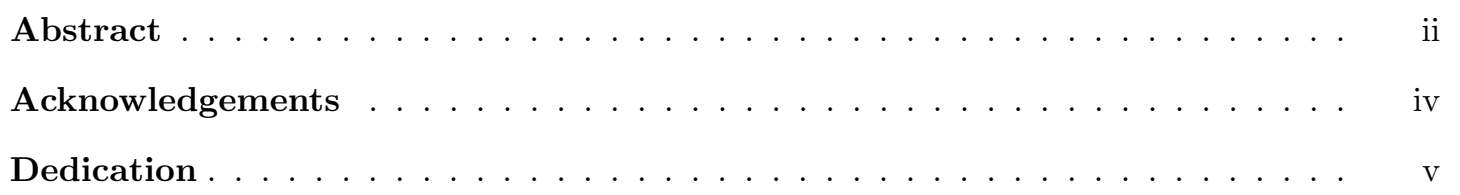

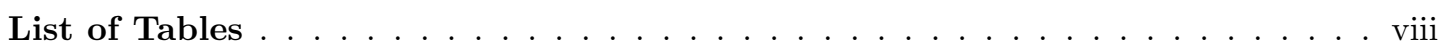

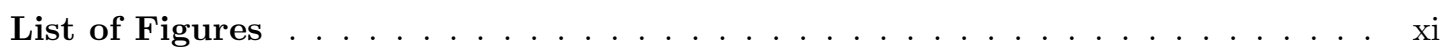

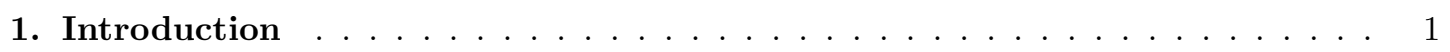

2. Revisiting the Role of Monetary Aggregates in U.S. . . . . . . . . . . . . 5

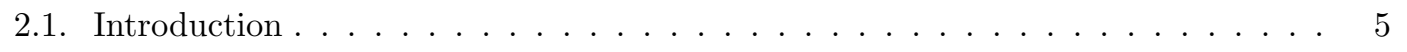

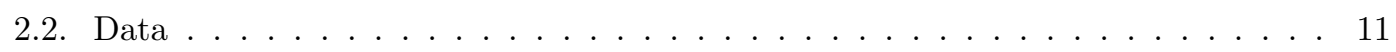

2.3. Models . . . . . . . . . . . . . . . . . . . . . . 11

2.4. Methodology . . . . . . . . . . . . . . . . . . 17

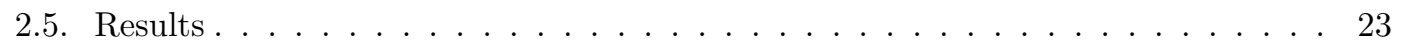

2.6. Concluding Remarks . . . . . . . . . . . . . . . . . 34

3. Inflation Targeting Intensity $\ldots \ldots \ldots \ldots \ldots \ldots$

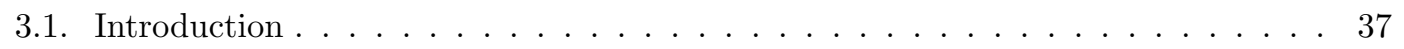

3.2. Monetary Policy Design Indexes _ . . . . . . . . . . . . . . . . . . 42

3.3. Sacrifice Ratio and Inflation Persistence Analysis . . . . . . . . . . . . . . 54

3.4. Concluding Remarks . . . . . . . . . . . . . . . . . . . 66

Appendix A. Tables of Chapter $2 \ldots \ldots \ldots \ldots$

Appendix B. Tables of Chapter $3 \ldots \ldots \ldots \ldots$

Appendix C. Figures of Chapter $2 \ldots \ldots \ldots 7 \ldots$

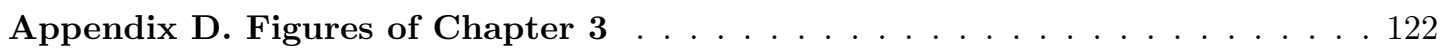




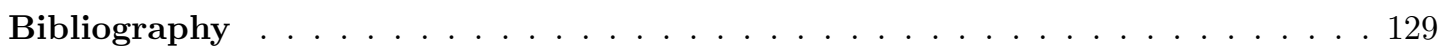

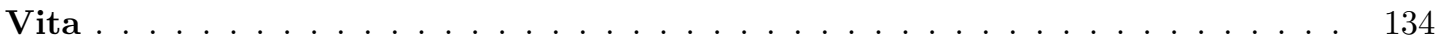




\section{List of Tables}

A.1. Parameter Estimates, DSGE models . . . . . . . . . . . . . . . . . . . . 69

A.2. Parameter Estimates, Strawman Models for Output . . . . . . . . . . . . . 70

A.3. Parameter Estimates, Strawman Models for Inflation . . . . . . . . . . . . 70

A.4. Parameter Estimates, VAR(p) Model Without Money . . . . . . . . . . . . . . 71

A.5. Parameter Estimates, VAR(p) Model With Money . . . . . . . . . . . . . . . 71

A.6. Mean Square Forecast Errors for Various Models - Inflation . . . . . . . . . . . . 72

A.7. Mean Square Forecast Errors for Various Models - Output . . . . . . . . . . . 73

A.8. CS Distributional Loss Measure for Various Models, Forecasted Series - Inflation 74

A.9. CS Distributional Loss Measure for Various Models, Forecasted Series - Output 75

A.10.CS Distributional Loss Measure, Simulated Series _ . . . . . . . . . . . 76

A.11.Distributional Accuracy Test, Forecasted Series / Benchmark Model: Threevariable VAR model - Alternative Models: Four-variable VAR and DSGE models 77

A.12.Distributional Accuracy Test, Forecasted Series / Benchmark Model: Threevariable VAR model - Alternative Models: Strawman models . . . . . . . . . . . 78

A.13.Confidence Interval Test, Forecasted Series / Est. Period: 1983Q1 - 2009Q4 Benchmark Model: Three-variable VAR model - Alternative Models: Four-variable VAR and DSGE models . . . . . . . . . . . . . . . . . . . . . . 79

A.14.Confidence Interval Test, Forecasted Series / Est. Period: 1960Q1 - 2009Q4 Benchmark Model: Three-variable VAR model - Alternative Models: Four-variable VAR and DSGE models . . . . . . . . . . . . . . . . . 80

A.15.Confidence Interval Test, Forecasted Series / Est. Period: 1983Q1 - 2009Q4 Benchmark Model: Three-variable VAR model - Alternative Models: Strawman Models . . . . . . . . . . . . . . . . . . . . . . . 81

A.16.Confidence Interval Test, Forecasted Series / Est. Period: 1960Q1 - 2009Q4 Benchmark Model: Three-variable VAR model - Alternative Models: Strawman Models ............................... 82 
A.17.Distributional Accuracy Test, Simulated Series / Benchmark Model: Threevariable VAR model - Alternative Models: Four-variable VAR and DSGE models 83

A.18.Distributional Accuracy Test, Simulated Series / Benchmark Model: Threevariable VAR model - Alternative Models: Strawman models . . . . . . . . . . . 84

A.19.Confidence Interval Test, Simulated Inflation / Benchmark Model: Three-variable VAR model - Alternative Models: Four-variable VAR and DSGE models . . . . 85

A.20.Confidence Interval Test, Simulated Output / Benchmark Model: Three-variable VAR model - Alternative Models: Four-variable VAR and DSGE models . . . . 86

A.21.Confidence Interval Test, Simulated Inflation / Benchmark Model: Three-variable VAR model - Alternative Models: Strawman Models . . . . . . . . . . . . . . 86

A.22.Confidence Interval Test, Simulated Output / Benchmark Model: Three-variable VAR model - Alternative Models: Strawman models . . . . . . . . . . . . . . . 87

A.23.Predictive Accuray Test, Forecasted Series / Benchmark Model: Three-variable VAR model - Alternative Models: Four-variable VAR and DSGE models . . . . . 88 A.24.Predictive Accuray Test, Forecasted Series / Benchmark Model: Three-variable VAR model - Alternative Models: Strwaman models . . . . . . . . . . . . . . . . 89

B.1. The Weighing Scheme . . . . . . . . . . . . . . . . . . 90

B.2. Descriptive Statistics of Monetary Policy Design Features . . . . . . . . . . . . 91

B.3. Monetary Policy Design Indices - Correlation Coefficients (\%) _ . . . . . . . . . 92

B.4. Average Index Value by Group of Countries . . . . . . . . . . . . . . . . . . 92

B.5. Inflation Targeting Index Scores . . . . . . . . . . . . . . . . . . . 92

B.6. Descriptive Statistics - Average Sacrifice Ratio and Inflation Persistence Statistics 96

B.7. Sacrifice Ratio Statistics by Groups . . . . . . . . . . . . . . . . . . . . . . 97

B.8. Inflation Persistence Statistics by Groups . . . . . . . . . . . . . . . . . 97

B.9. Estimates for the Impact of Inflation Targeting Indexes on Sacrifice Ratio . . . . 97

B.10.Estimates for the Impact of Inflation Targeting Indexes on Inflation Persistence . 99

B.11.Estimates for the Impact of Inflation Targeting Indexes on Sacrifice Ratio by Groups . . . . . . . . . . . . . . . . . . . . . . . . . . . . 100

B.12.Estimates for the Impact of Inflation Targeting Indexes on Inflation Persistence by Groups . . . . . . . . . . . . . . . . . . . . . . . 103

B.13.Estimates for the Impact of Individual Policy Design Characteristics . . . . . . . 104

B.14.Estimates for the Impact of the Change in Policy Design . . . . . . . . . . . . . 106

B.15.Factor Loadings . . . . . . . . . . . . . . . . . . . . . . . . . 106 
B.16. Discrete Choice Model on Underlying Factors . . . . . . . . . . . . . . . 106 


\section{List of Figures}

C.1. Impulse Response to Unanticipated Monetary Policy Shock . . . . . . . . . . . 107

C.2. Impulse Response to Unanticipated Technology Shock . . . . . . . . . . . . . 108

C.3. Historical and Forecasted Empirical Densities of Inflation Estimation Period: 1983Q1:2009Q4 - Forecasting period 1990Q1:1999Q4 … . . . . . . . . 109

C.4. Historical and Forecasted Empirical Densities of Inflation Estimation Period: 1983Q1:2009Q4 - Forecasting period 2000Q1:2009Q4 … . . . . . . . 110

C.5. Historical and Forecasted Empirical Densities of Inflation Estimation Period: 1983Q1:2009Q4 - Forecasting period 1990Q1:2009Q4 . . . . . . . . . . . 111

C.6. Historical and Forecasted Empirical Densities of Inflation Estimation Period: 1960Q1:2009Q4 - Forecasting period 1990Q1:1999Q4 . . . . . . . . . . . 112

C.7. Historical and Forecasted Empirical Densities of Inflation Estimation Period: 1960Q1:2009Q4 - Forecasting period 2000Q1:2009Q4 . . . . . . . . . . 113

C.8. Historical and Forecasted Empirical Densities of Inflation Estimation Period: 1960Q1:2009Q4 - Forecasting period 1990Q1:2009Q4 . . . . . . . . . . . . 114

C.9. Historical and Forecasted Empirical Densities of Output Estimation Period: 1983Q1:2009Q4 - Forecasting period 1990Q1:1999Q4 . . . . . . . . . . . . . . . 115

C.10.Historical and Forecasted Empirical Densities of Output Estimation Period: 1983Q1:2009Q4 - Forecasting period 2000Q1:2009Q4 . . . . . . . . . . . . . . 116

C.11.Historical and Forecasted Empirical Densities of Output Estimation Period: 1983Q1:2009Q4 - Forecasting period 1990Q1:2009Q4 . . . . . . . . . . . . . . 117

C.12.Historical and Forecasted Empirical Densities of Output Estimation Period: 1960Q1:2009Q4 - Forecasting period 1990Q1:1999Q4 . . . . . . . . . . . . . . 118

C.13.Historical and Forecasted Empirical Densities of Output Estimation Period: 1960Q1:2009Q4 - Forecasting period 2000Q1:2009Q4 . . . . . . . . . . . . . . . . 119

C.14.Historical and Forecasted Empirical Densities of Output Estimation Period: 1960Q1:2009Q4 - Forecasting period 1990Q1:2009Q4 . . . . . . . . . . . . . . 120

C.15.Historical and Simulated Empirical Densities of Inflation and Output . . . . . 121 
D.1. Monetary Policy Characteristics Inflation Targeting Countries . . . . . . . . . 123

D.2. Monetary Policy Characteristics Non-Inflation Targeting Countries . . . . . . . 124

D.3. Path of the Proxy for Monetary Policy Design . . . . . . . . . . . . . . . 125

D.4. Sacrifice Ratio and Inflation Persistence Statistics . . . . . . . . . . . . . . 126

D.5. $95 \%$ confidence interval for $\beta_{1,4} \ldots \ldots \ldots \ldots \ldots \ldots \ldots \ldots \ldots$

D.6. $95 \%$ confidence interval for $\alpha_{1,4} \ldots \ldots \ldots \ldots$. . . . . . . . . . . 128 


\section{Chapter 1 Introduction}

In this dissertation, I attempt to shed new light on the macroeconomic impact of central bank behavior. I do this in two ways. One aspect concerns the analysis of the underlying institutional structure of inflation targeting (IT) monetary policy regime. I contribute to the empirical literature by constructing for the first time sensible indexes of monetary policy design features. I apply these indexes to classify central banks and test several new hypotheses about its impact on two macroeconomic variables of interest. The other way concerns the effects associated with the use of specific monetary policy instruments on output and inflation simulations and forecasts. I revisit the argument about the redundancy of the monetary aggregates in the dynamics of the output and inflation. I contribute to the extant literature by jointly specifying general equilibrium models and time series models and applying novel model evaluation techniques developed for assessing predictive and simulation accuracy. I ask whether and through which model and transmission channel money matters.

The first study is titled Inflation Targeting Intensity. In this paper, I contribute to the empirical literature on inflation targeting by constructing indexes of monetary policy design for a broad range of countries. One purpose of the indexes is to measure how close central banks institutional characteristics are to that of an ideal inflation targeting framework. The second objective is to investigate whether the intensity of this regime matters for reaping potential macroeconomic benefits. I use the indexes to analyze the impact of IT intensity on the output cost of disinflation and on the inflation persistence.

Theoretical work on inflation targeting stresses the appeal of the regime for achieving heavily desired level of commitment alongside with constrained discretion. Considerable attention has also been devoted to the macroeconomic impact of this framework. Empirical studies control for the existence of inflation targeting through a simple dummy variable and deliver mixed results. More specifically empirical literature considers a central bank as inflation targeter based on de jure announcement of the regime. However a bivariate classification erodes heterogeneity regarding institutional arrangements among targeters and non-targeters alike. As such, U.S. and Japan are well known for their commitment to price stability and for their heavy use of 
inflation forecasts as guidance in monetary policy decisions. Yet their central banks hold out from announcing official targets. Bundesbank and Bank of Switzerland are mostly considered as implicitly pursuing a price stability goal in spite of explicit money growth rate targets. On the other hand, some de jure targeters are cited as failing to fully establish the characteristics associated with this regime, such as Korea and Peru. Therefore poor empirical findings may in part be because there is no substantial difference between these groups, or that those officially targeters may not be completely fulfilling the theoretical prerequisites. In my analysis, the impact of IT is for the first time assessed by directly measuring underlying monetary policy design features instead of solely accounting for its official announcement. This method enables the researcher to refrain from unduly praising or blaming the declaration of the regime. Introducing policy design characteristics also allows investigation of new hypotheses that are not addressed in the current literature.

The first part of the study calculates monetary policy design indexes. I use a comprehensive data set of 93 developed and developing countries based on a survey by the Central Bank of England conducted through the end of 1998. Several indexes are constructed aggregating those categories that are mentioned by the recognized definitions in the literature. Resulting index series vary between 0 and 100, where the highest score is associated with representative inflation targeter. The ranking of countries is then shown to in line with the descriptions provided in the literature. In the second part of this study, I analyze the cross sectional variation in the output cost of disinflation and inflation persistence. I both investigate the impact of the level of institutional design features and the extent of change undertaken to establish the inflation targeting regime.

Results indicate that higher intensity among targeters does not deliver significantly lower output cost of disinflation or inflation persistence. As for non-targeters, announcing official targets does not seem to provide additional benefit either. Among the OECD countries, inflation targeting intensity indexes significantly reduce inflation persistence. This result puts doubt on solely relying on the official announcement of IT. The significant impact on inflation persistence is found to work through increased transparency and reduced discretion. Meanwhile low degree of central bank discretion among OECD countries and limited financing of the government by the central bank in the full cross-sectional sample significantly reduce the inflation-output tradeoff. It is observed that institutional design features should be mature enough in order to benefit from a reconstructing towards inflation targeting. Finally, institutional reforms towards or under inflation targeting is not found to be significant.

In the second paper titled Revisiting the Role of Monetary Aggregates in the U.S., I address 
the argument about the redundancy of monetary aggregates for monetary policy. Recent models of monetary policy evaluation attach minimal role to monetary aggregates. Once a Taylor-type interest rate rule is introduced the equilibrium path of inflation, output and interest rate is determined without reference to a money market equation. The central bank in turn fully accommodates demanded quantity of money at given interest rate and output. Furthermore, on the empirical front, studies that undermine monetary aggregates mostly rely on reduced form VAR model estimation methods and Granger causality test.

In this study I investigate the usefulness of money in explaining the dynamics of output and inflation from a new perspective and testing approach. I add to the extant literature on this subject in two respects. First, I jointly specify a number of dynamic stochastic general equilibrium (DSGE) models and econometric time series models. Second, I evaluate the performance of these models via the use of novel testing methods developed for assessing predictive and simulation accuracy. The DSGE models evaluated include two baseline New Keynesian models. Models only differ in the specification of the monetary policy. In a simulated realtime "horse-race", these theoretical macroeconomic models are coupled with time series models including vector autoregression (VAR), random walk (RW), and various autoregressive (AR) and AR with exogenous variable (ARX) type models. The testing methods used involve the evaluation of out-of-sample point predictions and simulations as well as out-of-sample predictive and simulation type confidence intervals and conditional distributions. Particularly, I compare the empirical distribution of historical data with the marginal distribution of simulated series and the conditional distribution of forecasted series and the confidence interval thereof. I apply the testing approach suggested by Corradi and Swanson (2006a, 2007a). This approach allows for misspecification in competing models and is based on the distributional analog of the mean squared error. As for the pointwise accuracy of forecasted inflation and output, equal predictive accuracy is tested using the method by White (2000). This method compares multiple misspecified models using a loss function of prediction errors. Under both approaches the null hypothesis states that, no alternative model can deliver a better approximation to the true data than the benchmark model. I ask whether and through which model and transmission channel money matters. Meanwhile it is well known that DSGE models impose theoretical restrictions on VAR models. Therefore this study also sheds light to whether these restrictions are indeed necessary. Due to the widely recognized change in the U.S. monetary policy stance around 1980s, the analysis is conducted under two sample periods; including the period from 1960Q1 until 2009Q4 and from 1983Q1 to 2009Q4.

Main findings of this study are as follows. The study suggests new evidence for the usefulness 
of M2 money supply. I find that money matters for inflation simulations in the framework of simple econometric models through our ARX models in the post-1983 sample. However, money disappears as models get more complex. From the forecasting standpoint, among multivariate models, M2 monetary aggregate enters into the "forecast-best" VAR-type inflation models in our post-1960 sample. I also have several findings favoring marginal predictive content of money in the post-1983 sample, in contrast to the findings of single equation time series models. I also find that model selection is sensitive to the researcher's objective function, to target variable and forecast horizon. Particularly, when the objective is policy analysis, the examination of multivariate models show that DSGE-type models often outperform at longer horizons and mainly for output forecasts. In contrast, VAR-type models are winners for simulation purposes and short-horizon inflation forecasts. Meanwhile, from both forecasting and simulation standpoint univariate models generally dominate all theoretical and atheoretical multivariate models. Finally, impulse response analysis and findings from predictive and simulation analysis show that, results are in line with the post-war U.S. monetary policy stance. 


\section{Chapter 2 Revisiting the Role of Monetary Aggregates in U.S.}

\subsection{Introduction}

THE QUESTION of whether monetary aggregates can directly influence output and inflation is still subject to debate in academic literature. Latest models of monetary policy evaluation treat monetary aggregates as exogenous in the system of equations describing the economic environment. These models include money at best as providing utility to optimizing individuals; where the consumer's utility takes an additively separable form in real money balances and consumption. Central bank then fully accommodates demanded quantity of money at the given interest rate. The additional first order condition in these models only determine real money balances for given output and inflation. Thus, once a Taylor-type interest rate rule is introduced, the equilibrium path of inflation, output and interest rate is determined without reference to a money market equation. This strand of literature includes models in Woodford (2003b), Mc.Callum and Nelson (1999) and Rudebusch and Svensson (2002) among others. There are also studies that do not make any reference to money at all; for which we can name Rotemberg and Woodford (1998), Fuhrer and Moore (1995).

Meanwhile, results from the empirical front are opaque. Empirical literature can be grouped in three categories. One group of work mainly relies on F-tests in bivariate or multivariate reduced form VAR estimations and mean squared forecast error (MSFE) statistics. The second group's work draws on a more structural approach of identified VAR estimation. There is a limited work on the third group which analyzes DSGE models.

In the first category, studies by Bernanke (1986), Christiano and Ljungqvist (1988), Stock and Watson (1989), Feldstein and Stock (1993), Hafer and Kutan (1997), Swanson (1998), Meltzer (1999), Hoffman (2009) and Reynard (2009) provide evidence for the predictive power of monetary aggregates as opposed to the findings in Sims (1980), Litterman and Weiss (1985), Eichenbaum and Singleton (1986), Friedman and Kuttner (1992), Estrella and Mishkin (1997), Stock and Watson (1999), Amato and Swanson (2001) and Binner et al. (2010).

Sims (1980) study points out that, when the prime commercial paper rate is included to the 
three-variable vector autoregression equation of monthly money stock, prices and output, the role of M1 money stock innovations does not persist in the postwar period. In a four-variable VAR system, Litterman and Weiss (1985) examine monthly and quarterly U.S. data in the postwar era. Authors find that the real interest rate is exogenous to money and prices and that expected inflation has more predictive content for future output than the real or nominal interest rate and monetary aggregates. Eichenbaum and Singleton (1986) estimate several multivariate vector autoregressive models using monthly data. Authors use several measures of real interest rate and apply several stationarity assumptions. The hypothesis that real output is exogenous with respect to measures of inflation and money stock is not rejected. Friedman and Kuttner (1992) challenge the robustness of findings by Stock and Watson (1989) in two respects. First, the extension of the sample beyond 1990 makes money insignificant under Stock and Watson's specification. Secondly favorable findings vanish with the use of the commercial paper instead of the Treasury bill rate under the study's sample period ending in 1985. In the period from 1960 through 1995, Estrella and Mishkin (1997) test the strength and stability of the relationship among monetary aggregates, inflation and the nominal income. Authors also take into account two main adjustments to monetary aggregates; the time-variation in velocity and frequency decomposition of velocity. It is found that the three-variable VAR model fails to pass the Chow break test in October 1979. Additionally, monetary base and M2 money stock are insignificant for both nominal income and inflation for the latter part of the sample. Stock and Watson (1999), consider the twelve-month inflation forecasting using the U.S. monthly data from 1959:01 to 1997:09. They conclude that models that include money supply measures to a standard Phillips curve provide only marginal improvement for some subsamples and particularly cause deterioration for the 1970s and early 1980s. Amato and Swanson (2001) consider the issue of regular data revision in the period from 1959 through 1997. Granger-causality tests indicate that in-sample and out-of-sample predictive power of monetary aggregates evaporate under real-time data; albeit sustained useful information from M2 money supply at 1-year horizon out-of-sample forecast. Binner et al. (2010) investigate the forecasting ability of monetary aggregates for U.S. 6-month ahead annual inflation for the period from early to mid 2000s using a range of definitions for money. Authors apply recurrent neural networks and kernel recursive least squares regression techniques to obtain the best competing model against the benchmark random walk model. The non-linear autoregressive model for inflation is found to best fit U.S. inflation forecasts; as suggested by the latter technique.

Bernanke (1986) re-estimates Sims (1980) models in the period from 1954 to 1984 by adding a linear trend. He finds that the insignificance of money in terms of predictive power evaporates 
and that money shocks explain a significant portion of the forecast variance of output. Christiano and Ljungqvist (1988) study indicates that in a seven-lag bivariate VAR model between monthly log industrial production and log M1 money aggregate, in-sample granger causality from money to output is not rejected. Stock and Watson (1989) considers monthly U.S. data for the period 1960-85. They provide evidence that the quadratically detrended M1 money stock has statistically significant marginal predictive value for industrial production, both in a bivariate and in a multivariate model including three-month Treasury bill rate. Through an in-sample Granger causality test, Feldstein and Stock (1993) show that M2 monetary aggregate is a useful predictor of nominal GDP growth. This predictive power quantitatively improves over longer horizons and survives the inclusion of 90-day Treasury bill rate and Federal funds rate. Meanwhile, they also document that the predictive content of M2 money supply weakens over the period from 1970 to 1992. Hafer and Kutan (1997) findings underscore that the stationarity assumption on the data dramatically changes conclusions about the money-output relationship. Authors show that the failure in the explanatory power of money for output found in earlier studies evaporate when the data is assumed to be trend stationary as opposed to difference stationary. Swanson (1998) conducts out-of-sample Granger causality tests. As opposed to earlier studies, the author specifies the lag order with Schwarz and Akaike information Criteria and accounts for the long- run cointegrating relation among money, income, prices and interest rates. His findings suggest a marginal predictive content of money for income and are robust to measures of nominal interest rate. Meltzer (1999) focuses on deflation episodes in the U.S. economy; where it is possible to separate the importance of real interest rate effect from that of real balances in the monetary transmission process. Using several two-stage least square estimations, the author reports that aggregate consumption is strongly and statistically affected by changes in real M1 money supply and real money base after having controlled for real interest rate, income and stock prices. Hoffman (2009) analyzes out-of-sample predictive power of money growth for inflation in the Euro area from 1999Q1 to 2006Q3. He finds that controlling for persistent velocity shifts and using real-time data improves forecasting power of monetary aggregates. Using U.S. and Euro area data Reynard (2009) shows that misleading results from studies for inflation and money growth relation in the post-1980 period stems from ignoring the effect of velocity movements on money demand. Using a long-run money demand equation, the author restores proportional relationship between money growth and inflation and finds that causality runs from money growth to inflation. 
Among the second and third group of studies, findings by Favara and Giordani (2002), Ireland (Journal of Monetary Economics), Nelson (2002), Leeper and Roush (2003), AssenmacherWesche and Gerlach (2007), Andres et al. (2008) and Castelnuevo (2008) provide support for monetary aggregates. In the period from 1966 to 2001, Favara and Giordani (2002) find that shocks to monetary aggregates have persistent and strong effects on prices and output; with further prolonged responses as broader money definitions are used. Ireland (Journal of Monetary Economics) provides evidence for a causal role of money over real fluctuations. In an estimated DSGE model, the author shows that price stickiness on top of endogenous money is needed to successfully account for correlations in U.S. data between money stock and real variables in the postwar era. Nelson (2002) shows that the real monetary base is an important determinant of total output in U.S. Particularly, the author reports significant coefficients on growth of real base money in an estimation of extended IS equation. Additionally, Nelson (2002) analyzes a DSGE model where the long-term nominal interest rate is introduced to the money demand equation. Resulting theoretical impulse response functions display greater effect on aggregate demand from a shock to money growth. Leeper and Roush (2003) estimate several identified VAR models for the period from 1959:1 to 2001:6. They show that how money is introduced makes a difference for the identification of monetary shocks and in the responses to this shock. Particularly, they show that restricting the short-term policy rate to only respond to M2 money stock instead of current output and inflation improves the identification of exogenous monetary policy shocks and increases the size and persistence of output and price responses. Assenmacher-Wesche and Gerlach (2007) control for velocity effect on monetary aggregates using a frequency-domain analysis. In the period from 1970Q1 through 2005Q4 and under Phillips-curve estimations for U.S., U.K. and Japan low frequency money growth is documented to predict long-run inflation. In an estimated dynamic general equilibrium model with forward-looking money demand equation, Andres et al. (2008) document that real money balances provide information about the future natural interest rate; which in turn determines aggregate demand. Castelnuevo (2008) extends Favara and Giordani (2002) sample until 2007Q3. The author documents that money demand shocks affect U.S. output. Using several monetary structural VAR specifications and monetary New Keynesian models, he shows that short-run responses of output to innovations in money demand are significantly positive.

On the other hand, using quarterly U.S. observations, King et al. (1991) find that real interest rate shock appears to be an important source of short-run fluctuations in output and investment as opposed to the minimal role of nominal shocks. Leeper and Zha (2000) show that introducing an interaction between money demand and the behavior of policy rate changes 
interpretations about the behavior of the Federal Reserve in the postwar era. Rudebusch and Svensson (2002) shows that money growth is a poor indicator of future inflation. Additionally, they report that lagged money level and money growth rates are insignificant regressors in the AS-AD equations estimated for U.S. data. In a theoretical monetary business cycle model, Ireland (2004) allows money to simultaneously appear in the IS and Phillips curve specifications. Parameter estimates and impulse response functions reveal that money stock measured as M2 has a minimal role in the equilibrium dynamics of GDP and inflation. Under a standard forwardlooking dynamic general equilibrium model framework, Gunter et al. (2005) establish that when there are extensive revisions to real output data; low velocity shocks and high contemporaneous linkage between money demand and real output promote money's role as an indicator variable. Authors thus conclude that the poor link between actual M3 monetary aggregate and real output data hinders money from having information content for current output in the Euro area. Andres et al. (2006) estimate a sticky price general equilibrium model which introduces habit formation, autocorrelated shocks, interest rate rule including money growth and non-separable utility on consumption and real balances. The study rejects non-separability. Fluctuations in prices, output, nominal and natural rate of interest are found to be governed by real shocks.

Our intent in this study is to investigate the usefulness of money in explaining the dynamics of output and inflation from a new perspective and testing approach. We add to the extant literature on this subject in two respects. First, we jointly specify a number of dynamic stochastic general equilibrium (DSGE) models and econometric time series models. Second, we evaluate the performance of these models via the use of novel testing methods developed for assessing predictive and simulation accuracy. The DSGE models evaluated include two New Keynesian models. These models follow Gali (2002) and Rotemberg and Woodford (1998). Models only differ in the specification of the monetary policy. One model assumes an exogenous path for the growth rate of money supply, the other posits a feedback rule for interest rate. The feedback rule is formulated as the interest rate responding to its own lag and to lags of output gap and inflation. We estimate parameters of monetary policy and stochastic shock processes while we calibrate remaining structural parameters. In a simulated real-time "horse-race", these theoretical macroeconomic models are coupled with time series models including vector autoregression (VAR), random walk (RW), and various autoregressive (AR) and AR with exogenous variable (ARX) type models. The testing methods used involve the evaluation of point predictions and simulations as well as predictive and simulation type confidence intervals and conditional distributions. We apply those tests suggested by Corradi and Swanson (2006a, 2007a) to judge 
distributional accuracy and by White (2000) for pointwise accuracy. Due to the widely recognized change in the U.S. monetary policy stance around 1980s, we consider two sample periods including the period from 1960Q1 until 2009Q4 and from 1983Q1 to 2009Q4 ${ }^{1}$. We ask whether and through which model and transmission channel money matters. Meanwhile it is well known that DSGE models impose theoretical restrictions on VAR models. Therefore this study also sheds light to whether these restrictions are indeed necessary.

With this methodology we aim to make an alternative empirical case against the theoretical argument in favor of the redundancy of money aggregates in inflation and output dynamics. There are two dimensions of this analysis. The first dimension pertains to the use of simple DSGE models. In this respect we claim that as opposed to those conclusions from atheoretical models a simple structural model with money might potentially capture the dynamics of inflation and output series better than a one with a standard Taylor type policy rule. The second dimension relates to the evaluation technique. In this regard we hope to possibly extract new information not reflected in in-sample t, F and Granger causality tests. Finally we claim that post-1983 sample results are most critical in evaluating the merit of those models and tests we consider.

Our main findings are as follows. Our study suggests new evidence for the usefulness of money. We find that money matters for inflation simulations in the framework of simple econometric models through our ARX models in the post-1983 sample. However, money disappears as models get more complex. This is an interesting finding, given that more parsimonious models are often found to perform better than more complex models (see e.g. Swanson (1998), Amato and Swanson (2001), and the references cited therein), when the objective is to maximize predictive accuracy, while more complex models are usually preferred for policy analysis. From the forecasting standpoint, among multivariate models, M2 monetary aggregate enters into the "forecast-best" VAR-type inflation models in our post-1960 sample. We also have several findings favoring marginal predictive content of money in the post-1983 sample, in contrast to the findings of single equation time series models. We also find that model selection is sensitive to the researcher's objective function, to target variable and forecast horizon. Particularly, when the objective is policy analysis, the examination of multivariate models show that DSGEtype models often outperform at longer horizons and mainly for output forecasts. In contrast, VAR-type models are winners for simulation purposes and short-horizon inflation forecasts.

\footnotetext{
${ }^{1}$ We follow Leeper and Roush (2003) to determine the start of the smaller subsample.
} 
Meanwhile, from both forecasting and simulation standpoint univariate models generally dominate all theoretical and atheoretical multivariate models. Finally, our impulse response analysis and findings from predictive and simulation analysis show that our results are in line with the post-war U.S. monetary policy stance.

The rest of this paper is organized as follows. Section 2.2 presents data used for model comparison, model estimation. Section 2.3 describes DSGE and VAR models together with calibration and structural parameter estimation methods. Sections 2.4 describes the tests. While section 2.5 reports the results section 2.6 concludes.

\subsection{Data}

In this study we examine simulated and forecasted output and inflation series. Simulated and forecasted series from competing general equilibrium models, reduced form VAR models and other strawman models are compared to the quarterly historical U.S. data from 1960Q1 to 2009Q4. Given the widely recognized change in the U.S. monetary policy around 1980s, we consider two sub-samples within this period. We follow Leeper and Roush (2003) and analyze the periods from 1983Q1 to 2009Q4.and from 1960Q1 to 2009Q4. Inflation, output, interest rate and money supply data are taken from St. Louis Fed. In order to estimate models' parameters using historical data comparable to their counterpart in DSGE models we measured quarterly data as follows. Short-term nominal interest rate is the Federal funds effective rate. It is measured as the average quarter on quarter rate. Inflation is calculated as the quarter on quarter change in GDP deflator. Money growth is the quarter on quarter change in the end of quarter M2 money supply. Output is computed in per-capita terms. We considered civilian non-institutional population at age 16 and over to divide the real GDP. Resulting output per capita carries an upward trend. This series is detrended using Hodrick and Prescott (1997) filter. Data is expressed as percentage deviation from their respective long-run averages. The unit of measurement is percentage points.

\subsection{Models}

\subsubsection{Dynamic Stochastic General Equilibrium Models}

In this section, we describe two competing sticky price dynamic general equilibrium models. Models only differ in monetary policy function specification and are based on Gali (2002), Rotemberg and Woodford (1998) and Woodford (2003b). 
The representative infinitely-lived household is assumed to maximize the following objective function:

$$
E_{0}\left\{\sum_{t=0}^{\infty} \beta^{t} \Gamma_{t}\left(\frac{C_{t}^{1-\sigma}}{1-\sigma}-\Xi_{t} \frac{N_{t}^{1+\varphi}}{1+\varphi}\right)\right\}
$$

where $C_{t}$ aggregates quantities of different goods consumed and is assumed to be a constantelasticity-of-substitution index; $C_{t}=\left(\int_{0}^{1} C_{t}(i)^{\frac{\epsilon-1}{\epsilon}} d i\right)^{\frac{\epsilon}{\epsilon-1}}$ with $\epsilon>1$. Preference shocks are represented by $\Gamma_{t}$ and $\Xi_{t}$ and $\beta$ is the discount factor. The parameter $\varphi$ is the inverse of labor supply elasticity and $\sigma$ represents the inverse of intertemporal elasticity of substitution. Household's objective function is subject to a period budget constraint of the form

$$
P_{t} C_{t}+Q_{t} B_{t} \leq B_{t-1}+W_{t} N_{t}+T_{t}
$$

Aggregate price index for the final consumption good is given by $P_{t}=\left(\int_{0}^{1} P_{t}(i)^{1-\epsilon} d i\right)^{\frac{1}{1-\epsilon}}$; where $P_{t}(i)$ represents the price of good indexed as $i$ and $\epsilon$ is the elasticity of substitution between different types of goods. We assume there is a continuum of goods represented by the interval $[0,1]$.The budget constraint is supplemented by a standard solvency condition where $\lim _{T \rightarrow \infty} E_{t}\left\{B_{t}\right\} \geq 0 . \quad B_{t}$ represents purchases of one-period bonds. $Q_{t}$ represents the price of these bonds. $T_{t}$ denotes the lump-sum component of income; e.g. dividends from firms. Log-linearized optimality conditions for the household's problem take the form

$$
\begin{gathered}
c_{t}=E_{t}\left\{c_{t+1}\right\}-\frac{1}{\sigma}\left(i_{t}-E_{t}\left\{\pi_{t+1}\right\}+E_{t}\left\{\gamma_{t+1}\right\}-\gamma_{t}\right) \\
w_{t}-p_{t}=\sigma c_{t}+\varphi n_{t}+\xi_{t}
\end{gathered}
$$

where lowercase letters denote percentage deviation from the non-stochastic steady state. Nominal interest rate on one-period bond is denoted by $i_{t}$ and is determined as $Q_{t}=\left(1+i_{t}\right)^{-1}$. Equation (2.3) is the intertemporal consumption Euler equation, equation (2.4) shows the optimal labor supply decision.

It is assumed that there exists a continuum of firms $i \in[0,1]$ producing a differentiated good $\left\{Y_{t}(i)\right\}_{i \in[0,1]}$. The firm's production function is given by

$$
Y_{t}(i)=A_{t} N_{t}(i)^{1-\alpha}
$$

where $A_{t}$ denotes the exogenously evolving level of technology common to all firms. Aggregate 
final output is obtained through a CES technology as

$$
Y_{t}=\left(\int_{0}^{1} Y_{t}(i)^{1-\frac{1}{\epsilon}} d i\right)^{\frac{\epsilon}{\epsilon-1}}
$$

The optimal demand schedule for good $i$ is given by

$$
Y_{t}(i)=\left(\frac{P_{t}(i)}{P_{t}}\right)^{-\epsilon} Y_{t}
$$

All firms take this demand schedule, the aggregate price level $P_{t}$ and aggregate consumption index $C_{t}$ as given.

Following Calvo (1983), it is assumed that each firm may adjust its price with probability $1-\theta$ in each period; where $\theta$ represents price stickiness. The optimal price $P_{t}^{*}(i)$ chosen by the reoptimizing firm in period $t$ maximizes the following profit function.

$$
\max _{P_{t}^{*}(i)} \sum_{k=0}^{\infty} \theta^{k} E_{t}\left\{Q_{t, t+k} P_{t}^{*}(i) Y_{t+k \mid t}-\Psi_{t+k}\left(Y_{t+k \mid t}\right)\right\}
$$

subject to the demand schedule given in equation (2.7) for $k=0,1,2, \ldots$. The stochastic discount factor is given by $Q_{t, t+k} \equiv \beta^{k}\left(C_{t+k} / C_{t}\right)^{-\sigma}\left(P_{t} / P_{t+k}\right), \Psi_{t}($.$) is the cost function,$ and $Y_{t+k \mid t}$ represents the $t+k$ output of the reoptimizing firm that last reoptimized its price in period $t$. Optimal price-setting condition for the reoptimizing firm in log-linearized form around zero-inflation steady state is given by

$$
p_{t}^{*}(i)-p_{t-1}=(1-\beta \theta) \sum_{k=0}^{\infty}(\beta \theta)^{k} E_{t}\left\{\widehat{m c}_{t+k \mid t}+\left(p_{t+k}-p_{t-1}\right)\right\}
$$

where $\widehat{m c}_{t+k \mid t}$ is the percentage deviation of real marginal cost from its steady state value for a firm that last reoptimized its price in period $t$. Notice that in steady state real marginal cost is the inverse of desired markup under flexible prices.

Equilibrium conditions are given by

$$
Y_{t}(i)=C_{t}(i)
$$

and

$$
N_{t}=\int_{0}^{1} N_{t}(i) d i
$$

where equation (2.10) represents the goods market clearing condition while equation (2.11) is 
the labor market clearing condition.

Using the demand schedule (2.7), equilibrium conditions (2.10) and (2.11) and the production function (2.5), one can rewrite the optimal price setting equation in terms of the economy wide real marginal cost as follows

$$
p_{t}^{*}(i)-p_{t-1}=(\beta \theta) E_{t}\left\{p_{t+1}^{*}(i)-p_{t}\right\}+(1-\beta \theta) \Theta \widehat{m c}_{t}+\pi_{t}
$$

The percentage deviation of the economy wide real marginal cost from its steady state value is denoted by $\widehat{m c}_{t}=m c_{t}-m c, \pi_{t}$ denotes inflation and $\Theta \equiv \frac{(1-\alpha)}{(1-\alpha+\alpha \epsilon)}$. Aggregate price dynamics in log-linearized form is expressed as

$$
\pi_{t}=(1-\theta)\left(p_{t}^{*}(i)-p_{t-1}\right)
$$

Plugging equation (2.13) in equation (2.12) yields

$$
\pi_{t}=\beta_{t} E_{t}\left\{\pi_{t+1}^{*}\right\}+\frac{(1-\theta)(1-\beta \theta)}{\theta} \Theta \widehat{m c}_{t}
$$

The logarithm of the economy wide real marginal cost is defined as

$$
m c_{t}=\log \left(W_{t} / P_{t}\right)-m p n_{t}
$$

where $m p n_{t}$ is the log of the economy's marginal product of labor. Using the household's optimality condition (2.4) and the aggregate production derived from equation (2.5), real marginal cost can be expressed as

$$
m c_{t}=\log \left(\Xi_{t}\right)+\left(\sigma+\frac{\varphi+\alpha}{1-\alpha}\right) \log \left(Y_{t}\right)-\frac{1+\varphi}{1-\alpha} \log \left(A_{t}\right)-\log (1-\alpha)
$$

Under flexible prices equation (2.16) becomes

$$
m c=\log \left(\Xi_{t}\right)+\left(\sigma+\frac{\varphi+\alpha}{1-\alpha}\right) \log \left(Y_{t}^{n}\right)-\frac{1+\varphi}{1-\alpha} \log \left(A_{t}\right)-\log (1-\alpha)
$$

Under flexible prices real marginal cost is constant and is denoted as $m c$ and $Y_{t}^{n}$ is the natural level of output, defined as the equilibrium level of output under flexible prices. Percentage 
deviation of the economy wide real marginal cost from its steady state value is then

$$
\widehat{m c}_{t}=\left(\sigma+\frac{\varphi+\alpha}{1-\alpha}\right)\left(\log \left(Y_{t}\right)-\log \left(Y_{t}^{n}\right)\right)
$$

where $\left(\log \left(Y_{t}\right)-\log \left(Y_{t}^{n}\right)\right)$ is $\log$ output gap.

Equation (2.18) implies that

$$
\log \left(Y_{t}^{n}\right)=\frac{\left(-\mu-\log \left(\Xi_{t}\right)+\log (1-\alpha)\right)(1-\alpha)}{\varphi+\sigma+\alpha(1-\sigma)}+\frac{(1+\varphi) \log \left(A_{t}\right)}{\varphi+\sigma+\alpha(1-\sigma)}
$$

The steady state of the natural level of output is then given by

$$
\log \left(Y^{n}\right)=\frac{(-\mu+\log (1-\alpha))(1-\alpha)}{\varphi+\sigma+\alpha(1-\sigma)}
$$

where $\mu$ is the $\log$ of desired markup under flexible prices. We assume that the steady state levels of technology and the preference shocks are equal to one. Using equation (2.18) one can obtain the following relation for inflation

$$
\pi_{t}=\beta_{t} E_{t}\left\{\pi_{t+1}^{*}\right\}+\frac{(1-\theta)(1-\beta \theta)}{\theta} \Theta\left(\sigma+\frac{\varphi+\alpha}{1-\alpha}\right)\left(\log \left(Y_{t}\right)-\log \left(Y_{t}^{n}\right)\right)
$$

Substituting for the natural level of output we obtain the New Keynesian Phillips Curve

$$
\pi_{t}=\beta_{t} E_{t}\left\{\pi_{t+1}\right\}+\kappa y_{t}+\frac{\kappa \xi_{t}}{\varphi+\sigma+\alpha(1-\sigma)}-\kappa \psi_{y a} a_{t}
$$

where $\kappa=\frac{(1-\theta)(1-\beta \theta)}{\theta} \Theta\left(\sigma+\frac{\varphi+\alpha}{1-\alpha}\right)$ and $\psi_{y a}=\frac{(1+\varphi)}{\varphi+\sigma+\alpha(1-\sigma)}$. The second equation describing the equilibrium of the model is obtained by plugging in the goods market equilibrium condition to the consumption Euler equation (2.3) to get the dynamic IS equation

$$
y_{t}=E_{t}\left\{y_{t+1}\right\}-\frac{1}{\sigma}\left(i_{t}-E_{t}\left\{\pi_{t+1}\right\}+E_{t}\left\{\gamma_{t+1}\right\}-\gamma_{t}\right)
$$

We supplement these two equilibrium conditions with an ad-hoc log-linear money demand equation

$$
m_{t}-p_{t}=y_{t}-\eta_{t} i_{t}
$$

With respect to the monetary policy we consider two alternative specifications. The benchmark specification assumes a Taylor-type interest rate rule; expressed in log-linearized form 
as

$$
i_{t}=\rho_{i} i_{t-1}+\left(1-\rho_{i}\right) \phi_{y} y_{t-1}+\left(1-\rho_{i}\right) \phi_{\pi} \pi_{t-1}+\epsilon_{i, t}
$$

The model with money assumes an exogenous path for the growth rate of money supply and is given by the stationary $\mathrm{AR}(1)$ process

$$
\Delta m_{t}=\rho_{m} \Delta m_{t-1}+\epsilon_{m, t}
$$

Finally, stochastic exogenous processes are defined as follows

$$
\left(\begin{array}{c}
a_{t} \\
\gamma_{t} \\
\xi_{t} \\
\epsilon_{i, t} \\
\epsilon_{m, t}
\end{array}\right)=\left(\begin{array}{ccccc}
\rho_{a} & 0 & 0 & 0 & 0 \\
0 & \rho_{\gamma} & 0 & 0 & 0 \\
0 & 0 & \rho_{\xi} & 0 & 0 \\
0 & 0 & 0 & 0 & 0 \\
0 & 0 & 0 & 0 & 0
\end{array}\right)\left(\begin{array}{c}
a_{t-1} \\
\gamma_{t-1} \\
\xi_{t-1} \\
\epsilon_{i, t-1} \\
\epsilon_{m, t-1}
\end{array}\right)+\left(\begin{array}{ccccc}
\sigma_{a} & 0 & 0 & 0 & 0 \\
0 & \sigma_{\gamma} & 0 & 0 & 0 \\
0 & 0 & \sigma_{\xi} & 0 & 0 \\
0 & 0 & 0 & \sigma_{i} & 0 \\
0 & 0 & 0 & 0 & \sigma_{m}
\end{array}\right)\left(\begin{array}{c}
\nu_{a, t} \\
\nu_{\gamma, t} \\
\nu_{\xi, t} \\
\nu_{i, t} \\
\nu_{m, t}
\end{array}\right)
$$

Dynamics of the economy without money is described by the equilibrium Euler equation (2.21), the Phillips curve equation (2.20), the monetary policy rule (2.23) and the exogenous processes for preference shocks $\gamma_{t}$ and $\xi_{t}$, monetary policy shock $\epsilon_{i, t}$ and technology. The monetary front of the model with money is described by equations (2.24) and (2.22) instead of the interest rate rule in equation (2.23). In turn, exogenous processes include shocks to money growth instead of shocks to nominal interest rate. Systems for the model with and without money are solved using the solution technique proposed by Sims (2001). Accordingly the solution for these models have the form $x_{t}=\Theta x_{t-1}+\Psi z_{t}$, where the vector $x_{t}$ has the variables of the economy, matrices $\Theta$ and $\Psi$ are functions of the structural parameters and exogenous disturbances are stored in vector $z_{t}$. For the model with interest rate rule $x_{t}=$ $\left(y_{t}, \pi_{t}, i_{t}, a_{t}, \gamma_{t}, \xi_{t}, \epsilon_{i, t}\right)^{\prime}$ and $z_{t}=\left(\nu_{a, t}, \nu_{\gamma, t}, \nu_{\xi, t}, \nu_{i, t}\right)^{\prime}$. The model with an exogenous money growth equation has $x_{t}=\left(y_{t}, \pi_{t}, \Delta m_{t}, a_{t}, \gamma_{t}, \xi_{t}, \epsilon_{m, t}\right)^{\prime}$ and $z_{t}=\left(\nu_{a, t}, \nu_{\gamma, t}, \nu_{\xi, t}, \nu_{m, t}\right)^{\prime}$.

Coefficients of shock processes and monetary policy equations are estimated by the maximum likelihood method using Kalman Filter as outlined in Hamilton (1994). Parameter estimates together with associated standard errors are reported in Table A.1. Due to the existence of break in the monetary policy around 1980s, we estimate policy equation and shock process' parameters separately under two sample periods.

We calibrate remaining structural parameters of DSGE models. These parameters are $\alpha, \beta$, $\sigma, \theta, \varphi, \epsilon$ and $\eta$. We follow Gali (2002). Namely, the instantaneous household utility function is assumed to be logarithmic in consumption yielding $\sigma=1$. Labor wage elasticity $\varphi$ is set equal to 
one. Consumer discount factor $\beta$ is equal to $99 \%$ yielding an average annual real rate of return of $4 \%$. Price stickiness is determined as $\theta=0.75$. This degree of price stickiness implies that prices are updated every year. This is a common value obtained from econometric estimates ${ }^{2}$. Interest elasticity of money demand is set as $\eta=1$. Dixit-Stiglitz elasticity of substitution $\epsilon$ is set to 11 . This value is consistent with a $10 \%$ markup in the steady state. We set the parameter of labor share in production, $1-\alpha$ equal to $2 / 3$.

\subsubsection{VAR Models}

In this section we present two competing VAR models. These models use the same variables in DSGE models described above. Accordingly, VAR models are specified using inflation, output, interest rate and money growth series. Estimation of these models is undertaken using the ordinary least square method. Reduced form VAR models take the following form.

$$
\begin{aligned}
& y_{0, t}=\sum_{j=1}^{\gamma} \beta_{0, j} y_{0, t-j}+u_{0, t} \\
& y_{1, t}=\sum_{j=1}^{q} \beta_{1, j} y_{1, t-j}+u_{1, t}
\end{aligned}
$$

where $y_{0, t}=\left(y_{t}^{g}, \pi_{t}, r_{t}\right)^{\prime}, y_{1, t}=\left(y_{t}^{g}, \pi_{t}, r_{t}, \Delta m_{t}\right)^{\prime}$ and $\beta_{0}$ and $\beta_{1}$ are parameter matrices. The number of lags $\gamma$ and $q$ are selected using the SIC, starting the search with a maximum lag of 4 quarters.

\subsection{Methodology}

\subsubsection{Distributional Comparison Test}

We assess the performance of competing models with respect to their ability of replicating the distribution of historical inflation and output series. To this end we apply the testing approach suggested by Corradi and Swanson Corradi and Swanson (2006b, 2007a). This testing approach is based on the distributional analog of the mean squared error. The aim is to compare empirical distributions of historical series with those of simulated and forecasted series for a real valued random variable. We form nonparametric conditional distributions for the predicted series given past information. Meanwhile we form nonparametric unconditional distributions for simulated series. We then pick the model that generate simulated or forecasted series with

\footnotetext{
${ }^{2}$ See Blinder et al. (1998), Gali and Gertler (1999) and Smets and Wouters (2003) among others.
} 
best approximation to its historical counterpart. In this section we briefly discuss this testing framework.

The testing procedure begins with fixing one model as the benchmark. Accordingly, suppose there are $m$ competing models with model 1 being the benchmark. At least one of the competing models is required to be nonnested with respect to the benchmark model. Let $Y_{t}$ denote the actual historical data where $t=1 \ldots . T$. Denote $Y_{j, i}(\widehat{\theta})$ to be the simulated or forecasted series evaluated at the parameters (estimated and/or calibrated) under model $j$ for $j=1, \ldots, m$. For simulated series $i=1, \ldots, S$, with $S$ representing the size of the simulated series. For forecasted series $i=1, \ldots, P$, with $P$ representing the amount of prediction points. In general, actual, forecasted and simulated series are required to be strictly stationary and mixing. Let the vector $Z^{t}$ incorporate the information up to period $t$ of all the variables in the model such that $Z^{t}=\left(Y_{t}, . . Y_{t-s_{1}+1}, X_{t}, . ., X_{t-s_{2}+1}\right), t=s, \ldots, \widetilde{T}, \ldots T$ with $s=\max \left\{s_{1}, s_{2}\right\}$, and hence $\widetilde{T}$ denoting the effective sample size. Finally denote the true distribution of $Y_{t}$ evaluated at some $u$ as $F_{0}\left(u ; \theta_{0}\right)$ for the simulation analysis and as $F_{0}\left(u \mid Z^{t}, \theta_{0}\right)$ for the forecasting analysis; where $u \in U \subset \Re^{2}$, possibly unbounded. Then $F_{j}\left(u ; \theta_{j}^{\dagger}\right)$ and $F_{j}\left(u \mid Z^{t}, \theta_{j}^{\dagger}\right)$ will be the respective distribution of $Y_{j, i}\left(\theta_{j}^{\dagger}\right)$; where $\left(\theta_{j}^{\dagger}\right)$ is the probability limit of $\widehat{\theta}_{j, T}$ as $T \rightarrow \infty$.

The squared (approximation) error measure of accuracy is defined as the weighted average over $U$ of $E\left(\left(\left(F_{j}\left(u ; \theta_{j}^{\dagger}\right)-F_{0}\left(u ; \theta_{0}\right)\right)^{2}\right)\right.$ for simulations and $E\left(\left(\left(F_{j}\left(u \mid Z^{t}, \theta_{j}^{\dagger}\right)-F_{0}\left(u \mid Z^{t}, \theta_{0}\right)\right)^{2}\right)\right.$, for predictions. Model 1 would then outperform model 2 if

$$
\int_{U} E\left(\left(\left(F_{1}\left(u ; \theta_{1}^{\dagger}\right)-F_{0}\left(u ; \theta_{0}\right)\right)^{2}-\left(F_{2}\left(u ; \theta_{2}^{\dagger}\right)-F_{0}\left(u ; \theta_{0}\right)\right)^{2}\right) \phi(u) d u \leq 0\right.
$$

for simulated series or

$$
\int_{U} E\left(\left(\left(F_{1}\left(u \mid Z^{t}, \theta_{1}^{\dagger}\right)-F_{0}\left(u \mid Z^{t}, \theta_{0}^{\dagger}\right)\right)^{2}-\left(F_{2}\left(u \mid Z^{t}, \theta_{2}^{\dagger}\right)-F_{0}\left(u \mid Z^{t}, \theta_{0}^{\dagger}\right)\right)^{2}\right) \phi(u) d u \leq 0\right.
$$

for the predicted series; where $\int_{U} \phi(u) d u=1$ and $\phi(u) \geq 0$, for all $u \in U$, and $U \subset \Re^{2}$.For any evaluation point, this measure of accuracy defines a norm and it implies a usual goodness of fit measure. The null and the alternative hypotheses for this test are then formulated as follows:

$$
H_{0}: \max _{j=2, \ldots, m} \int_{U} E\left(\left(F_{0}\left(u ; \theta_{0}\right)-F_{1}\left(u ; \theta_{1}^{\dagger}\right)\right)^{2}-\left(F_{0}\left(u ; \theta_{0}\right)-F_{j}\left(u ; \theta_{j}^{\dagger}\right)\right)^{2}\right) \phi(u) d u \leq 0
$$


versus

$$
H_{A}: \max _{j=2, \ldots, m} \int_{U} E\left(\left(F_{0}\left(u ; \theta_{0}\right)-F_{1}\left(u ; \theta_{1}^{\dagger}\right)\right)^{2}-\left(F_{0}\left(u ; \theta_{0}\right)-F_{j}\left(u ; \theta_{j}^{\dagger}\right)\right)^{2}\right) \phi(u) d u>0
$$

for simulated series and as

$$
\begin{gathered}
H_{0}: \max _{j=1, \ldots, m} \int_{U} E\left(\left(F_{0}\left(u \mid Z^{t}, \theta_{0}\right)-F_{1}\left(u \mid Z^{t}, \theta_{1}^{\dagger}\right)\right)^{2}\right. \\
\left.-\left(F_{0}\left(u \mid Z^{t}, \theta_{0}\right)-F_{j}\left(u \mid Z^{t}, \theta_{j}^{\dagger}\right)\right)^{2}\right) \phi(u) d u \leq 0
\end{gathered}
$$

versus

$$
\begin{gathered}
H_{A}: \max _{j=1, \ldots, m} \int_{U} E\left(\left(F_{0}\left(u \mid Z^{t}, \theta_{0}\right)-F_{1}\left(u \mid Z^{t}, \theta_{1}^{\dagger}\right)\right)^{2}\right. \\
\left.-\left(F_{0}\left(u \mid Z^{t}, \theta_{0}\right)-F_{j}\left(u \mid Z^{t}, \theta_{j}^{\dagger}\right)\right)^{2}\right) \phi(u) d u>0
\end{gathered}
$$

for predicted series. Hence for a given $u$, distributions are compared in terms of their average distance to the true distribution. In order to test $H_{0}$ against $H_{A}$, the test statistic is $\sqrt{T} Z_{T, S}$, where

$$
Z_{T, S}=\max _{j=2, \ldots, m} \int_{U} Z_{j, T, S}(u) \phi(u) d u
$$

and where

$$
\begin{gathered}
Z_{j, T, S}(u)=\frac{1}{T} \sum_{t=1}^{T}\left(1\left\{Y_{t} \leq u\right\}-\frac{1}{S} \sum_{n=1}^{S} 1\left\{Y_{1, n}\left(\widehat{\theta}_{1, T}\right) \leq u\right\}\right)^{2} \\
-\frac{1}{T} \sum_{t=1}^{T}\left(1\left\{Y_{t} \leq u\right\}-\frac{1}{S} \sum_{n=1}^{S} 1\left\{Y_{j, n}\left(\widehat{\theta}_{j, T}\right) \leq u\right\}\right)^{2}
\end{gathered}
$$

Meanwhile the test statistic for the predicted series takes the form

$$
Z_{P}=\max _{j=1, \ldots, m} \int_{U} Z_{j, P}(u) \phi(u) d u
$$

where 


$$
\begin{gathered}
Z_{j, P}(u)=\frac{1}{\sqrt{P}} \sum_{t=R}^{T-h}\left(1\left\{Y_{t+h} \leq u\right\}-\frac{1}{P} \sum_{n=1}^{P} 1\left\{Y_{1, n}\left(\widehat{\theta}_{1, t}\right) \leq u\right\}\right)^{2} \\
-\frac{1}{\sqrt{P}} \sum_{t=R}^{T-h}\left(1\left\{Y_{t+h} \leq u\right\}-\frac{1}{P} \sum_{n=1}^{P} 1\left\{Y_{j, n}\left(\widehat{\theta}_{j, t}\right) \leq u\right)^{2}\right.
\end{gathered}
$$

with $R$ being the corresponding in-sample size from which the parameter estimates $\widehat{\theta_{j, t}}$ are obtained and $P$ is the amount of predicted points.

Under the null hypothesis, when all competing models provide an approximation to the true distribution that is as accurate as that provided by the benchmark, Corradi and Swanson (2006a, 2007a) show that the limiting distribution of these test statistics are zero mean Gaussian processes with a covariance kernel which is not nuisance parameters free. Hence the critical values are to be bootstraped using the block bootstrap method. In this process we assumed that the parameter estimation error vanishes. This is mainly motivated by the use of calibrated structural parameters in the general equilibrium models. Meanwhile, for the simulation analysis we construct critical values accounting for simulation error as well.

For the test applied to the simulated series, we report the valid critical values constructed in Corradi and Swanson (2007a). We report those in Corradi and Swanson (2006b) for the predicted series; which might not be valid in our case of fixed estimation scheme. For this reason and for the sake of robustness we also report distributional loss measures used in the construction of the above test statistics. These are

$$
C_{T, S}(j)=\int_{U} \frac{1}{T} \sum_{t=1}^{T}\left(1\left\{Y_{t} \leq u\right\}-\frac{1}{S} \sum_{n=1}^{S} 1\left\{Y_{j, n}\left(\widehat{\theta}_{j, T}\right) \leq u\right\}\right)^{2} \phi(u) d u
$$

and

$$
C_{P}(j)=\int_{U} \frac{1}{\sqrt{P}} \sum_{t=R}^{T-h}\left(1\left\{Y_{t+h} \leq u\right\}-\frac{1}{P} \sum_{n=1}^{P} 1\left\{Y_{j, n}\left(\widehat{\theta}_{j, t}\right) \leq u\right)^{2} \phi(u) d u\right.
$$

for the simulated and the predicted series respectively. CS loss measure and the distributional accuracy test statistics are constructed using grids of 100 values for $u$, distributed uniformly across the historical data ranges of inflation and output. 


\subsubsection{Confidence Interval Accuracy}

We also conduct an analogous test where we compare simulated and forecasted confidence intervals for inflation and output to their respective historical counterpart. Our interest in this analysis is mainly to focus on the tails of emprical distributions for inflation and output. The null and the alternative hypotheses in this case are modified as:

$$
\begin{aligned}
H_{0}: & \max _{j=2, \ldots, m} E\left(\left(\left(F_{0}\left(\bar{u} ; \theta_{0}\right)-\left(F_{0}\left(\underline{u} ; \theta_{0}\right)\right)-\left(F_{1}\left(\bar{u} ; \theta_{1}^{\dagger}\right)-F_{1}\left(\underline{u} ; \theta_{1}^{\dagger}\right)\right)^{2}\right.\right.\right. \\
& -\left(\left(F_{0}\left(\bar{u} ; \theta_{0}\right)-\left(F_{0}\left(\underline{u} ; \theta_{0}\right)\right)-\left(F_{j}\left(\bar{u} ; \theta_{j}^{\dagger}\right)-F_{j}\left(\underline{u} ; \theta_{j}^{\dagger}\right)\right)^{2} \leq 0\right.\right. \\
H_{A}: & \max _{j=2, \ldots, m} E\left(\left(\left(F_{0}\left(\bar{u} ; \theta_{0}\right)-\left(F_{0}\left(\underline{u} ; \theta_{0}\right)\right)-\left(F_{1}\left(\bar{u} ; \theta_{1}^{\dagger}\right)-F_{1}\left(\underline{u} ; \theta_{1}^{\dagger}\right)\right)^{2}\right.\right.\right. \\
& -\left(\left(F_{0}\left(\bar{u} ; \theta_{0}\right)-\left(F_{0}\left(\underline{u} ; \theta_{0}\right)\right)-\left(F_{j}\left(\bar{u} ; \theta_{j}^{\dagger}\right)-F_{j}\left(\underline{u} ; \theta_{j}^{\dagger}\right)\right)^{2}>0\right.\right.
\end{aligned}
$$

and for predicted series as

$$
\begin{aligned}
H_{0}: & \max _{j=2, \ldots, m} E\left(\left(\left(F_{0}\left(\bar{u} \mid Z^{t}, \theta_{0}\right)-\left(F_{0}\left(\underline{u} \mid Z^{t}, \theta_{0}\right)\right)-\left(F_{1}\left(\bar{u} \mid Z^{t}, \theta_{1}^{\dagger}\right)-F_{1}\left(\underline{u} \mid Z^{t}, \theta_{1}^{\dagger}\right)\right)^{2}\right.\right.\right. \\
& -\left(\left(F_{0}\left(\bar{u} \mid Z^{t}, \theta_{0}\right)-\left(F_{0}\left(\underline{u} \mid Z^{t}, \theta_{0}\right)\right)-\left(F_{j}\left(\bar{u} \mid Z^{t}, \theta_{j}^{\dagger}\right)-F_{j}\left(\underline{u} \mid Z^{t}, \theta_{j}^{\dagger}\right)\right)^{2} \leq 0\right.\right. \\
& \\
H_{A}: & \max _{j=2, \ldots ., m} E\left(\left(\left(F_{0}\left(\bar{u} \mid Z^{t}, \theta_{0}\right)-\left(F_{0}\left(\underline{u} \mid Z^{t}, \theta_{0}\right)\right)-\left(F_{1}\left(\bar{u} \mid Z^{t}, \theta_{1}^{\dagger}\right)-F_{1}\left(\underline{u} \mid Z^{t}, \theta_{1}^{\dagger}\right)\right)^{2}\right.\right.\right. \\
& -\left(\left(F_{0}\left(\bar{u} \mid Z^{t}, \theta_{0}\right)-\left(F_{0}\left(\underline{u} \mid Z^{t}, \theta_{0}\right)\right)-\left(F_{j}\left(\bar{u} \mid Z^{t}, \theta_{j}^{\dagger}\right)-F_{j}\left(\underline{u} \mid Z^{t}, \theta_{j}^{\dagger}\right)\right)^{2}>0\right.\right.
\end{aligned}
$$

Consequently the test statistic is also similar to that provided for the distributional accuracy test. The test statistic is formulated as $\sqrt{T} V_{T, S}$ :

$$
V_{T, S}=\max _{2=1, \ldots, m} V_{T, S, \bar{u}, \underline{u}}(j)
$$


where

$$
\begin{gathered}
V_{T, S, \bar{u}, \underline{u}}(j)=\frac{1}{T} \sum_{t=1}^{T}\left(1\left\{\underline{u} \leq Y_{t} \leq \bar{u}\right\}-\frac{1}{S} \sum_{n=1}^{S} 1\left\{\underline{u} \leq Y_{1, n}\left(\widehat{\theta}_{1, T}\right) \leq \bar{u}\right\}\right)^{2} \\
-\frac{1}{T} \sum_{t=1}^{T}\left(1\left\{\underline{u} \leq Y_{t} \leq \bar{u}\right\}-\frac{1}{S} \sum_{n=1}^{S} 1\left\{\underline{u} \leq Y_{j, n}\left(\widehat{\theta}_{j, T}\right) \leq \bar{u}\right\}\right)^{2}
\end{gathered}
$$

while the test statistic for the prediction case is

$$
V_{P}=\max _{j=1, \ldots, m} V_{P, \bar{u}, \underline{u}}(j)
$$

with

$$
\begin{aligned}
V_{P, \bar{u}, \underline{u}}(j)= & \frac{1}{\sqrt{P}} \sum_{t=R}^{T-h}\left(1\left\{\underline{u} \leq Y_{t+h} \leq \bar{u}\right\}-\frac{1}{P} \sum_{n=1}^{P} 1\left\{\underline{u} \leq Y_{1, n}\left(\widehat{\theta}_{1, t}\right) \leq \bar{u}\right\}\right)^{2} \\
& -\frac{1}{\sqrt{P}} \sum_{t=R}^{T-h}\left(1\left\{\underline{u} \leq Y_{t+h} \leq \bar{u}\right\}-\frac{1}{P} \sum_{n=1}^{P} 1\left\{\underline{u} \leq Y_{j, n}\left(\widehat{\theta}_{j, t}\right) \leq \bar{u}\right\}\right)^{2}
\end{aligned}
$$

We construct critical values using bootstraped statistics applying the corresponding techniques as mentioned for the case of the distributional accuracy test, see Corradi and Swanson (2006a). We examine intervals $\bar{X} \pm 0.5 \sigma_{X}$ and $\bar{X} \pm \sigma_{X}$; where $\bar{X}$ and $\sigma_{X}$ are the mean and the standard deviation of historical data. These intervals cover on average $34 \%$ and $70 \%$ of true output data and $44 \%$ and $75 \%$ of true inflation data.

\subsubsection{Pointwise Evaluation}

To evaluate the pointwise accuracy of predicted inflation and output series generated from the time series and DSGE models, we apply the test suggested by White (2000). White (2000) proposes a test for choosing one among many competing models. There are $m$ models and one model is selected as benchmark. It is required that at least one of the alternative models be nonnested with the benchmark model. A model among the set of m-1 models is chosen if it yields more accurate forecasts than the benchmark. This test assumes that prediction errors are strictly stationary, allows for model misspecification and does not explicitly account for parameter estimation error. The test statistic is specified as

$$
S_{P}=\max _{k=2, \ldots, m} S_{P}(1, k)
$$


where

$$
S_{P}(1, k)=\frac{1}{\sqrt{P}} \sum_{t=R}^{T-h}\left[g\left(\widehat{u_{1, t+h}}\right)-g\left(\widehat{u_{k, t+h}}\right)\right], \quad k=2, \ldots, m
$$

with $g$ being the loss function, $R$ the in-sample size, $P$ the amount of predicted data and the forecast horizon $h \geq 1$. The forecast error is $u_{i, t+h}=y_{t+1}-\kappa_{i}\left(Z^{t}, \theta_{i}^{\dagger}\right)$, and let $\widehat{u_{i, t+h}}=$ $y_{t+1}-\kappa_{i}\left(Z^{t}, \widehat{\theta_{i, t}}\right)$, where the function $\kappa_{i}$ is the conditional mean function under model $i$, and $\widehat{\theta_{i, t}}$ is an estimator obtained using past observations from 1 to $t$. The null and the alternative hypotheses are formulated as follows.

$$
\begin{gathered}
H_{0}: \max _{k=2, \ldots, m} E\left(g\left(u_{1, t+h}\right)-g\left(u_{k, t+h}\right)\right) \leq 0 \\
H_{A}: \max _{k=2, \ldots, m} E\left(g\left(u_{1, t+h}\right)-g\left(u_{k, t+h}\right)\right)>0
\end{gathered}
$$

The limiting distribution of the test statistic under $H_{0}$ is a zero mean Gaussian process with a covariance kernel that reflects the effect of parameter estimation error unless $P / R \rightarrow 0$ or the same loss function is used for parameter estimation and model evaluation. We specify the loss function as the square of the error term. We assume that $P / R \rightarrow 0$. We obtain valid critical values using the block bootstrap procedure ${ }^{3}$.

\subsection{Results}

Models described in section 3 together with other strawman models; namely VAR, RW, AR and ARX models generate inflation and output simulations and forecasts. Tables A.1 through A.5 report parameter estimates. Time series models are estimated using least squares and lags are determined using the SIC technique. We start our model evaluation by comparing theoretical impulse response functions of DSGE models. We then proceed to analyze inflation and output forecasts. Particularly, we compare predictive densities and mean square forecast error statistics. Finally we analyze inflation and output simulations with respect to their distributional accuracy. Notice that the verdict of post-1983 findings about the usefulness of money is definitely the most crucial. Recall that since 1980s U.S. monetary policy has re-focused on short-term interest rates' movements. As will be seen below, our study reveals evidence against the redundancy

\footnotetext{
${ }^{3}$ White (2000) suggests using stationary bootstrap method by Polotis and Romano (1994). As suggested in Corradi and Swanson (2006b), stationary and block bootstrap procedures yield the same asymptotic critical values.
} 
of monetary aggregates, from either forecasting or simulation perspective, in numerous cases where information from this episode is introduced.

\subsubsection{Impulse Response Analysis}

In this section we carry out a theoretical impulse response function analysis. One aim of this analysis is to compare inflation and output dynamics of competing DSGE models in response to unanticipated monetary policy and technology shocks. The other aim is to gauge the sensibility of estimated structural parameters. Figures C.1 and C.2 show responses of inflation and output to the favorable technology shock and unanticipated monetary shock using parameters estimated in the post-1983 sample ${ }^{4}$. In each graph, x-axis represents the number of quarters after the shock.

We start by examining responses to an unanticipated monetary policy shock which implies an increase of 1 percentage point in the annualized nominal interest rate. Under the model with an interest rate rule, the shock corresponds to an approximately 0.25 percentage point increase in $\epsilon_{i, t}{ }^{5}$. The model with money growth rule needs a 1.0025 percentage point rise in $\epsilon_{m, t}{ }^{6}$ As shown in Figure C.1, the monetary policy shock proves to be contractionary for the former model while it is expansionary for the latter. Namely, the exogenous rise in the interest rate results in an $0.7 \mathrm{pp}$ decline in output on impact in the model with interest rate rule. Output then goes back to its initial level. In contrast output increases by almost 1.6pp in the model with money growth rule. Note however that the response of output dies out much more slowly under the model with money growth rule. As implied by the New Keynesian Phillips curve in equation (2.20), with $\kappa>0$ dynamics of inflation in response to the monetary policy shock also differ across models. While inflation falls in the model with interest rate rule, it increases in the other model. In both cases inflation steadily reverts back to its initial level. The reversion is again slow for the model with model.

We then examine the response to a favorable technology shock. This shock is a positive realization of $\nu_{a, t}$ leading to an $0.97 \mathrm{pp}$ increase in $a_{t}{ }^{7}$. Under the favorable technology shock, inflation and output dynamics display similarities. Under both models output increases persistently. The rise in output however falls behind that of its natural rate. This in turn leads to

\footnotetext{
${ }^{4}$ Results in the post-1960 sample are qualitatively similar.

${ }^{5}$ Given the estimate for $\sigma_{i}$ in Table A.1, this is a 0.77 percentage point increase in $v_{i, t}$.

${ }^{6}$ Given the estimate for $\sigma_{m}$ in Table A.1, this is a 0.99 percentage point increase in $v_{m, t}$.

${ }^{7}$ This increase in the level of technology corresponds to an increase of $\nu_{a, t}$ by 0.8 and 1 standard deviation in models with interest rate rule and money growth rule respectively.
} 
a fall in output gap ${ }^{8}$ and hence in inflation. Quantitatively, however, notice that the increase of output is higher under the model with the interest rate rule. This in turn results in a bigger fall of output gap in the model with the money growth rule. As a result the fall in inflation also differs in magnitude across models.

Responses to the monetary policy and technology shocks are qualitatively meaningful compared to the calibrated basic New Keynesian model in Gali (2008). Accordingly, the policy shock generates contraction (expansion) in output in the model with interest rate rule (money growth rule); in line with the rise (fall) in the real interest rate. Again in line with Gali (2008), responses to policy shock dies out faster in the model with interest rate rule. Similarly, responses to technology shock vanish faster in the model with money growth rule. Meanwhile, there is an initial kink in output response to the policy shock in our model with money. The value for the interest elasticity of money demand is responsible for this shape. Gali (2008) sets the elasticity to 4 based on an OLS regression with quarterly data over the period 1960:1 to 1988:1. In line with Mankiw and Summers (1986), and Stock and Watson (1993) among others, we let the value of interest elasticity to 1.

\subsubsection{Prediction Analysis}

Out-of-sample forecasts for inflation and output series are generated under both subsamples from DSGE and strawman models. We produce 1, 3,6 and 12 quarter ahead predictions. For forecasts of horizons $h>1$ we iterate on the one-period ahead forecast. We adopt a fixed estimation and forecasting scheme. We keep the amount of forecast points fixed. Under this scheme, we analyze three forecast windows. Forecast windows are from periods 1990Q1 to 1999Q4, from 2000Q1 to 2009Q4 and from 1990Q1 to 2009Q4. The start and the end of insample periods for parameter estimation is determined as follows. The in-sample period starts at the beginning of the sub-sample. The end of the in-sample period is determined by the start of the forecasting window and the forecast horizon. The lag order of reduced form models and parameter estimates of all models are individually obtained for each in-sample period. To better illustrate consider the following example. Recall that the analysis of monetary aggregates is conducted under two subsamples. Suppose that we conduct the forecasting analysis under the smaller subsample and that the forecasting window runs from 1990Q1 to 1999Q4. Suppose also that we want to obtain one period-ahead forecast. The fixed in-sample period then runs from 1983Q1 to 1989Q4. To obtain three quarter-ahead prediction, the in-sample period then ends

\footnotetext{
${ }^{8}$ Dynamics of output gap and the analytical solution for the natural level of output in terms of the level of technology can be obtained from the author upon request.
} 
in 1989Q2. Suppose now that we conduct the forecasting analysis under the larger subsample to predict inflation or output one quarter ahead. The fixed in-sample period then runs from 1960Q1 until 1989Q4.

Inflation and output forecasts from theoretical models are constructed using the DSGE solution $x_{t}=\Theta x_{t-1}+\Psi z_{t}$. As the starting point, we use historical values of observable variables and steady-state values for exogenous shock processes. We set the steady state of exogenous processes to zero. DSGE models in section 3 describe the behavior of economic variables in terms of their deviations from corresponding steady-state values. Therefore, we deduct the long-run mean of the historical observations to obtain comparable data to the ones generated by DSGE models. To generate real-time forecasts we compute the mean using only in-sample observations. For predictive density analysis, forecasted inflation and output for the period $t+1$ are obtained as follows:

$$
x_{t+1 \mid t}=\Theta x_{t}+\Psi z_{t+1}, R-(h-1) \leq t \leq T-h
$$

where $T=R+P$ denotes the size of the actual historical series, $P$ is the length of the prediction period and $h$ represents the forecast horizon. We also draw shock processes from a normal distribution using parameter estimates for variance-covariance matrix ${ }^{9}$. For pointwise predictive accuracy analysis, however, we assume that shocks are zero. This makes predictions from our reduced form models and theoretical models directly comparable. Finally, we add the long-run mean to $x_{t+1 \mid t}$ to make it comparable its historical value.

Conditional $h$-period ahead predictions for the $\operatorname{VAR}(p)$ models are formed by iterating on:

$$
\begin{aligned}
y_{0, t+k \mid t} & =\sum_{j=1}^{\gamma} \widehat{\beta_{0, j}} y_{0, t-j} \\
y_{1, t+k \mid t} & =\sum_{j=1}^{\gamma} \widehat{\beta_{1, j}} y_{1, t-j}, \quad R-(h-1) \leq t \leq T-h
\end{aligned}
$$

for $k=1,2, \ldots h$.

Results of prediction analysis are reported in Tables A.6 through A.9, Tables A.11 through A.16, Table A.23 and A.24. Figures C.3 through C.14 report predictive densities.

\footnotetext{
${ }^{9}$ Predictive densities in DSGE models with shocks are superior to models without shocks.
} 


\section{Predictive density analysis}

As an initial way to compare predicted and historical densities, we analyze marginal density plots in Figure C.3 through C.14. First parts of Figures C.3 through C.14 show predictive densities for output and inflation forecasts obtained from the VAR and DSGE models for three forecasting periods. The most important observation among the plots of complex models is that at all in-sample period/forecast window combinations the performance of theoretical models is sensitive to forecast horizon. Namely, the dispersion of more restrictive models appear to improve and outperform at long horizons. Particularly, in the post-1983 sample predictive densities of output and inflation from the DSGE model without money accurately replicate its historical counterpart. Meanwhile the three-variable VAR model fairs well at moderate horizons. In contrast, the dispersion of the larger VAR model dramatically increases with forecast horizon. This results may in part be due to low in-sample period as opposed to high amount of parameter estimates. As for the post 1960-sample, irrespective of target variable, it is clear that VAR models perform better than DSGE models at short to medium horizons. Meanwhile there seems to be little to choose between VAR models. As an exception though, at the forecasting period from 2000Q1 to 2009Q4, one-quarter ahead densities from the DSGE model with money looks close to true densities.

Second parts of Figures C.3 through C.14 display predictive densities from the smaller VAR model against other strawman models. It is worth highlighting that model simplicity is a key selection criterion here. Specifically, there is no doubt that the random walk model almost always performs better than other time series models. Meanwhile other models also fair well as the forecast horizon shortens. Particularly, densities from all models appear to be close to their historical counterpart at one-quarter ahead horizon forecasts for both variables in the post 1960-sample and for output in the post 1983-sample. Similarly, predictive densities from the three-variable VAR model appears similar to that from the RW model in the forecasting period from 2000Q1 to 2009Q4.

We now look at the comparison of seven alternative models for inflation and output using the CS distributional loss measure, $Z_{P}$ test statistics and the confidence interval test. Tables A.8 and A.9 show CS distributional loss measure. First we focus on the comparison of two alternative DSGE models. The model with lowest loss is indicated in italic. We observe that the performance of the DSGE model with money depends on the conditioning information set. Particularly, the DSGE model with money mainly appears with lowest CS value in the post 1960-sample. More importantly, in both estimation samples, this larger model always records 
lowest one-quarter ahead CS measure at the forecasting window from 2000Q1 to 2009Q4. This is an interesting observation as it is in line with the Federal Reserve's monetary policy stance at the time. Of note is also that, the model with money records minimum loss measure at short horizons for inflation versus at longer horizons for output predictions. Also in accord with the theoretical literature the post-1980 sample is dominated by the DSGE model with Taylortype policy rule. This model wins 11 times out of 12 prediction period/prediction horizon combinations.

Whe then add VAR models to CS loss measure comparison. Entries tagged with $\uparrow$ denote the lowest CS measure among the four models. Notice that we have evidence that money matters for predictive density in the post-1960 sample. Particularly, models with money; VAR and DSGE models combined; register 9 and 10 minimum loss statistics for inflation and output forecasts. Most importantly, in accordance with U.S. monetary policy experience, best performances are recorded on panels $\mathrm{A}$ and $\mathrm{C}$ of Tables A.8 and A.9. Furthermore, it is an interesting finding that models with money show up with minimum CS measure on panel B as well. Notice that forecasts for this window uses almost two decades of information from the new monetary policy stance period. Of additional note, in line with the analysis of predictive density plots, more restrictive models are preferred as the forecast horizon increases. For example, in the post-1983 sample, the DSGE model without money records the minimum CS value at long horizons for both variables, as opposed to the cashless VAR model. In the larger subsample however, the four-variable VAR emerges as the winner at short to medium horizon forecasts. Finally, when we add other strawman models to the mix, a clear-cut observation emerges. Bold entries denote the lowest CS score among all models. The random walk model almost always beats time series and theoretical alternatives at all forecast period/horizon cases in both subsamples. As a final note, notice that no matter which group of models are compared, model assessment based on the distributional loss measure does not depend on target variable. Notice also that this result greatly matches the graphical representation of predictive densities in second parts of Figures C.3 through C.14.

Test statistics associated with CS distributional loss measures are gathered in Tables A.11 and A.12. First we compare complex models and we set the three-variable VAR model equal to the benchmark; see Table A.11. Rejections of the null hypothesis are in line with CS distributional loss measure results in Tables A.8 and A.9. Particularly, in the post-1983 sample we observe that at some cases the null-hypothesis is rejected at long horizons. We obtain even more rejections of the benchmark model when the post-1960 sample period is analyzed. Inflation forecasts from the benchmark model are outperformed by at least one of the alternative 
models in at least one horizon at each forecasting period. The distributional performance of the benchmark model is also beaten for output at long horizons in the forecasting periods from 1990Q1 to 2009Q4 and 2000Q1 to 2009Q4. Meanwhile, when all forecasting period/forecast horizon combinations are considered, there is little to choose between theoretical and atheoretical models for output and inflation. This result may show that the CS distributional loss measure of the DSGE model without money and the four-variable VAR model is generally not statistically lower than that of the three-variable VAR model; in the post-1983 and post 1960-sample respectively. The amount of prediction points in our study may also in part be responsible for the failure to reject the benchmark model. Corradi and Swanson (2005) show that the power of the test at small sample is reasonable but somewhat low. Tables A.12 shows the results of the distributional accuracy test where the three-variable VAR model is now set as the benchmark against the strawman models. Results are in general in line with the distributional loss measure statistics. The benchmark model is mostly rejected against at least one of the alternative models. Interestingly, a remarkable exception is observed for output forecasts in the period from 1990Q1 to 1999Q4 which are obtained from the post-1960 estimation period.

When we focus on specific confidence intervals, we observe in Tables A.13 and A.14 that rejections of the null hypothesis mainly occur for predictive densities of inflation in the post1960 sample. Rejections are recorded at long horizons of each forecasting period and mostly in the narrower confidence interval. The comparison of Table A.11 show that $Z_{T, P}$ and $V_{T, P}$ test results are usually qualitatively same; i.e. rejections of the null hypothesis match. Noticeable exception however pertains to output forecasts generated using the post 1960-sample. Results of the confidence interval test thus shed light on rejections or lack thereof of the null hypothesis in Table for $Z_{T, P}$ test. Accordingly, we notice that for forecasting periods from 2000Q1 to 2009Q4 and from 1990Q1 to 2009Q4, long-horizon output forecasts from the benchmark model poorly replicate the distribution of its historical counterpart in the tail region. Additionally, the failure to reject the null hypothesis in the forecasting period from 1990Q1 to 1999Q4 appears to be due to the better distributional accuracy by the cashless VAR model in the tail region. When we introduce strawman models against the three-variable VAR model, the latter is mostly rejected in post-1983 sample for both confidence intervals. Compared with panel A of Table A.12, the lack of rejection of inflation forecasts in panel A of Table A.15 appears to point out to the poor performance of the VAR model without money in the tail region. Interestingly however, there is little to choose among the alternative models in the post 1960-sample. This finding points out that the benchmark model is rejected in Table A.12 due to its failure in the tail region.

As a final note on the predictive density analysis, notice that which group of models are 
compared changes the answer to our main question of whether money matters. Particularly, when univariate models are introduced, model simplicity appears to be the key irrespective of sample period, forecast window and forecast horizon.

\section{Mean square forecast error analysis}

We first examine mean square forecast error statistics of seven alternative models. Table A.6 and A.7 gathers these findings ${ }^{10}$. We should highlight that the evidence of usefulness of money increases as models become more complex and restrictive. Turning first to the comparison of DSGE models, a clear pattern is revealed for both variables. First and foremost, notice that the model with money dominates short horizon forecasts. This is a reasonable result given that sticky price models of the literature point out that money is neutral in the long run. Furthermore, the model with money mainly dominates in the forecasting windows from 1990 to 1999 and from 1990 to 2009. Considering the in-sample periods for these forecasting windows, this result underscores the sensibility of our models together with their parameters. Another worth mentioning finding is that the larger theoretical model records minimum CS measure in the post-1983 sample as well. This is an evidence against the literature argument for the redundancy of monetary aggregates. Additionally, in line with this strand of literature, the model with Taylor-type interest rate rule performs better in the shorter subsample for inflation. Finally, notice that money mainly matters for inflation.

When VAR models are introduced, a worth noting finding is that DSGE models maintain their minimum MSFE record against output forecasts from these atheoretical models. As another important observation, similar to CS measure results, more restrictive models dominate longer horizons for output. However, the same cannot be said for inflation forecasts. Namely, VAR-type models register lowest MSFE statistics at almost all horizons. Finally, it is worth underscoring that, in line with recent U.S. monetary policy history models with money dominate post-1960 forecasts in the forecasting windows from 1990 to 1999 and from 1990 to 2009. When all seven alternative models are considered, an important evidence emerges for the usefulness of money for inflation. Namely, time series models with money register lowest MSFE at onequarter ahead horizon in the post-1960 sample. This is a new finding as opposed to the earlier studies' support for random walk model at all horizons. Meanwhile, the random walk model

\footnotetext{
${ }^{10}$ In the post-1983 sample, an insanity filter has been applied to 12-quarter ahead forecasts in the following four cases: output and inflation forecasts in the forecasting window from 1990Q1 to 1999Q4, inflation and output forecasts in the forecasting window from 1990Q1 to 2009Q4. Forecasts obtained in these cases are insensible. Therefore, MSFE entries of the four-variable VAR model are replaced by those from the three-variable VAR model. This insensibility is related to high lag order and amount of parameter estimates from a rather short estimation period.
} 
dominates inflation forecasts in other cases under all subsamples. The weakest performance is observed in the forecasting period from 2000Q1 to 2009Q4; where the AR model registers lower MSFE. As for output forecasts, the AR model is the preferred model. It is also worth stressing that, for both output and inflation forecasts, models with money appear to survive at some occasions in both estimation periods. This observation is opposed to the results from CS loss measure statistics. None of the three models with money recorded lowest CS loss measure.

As an additional note, we find some differences between the examination of conditional mean predictions versus entire predictive densities. First, in the former case, MSFE statistics reveal that across all model group comparisons, the decision of preferred model is sensitive to the variable of interest. Second, when interest focuses on output forecasts, different models are in general preferred across these two methods of analysis. Finally, in line with the predictive density analysis, preferred model changes with respect to group of models examined.

Tables A.23 and A.24 display the results of White reality check test. Table A.23 sets the benchmark equal to the three-variable VAR model. Findings are qualitatively similar to those from the predictive density analysis above. Accordingly, rejections of the null hypothesis are observed in the post-1960 sample. Money appears to mainly matter for inflation forecasts at shortest and longest horizons. In the post-1983 sample, no alternative model can improve upon the inflation and output forecasts from the benchmark model. White test results are in general in contrast with the MSFE statistics in Tables A.6 and A.7. The only exception pertains to MSFE statistics for inflation in the post-1980 sample where the three-variable VAR model is the preferred model. This shows that under other cases, MSFE records of alternative models are not statistically lower than that of the benchmark model.

When we test the predictive accuracy of the VAR model without money against other strawman models, the benchmark model is in general beaten by at least one of the alternative models for output and inflation forecasts in both estimation periods. However, when we focus on forecasting periods individually we observe that the benchmark model is not rejected for output forecasts at medium to long horizons in the 1990Q1 to 1999Q4 period. This shows that MSFE statistics from the AR model are not significantly low enough.

\subsubsection{Simulation analysis}

Simulated inflation and output series are generated under both subsamples from DSGE and strawman models. Parameter estimates obtained from the smaller subsamples are used to generate simulated series that are compared to the historical data from 1983Q1 to 2009Q4. 
Similarly, parameter estimates found in the larger subsample are used to obtain simulated series that are compared to data from 1960Q1 to 2009Q4. We assume that innovations are i.i.d. normally distributed with zero mean. Standard deviations are set to estimated magnitudes. We generate simulations of size 20 and 40 times the size of the corresponding historical data, $T$. Initial values for simulated series are set equal to zero. First 200 hundred simulated observations are then discarded for each series.

As a first step to compare simulated and historical distributions we look at simulated densities of output and inflation in both sub-samples as displayed in Figure C.15. The first part of Figure C.15 shows that VAR models are remarkably good at replicating the true historical density of output. The performance of VAR models somewhat deteriorates for inflation simulations. Particularly the dispersion of simulations from DSGE models are much lower for inflation compared to output. Moreover, in the post-1960 sample, inflation simulations from the smaller DSGE model appears to outperform. Of note is that, when other strawman models are introduced in the second part of Figure C.15 simulations from the RW model clearly fall behind those from alternative time series models. Among these alternatives, the dispersion of autoregressive models looks higher than that from the smaller VAR model.

We then look at the comparison of seven alternative models for inflation and output using the CS distributional loss measure, $Z_{T, S}$ test statistics and the confidence interval test. Table A.10 reports CS distributional loss measure. First we focus on DSGE models. In line with the monetary policy stance of the time, the model with exogenous money growth rate rule has minimum loss measure for output in the post-1960 sample as far as output simulations are concerned. In the post-1983 sample the model without money is the winner for both variables and irrespective of the simulation size. Meanwhile, we see that theoretical models fail when VAR models are introduced. Particularly the three-variable VAR model greatly improves simulated distributions of output and inflation towards their historical counterpart. More importantly, we observe that money does not matter as far as simulated densities are concerned. When we introduce the strawman models, the most important finding is that the ARX model emerges as the preferred model for inflation in the post-1983 sample at all simulation sizes and for output in the post-1960 sample at the larger simulation size. This is an interesting finding, given that more parsimonious models are often found to perform better than more complex models (see e.g. Swanson (1998), Amato and Swanson (2001), and the references cited therein), when the objective is to maximize predictive accuracy, while more complex models are usually preferred for policy analysis. Furthermore, the three-variable VAR model loses its dominance against autoregressive models. In sum, when all seven models are considered, we observe that 
no alternative model universally dominate for given target variable. Instead, the choice of preferred model is sensitive to the assessed variable, sample period and simulation size. As a final remark, notice that the result of distributional accuracy analysis depends on whether densities are constructed from predicted versus simulated series.

Tables A.17 and A.18 report distributional accuracy test results. We first test the threevariable VAR model against the VAR model with money and theoretical models. Inspection of Table A.17 immediately shows that none of the alternative models can better replicate simulated distribution of output and inflation. This finding is in line with the CS loss measure results. When we set other strawman models as alternatives against the three-variable VAR, Table A.18 indicates that the latter is rejected across the board. Simulations from at least one of the strawman models appear to better approximate the historical output and inflation distribution.

We now turn to the analysis of confidence intervals. Tables A.19 and A.20 report results of $V_{T, S}$ test. It is clear in Table A.19 that, under both intervals, three-variable VAR model is mostly not rejected. This finding is usually robust to bootstrap method, block length and simulation size and is in line with the analysis of the whole support region under the $Z_{T, S}$ test. The only exception pertains to inflation simulations in the post 1960-sample. The benchmark model is rejected in the larger confidence interval under bigger simulation size and block length. This indicates that the VAR model's distributional accuracy performance rather applies to the tail region in this sample. When strawman models are set as alternative models, we find that in the post-1980 sample at least one alternative model can better simulate the true historical distribution of output and inflation in the analysis of one and two standard deviation wide intervals. Findings of post 1960-sample signal that simpler time series models appear to perform better as one moves always from the center. More specifically, the benchmark model is not rejected for 0.5 standard deviation interval around the mean at all simulation sizes for output and at smaller size for inflation. Comparing with panels 1B and 2B of Table A.18, this failure of rejection shows that the VAR model perform poorly in tail region for output and inflation under the corresponding simulation sizes. In sum, the rejection of inflation and output simulations from the VAR model without money is sensitive to the size of interval or the simulation.

In sum, across the forecasting and simulation analysis, we observe the following. First and foremost, findings of our predictive and simulation analysis is in line with the post-war U.S. monetary policy history. Namely, models without money mainly dominate the post-1983 sample. This is a crucial result as it highlights the sensibility of our models and associated parameter estimates. Also, Amato and Swanson (2001) and Swanson (1998) suggest, simple time series models emerge as winners at the forecasting front. Second, there is evidence for the usefulness 
of M2 money aggregate. The most important evidence comes from the simulation standpoint. When all models are compared, the ARX model for inflation simulation is the preferred one in the post-1983 sample. As model complexity increases, predictive distributional loss measure and MSFE statistics show that money matters mostly in the post-1960 sample period and usually via the four-variable VAR. More importantly, in the framework of multivariate models, we have several findings favoring marginal predictive content of money in the post-1983 sample, in contrast to the findings of single equation time series models. As far as the target variable is concerned, M2 money supply appears to mainly affect inflation forecasts and simulations. As an additional note, we observe that, when complex models are considered, DSGE-type models often outperform at longer horizons and mainly for output forecasts. In contrast, VARtype models are winners for simulation and short-horizon inflation forecasts. Finally, when strawman models are brought into the picture, complex models for inflation and output are beaten. Precisely, random walk model appears to be the best model for inflation forecasts. The univariate autoregressive model emerges to best simulate the density and predict the conditional mean of output. All these findings thus stress that model selection is sensitive to researcher's perspective.

\subsection{Concluding Remarks}

In this study we address the theoretical argument about the redundancy of monetary aggregates in the dynamics of inflation and output. We add to the extant literature on this subject in two respects. First, we jointly specify a number of dynamic stochastic general equilibrium (DSGE) models and econometric time series models. Second, we evaluate the performance of these models via the use of novel testing methods developed for assessing predictive and simulation accuracy. The DSGE models evaluated include two New Keynesian models. Models only differ in the specification of the monetary policy. In a simulated real-time "horse-race", these theoretical macroeconomic models are coupled with time series models including vector autoregression (VAR), random walk (RW), and various autoregressive (AR) and AR with exogenous variable (ARX) type models. The testing methods used involve the evaluation of point predictions and simulations as well as predictive and simulation type confidence intervals and conditional distributions. We apply those tests suggested by Corradi and Swanson (2006a, 2007a) to judge distributional accuracy and by White (2000) for pointwise accuracy. Due to the widely recognized change in the U.S. monetary policy stance around 1980s, we consider two sample periods including the period from 1960Q1 until 2009Q4 and from 1983Q1 to 2009Q4. We ask whether 
and through which model and transmission channel money matters. Meanwhile it is well known that DSGE models impose theoretical restrictions on VAR models. Therefore this study also sheds light to whether these restrictions are indeed necessary.

Our study suggests new evidence for the usefulness of M2 money supply. We find that money matters for inflation simulations in the framework of simple econometric models through our ARX models in the post-1983 sample. However, money disappears as models get more complex. From the forecasting standpoint, among multivariate models, M2 monetary aggregate enters into the "forecast-best" VAR-type inflation models in our post-1960 sample. We also have several findings favoring marginal predictive content of money in the post-1983 sample, in contrast to the findings of single equation time series models. We also find that model selection is sensitive to the researcher's objective function, to target variable and forecast horizon. Particularly, when the objective is policy analysis, the examination of multivariate models show that DSGE-type models often outperform at longer horizons and mainly for output forecasts. In contrast, VAR-type models are winners for simulation purposes and short-horizon inflation forecasts. Meanwhile, from both forecasting and simulation standpoint univariate models generally dominate all theoretical and atheoretical multivariate models. Finally, our impulse response analysis and findings from predictive and simulation analysis show that our results are in line with the post-war U.S. monetary policy stance.

In future work we plan to extend this study in several directions. First, the analysis in this study is conducted using M2 monetary aggregate. We leave the robustness check under broader money aggregates and real time measures to future research. Second, this study focused on two baseline New Keynesian sticky price models. Variants of these standard models including features like habit formation, stochastic money demand, portfolio adjustment costs or further microfoundations with respect to the banking sector may potentially deliver different answers. Third, it is also worth analyzing whether a non-linear time series model with money could beat linear univariate winners of this study. Finally, in another study, we also plan to reiterate the current analysis using German data. Conducting the analysis of this study for Germany would provide valuable information by serving two purposes. First, Bundesbank is known to explicitly target monetary aggregates. Therefore it can be considered similar to the central bank of U.S. in the pre-1980 period. Existence of multiple equilibra in the pre-1980 U.S. data; as documented by Corradi and Swanson (2005); prevented us from analyzing this sample. German data would therefore fill this gap. Additionally, one would a priori expect more favorable results for the model with money under German data. Such finding in fact would then confirm the validity of our results for U.S. data. 


\section{Chapter 3 \\ Inflation Targeting Intensity}

\subsection{Introduction}

DURING 1990s, several industrial and developing countries opted for formal inflation targeting regime in order to establish price stability; abandoning intermediate targets for monetary aggregates and exchange rates. Starting with New Zealand in the verge of 1990s, Canada, Chile, Israel and U.K. immediately followed suit. At the time of writing, the number of central banks operating monetary policy under inflation targeting regime has reached twenty one and includes a broader range of countries.

Theoretical work stresses its appeal for achieving heavily desired level of commitment ${ }^{1}$ alongside with constrained discretion, see Woodford (2003a), Svensson (2001) and Bernanke et al. (1999) among others. Considerable attention has also been devoted to the macroeconomic effects of this new regime in practice. Many of these studies use simple dummy variables to control for its existence. Edwards (2006) analyzes exchange rate volatility and evolution of the exchange rate pass-through with time-series data in five emerging and two advanced inflation targeting countries. It is found that this regime reduced both the short-run and the long-run pass-through with no significant increase in exchange rate volatility. Ball et al. (2003) investigate the behavior of inflation, output and interest rates in twenty OECD countries. Authors show that the stronger improvement of inflation targeters represented a mean reversion instead of a direct implication of this regime. Kuttner (2005) applies the methodology in Ball et al. (2003) to 35 emerging countries. The author provides evidence for lower inflation, inflation expectations and volatility despite the initial weaknesses in institutional preconditions. $\mathrm{Wu}$ confirms the result on reduced inflation in the case of OECD countries under a multi-period differences-in-differences method. Mishkin and Schmidt-Hebbel (2006) extend the earlier research by disaggregating the treatment group into converging and stationary targeters. They reconcile earlier results by showing that that the evidence heavily depends on the control group.

\footnotetext{
${ }^{1}$ The famous paper by Kydland and Prescott (1977), favor a policy committed to an a-priori well defined goal to pursuing a discretionary monetary policy.
} 
Examining the macroeconomic performance under this regime based solely on de jure announcement of an inflation target has some flaws. First and foremost, whom can we call inflation targeter. Classifying European Union countries as non-targeters is clearly arbitrary. Not only these central banks have similar institutional design features as targeters should, but they also have to maintain certain inflation level to meet the requirements of the Union. Same argument applies for Japan and U.S. with respect to monetary policy institutions. Furthermore, Bundesbank and Bank of Switzerland are mostly considered as implicitly pursuing a price stability goal in spite of explicit money growth rate targets. Meanwhile some formal targeters are known to violate their sole objective of price stability. Therefore the binary classification accounts poorly for monetary policy design features that are embedded in the inflation targeting regime. Grouping countries under the dummy variable umbrella of value zero or one erodes this heterogeneity among targeters and non-targeters alike. Second, in the studies mentioned above diverse institutional characteristics are at best accounted for by focusing on smaller samples like emerging market countries or OECD countries. This level of differentiation is also poor. While Korea shows up as an outlier among the OECD countries, Israel distinguishes itself among the group of emerging inflation targeters. Thirdly, the tested hypotheses can only address the adoption of the target. This leads one to believe that the mere existence of this regime is sufficient enough to excel without assigning an independent role to its underlying institutional and operational aspects. Likewise, one would mistakenly blame the explicit announcement of inflation targeting for a poor economic performance. However, poor empirical findings maybe because there is no substantial difference between these groups, or those that are officially targeters may not be completely fulfilling the theoretical prerequisites. In sum we believe that the results of the early studies offer very limited insight.

Motivated by these weaknesses, we construct indexes of monetary policy design using the survey conducted by Fry et al. (2000). Indexes assign a value between zero and hundred for each central bank in the sample. The highest value is intended to represent a conventional inflation targeting central bank. First and foremost this continuous measure provides a more appropriate classification of central banks based on their underlying institutional design, rather than an officially declared regime. These indexes can also be used to reassess the performance of inflation targeting regime in terms of inflation and output dynamics. Thus we can understand whether the findings of previous empirical work are misleading or not. Furthermore, it is possible to ask new policy questions. Should targeting emerging countries be advised to put effort to reach the institutional proficiency of those counties like New Zealand and England? Would U.S. or Japan potentially benefit from explicitly declaring inflation targets? Additionally, absence of 
instantaneous gains from adopting inflation targeting has been noted by several studies; Levin et al. (2004) and Bernanke et al. (1999) among others. Thus it is important to analyze how these policy design features evolved in the run up to formal targeting or while the regime is in place. Such evolutions might potentially have bearings on the macroeconomic performance over a longer period.

The survey conducted by Fry et al. (2000) captures all aspects of a monetary policy design for a broad range of countries as of end-1999. We follow recognized definitions of the inflation targeting regime to select the relevant aspects. We then obtain several indexes aggregating these characteristics in two major ways. In the first one we simply assign weights, equal or subjective. In the other approach, we run a probit regression on the latent determinants of the correlation matrix of these characteristics. Latent variables are obtained through the factor analysis method.

This study is the first attempt to measure how close a monetary policy framework is to that of an IT regime for a broad range of countries. An earlier exercise is provided by Masson et al. (1997). While this analysis uses a similar questionnaire, it is applied to only five developing countries and relies on the views of IMFs area departments staff. Masson et al. quantify the policy frameworks of Chile, Colombia, Mexico, Indonesia and Philippines; countries that are identified by the IMF staff as currently or potentially close to an IT country out of 150 developing and transition economies. Among these countries Chile is named as the only country close to the monetary policy design of an inflation targeting. Another study in this area is provided byCarare and Stone (2006). Authors define three inflation targeting regimes; namely a full-fledged targeting, an eclectic targeting and an inflation targeting lite. The classification is conducted on countries with some form of flexible exchange rate. It is based on authors judgment of central banks clarity of commitment and on measures of credibility. Operational issues such as the use of inflation expectations, models and forecasts in formulating the monetary policy are disregarded. However, these aspects are believed to be the key characteristics of an inflation targeting ${ }^{2}$. With this metric, Brazil, Chile, Colombia, Korea and Poland are placed in the group of full fledged targeters with countries like New Zealand, U.K., Sweden and Canada.

We use our indexes to investigate two variables of interest in assessing the success of this monetary policy regime. We ask whether the intensity of this regime has an impact on the cross-sectional variation in output cost of disinflation and inflation persistence. The theoretical

\footnotetext{
${ }^{2}$ See Agenor (2001) and Svensson (1997a, 1999) among others.
} 
argument about the relation between inflation targeting regime and the output-inflation tradeoff mainly concerns central bank credibility ${ }^{3}$. Under a credible commitment to a lower inflation rate, market expectations would quickly adjust and thus prices and wages will be rapidly reset. In the context of expectations-augmented Phillips curve, this adjustment induces a lower rise in unemployment. Svensson (1999) notes that inflation targeting generates mechanisms for a credible commitment to an explicit policy loss function. These mechanisms, he argues, particularly involve increased transparency about this function and the accountability of the central bank. These aspects are put forward to ensure the public monitoring of the central banks loss minimization problem. Therefore, this policy is believed to reduce the central banks inflationary bias.Clarida et al. (1999) additionally stress the impact of inflation targeting on the price-setting behavior. Accordingly, this regime is argued to induce forward-looking expectations. Together with higher central bank credibility of commitment to price stability, the short-run output-inflation tradeoff is then predicted to decline.

We also investigate the performance of inflation persistence. By persistence we consider how fast inflation adjusts to shocks from different sources. In other words, persistence relates to whether the current value of inflation strongly depends on its past value. The potential for inflation targeting to modify inflation persistence has to do with increased communication. Explanation of policy through regular reports is supposed to promote central bank transparency. Higher transparency is in turn believed to anchor long-run inflation expectations; thereby breaking the link of current inflation to its history. This part of our study serves two purposes. First and foremost; measures of inflation persistence are subject to less controversy. In contrast, sacrifice ratio estimates are heavily criticized on the grounds that measures of potential output are difficult to construct. Secondly, recent empirical work provides more favorable findings as apposed to the performance of cost of disinflation. Thus we also indirectly check whether indexes provided in this study are sensible.

Earlier studies about sacrifice ratio reach conflicting results. Bernanke et al. (1999) consider the inflation targeting experience of New Zealand, Canada, Sweden and U.K.. The output cost is analyzed using sacrifice ratios as well as the parameter stability tests on estimated Phillips curves. Both of these methods suggest that achieving lower inflation is not less costly under inflation targeting at least for the early stages of this new regime. In the analysis by Corbo et al. (2002) for the 1980 to1999 period, GDP-based sacrifice ratios are reported to deteriorate after the adoption of IT. Meanwhile sacrifice ratios based on industrial production

\footnotetext{
${ }^{3}$ See Posen (1998), Clarida et al. (1999), Baltensperger and Kugler (2000) and Sargent (1999).
} 
display a remarkable drop after the adoption of the target and are well below those of nontargeters. In another study Corbo et al. (2001) document support for Latin American emerging economies that started their stabilization at moderate to high levels of inflation as opposed to the industrialized countries. In a framework of expectation-augmented Phillips curve, Clifton et al. use a smooth transition regression model. Authors show that unemployment-inflation trade-off in OECD countries adopting inflation targeting has diminished over time as the credibility of the central bank is enhanced.

Our investigation uses Ball (1993) to estimate the output cost of lowering inflation during disinflation episodes. Sacrifice ratios are calculated for disinflation episodes recorded in the post1990 period. Due to the limited time dimension of the survey, the episodes that are around 1999 are considered for the cross-sectional analysis. We conduct the analysis under two samples, OECD countries and the full sample of surveyed countries for which the output cost could be calculated. The sample period has two disinflationary episodes that are not directly intended by the central banks. First and foremost, 1990s is characterized by a major productivity increase in the world economy ${ }^{4}$. This brings about increased output along with falling prices that are not attributable to monetary policy actions. Secondly, the end of the century is marked by the Asian financial crisis that later spread to some emerging Latin American countries. The subsequent failure of banks and finance companies provoked recession and deterioration in these exchange rates. Asian and Latin American central banks then raised short-term interest rates to offset the shock to the economy. To control for this experience, we introduced a dummy variable. As for the former, we rerun the regressions for the costly disinflation periods alone.

Numerous studies provide supportive evidence for the lower persistence in inflation among industrialized countries. In a sample running from the first quarter of 1994 to the second quarter of 2003 Levin et al. (2004) (LNP) compute inflation persistence for twelve industrialized countries including five IT experiences. Authors show that the persistence is dramatically lower in IT countries particularly under the core consumer prices. For a sample of two-year rolling inflation from 1968 to 1996, Siklos (1991) document a big drop in New Zealand and Canadian inflation persistence in 1980s. Additional support for lower persistence in Sweden and U.K. compared to the period prior to the adoption of IT regime is provided by Benati (2002) and Kuttner and Posen (2001) respectively.

Our findings can be summarized as follows. Index scores reveal that Japan consistently comes close to the monetary policy conduct of IT countries. This is usually followed by Armenia and

\footnotetext{
${ }^{4}$ The methodology in Ball assumes that the only source of changes in inflation is shifts in demand.
} 
occasionally by U.S. It is a new finding that Armenian central bank performs remarkably well. This country is not cited in the literature as a potential targeter. Across the indexes, Sweden, New Zealand and U.K. often come up as the top three countries; with U.K. constantly taking the lead. Meanwhile, Canada keeps up with this group when the index is broadened. Indexes confirm the impact of the inflation targeting regime on the lower inflation persistence among industrial countries. Finally it is also observed that, compared with the anecdotal evidence in the recent studies, indexes point out to noticeable structural changes in Mexico and Peru along with the potential targeters of the time. This study therefore argues the need for an immediate update of the survey for capturing the progress of the incumbents and new targeters alike.

As for the performance of our macroeconomic variables, we observe the following. Firstly, better institutional characteristics for targeters or officially declaring the policy on top of these characteristics do not deliver significantly lower inflation persistence or sacrifice ratio. For both the output cost of disinflation and inflation persistence we observe even poorer results for the group of all countries. On the other hand, indexes are found to significantly reduce inflation persistence in the group of OECD countries. This finding puts doubt on pure policy announcement effect. Secondly, there is evidence of a threshold index level after which more favorable results for inflation persistence and the sacrifice ratio are obtained. Thirdly, transparency in the implementation of the targeting policy appears as an important tool for lowering inflation persistence among the OECD countries. As for the sacrifice ratio the degree of discretion and the central bank financing of the government appear to be significant aspects in OECD countries and in the full sample respectively. Finally, the change in institutional design features under or going to inflation targeting has no significant impact on the output cost of disinflation.

The rest of the paper is structured as follows. Section 3.2 describes the construction of the monetary policy design indexes and discusses the results. Section 3.3 presents the methodology for the analysis of the sacrifice ratio and inflation persistence. This section also reports the regression results. Section 3.4 concludes and presents directions for further research.

\subsection{Monetary Policy Design Indexes}

\section{Construction of the Index}

The data used in the construction of the indexes draws on the survey conducted by the Central Bank of England about the monetary policy framework characteristics of a broad range of 
central banks ${ }^{5}$. The survey captures these characteristics for 92 central banks as of beginning of 1998 for CEFTA countries ${ }^{6}$ and beginning of 1999 for the remaining participants ${ }^{7}$. The questionnaire measures the four following aspects. First, central banks are asked about the short and medium term policy focus on particular objectives like exchange rate, money and inflation. The survey requires central banks to assign a score to themselves in each individual policy categories. A degree of discretion is then derived based on these answers ${ }^{8}$. Secondly institutional characteristics such as independence, accountability to government and transparency are considered. Central bank independence is broken into target and instrument independence, together with the terms of office of governor, central bank financing of government deficit and whether the price stability is the legal objective. Thirdly, the use and importance of various forms of monetary analysis is investigated. This is done by asking to what extent the analysis of inflation expectations together with models and forecasts are undertaken and how important is the analysis of money and the banking sector. Finally the importance given to financial sectors stability is taken into account. The score for each of these four categories changes between 0 and 100 and it is a weighted sum of the corresponding sub-questions.

To construct our indexes we selected those characteristics mentioned as distinguishing features of an inflation targeting regime in earlier studies. This selection mainly relies on the following recognized definitions by Leiderman and Svensson (1995), Svensson (1997b), Masson et al. (1997), Cotarelli and Giannini (1997) and Mishkin (2000). Referring to some old targeters of New Zealand, Canada, U.K., Sweden and Finland, Leiderman and Svensson (1995) highlight two characteristics:

- an explicit quantitative inflation target; specifying the index, the target level, the tolerance interval, the time frame, and possible situations under which the inflation target will be modified or disregarded

- the absence of an explicit intermediate target for monetary aggregates or exchange rates

\footnotetext{
${ }^{5}$ See Fry et al. (2000) for a detailed description of the survey and detailed survey results can be found at http://www.bankofengland.co.uk/education/ccbs/publications/mpfagc.htm

${ }^{6}$ CEFTA countries consist of the Czech Republic, Hungary, Poland, Slovenia and Slovakia.

${ }^{7}$ The survey is missing information on the transparency and the accountability of Denmarks and Japans central banks respectively. We fill in the former by taking the average of the score of those surveyed countries that were members of EU as of 1999. These countries are Austria, Belgium, Finland, France, Germany, Greece, Ireland, Italy, Netherlands, Portugal, Spain, Sweden and U.K. The survey does not have data on Luxemburg which was also an EU member in 1999. For the latter we referred to the U.S. central bank which looked alike to that of Japan on several institutional aspects.

${ }^{8} \mathrm{~A}$ discretion score is calculated as twice the maximum score among that of the inflation, exchange rate and money focus minus the sum of the other two. The resulting number is then converted to an index between 0 and 100. A high score implies more discretion.
} 
Later, Svensson $(1997 \mathrm{~b})^{9}$ also indentifies this regime as "inflation forecast targeting" and adds "a high degree of transparency and accountability" as another important aspect. On the other hand four aspects mentioned byMasson et al. (1997) are:

- explicit quantitative targets for the rate of inflation some period(s) ahead.

- clear and unambiguous indications that the attainment of the inflation target constitutes the overriding objective of monetary policy in the sense that it takes precedence over all other objectives.

- a methodology for producing forecasts that uses a number of variables and indicators containing information on future inflation.

- a forward-looking operations procedure in which the setting of policy instruments depends upon the assessment of inflation pressures and where the inflation forecasts are used as the main intermediate target.

Authors also mention central bank instrument independence as a requirement for the adoption of IT; which itself can only be accomplished via a freedom from fiscal dominance. Cotarelli and Giannini (1997) stress that this regime is not a mere announcement of the inflation target by the government but that it is rather about

- an inflation path extending up to a few years ahead.

- the setting up of procedures for public monitoring of how the monetary authorities pursue their objective.

Finally Mishkin (2000) summarizes the framework in five main elements:

- the public announcement of medium-term numerical targets for inflation.

- an institutional commitment to price stability as the primary goal of monetary policy, to which other goals are subordinated.

- an information-inclusive strategy in which many variables, and not just monetary aggregates or the exchange rate are used for deciding the setting of policy instruments.

- increased transparency of the monetary-policy strategy through communication with the public and the markets about the plans, objectives, and decisions of the monetary authorities.

- increased accountability of the central bank for attaining its inflation objectives.

These definitions imply that this monetary framework is not merely about policy objectives. It also involves increased central bank transparency through increased communication of how objectives are pursued and high accountability for attaining its goal; accompanied by special

\footnotetext{
${ }^{9}$ Forthcoming in New Palgrave Dictionary of Economics.
} 
operational characteristics. Interestingly, none of these definitions strongly allude to central bank independence, except for Masson et al. (1997) mentioning of fiscal dominance as a more modest form of instrument independence. Additionally, Bernanke et al. (1999) point out that inflation targeting combines, possibly as a unique characteristic, "(...) some of the advantages traditionally ascribed to rules with those ascribed to discretion "; thereby pointing out that it involves a "framework rather than a rule". Amato and Gerlach (2002) criticize such rigorous definitions of inflation targeting framework on several grounds. Authors argue that the characteristics of the Bundesbank, Swiss National Bank and the European Central Bank are in line with the spirit of an IT regime. Additionally, it is claimed that a decent degree of transparency prevails in the modern central banking practice. Therefore, authors put forward only two elements that discriminate IT from other policy strategies: (an) announcement of a numerical inflation objective and a desire () to achieve this objective accomplished by an active adjustment of the policy instrument in response to changes in expected inflation. Authors argument therefore implies that we should base our index solely on the policy focus aspects and on the use of analytical tools so as to capture the active policy adjustment property.

These formal definitions also appear to rule out any possibility of an alternative nominal anchor, like exchange rate or a monetary aggregate, to coexist with the primary objective of an inflation target. However, the optimal policy in a conventional inflation targeting regime as developed in Svensson (1999) leaves room for nominal variables to play a role in the monetary policy. This is made possible as long as these variables signal any change in the desired path of the inflation target. The policy instrument is then allowed to respond to these signals with the aim to achieve this ultimate goal. Furthermore, Chang (2007) recently documents Latin American countries strong reserve accumulation and interventions in the foreign exchange markets in the absence of an inflationary pressure and without any commitment to an exchange rate level. These practices are shown to deviate from the motivation suggested in Svensson (1999) and other standard theoretical explanations. Thus these studies convey that other monetary variables can be and seem in practice to be used as a means of achieving the pre-announced inflation target.

Aggregation of the surveys indicators to a single index from the perspective of the inflation targeting regime tried to incorporate all these considerations. We used the guidance of these definitions in selecting the relevant indicators from the survey and designed indexes based on this selection. As for the indicator selection matter, we isolated out the indexes from three issues. Firstly, we excluded the survey questions about how much central banks care for the financial stability and which method they find most important in the analysis of the money 
and the financial sector. These characteristics do not constitute a feature of a representative inflation targeter. Secondly, we excluded those issues related to the implementation of the IT policy regime such as the target horizon, the price index to monitor, the relevance of asset prices etc. Finally, we did not append an inflation targeting dummy to the set of indicators to avoid automatic awarding of its mere existence. This would disguise the performance of those countries that possess similar policy arrangements to inflation targeting. It would also prevent an accurate placement of the weak targeters. We are then left with the following measures: the policy focus, central bank accountability, its instrument independence, and its financing of the government, policy explanations, analysis of inflation expectations and analysis using different forecasting and simulation methods.

As for the designing of the indexes, two issues are involved. One is about taking into account the role of nominal aggregates other than the inflation target in the implementation of the policy. The other concerns the constraint discretion under the inflation targeting. To incorporate the former, we found the following adjustment suitable. Particularly, we took a closer look at the answers to sub-questions about the policy focus on the money aggregates and the exchange rate. We then selected those sub-questions that we thought might give signals that these nominal variables are not themselves the primary objective. After this selection, for a given sub-question, we let a specific response to serve as a tolerance level. At or below the code to which this response corresponds, we did not penalize a central bank for its overall score. As an additional constraint, we required central banks not to state either the exchange rate or the money as the main objective and not to specify any target for the latter. To illustrate, we picked the sub-question 4 for the exchange rate as the question from which we can deduce that this variable is monitored without being the primary target. We then let the response exchange rate sometimes prevails to serve as a tolerance level; the coding of which is 25. Suppose now that a central bank picking this answer did not mention the exchange rate or money as characterizing the primary objective and did not assign a target on the latter. Therefore a value of zero is recorded for the first sub-question about exchange rate objective and for the second sub-question about money objectives. In this case the central banks overall score is not subject to a penalty. However, if instead at least one of the requirements is violated, 25 times the associated weight for the exchange rate objective is deducted. Under the framework of inflation targeting, we do not find such high attention on either the exchange rate or money acceptable. These subquestions and levels are chosen to the authors discretion and by the limits of the survey coding. The latter issue is addressed by setting a threshold to the degree of discretion, analogous to the tolerance levels. This threshold corresponds to the median discretion level among twelve 
inflation targeters which comes up as 14 .

With this setup, we constructed four sets of indexes to generate 7 index series. These indexes measure the distance of a given central banks monetary policy framework vis- -vis an IT regime. In each case a central bank is assigned a score varying between 0 and 100 . The highest score is associated with a representative inflation targeting country. The first three sets are based on simple weighted average of the combination of the selected indicators from the survey. In the last one we let the data determine the score of the central banks. These first three sets are constructed with the aim of carefully observing the effect of distinct combinations of these characteristics, the weighting scheme and the tolerance for the use of additional nominal variables. The first two sets only include policy focus indicators. Index I, did not differentiate among the sub-questions to the exchange and money focus and thus took into account their aggregate score. Index II, applied the tolerance method described above. The third set, named as index III, extended index II by adding all other selected indicators. Each of these three combinations generated two series according to two weighting schemes. One of these schemes is computing an equally weighted average. The other involved more subjectivity. Accordingly, some indicators are grouped under a 70

Alternatively, we also let the data speak for itself by estimating a probit model for the binary choice of adopting the inflation targeting regime. We used all the selected indicators of the survey together with the sub-questions to the measure of focus for the exchange rate and the monetary aggregates. Before estimating the probabilities of adopting IT, we reduced the dimension of these indicators ${ }^{10}$. To do so we applied the factor analysis methodology. This methodology aims at approximating the covariance structure of a given set of variables via a few underlying factors. The first step in this methodology consists of choosing the number of underlying factors to be extracted from the data set. In determining this number we used the guidance of the scree test. Once the number of underlying factors is determined, the factor model analysis proceeds by obtaining the loadings in order to identify the factors and estimating the factor scores ${ }^{11}$. We found these matrices applying the principal component solution method ${ }^{12}$. As displayed in Table B.14 the pattern of loadings shows that each variable loads strongly to a

\footnotetext{
${ }^{10} \mathrm{~A}$ direct estimation of a probit model without reducing the dimension of the original set of variables did not provide the parameter estimates due to a failure in the calculation of the Hessian in the maximum likelihood routine.

${ }^{11}$ The factor analysis is conducted using the PROC FACTOR procedure in SAS. Factor loadings obtained from the principal component method are rotated using the VARIMAX orthogonal rotation option to simplify their interpretation.

${ }^{12}$ The details of these steps can be followed in Johnson and Wichern (1992).
} 
single factor ${ }^{13}$. These factors constitute the independent variables in the discrete choice model for adopting the inflation targeting regime ${ }^{14}$. Estimated probabilities from this regression then constituted an alternative index. Table B.15 shows the results of this regression . Given the factor loadings the sign of the parameters look meaningful.

Table B.2 reports the average score on the survey questionnaire categories and the correlation of these categories with having the policy in place. We consider a central bank to be under an inflation targeting regime if this is publicly announced to have been adopted until mid-1999. The sample of targeting countries consists of twelve countries ${ }^{15}$ and the dates of target adoption follow Mishkin and Schmidt-Hebbel (2006). We excluded Finland and Spain from this sample as their central banks opted from inflation targeting to join the Euro in 1999. Our index is not based on a de jure announcement of an inflation target. Yet our main interest in this Table is to make the following observations and thus justify the design of our indexes. We want to assess to what extent survey scores justify the description of this regime by these recognized researchers in this literature. We also want to identify the most distinguishing aspects. The Table shows that, the average scores are in general in line with the authors claims. De jure IT countries display a high focus on inflation and a strong use of analytical tools. As put forward by Bernanke et al. (1999), the level of discretion is attention grabbing, with an average of mere 20.1. In accordance with Masson et al. (1997), not all aspects of the central bank independence are strongly associated with the inflation targeting. The focus on price stability appears to be ubiquitous as this aspect became the main mandate of the modern central banking. In contrast the target independence and a high level for the term of office of the central bank governor are almost non-existing. All these three characteristics have very low correlation with IT. However, instrument independence and central bank financing of the government deficit appear to be distinct characteristics compared to other non-IT countries. These averages however prove Amato and Gerlach wrong with respect to central bank transparency and accountability. The average on these aspects shows that the European Union $\operatorname{countries}^{16}$ are not similar to

\footnotetext{
${ }^{13}$ The sign of the factor loadings indicate the direction of the correlation between the observed variable and the underlying factor.

${ }^{14}$ As a caveat, it should be noted that the indicators selected from the survey might potentially be endogenous to the choice of inflation targeting.

${ }^{15}$ These countries are Australia, Canada, Chile, Czech Republic, Israel, Korea, Mexico, New Zealand, Peru, Poland, Sweden and U.K. To avoid the subjectivity in identifying the start of a full-fledged inflation targeting, authors suggest a more explicit distinction in terms of the stationarity in the target announcement. They identify two periods, converging-target period where inflation targets are typically adjusted downwards and are based on multi-annual and stationary-target period where the announcement is done once for an indefinite future. We considered the converging period where applies to label a country as inflation targeter.

${ }^{16}$ The European Central Bank (ECB), which formally replaced the European Monetary Institute in June 1998, actively started to exercise its full power with the introduction of the euro in January 1999. As the Bank of Englands survey of the monetary policy framework applies to the beginning of 1999 for the European countries,
} 
IT countries. Furthermore, these features appear to strongly separate this regime from other non-IT countries as well. Therefore we did not exclude these characteristics from the indexes.

Figures D.1 and D.2 plot each selected indicator for de jure IT countries and non-IT countries. These plots clearly highlight the heterogeneity among countries in each subcategory. Figure D.1 shows that as of 1999, there are those IT countries with considerable monitoring of the exchange rate and monetary aggregates. This is reflected in above average discretion level for Chile, Korea, Peru and Poland and Korea. These countries also display failure on other policy design characteristics, like very low central bank accountability and transparency. Additionally, Mexico and Israel display some weakness in terms of central bank financing of government deficit and central bank transparency. It is also interesting to observe a high dispersion for the analytical characteristics. In this regard, only Canada, New Zealand and U.K. record a value above 90 for both categories. Among non-IT countries on Figure D.2 a bigger heterogeneity meets the eye, except for the central bank independence. While the use of exchange rate or monetary aggregates looks to prevail in many countries, analysis of inflation expectations, together with the models and forecasts look much less common. Among these countries, it is worth mentioning that; nothing but an explicit policy focus on inflation and high discretion appear to prevent Japan and U.S. from being labeled as an official inflation targeter. Additionally, Armenia appears to be a potential inflation targeter, due to high inflation focus accompanied by central bank independence, accountability and transparency.

Information gathered in this survey provides a highly valuable dataset for analyzing the monetary policy design features of a comprehensive group of countries. Especially detailed information on an exhaustive list of indicators helps us to design sophisticated indexes. Meanwhile, the survey comes with some drawbacks. Firstly, it is disappointing to note the lack of information from the central banks of Colombia and Brazil that limits the range of Latin American experience to Peru, Chile and Mexico. Secondly, the lack of time dimension to the survey presents another constraint. It is not possible to analyze the transition of the policy design going towards or its evolution under inflation targeting. The researcher is thus forced to work on just a snapshot of this evolutionary policy. This also forces us to make a choice among several disinflationary episodes for a given country in the following analysis of sacrifice ratio. Thirdly the timing of the survey limits the chance of exploring more recent inflation targeters like Norway, Iceland, Hungary, South Africa, Philippines, Thailand and more recently Turkey. In an attempt to address these two issues we construct a proxy that we expect to trace the 
transition in the monetary policy design features of official targeters. Finally, responses to the questionnaire are prone to be contaminated by the subjective opinions of the central bank officers resulting in a measurement error. We believe that these weaknesses indeed require caution. Nevertheless, we tolerate them on the basis that this work is the only survey that summarize monetary policy design features of a broad range of central banks in late 1990s and that is made publicly available. As for the measurement error, we believe that there is no systematic misrepresentation for any given indicator and thus that any mismeasurement applies to some extent to all central banks. Therefore, we do no expect any correlation of the regressors with the error term in this respect in the sacrifice ratio regressions.

\section{Construction of the Proxy}

The fact that Central Bank of Englands survey is conducted only once in a specific period in time brings about some limitations as mentioned above. In an attempt to address these two issues we construct a proxy that adds a time dimension in our analysis. We expect this series to trace the transition in monetary policy design features of official targeters. As we have shown in Figure D.1, the group of de jure inflation targeters is not homogenous. Thus we believe that, it is conceivable to expect the monetary policy design changes to have been stronger for the less advanced countries. Furthermore we suspect such differences to have implications on the sacrifice ratio.

The proxy uses data on exchange rate arrangements in the International Financial Statistics (IFS) and Moodys ratings on foreign currency government bonds. The choice of these variables is motivated by Carare and Stone (2006) and Hauner et al. (2007) respectively. In the former study, it is presumed that countries with some form of floating exchange rate make a commitment to an inflation target. MeanwhileHauner et al. (2007) use sovereign debt ratings as a measure of policy credibility. Particularly authors analyze whether EU accession affected credibility. Carare and Stones classification however uses ratings on long-term local currency government debt. These ratings are taken as a measure of credibility of commitment to a target. The intuition for this measure is provided by the fact that ratings reflect confidence on currency and the strength of fiscal position, which would be guaranteed due to a credible central banker. Meanwhile we did not observe major variations in these ratings over the time span that this study focuses.

As for exchange rate arrangements, a dummy variable for flexible exchange rate regime is calculated from the IFS data. Accordingly, a value of one indicates that a country adopts one of the three flexible exchange rate arrangements. We did not restrict the dummy variable to 
the independently floating arrangement with the same concern for incorporating some flexibility in the implementation of the inflation targeting regime by also monitoring other nominal variables $^{17}$. We aggregated this dummy variable with credit ratings, by assigning an equal weight, to obtain an annual series between zero and hundred ${ }^{18}$. The change in this series for each individual country is then computed as the difference between its average during the disinflation episode, for which the sacrifice ratio is computed, and its value three years before the start of this episode. One could have chosen the level of the proxy in the first year of the disinflation episode rather than the average thereof. Yet, it is observed that in some cases this proxy changes during these episodes. This mainly applies when such periods are long or the adoption of the inflation target is officially adopted sometime during this period. Greece is a good example for the former case, where a disinflation is recorded from 1990 to 2000. The latter case occurs in Czech Republic, Hungary, Finland, Korea, Mexico, New Zealand and Sweden.

Figure D.3 plots the path of the proxy since 1985 for de jure targeters. It is observed that more developed targeters did not display major movements in the last two decades except for Sweden in 1992. Among other targeters, a remarkable jump is observed in Czech Republic, Finland, Hungary, Peru, Iceland, Israel and Thailand shortly before the adoption of the regime. In the sequel we investigate the possible effect of this difference in sacrifice ratio regressions by interacting an IT dummy with the change in the proxy calculated as described above.

\section{Results}

Table B.3 displays the correlation coefficients among the seven indexes. The Table shows that the content of the indexes differentiate the series IIIA, IIIB and IV from the restricted series IA to IIB. The correlations across these two groups are in general less than $85 \%$. The Table also signals that indexes are not sizably differentiated with regard to the weighting scheme or the treatment of the sub-questions for the alternative policy choices. As for the former issue, the correlations between series IA and IB, IIA and IIB and IIIA and IIIB are around 90\%. As for the latter, when the detailed policy aspects are considered under index II, the correlation with the series $\mathrm{I}$ is 99

Table B.5 shows the index scores in alphabetical order and Table B.4 reports group averages. Following main points emerge from these scores. First, it is confirmed that the framework of the

\footnotetext{
${ }^{17}$ Levin et al. (2004) Levy-Yeyati and Sturzeneggers (2000) find discrepancies between their classification, based on the exchange rate and reserve data, and that of the IFS based on the self-report of the central banks. Nevertheless, we believe that any systematic error in the IFS classifications would have no bearing on our analysis as we are interested on the change of the proxy over time rather than its specific level in a point in time.

${ }^{18}$ The proxy series for 1999 has a $57 \%$ correlation with the index constructed from the probit regression.
} 
12 targeting countries is far from being identical. Indexes place Korea, Peru and Chile far behind their more developed peers. Scores of the central banks of Korea and Peru are consistently below 55 and the worst among targeters. Chilean central banks characteristics appear to be well below some industrialized and developing countries central banks under indexes III and IV. In contrast to these countries, Sweden, New Zealand and U.K. usually come up as the top three countries while U.K. constantly takes the lead. Either Mexico or Australia take the fourth rank under the index I. Canada replaces them when the index is broadened. This is mainly due to the Canadas slightly lower inflation focus compared to these countries.

Second, our indexes are sensible with regard to Truman (2003) description of G3 countries monetary policy framework. Truman (2003) indicates the group of G3 countries (United States, Euroland ${ }^{19}$ and Japan) as potential industrialized targeters ${ }^{20}$. This identification is based on their well known commitment to price stability, that show up as low inflation record in the past decades together with their heavy use of inflation forecasts for guidance in the monetary policy decisions. In our indexes, the score of Japan and U.S. consistently come close to those of the formal inflation targeters, especially under index IIIA and IV. When all indicators are covered, EU countries score higher on average than other non-targeters particularly under indexes IIIA and IIIB.

A third interesting finding from the indexes pertains to the observation that Armenia consistently follows closely the inflation targeters with decent index score. Meanwhile, to our knowledge, this country has not been pointed out as a potential targeter in earlier studies.

Finally, compared with earlier analyses of individual experiences, we notice that some countries display rapid changes in their policy design features. Therefore we argue that surveys in the spirit of the one conducted by the Central Bank of England should be repeated more frequently. As such, we observe that Mexicos score strongly takes over that of Chile. However, in Masson et al. (1997) Chile was mentioned as the country that comes closest, among Colombia, Indonesia, Mexico and Philippines, to representative targeters like U.K., New Zealand, Canada and Austria. Truman (2003) puts forward that Argentina, Indonesia, Russia and Turkey are actively aspiring to adopt this regime as of 2002. These countries index levels are below 60 , with considerably low score for Turkey which adopted some form of targeting as of 2003. Truman (2003) also documents that as of 2002, Peru is reported to have the price stability as the sole objective, while its central bank is shown to give more priority to monetary stability as of 1999

\footnotetext{
${ }^{19}$ The group of Euroland countries does not include Denmark, which is a member of the EU as of 1999. Our finding is however maintained when Denmarks score is excluded.

${ }^{20}$ Truman mentions an inflation rate of $10 \%$ or less as one indicator to classify a country as a potential targeter. Achieving such a low rate is interpreted as a must before a country even considers adopting this framework.
} 
in the records of the Bank of England Survey.

Other worth mentioning observations are as follows. The comparison of the first two sets of indexes to the broader ones stresses that the inflation targeting does not only involve a high and clear focus on price stability. When only the policy focus is considered, Armenia and Albania rank close to decent inflation targeters, with scores above 70. Meanwhile their low grade in other institutional and analytical aspects makes them loose their position, particularly for Albania. Under index III that combines all indicators, Ecuador, Finland, Netherlands and Portugal instead become close to de jure targeters. Table B.6 also shows that other non-IT countries fall behind OECD members when all indicators are aggregated.

As was highlighted across the correlation coefficients, the impact of weighting scheme or the tolerance on alternative policy is limited. The improvement due to the tolerances on the sub-questions of the exchange rate focus and money focus can be traced across indexes I and II. This impact is limited to $4 \%$ and $5 \%$ on average for inflation targeting countries under the equal and unequal weighting scheme respectively. Yet this easing has much bigger impact for some other countries which could benefit from these tolerance levels across many subcategories; collectively. These are Belize with a 50\% increase, Botswana and Sierra Leon with a $35 \%$ increase. Nevertheless; when other characteristics are introduced to the index, despite these big jumps, these countries rank well below inflation targeters, with only Botswana somewhat catching up. As for the effect on the ranking of IT countries, a few interesting points with this adjustment are that Australia, with its zero exchange rate focus surpasses Sweden when details are ignored. Meanwhile Chile and Poland manage to defeat Albania and Armenia depending on the weighting scheme. As for the weighting scheme, the equal weighting of the indicators undermines the score of those countries which have a decent inflation focus, or low exchange rate focus as opposed to other characteristics. The impact shows up remarkably in the case of Armenia and Albania which score above 80 when these two aspects are given higher weights. Other such countries are Croatia, Kyrgyzstan, Mongolia and Jamaica. The impact on the high score inflation targeters is unsurprisingly minimal. This is because these countries already display decent records across all indicators compared to other countries.

Index IV which is determined through estimated probabilities of adopting inflation targeting, strongly separates weak targeters and non-targeters. As such after Polands score of 51.5, all other countries are graded below 28.9 with 29 of them being assigned zero probabilities. It is highly important that central banks of Japan and U.S. are maintained among high score countries. This separation is also underscored in Table B.6 where all non-IT country groups except Japan and U.S. score less than 10 on average. 


\subsection{Sacrifice Ratio and Inflation Persistence Analysis}

\subsubsection{Calculation of Sacrifice Ratio}

To compute output costs of disinflation, we collected quarterly real GDP and CPI data for late 1980s until 2007. All data is taken from the International Financial Statistics except for the GDP series of Kuwait that comes from the historical statistics in Maddison (2007) ${ }^{21}$. For the following 16 countries, quarterly data on GDP was not available either for the whole decade or for the disinflationary period: Bahrain, Bangladesh, Barbados, Belize., Egypt, Fiji, Greece, Hungary, Iceland Kenya, Kuwait, Mauritius, Namibia, Sierra Leone, Sri Lanka and Uganda. For these countries, corresponding annual series were interpolated.

Sacrifice ratio estimates are obtained using the method developed by Wu. Accordingly, first, disinflation episodes in trend inflation are identified. Trend inflation is measured as the centered 9-month moving average of actual annual inflation. A disinflationary episode then corresponds to drops between the peak and trough of the trend inflation. The peak (trough) is the quarter in which the trend inflation exceeds (remains lower than) the rate in the four previous and following quarters. Output cost is computed as the accumulated difference of the real GDP (in logarithms) from its trend. Trend output is obtained by fitting a line between the two points where output (in logarithms) is at full employment level. These full employment points are assumed to correspond to the start of the disinflation period and to four quarters after the end of this period. Accumulated output loss is computed as the trend minus the actual level. Negative sacrifice ratio record thus indicates a more favorable output-inflation trade-off than a positive one. Unlike Ball (1993), we also calculated sacrifice ratios for disinflation episodes with a drop of less than two percentage points and those starting at an inflation rate of up to $35 \%$ are also considered. This cutoff corresponds to the Mexican inflation rate; which we wanted to keep in the sample.

Sacrifice ratios for 53 countries are included in the regressions. This drop in the sample size from those 92 countries covered by the survey is caused by three issues. The first trimming is imposed by the upper limit set on the starting inflation. Accordingly, disinflation episodes starting at a rate above $35 \%$ are excluded. Two more constraints are due to data availability in some developing countries. One of these constraints pertains to the lack of either GDP or inflation data. We were thus unable to calculate output-inflation trade-off for such cases. The other restriction came from the missing data for variables used as instruments for the two-stage

\footnotetext{
${ }^{21}$ Data until 2003 can be reached at http://www.ggdc.net/maddison/ and the update through 2007 at http://www.conference-board.org/economics/database.cfm\#1
} 
least square estimations. As explained in more detail in the sequel, these instrumental variables are measured for a time span going back until 1985. Such data is typically missing for those countries which were under the rule of the former Soviet Union until 1991.

Most of the countries had more than one disinflation episodes. Due to the fact that the survey data is available only for a particular period, we targeted the disinflationary years that best coincided with the characteristics summarized in the indexes. Otherwise, index records may under-represent the policy design of a central bank for even a near future. A change may occur soon in countries that opted for a different regime, like Hungary, Iceland, Norway and Switzerland in this case; which converted to inflation targeting in the verge of 2000. In line with this above-mentioned aim, we then applied the following procedure in the selection of the disinflation episodes as long as the data allowed. We wanted the start of the disinflation to be possibly close to the measurement of the survey. This concerns the first half of 1998 for CEFTA countries and the first half of 1999 for others. At the same time we imposed for a long enough period of time spent under falling inflation following 1999:01 and 1999:02; the quarters through which surveyed central banks were filling out the questionnaire ${ }^{22}$. Some adjustment is done to this scheme for the new inflation targeters in 2000s; i.e. Hungary, Iceland, Norway and Switzerland. Accordingly, instead of the later disinflation periods which coincide with their inflation targeting experiences, we chose the ones that go far back in 1990s. This is because; International Financial Statistics records of the IMF regarding the exchange rate arrangements clearly indicate a change in the monetary policy focus. As such; these countries are classified as following pegged exchange rates, managed floating exchange rates and monetary aggregate targets accompanied by freely floating exchange rates respectively in the April 1999 report. By December 2001, Iceland and Norway become inflation targeter under free float, and Switzerland opt out from money aggregate target. As for Hungary; IFS shows that its exchange rates is within crawling pegs. Nevertheless, with a possible higher inflation focus along with a removal of the exchange rate as the main objective, Hungarys index scores almost doubles with a back of the envelope calculation.

Panel A of Table B.6 shows the average sacrifice ratio statistics for the country groups and alternative time periods for which the sacrifice ratios are calculated. When sacrifice ratios for periods close to the index are considered Finland, Hungary, Iceland, Norway, South Africa, Spain, Switzerland and Thailand are dropped from the sample of IT countries. Although our empirical investigation does not rely on de jure existence of the IT framework, this is still the

\footnotetext{
${ }^{22}$ This implies that, some of the disinflation experiences started after the survey was conducted; like for Australia, Barbados and Canada among many others.
} 
basis of the grouping in Table B.6. The Table mainly aims to have a cursory look at the impact of restricting the sample for the two reasons mentioned above: the timing of the survey and data availability.

Table B.6 reveals the following points. First, in the biggest time series sample at line four shows that the figures for OECD countries are worse than the non-OECD group be it inflation targeter or not. This performance may be reflecting the effect of wage rigidities. This pattern is also observed in the smaller time series samples among the non-IT countries. Second, the statistics across lines 5 and 6 in Table B.6 shows that, excluding observations due to the lack of instrumental variable data does not have sizeable impact. Meanwhile a remarkable change appears when he sample narrows down towards the date of the survey. Average sacrifice ratio statistics improves for most of the groups. This implies that the odds of finding support for stronger institutional design appear to be bigger in our regressions. More specifically, more favorable figures are for the overall targeters. The same improvement is observed between the high versus low score index group of countries. Meanwhile a closer look at the sacrifice ratios for all disinflationary episodes reveal that there is no clear pattern in the direction of the sacrifice ratio after the adoption of inflation targeting regime. Except for Australia, Czech Republic, Korea, Sweden and U.K., it is hard to observe a continuous downward movement ${ }^{23}$.

\subsubsection{Inflation Persistence}

To construct inflation persistence we collected quarterly CPI data from International Financial Statistics. We measure inflation as the annualized quarterly change in CPI. Data runs from the first quarter of 1994 to the second quarter of 2003. This is the sample period used by Levin et al. (2004). We found this sample period suitable for our study because our inflation targeting intensity indexes only pertain to 1999. We also followed Levin et al. (2004) to account for outliers in the inflation data for Australia, Canada and Japan. Accordingly, we modified the data where a jump in inflation occurs due to a change in taxes ${ }^{24}$. Franses and Hans (1994) show that outliers bias estimates of persistence. Therefore, the median of six adjacent inflation figures are calculated to replace such data. We examine inflation persistence for the same group of countries as in the sacrifice ratio analysis.

\footnotetext{
${ }^{23}$ The detailed account of the sacrifice ratios and the episodes considered for the regressions are available from the author upon request.

${ }^{24}$ Levin et al. (2004) identifies changes in consumer taxes in Australia in the third quarter of 2000, in Canada in the first two quarters of 1994 and finally in the second quarter of 1997 for Japan.
} 
Following Andrews and Hong-Yuan (1994), we measured persistence as the sum of autoregressive coefficients in a univariate AR process for inflation ${ }^{25}$. Authors note that this sum is monotonically related to the cumulative impulse response of future inflation to a contemporary shock. A median unbiased estimate of the autoregressive coefficients sum is calculated for each country using Hansen (1999) method of grid bootstrap ${ }^{26}$.

Another common approach to measure persistence is to calculate the largest autoregressive $\operatorname{root}^{27}$. The largest root governs the effect of shocks at long horizons. Stock (1991) provides asymptotic confidence intervals for this root when it is close to unity. On the other hand, monetary policy changes cause shifts in the mean of inflation process. Persistence might be observed due those structural breaks. Such breaks are typically due to shifts in monetary regimes. These shifts bias inflation persistence estimates to values close to unity ${ }^{28}$. Reduced form equations like those utilized in this study can account for these breaks in the following manners: allowing for a change in the mean of inflation or utilizing a shorter sample period belonging to a single monetary regime. Our sample period is limited to a decade. Nevertheless, some countries are known to have experienced policy changes ${ }^{29}$. We leave formal robustness checks related to these two issues for further research.

Average inflation persistence estimates are reported on panel B of Table B.6. In order to see whether restricting the time series sample for regression purposes makes a difference, we also report inflation persistence statistics for the period running from 1Q1990 until 4Q2007 30. A clear cut observation is that for both time series samples, the difference between the high index group and low index record group is remarkable. Moreover, when the regression sample is considered, de jure targeters appear to have lower inflation persistence compared to officially non-targeters. This applies to the group of OECD countries; 0.78 versus 0.70 ; and the whole group; 0.61 versus 0.69 . This pattern is in line with the findings of the literature. The same cannot be told, however, when we extend the sample back to 1Q1990. This may in part be due to the pool of IT countries in the larger period. Particularly, this pool adds

\footnotetext{
${ }^{25}$ Autoregressive lag orders are chosen based on the Akaike information criterion with a maximum lag order of four.

${ }^{26}$ Hansen (1999) develops the grid bootstrap method to construct confidence intervals to be used when an autoregressive root is close to one. It is known that asymptotic confidence intervals based on normal distribution is not valid in such a case.

${ }^{27}$ Levin et al. (2004), Watson (1999), Kuttner and Posen (2001) among others.

${ }^{28}$ To contrast estimates allowing for statistically significant structural breaks in the mean see persistence figures for Euro area since 1970 in Gadzinski and Orlandi (2004), Marques (2004) and O'Reilly and Whelan (2004).

${ }^{29}$ Finland and Spain abandoned inflation targeting regime in 1998; while Norway and Switzerland adopted IT in the last decade. These countries are among those which potentially have break in their inflation processes.

${ }^{30}$ Notice that data for former Soviet Union countries goes back until 1991 only
} 
up to the IT countries in the regression; by including those central banks that announced the regime around 2001. Meanwhile, this additional group experience a rather long period under other monetary policy regimes until back to1Q1990. As a final note, as observed in the average sacrifice ratio statistics, in the group of non-targeters OECD countries performance falls behind that of non-OECD countries.

\subsubsection{Models and Results}

This part of the study seeks to explore the impact of the monetary policy design features compatible with the inflation targeting regime on the sacrifice ratio and inflation persistence. Models in our analysis are estimated under two samples. The first sample solely included OECD countries; thereby providing a more homogenous group of countries in terms of economic development. The second sample includes all countries; thereby adding Chile and Israel to the group of inflation targeters. Regressions for inflation persistence have only inflation targeting indexes and inflation targeting dummy as regressors. As for the other variable, the methodology draws on augmenting a simple sacrifice ratio equation that includes its two basic determinants. These are initial inflation, as a proxy for nominal rigidity, and the speed of disinflation. With quarterly data on moderate inflation OECD countries for the period from 1960 to 1990, Ball (1993) report that these regressors have a significant negative impact.

The author also documents that Bruno and Sachs (1985) index of nominal wage responsiveness that controls the characteristics of the wage-setting institutions, has a significant role in reducing the sacrifice ratio. This responsiveness measure exists for only 17 OECD countries. We run a regression in this smaller sample on the responsiveness measure and the speed of disinflation. We found that the coefficient on the former has correct sign but it is insignificant. We also augmented the index to all OECD countries in our analysis. We fill in the index for Greece, Hungary, Iceland, Ireland, Portugal and Spain with the average index value for the European Union countries. For Czech Republic, Korea and Mexico we used the median of the index. Regressions still did not deliver significant results. Therefore we did not include this direct measure of nominal wage rigidity in our empirical models. Instead, we added an OECD dummy to the full sample regressions to control for the sticky wages along with other country specific effects for this group. The theory also suggests a role for the openness of the economy in delivering significantly different output costs ${ }^{31}$. Our data did not support this prediction either. We thus excluded this factor as well.

\footnotetext{
${ }^{31}$ Levin et al. (2004) While Romer (1991) predicts a negative relationship, Daniels et al. propose a model with imperfectly competitive product markets that yield a positive impact on the sacrifice ratio.
} 
The sample period in which the output costs are evaluated witnesses two special not genuinely intentional disinflations. First, the turn of the 20th century is marked by the Asian financial crisis that later spread to some emerging Latin American countries. The subsequent bankruptcies of banks and finance companies provoked recession. Asian countries responded to the deterioration of the exchange rates by raising the short-term interest rates. This policy action however intended to offset the shock to the economy rather than to primarily induce disinflation. Second interesting feature of the sample period pertains to the productivity shock of the 1990s. This positive supply shock leads to non-policy induced fall in inflation accompanied by increased output. To isolate from the former experience, we added a dummy variable that takes on a value of one when the outbreak of the crises coincides with the period for which the output cost is calculated. This coincidence applies to the sacrifice ratios of Hong Kong, India, Korea, Malaysia, Singapore and Thailand. The latter issue is handled by estimating the models presented below, only for the costly disinflation episodes ${ }^{32}$.

Figure D.4 plots sacrifice ratio and inflation persistence figures against countries in an increasing order, from left to right, with respect to their index value. The graphs on the left panel suggest that among the targeters, establishing institutions consistent with this framework pays off. Meanwhile Chile and Sweden appears to be an outlier for the output cost. On the other hand, Koreas inflation persistence is remarkably low despite its low rank in the index. The right panel of the graph reveals that even countries with decent index values, e.g. Japan and U.S., have unfavorable sacrifice ratio or inflation persistence. It looks hard to fit a downward sloping line on this non-IT group in the overall. We design our linear regression models that investigate the effect of the policy features in motivation of these observations.

The main hypothesis in our empirical analysis of the cross-sectional variation in the sacrifice ratio and inflation persistence is that the monetary policy design characteristics compatible with inflation targeting carry richer information than the mere announcement of the inflation targeting policy. We start the investigation of this hypothesis with a benchmark model that appends a dummy variable controlling for the existence of this regime. The benchmark models take the following forms.

$$
\begin{aligned}
\operatorname{Sr}_{i} & =c+\beta_{0,1} \pi_{0, i}+\beta_{0,2}\left(1 / l_{i}\right)+\beta_{0,3} d_{c}+\beta_{0,4} d_{I T} \\
\text { Pers }_{i} & =c+\alpha_{0,4} d_{I T}
\end{aligned}
$$

\footnotetext{
${ }^{32}$ As the major findings are maintained, we do not report the results under the indexes IA to IIB for the sake of brevity. These are available from the other on request.
} 
where $i$ indicates the individual country, $\pi_{0, i}$ is the initial inflation, $l_{i}$ measures the length of the disinflation period in quarters. The inverse of this length is called the velocity and is used as a proxy for the speed of disinflation. The dummy variable $d_{I T}$ takes the value one when the country adopts the inflation targeting regime. The dummy variable $d_{C}$ takes the value one if the disinflation episode of those countries affected by this crisis coincides with its outbreak. We contrast the results of this model to the ones that incorporates the monetary policy design indexes. Initially, we simply substitute theses indexes for the dummy variable in equation (3.1) to obtain

$$
\begin{aligned}
S r_{i} & =c+\beta_{1,1} \pi_{0, i}+\beta_{1,2}\left(1 / l_{i}\right)+\beta_{1,3} d_{c}+\beta_{1,4} I_{j, i} \\
\operatorname{Pers}_{i} & =c+\alpha_{1,4} I_{j, i}
\end{aligned}
$$

where $I_{j, i}$ is the monetary policy design index with $\mathrm{j}=\mathrm{IA}, \mathrm{IB}, \ldots \mathrm{IV}$. We name these equations Model 1. In the context of these first two equations, stronger information content would be best supported when the parameter $\beta_{1,4}\left(\alpha_{1,4}\right)$ is significant as opposed to $\beta_{0,4}\left(\alpha_{0,4}\right)$.

Columns two, three, six and seven of Tables B.9 and B.10 report the coefficient estimates and the associated t-statistics. When we look at the OECD countries, results show that parameters of interest are of expected sign. Accordingly, officially announcing inflation targeting regime alone or having a strong institutional design lower both sacrifice ratio and inflation persistence. Meanwhile, estimates are significantly negative for the latter variable. This finding casts shadow on the support for the pure de jure announcement effect for improved inflation persistence. In other words, more favorable persistence record may well also be due to the establishment of correct institutions. When we turn to the sample of all countries, we notice that the $\Re^{2}$ statistic is remarkably lower than in the OECD countries. Furthermore, no significant coefficient of interest is recorded for the sacrifice ratio and the inflation persistence. A correct sign is only observed for the inflation targeting dummy in the regression of the former variable.

We then proceed to consider the interaction of the dummy variable with the indexes in two different manners. In Model 2, we argue that the central bank's characteristics akin to that of an inflation targeter may not suffice without a public declaration of a commitment to price stability. This model is thus formulated as

$$
\begin{aligned}
S r_{i} & =c+\beta_{2,1} \pi_{0, i}+\beta_{2,2}\left(1 / l_{i}\right)+\beta_{2,3} d_{c}+\beta_{2,4} I_{i}+\beta_{2,5} d_{I T} I_{j, i} \\
\operatorname{Pers}_{i} & =c+\alpha_{2,4} I_{j, i}+\alpha_{2,5} d_{I T} I_{j, i}
\end{aligned}
$$


This argument would be supported by a significant $\beta_{2,5}\left(\alpha_{2,5}\right)$. Tables B.9 and B.10 show that no significant result for this parameter is obtained; except for index IIIB in the regression for the output cost of disinflation under the sample of OECD countries. Additionally, $\Re^{2}$ statistic in the bigger sample is less than half of the one for the group of OECD countries. Correct negative sign is only observed for the output cost of disinflation. Meanwhile $\beta_{2,5}$ is mostly bigger under the sample of OECD countries. Thus in sum there is no strong payoff, in terms of either variable, to announce inflation targeting for a central bank that has comparable institutional design features to those of another central bank.

Model 3 focuses on the heterogeneity among the group of inflation targerters. Here we conjecture that the impact of the existence of this regime is reinforced when all the institutional requirements are fulfilled. The effect is captured by the following equations

$$
\begin{aligned}
S r_{i} & =c+\beta_{3,1} \pi_{0, i}+\beta_{3,2}\left(1 / l_{i}\right)+\beta_{3,3} d_{c}+\beta_{3,4} d_{I T}+\beta_{3,5} d_{I T} I_{i} \\
\text { Pers }_{i} & =c+\alpha_{3,4} d_{I T}+\alpha_{3,5} d_{I T} I_{j, i}
\end{aligned}
$$

where the reinforcement is reflected in the parameter $\beta_{3,5}\left(\alpha_{3,5}\right)$. Results on the fourth columns for each sample suggest that neither sacrifice ratio nor inflation persistence is statistically lower enough. The result applies to both country samples. Furthermore, for both variables findings worsen in the group of all countries; with respect to coefficient estimates and $\Re^{2}$ statistics. In sum entirely fulfilling the institutional requirements of inflation targeting does not bring along strongly lower persistence or sacrifice ratio.

In the second part of our analysis, we investigate the possibility of a non-linear relation between the monetary policy design features and our macroeconomic variables. This is accomplished by dividing the indexes into four equal parts with the use quartiles. Group 1, which corresponds to the first quartile, has the poorest policy design characteristics, while group 4 has the strongest.

Sacrifice ratio statistics in this breakdown are reported on panels A and B of Table B.7. The figures for the OECD countries reveal the following. Group 4 displays the lowest cost of disinflation. Furthermore, the average sacrifice ratio worsens going from quartile 1 to 3 . This is also reflected in the positive correlation with the indexes reported on the second line of Panel B. Additionally, when the group 1 is excluded, this correlation remarkably improves. When we turn to the full sample, the right panel of Table B.7 points out that countries in group 1 have the lowest cost of disinflation. Furthermore, the average sacrifice ratio improves going from quartile 2 to 4 . Consequently, as in the restricted sample, when the countries in the first group 
are excluded, there is a higher negative correlation between our indexes and the output cost.

Figures for inflation persistence in the bigger cross-sectional sample in Table B.8, show that there is a clear linear negative relation between inflation persistence and inflation targeting intensity indexes. Persistence increases from group 1 to group 3. Central banks in the group 4 have the lowest inflation persistence under two indexes. This is also apparent across the correlation statistics on panel B. The last row of panel B shows that the correlation remarkably increases in absolute terms when the best three groups of central banks are considered. Meanwhile no such non-linearity is observed for OECD countries. The left panel of Table B.8 however shows that the average inflation persistence statistics and the correlation figures monotonically changes across different groupings.

We analyze whether these observations are significant by estimating the following equations.

$$
\begin{aligned}
\operatorname{Sr}_{i} & =c+\beta_{4,1} \pi_{0, i}+\beta_{4,2}\left(1 / l_{i}\right)+\beta_{4,3} d_{c}+\sum_{j}^{j+2} \varphi_{4, i} d_{g j} \\
\operatorname{Per}_{i} & =c+\sum_{j}^{j+2} \varphi_{4, i} d_{g j} \\
\operatorname{Sr}_{i} & =c+\beta_{5,1} \pi_{0, i}+\beta_{5,2}\left(1 / l_{i}\right)+\beta_{5,3} d_{c}+\beta_{5,4} I_{H, i} \\
\operatorname{Pers}_{i} & =c+\alpha_{5,1} I_{H, i}
\end{aligned}
$$

where the dummy variable $d_{g j}$ indicates that a country's central bank's features correspond to the $j^{\text {th }}$ group and $I_{H, i}$ represents the index series for the three highest group of policy design features. These equations are named Models 4 and 5 respectively. In the former, the base model base is the one for the group 4. In the latter, the base model is constructed for the countries in the group 1 . Thus $j=1$ in model 4 while $j=2$ in model 5 .

Regression results displayed in Table B.11 support our suspicion of a non-linear relationship. When we look at the sub-sample of OECD countries, column three of Table B.11 presents that the sacrifice ratio of all groups are above that of the highest index score group 4. Meanwhile, interestingly the output cost for the lowest quartile never appears significantly worse than the base one. When we turn to the full sample, results reflect the statistics in Table B.7 only under the index IV, albeit insignificance of the parameter estimates. Accordingly, as the fifth column of Table B.11 shows, the value of the dependent variable for all groups is greater than that for the base group of low index countries. 
The restriction of excluding the lowest index group makes a difference among the group of OECD countries. When compared with the columns two of Table B.11, for this group the coefficients associated with the indexes are smaller in the restricted samples. This is in line with our observation in Table B.7 that there is a stronger negative correlation with the sacrifice ratio, when the lowest ranked group is taken out. These restricted samples also come with improved $\Re^{2}$ statistics.

When we turn to the regression results in Table B.12, the statistics for the group of OECD show the following. It is worth noting that, inflation persistence in the two lowest index groups are significantly worse than that of the strongest index group. Additionally, the coefficients on the dummy variables for groups 1 through 3 are unsurprisingly positive. The variable Index $_{H i g h}$ has correct sign and is significant yet the associated coefficient is smaller then the ones in model 1-b. Furthermore, $\Re^{2}$ statistic in this restricted sample is smaller than the ones reported in Table B.10. These findings are in line with the lower and declining correlations reported on panel B of Table B.8. Right panel of Table B.12, on the other hand shows that excluding the lowest index group remarkably improves on the sign associated with the indexes. Additionally, $\Re^{2}$ statistic markedly improves compared to the one in Table B.10. On the other hand, as seen on the last column of Table B.12, the non-linearity observed in the average persistence statistics is not fully correctly reflected in the regression results.

We further analyze how relevant this stronger negative impact on the output cost and inflation persistence is by constructing $95 \%$ confidence intervals for the parameter $\beta_{1,4}\left(\alpha_{1,4}\right)$. These intervals are computed by estimating Equations (3.2) each time the lowest grade country is dropped until the sample size falls to 20. These confidence bands are plotted in Figures D.5 and D.6. X-axes show the sample size. Dashed lines in Figures D.5 and D.6 mark the end of the lowest grade group. For the sacrifice ratio of OECD countries intervals display a remarkable downward move. For the full sample an improvement shows up for a slightly bigger trimming than the exclusion of just the countries in group 1. This pattern demonstrates that the lowest group appears to be interfering with the results. As for the inflation persistence, we plot confidence interval graphs for the group of all countries only. Notice that the $95 \%$ confidence interval moves steadily down for the indexes IIIA and IIIB. This downward move goes until the 18th lowest central bank is eliminated. The improvement in the beta coefficient is less remarkable under the index IV. In sum, it is only after a reasonable level of index that one can see more meaningful return to institutional design in terms of lower sacrifice ratio and inflation persistence.

Additionally, in place of total indexes we analyze the impact of its components. Our aim is 
to gauge whether there is any particular aspect that would be driving the results for the overall index. The Model 6 then takes the form

$$
\begin{aligned}
\operatorname{Sr}_{i} & =c+\beta_{6,1} \pi_{0, i}+\beta_{6,2}\left(1 / l_{i}\right)+\beta_{6,3} d_{c}+\sum_{1=1}^{10} \varphi_{6, i} \text { indicator }_{i} \\
\text { Pers }_{i} & =c+\sum_{1=1}^{10} \alpha_{6, i} \text { indicator }_{i}
\end{aligned}
$$

where indicators 1 to 10 are those selected characteristics from the survey shown in Table B.2.

Examination of the individual components of the policy design, two characteristics emerge as significantly reducing the sacrifice ratio. The degree of discretion in the policy focus under a particular main objective comes up as a distinct feature for the group of OECD countries. A unit fall in discretion decreases the cost of disinflation by 0.2 percentage points. As for the full sample, the financing of the government by the central bank is responsible for significantly affecting the output cost. Under the survey a higher value for this characteristic indicates fewer monetary provisions to the government. The impact of this component is found to be a 0.4 percentage point relief in the output-inflation tradeoff. These findings provide support for the studies by Bernanke et al. (1999) and Masson et al. (1997) respectively. Bernanke et al. have pointed out the room for a limited discretion as a special feature of this policy framework. Masson et al. (1997) have stressed the "freedom from fiscal dominance" as an important aspect of this regime. These two characteristics have also been expressed to be attention grabbing in the previous section based on the descriptive statistics reported in Table B.2 and Figures D.1 and D.2. The average discretion level noticeably differentiated IT countries. The heterogeneity with this regard is apparent among targeters and non-targeters alike. As for the government deficit financing, the de jure targeter group looks more homogenous. More interesting observation however is that, the EU countries along with Japan and U.S. are similar to targeters in this respect ${ }^{33}$.

As for inflation persistence, in the sample of OECD countries, the significant impact of underlying policy design features work through the channel transparency. This is consistent with Kuttner and Posen (2001) finding. Authors report that monetary policy regimes that

\footnotetext{
${ }^{33}$ These indicators are also used in place of the total index in models 1 to 3 . The insignificance of the parameter of interest in each model remained unchanged, with correct signs in general.
} 
have short-run flexibility in responding to real shocks due to transparency can anchor longrun inflation expectations and thus reduce inflation persistence. Likewise, though insignificant, the coefficient of the 'analysis of expectations' is also negative. Meanwhile it is interesting to observe that higher central bank discretion is related to higher persistence among OECD countries. As for the bigger sample, none of these three characteristics is significant and has correct sign. Furthermore there is no other institutional design feature that strongly reduces inflation persistence. As a final remark, like in the regressions for the output cost of disinflation, the outstanding increase in the R2 statistic for both samples is attention grabbing.

Finally we explore the difference in the extent of institutional change among inflation targeters ${ }^{34}$. Our hypothesis is that, stronger reformation going to a new monetary policy regime, might have spurred a remarkable credibility improvement in the commitment to lower future prices. This in turn is expected to show up in smaller output costs as opposed to those inflation targeting countries which already had in place a strong central bank. The model 7 expresses this hypothesis as

$$
S r_{i}=c+\beta_{7,1} \pi_{0, i}+\beta_{7,2}\left(1 / l_{i}\right)+\beta_{7,3} d_{c}+\beta_{1,4} d_{I T} I_{\text {change }}
$$

where $I_{\text {change }}$ represents the institutional reconstruction. This phenomenon is measured through the variable that combines the central bank's exchange rate arrangement with the Moody's foreign debt credit ratings. In this equation, all disinflationary episodes of 1990s for a given country are included as opposed to a subset in the previous models ${ }^{35}$.

The fixed effect models' estimates for the panel regression about the change in institutions reveal no significant impact. Further disappointing is that the parameter estimate associated with the measure of change is positive. Nevertheless, it would be hard to believe the institutional reconstruction was of the same strength for both industrialized and emerging countries experience. Thus this result might rather be suggesting that the measure we constructed is poor. Therefore we believe that this issue requires further investigation.

In our analysis the existence of a policy choice variable $d_{I T}$ creates an unobserved heterogeneity problem in the error term. This problem relates to the possibility that the policy choice of the countries may be driven by some unobservable characteristics that also affect their sacrifice ratio. This in turn results in a correlation between the error term and the decision to adopt

\footnotetext{
${ }^{34}$ This analysis is not conducted for the inflation persistence. Inflation persistence is calculated for only one sample period for each country.

${ }^{35}$ The sacrifice ratio data is missing only when there is no information on either the exchange rate arrangement or the credit rating.
} 
inflation targeting. In other words $d_{I T}$ is endogenous. Additionally, notice that by the time the central bank survey was conducted, ten countries had already adopted the inflation targeting. Consequently, as we have demonstrated in the descriptive statistics, the policy features of these central banks are on average different than the rest of the sample. In other words, the policy choice is accompanied by higher average scores in the survey questionnaire. Consequently, indexes appear to be a function of the inflation targeting dummy. Therefore, we conjecture that this variable is also correlated with the error term due to the same unobserved heterogeneity issue and thus is endogenous.

The OLS estimation of equations with endogenous variables results in inconsistent estimators of all parameters in the model. In the cross-sectional models, we address this problem using two-stage least square method of estimation. For the pooled regression Model 9, we solved this problem of unobserved heterogeneity using the fixed effect estimation approach. It is found that in most cases exogeneity is not rejected. Hence 2SLS results are reported only where it applies. Full results of the first stage analysis pertaining to exogeneity, overidentifying restriction and weak instrument tests are available from the author upon request.

Finally, the results related to the sacrifice ratio analysis are found to be robust across the following analyses. First, we have deviated from Ball (1993) by also considering the sacrifice ratio estimates of disinflations less than 2 percentage points. This threshold is meant to leave aside those disinflations induced by shocks. To control for these instances, we augmented the regressions with a dummy variable taking the value one for minor fall in inflation. Second, to obtain instrumental variables we had to eliminate 14 observations. We run regressions including these countries as well. In both cases the insignificance of the total index was maintained. As for the model 6, results were maintained for the 'discretion' characteristic in the sample of OECD countries. Meanwhile the central bank financing of the government is the only indicator that is significant when included univariately to the regressions for the full sample.

\subsection{Concluding Remarks}

This study proposes indexes of monetary policy design characteristics in line with those under inflation targeting (IT). Indexes measure how close central banks' institutional characteristics are to that of an inflation targeting framework for a broad range of countries through series varying between 0 and 100. One purpose of the indexes is to provide a more useful classification of central banks. We find the categorization in the current literature arbitrary as it is exclusively based on a self declaration as inflation targeter. This approach erodes heterogeneity 
among targeters and non-targeters alike. The second objective is to examine whether "inflation targeting intensity" matters. In this regard, our study addresses two weakness of the recent empirical literature. First, for the first time, the impact of IT is reassessed by directly measuring the underlying monetary policy design features instead of solely controlling for its official announcement. Thus with this method, we can refrain from mistakenly favor or blame the explicit existence of the regime. Second; our indexes also allow us to analyze new hypotheses that are not addressed in the current literature.

The first set of results is as follows. Index scores reveal that in line with the literature's description of their monetary policies, U.S. and Japan are ranked remarkably close to the early targeters of New Zealand, U.K., Canada and Australia. Chile, Korea and Peru score noticeably weak in conducting this regime. The sensibility of the indexes is also supported by the negative correlation with the inflation persistence. The indexes confirm the impact of the inflation targeting regime on the lower inflation persistence among industrial countries reported in several studies. As a new finding, the Armenian central bank is detected to perform remarkably well while it is not cited in the literature as a potential targeter. Finally it is also observed that, compared with the anecdotal evidence in the recent studies, indexes point out to noticeable structural changes in Mexico and Peru along with the potential targeters of the time. This study therefore argues the need for an immediate update of the survey for capturing the progress of the incumbents and new targeters alike.

In the second set of results pertaining to the examination of the sacrifice ratio and inflation persistence we observe the following. The whole institutional design features; either alone or in interaction with the announcement of the targeting regime; do not have a significant impact on the sacrifice ratio. No significant interaction effect is observed in inflation persistence either. In other words, better institutional characteristics for targeters or officially declaring the policy on top of these characteristics do not deliver significantly lower inflation persistence or sacrifice ratio. Especially the latter case carry important policy implications for U.S., Japan and EU countries that differ from the targeting countries in terms of policy focus aspects only. For both the output cost of disinflation and inflation persistence we observe even poorer results for the group of all countries: $\Re^{2}$ statistic is very low and parameters of interest have mostly wrong sign. On the other hand, the results from the inflation persistence for OECD countries bring about skepticism on pure policy announcement effect. Accordingly, both the inflation targeting dummy and inflation targeting intensity indexes are found to significantly lower inflation persistence. The separation of total indexes into four equal parts by the use of quartiles confirms a nonlinear relation between the monetary policy aspects and the sacrifice ratio. This non-linearity 
also applies to the sample of all countries for inflation persistence. A stronger improvement in the sacrifice ratio and inflation persistence is observed when the lowest index grade group is excluded from both subsamples. Thus there seems to be evidence of a threshold index level after which more favorable results for inflation persistence and the sacrifice ratio are obtained. When each individual component of the indexes is analyzed, transparency in the implementation of the targeting policy appears as an important tool for lowering inflation persistence among the OECD countries. As for the sacrifice ratio the degree of discretion and the central bank financing of the government appear to be significant aspects in OECD countries and in the full sample respectively. Finally, the difference in the extent of institutional reforms among the inflation targeting is not found to be significantly lowering sacrifice ratios.

In a further research, we plan to extend this study in four directions. One pertains to adding time dimension to our monetary policy design indexes. Bank of England survey used to construct these indexes is conducted only in 1999. Since then, many other countries adopted inflation targeting and existing targeters evolved in their monetary policy design features. We consider two ways to implement this extension. First, time series path of a credibility measure, e.g. domestic interest rate differential; can be used to update the index score. A current credibility measure would then reflect a policy change in the recent past ${ }^{36}$. Secondly, a recent study by Crowe and Meade report a time series of central bank independence and transparency measures for a broad range of countries. The second extension concerns the measurement of sacrifice ratio and inflation persistence. Another common method for computing this measure of output cost is suggested by Hutchinson and Walsh (1988). This method relies on time-series estimates of short-run Phillips curves for each individual country. We can thereby check the robustness of the results reported in this paper about the sacrifice ratio. As for inflation persistence, another common approach is to calculate the largest autoregressive root. Additionally structural breaks in the inflation process; which are mainly due to monetary policy changes; bias inflation persistence estimates to values close to unity. A robustness check of inflation persistence results accounting for these issues remains to be accomplished. A third dimension pertains to a closer look to the extent of central bank discretion and the financing of government. We consider investigating the out-of-sample performance of these aspects and formulate forecasts of sacrifice ratios and inflation persistence for potential targeters. We also plan to construct a time series for these variables. Finally, we leave the analysis of other macroeconomic variables of interest; such as the volatility of output growth, the level and volatility of inflation, for future research.

\footnotetext{
${ }^{36}$ Leiderman and Svensson (1995) document that in early targeters the spread on the long-term domestic debt interest rate improved few years later then the official announcement of inflation targeters.
} 


\section{Appendix A}

\section{Tables of Chapter 2}

Table A.1: Parameter Estimates, DSGE models

\begin{tabular}{|c|c|c|c|c|}
\hline & \multicolumn{2}{|c|}{ 1983Q1 - 2009Q4 } & \multicolumn{2}{|c|}{ 1960Q1 - 2009Q4 } \\
\hline & Model without Money & Model with Money & Model without Money & Model with Money \\
\hline \multirow[t]{2}{*}{$\rho_{i}$} & 0.769 & & 0.665 & \\
\hline & $(0.875)$ & & $(0.896)$ & \\
\hline \multirow[t]{2}{*}{$\phi_{y}$} & 0.138 & & -0.001 & \\
\hline & $(0.549)$ & & $(0.911)$ & \\
\hline \multirow{2}{*}{$\phi_{\pi}$} & 1.493 & & 1.494 & \\
\hline & $(1.003)$ & & $(1.000)$ & \\
\hline \multirow[t]{2}{*}{$\rho_{m}$} & & 0.621 & & 0.600 \\
\hline & & $(0.997)$ & & $(1.000)$ \\
\hline \multirow[t]{2}{*}{$\rho_{a}$} & 0.885 & 0.710 & 0.900 & 0.705 \\
\hline & $(0.652)$ & $(0.993)$ & $(0.770)$ & $(1.041)$ \\
\hline \multirow[t]{2}{*}{$\rho_{\gamma}$} & 0.956 & 0.846 & 0.814 & 0.758 \\
\hline & $(1.221)$ & $(0.869)$ & $(0.956)$ & $(3.524)$ \\
\hline \multirow[t]{2}{*}{$\rho_{\xi}$} & 0.745 & 0.844 & 0.789 & 0.676 \\
\hline & $(0.976)$ & $(0.960)$ & $(0.958)$ & $(1.719)$ \\
\hline \multirow[t]{2}{*}{$\sigma_{a}$} & 1.102 & 0.972 & 1.076 & 1.018 \\
\hline & $(0.938)$ & $(0.998)$ & $(0.975)$ & $(0.032)$ \\
\hline \multirow[t]{2}{*}{$\sigma_{\gamma}$} & 2.972 & 2.725 & 2.999 & 2.978 \\
\hline & $(0.991)$ & $(0.726)$ & $(1.000)$ & $(1.645)$ \\
\hline \multirow[t]{2}{*}{$\sigma_{\xi}$} & 2.016 & 2.057 & 2.017 & 2.026 \\
\hline & $(0.997)$ & $(0.964)$ & $(0.999)$ & $(1.790)$ \\
\hline \multirow[t]{2}{*}{$\sigma_{i}$} & 0.324 & & 0.490 & \\
\hline & (1.413) & & (1.001) & \\
\hline \multirow[t]{2}{*}{$\sigma_{m}$} & & 1.010 & & 1.011 \\
\hline & & (0.999) & & (1.190) \\
\hline
\end{tabular}

Notes: The table reports maximum likelihood estimates of structural parameters from theoretical models described in section 2.3. Maximum likelihood estimates of standard errors are shown in parantheses. The first row indicates the estimation sample. The second and fourth columns show estimates from the models with the monetary policy specified as a Taylor-type interest rate rule. Entries on third and fifth columns pertain to the model with exogenous money growth rate. 
Table A.2: Parameter Estimates, Strawman Models for Output

\begin{tabular}{ccccccc}
\hline & \multicolumn{2}{c}{ AR } & \multicolumn{2}{c}{ ARX } & \multicolumn{2}{c}{ RW } \\
& Sample 1 & Sample 2 & Sample 1 & Sample 2 & Sample 1 & Sample 2 \\
\hline \hline$y_{t-1}$ & 1.009 & 1.036 & 1.014 & 1.037 & 1 & 1 \\
& 0.138 & 0.071 & 0.144 & 0.072 & 0.062 & 0.044 \\
& 10.806 & 14.883 & 10.656 & 14.849 & 20.215 & 26.514 \\
$y_{t-2}$ & 0.11 & -0.015 & 0.108 & -0.013 & & \\
& 0.19 & 0.106 & 0.192 & 0.105 & & \\
& 0.802 & -0.151 & 0.788 & -0.13 & & \\
$y_{t-3}$ & -0.351 & -0.249 & -0.359 & -0.249 & & \\
& 0.074 & 0.077 & 0.073 & 0.077 & & \\
& -3.818 & -3.601 & -3.755 & -3.6 & & \\
$\Delta m_{t-1}$ & & & 0.021 & 0.018 & & \\
& & & 0.058 & 0.056 & & \\
$\Re^{2}$ & 0.796 & 0.775 & 0.797 & 0.775 & 0.725 & 0.713 \\
Adj. $\Re^{2}$ & 0.790 & 0.771 & 0.788 & 0.770 & 0.723 & 0.711 \\
\hline \hline
\end{tabular}

Notes: The first row of the table shows the univariate model. The second row of the table indicates the estimation sample. Columns two to six of the table shows regression coefficient estimates with associated t-statistics in parantheses and Newey-West standard error estimates. Sample 1 runs from 1983Q1 to 2009Q4 while sample 2 runs from 1960Q1 to 2009Q4. Last two rows report $\Re^{2}$ and the adjusted $\Re^{2}$ statistics .

Table A.3: Parameter Estimates, Strawman Models for Inflation

\begin{tabular}{lcccccc}
\hline & \multicolumn{2}{c}{ AR Models } & \multicolumn{2}{c}{ ARX Models } & \multicolumn{2}{c}{ RW Models } \\
& Sample 1 & Sample 2 & Sample 1 & Sample 2 & Sample 1 & Sample 2 \\
\hline \hline$y_{t-1}$ & 0.303 & 0.668 & 0.305 & 0.602 & 1 & 1 \\
& 0.094 & 0.087 & 0.107 & 0.112 & 0.178 & 0.047 \\
& 3.113 & 9.618 & 3.031 & 8.272 & 10.385 & 28.692 \\
$y_{t-2}$ & 0.168 & 0.246 & 0.167 & 0.12 & & \\
& 0.097 & 0.093 & 0.098 & 0.095 & & \\
& 1.669 & 3.541 & 1.653 & 1.434 & & \\
$y_{t-3}$ & 0.085 & & 0.083 & 0.078 & & \\
& 0.09 & & 0.09 & 0.072 & & \\
& 0.842 & & 0.799 & 0.912 & & \\
$y_{t-4}$ & 0.285 & & 0.286 & 0.143 & & \\
& 0.118 & & 0.116 & 0.084 & & \\
& 2.907 & & 2.891 & 1.977 & & \\
$\Delta m_{t-1}$ & & & 0.003 & -0.007 & & \\
& & & 0.029 & 0.022 & & \\
$\Re^{2}$ & 0.397 & 0.788 & 0.397 & 0.796 & 0.067 & 0.761 \\
$A d j . \Re^{2}$ & 0.373 & 0.786 & 0.367 & 0.791 & 0.058 & 0.760 \\
\hline \hline
\end{tabular}

Notes: See notes to table A.2. 
Table A.4: Parameter Estimates, VAR(p) Model Without Money

\begin{tabular}{|c|c|c|c|c|c|c|}
\hline & \multicolumn{3}{|c|}{ 1983Q1:2009Q4 } & \multicolumn{3}{|c|}{ 1960Q1:2009Q4 } \\
\hline & $r_{t}$ & $\pi_{t}$ & $y_{t}$ & $r_{t}$ & $\pi_{t}$ & $y_{t}$ \\
\hline \multirow[t]{3}{*}{$r_{t-1}$} & 1.461 & -0.236 & 0.83 & 0.902 & 0.061 & -0.18 \\
\hline & 0.128 & 0.189 & 0.437 & 0.032 & 0.035 & 0.15 \\
\hline & $(16.477)$ & $(-1.296)$ & $(1.927)$ & $(34.220)$ & $(1.717)$ & $(-1.834)$ \\
\hline \multirow[t]{3}{*}{$r_{t-2}$} & -0.500 & 0.282 & -0.666 & & & \\
\hline & 0.115 & 0.192 & 0.403 & & & \\
\hline & $(-5.82)$ & $(1.597)$ & $(-1.596)$ & & & \\
\hline \multirow[t]{3}{*}{$\pi_{t-1}$} & 0.036 & 0.375 & 0.088 & 0.093 & 0.823 & 0.068 \\
\hline & 0.064 & 0.111 & 0.201 & 0.064 & 0.053 & 0.204 \\
\hline & $(0.743)$ & $(3.804)$ & $(0.380)$ & $(2.767)$ & $(18.307)$ & $(0.542)$ \\
\hline \multirow[t]{3}{*}{$\pi_{t-2}$} & 0.012 & 0.245 & -0.259 & & & \\
\hline & 0.043 & 0.092 & 0.251 & & & \\
\hline & $(0.249)$ & $(2.521)$ & $-(1.131)$ & & & \\
\hline \multirow[t]{3}{*}{$y_{t-1}$} & 0.047 & 0.129 & 1.018 & 0.040 & 0.029 & 0.866 \\
\hline & 0.026 & 0.048 & 0.184 & 0.013 & 0.01 & 0.042 \\
\hline & $(2.262)$ & $(2.985)$ & $(9.993)$ & $(4.002)$ & $(2.171)$ & $(23.493)$ \\
\hline \multirow[t]{3}{*}{$y_{t-2}$} & -0.056 & -0.112 & -0.236 & & & \\
\hline & 0.026 & 0.050 & 0.180 & & & \\
\hline & $(-2.826)$ & $(-2.749)$ & $(-2.440)$ & & & \\
\hline$\Re^{2}$ & 0.973 & 0.4065 & 0.783 & 0.929 & 0.785 & 0.741 \\
\hline$A d j \cdot \Re^{2}$ & 0.971 & 0.371 & 0.770 & 0.928 & 0.782 & 0.737 \\
\hline
\end{tabular}

Notes: The first row of the table indicates the estimation sample. The second row of the table shows the endogenous variable. Columns two to six of the table show regression coefficient estimates with associated tstatistics in parantheses and Newey-West standard error estimates. Last two rows report $\Re^{2}$ and adjusted $\Re^{2}$.

Table A.5: Parameter Estimates, VAR(p) Model With Money

\begin{tabular}{|c|c|c|c|c|c|c|c|c|}
\hline & \multicolumn{4}{|c|}{ 1983Q1:2009Q4 } & \multicolumn{4}{|c|}{ 1960Q1:2009Q4 } \\
\hline & $r_{t}$ & $\pi_{t}$ & $y_{t}$ & $\Delta m_{t}$ & $r_{t}$ & $\pi_{t}$ & $y_{t}$ & $\Delta m_{t}$ \\
\hline \multirow[t]{3}{*}{$r_{t-1}$} & 0.978 & 0.082 & 0.19 & 0.064 & 0.902 & 0.061 & -0.18 & 0.081 \\
\hline & 0.041 & 0.063 & 0.162 & 0.174 & 0.032 & 0.036 & 0.149 & 0.08 \\
\hline & $(39.857)$ & $(1.877)$ & $(1.853)$ & $(0.474)$ & $(34.273)$ & $(1.741$ & $(-1.826$ & $(0.896)$ \\
\hline \multirow[t]{3}{*}{$\pi_{t-1}$} & 0.079 & 0.426 & 0.017 & -0.016 & 0.086 & 0.81 & 0.052 & 0.167 \\
\hline & 0.068 & 0.154 & 0.267 & 0.352 & 0.064 & 0.055 & 0.206 & 0.11 \\
\hline & $(1.480)$ & $(4.473)$ & $(0.077)$ & $(-0.053)$ & $(2.5430$ & $(17.900)$ & $(0.411)$ & (1.434) \\
\hline \multirow[t]{3}{*}{$y_{t-1}$} & 0.023 & 0.017 & 0.062 & 0.067 & 0.013 & 0.01 & 0.044 & 0.04 \\
\hline & -0.011 & 1.156 & 15.523 & 2.369 & 4.187 & 2.556 & 22.962 & -2.088 \\
\hline & $(0.000)$ & $(0.025)$ & $(0.797)$ & $(0.160)$ & $(0.043)$ & $(0.035)$ & $(0.873)$ & $(-0.073)$ \\
\hline \multirow[t]{3}{*}{$\Delta m_{t-1}$} & -0.024 & 0.001 & -0.063 & 0.414 & 0.021 & 0.042 & 0.051 & 0.513 \\
\hline & 0.021 & 0.02 & 0.082 & 0.081 & 0.019 & 0.019 & 0.078 & 0.072 \\
\hline & $(-1.706)$ & $(0.049)$ & $(-1.059)$ & $(5.268)$ & $(1.232)$ & $(1.805)$ & $(0.786)$ & $(8.553)$ \\
\hline$\Re^{2}$ & 0.960 & 0.322 & 0.763 & 0.267 & 0.930 & 0.789 & 0.742 & 0.358 \\
\hline $\operatorname{Adj} . \Re^{2}$ & 0.958 & 0.295 & 0.753 & 0.238 & 0.928 & 0.784 & 0.737 & 0.345 \\
\hline
\end{tabular}

Notes: See notes to table A.4 
Table A.6: Mean Square Forecast Errors for Various Models - Inflation

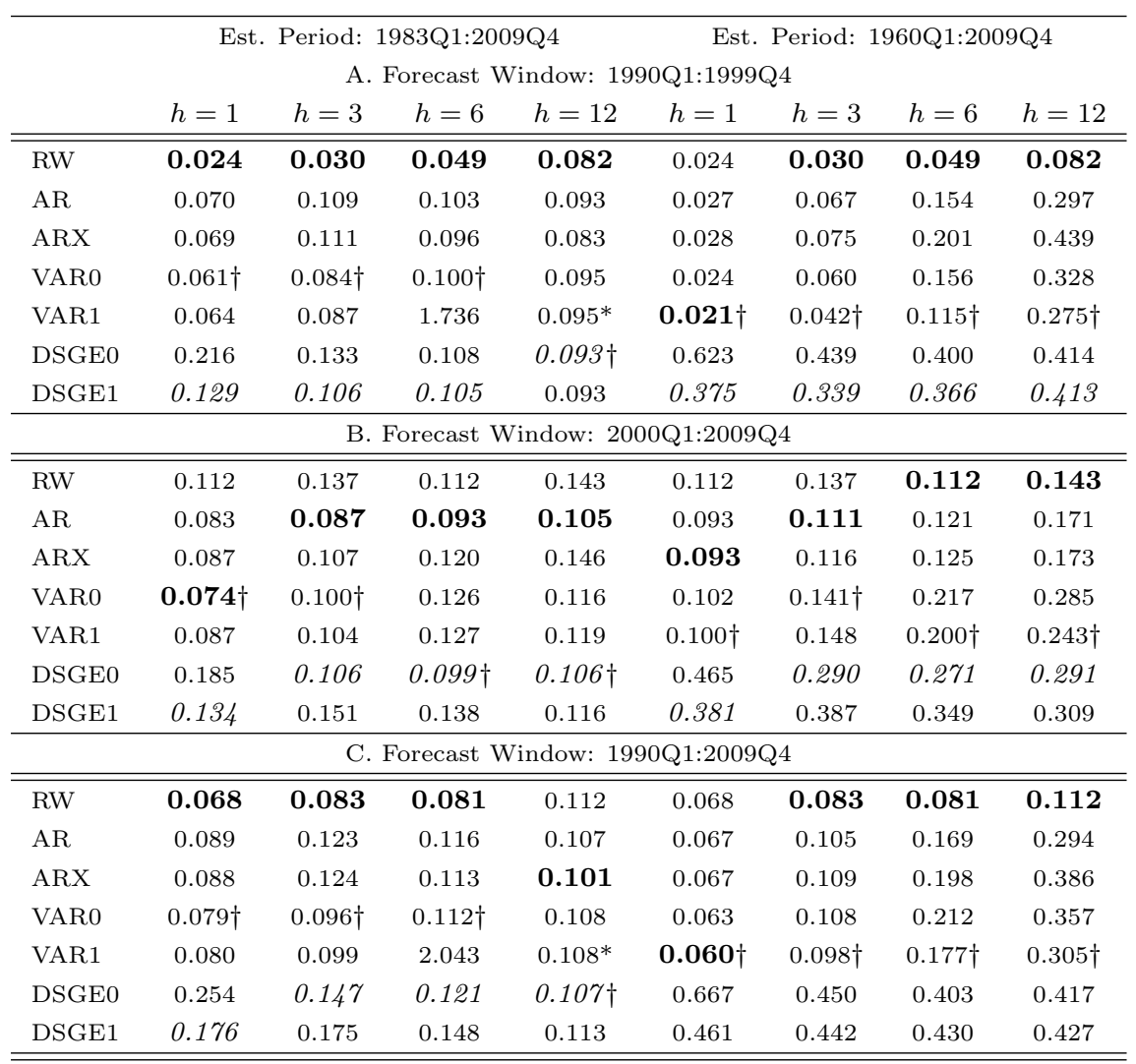

Notes: Table A.6 reports forecast accuracy results for inflation. Numerical entries are mean square error statistics based on fixed estimation and prediction construction schemes for deviations of inflation from its long-run mean, Boldface entries denote the minimum mean square error among all models. Entries in italic show the minimum mean square error between DSGE models. Entries tagged with $\dagger$ indicate the minimum mean square error among DSGE and VAR models. Panels A, B and C indicate the start and the end of forecasting periods. The first column shows models for inflation forecasts. RW is the random walk model without drift. AR is a univariate autoregressive model. ARX is an autregressive model for inflation including money growth. VAR0, VAR1, DSGE0 and DSGE1 are described in section 2.3. VAR0 is the three-variable vector autoregressive model without money growth. VAR1 includes money growth to VAR0. DSGE0 is the New Keynesian model with the monetary policy described as Taylor-type interest rate rule. DSGE1 is the New Keynesian model with the monetary policy described as exogenous money growth equation. Columns show forecast horizons as $1,3,6$ and 12 quarter-ahead forecasts. *Refer to footnote 10 . 
Table A.7: Mean Square Forecast Errors for Various Models - Output

\begin{tabular}{|c|c|c|c|c|c|c|c|c|}
\hline & \multicolumn{4}{|c|}{ Est. Period: 1983Q1:2009Q4 } & \multicolumn{4}{|c|}{ Est. Period: 1960Q1:2009Q4 } \\
\hline \multicolumn{9}{|c|}{ A. Forecast Window: 1990Q1:1999Q4 } \\
\hline & $h=1$ & $h=3$ & $h=6$ & $h=12$ & $h=1$ & $h=3$ & $h=6$ & $h=12$ \\
\hline RW & 0.226 & 0.921 & 1.939 & 2.547 & 0.228 & 0.938 & 1.994 & 2.659 \\
\hline $\mathrm{AR}$ & 0.230 & 0.600 & 0.822 & 0.849 & 0.197 & 0.584 & 0.829 & 0.877 \\
\hline ARX & 0.260 & 0.981 & 0.764 & 0.937 & 0.243 & 0.970 & 2.772 & 6.684 \\
\hline VAR0 & 0.492 & 1.138 & 1.103 & 0.889 & 0.211 & 0.681 & 0.995 & 0.907 \\
\hline VAR1 & 0.496 & 1.118 & 1.939 & $0.889^{*}$ & 0.191 & 0.587 & 0.948 & 0.986 \\
\hline DSGE0 & 5.116 & 1.187 & $0.860 \dagger$ & $0.855 \dagger$ & 4.882 & 1.104 & $0.874 \dagger$ & 0.870 \\
\hline DSGE1 & $0.261 \dagger$ & 0.522 & 0.950 & 0.921 & 0.182 & 0.510 & 0.923 & 0.939 \\
\hline \multicolumn{9}{|c|}{ B.Forecast Window: 2000Q1:2009Q4 } \\
\hline RW & 0.453 & 1.730 & 3.106 & 4.320 & 0.453 & 1.730 & 3.106 & 4.321 \\
\hline AR & 0.407 & 1.123 & 1.557 & 1.628 & 0.341 & 1.133 & 1.567 & 1.619 \\
\hline ARX & 0.354 & 1.333 & 1.882 & 2.105 & 0.349 & 1.220 & 1.720 & 1.790 \\
\hline VAR0 & $0.412 \dagger$ & $1.238 \dagger$ & 1.867 & 2.354 & $0.521 \dagger$ & $1.857 \dagger$ & 2.166 & 1.519 \\
\hline VAR1 & 0.488 & 1.282 & 1.884 & 2.395 & 0.569 & 1.902 & 2.106 & 1.482 \\
\hline DSGE0 & 9.319 & 2.487 & $1.677 \dagger$ & $1.631 \dagger$ & 8.490 & 2.199 & $1.658 \dagger$ & 1.640 \\
\hline DSGE1 & 1.409 & 1.936 & 1.882 & 1.759 & 1.301 & 1.912 & 1.879 & 1.758 \\
\hline \multicolumn{9}{|c|}{ C. Forecast Window: 1990Q1:2009Q4 } \\
\hline RW & 0.339 & 1.326 & 2.522 & 3.433 & 0.340 & 1.334 & 2.550 & 3.490 \\
\hline AR & 0.285 & 0.875 & 1.231 & 1.243 & 0.268 & 0.860 & 1.200 & 1.266 \\
\hline ARX & 0.325 & 1.048 & 1.261 & 1.538 & 0.353 & 1.302 & 2.954 & 5.661 \\
\hline VAR0 & $0.508 \dagger$ & 1.294 & 1.540 & 1.405 & 0.372 & 1.316 & 1.649 & 1.247 \\
\hline VAR1 & 0.512 & $1.256 \dagger$ & 3.222 & $1.405^{*}$ & $0.370 \dagger$ & $1.247 \dagger$ & 1.575 & 1.286 \\
\hline DSGE0 & 8.514 & 1.865 & $1.276 \dagger$ & $1.249 \dagger$ & 7.575 & 1.792 & $1.271 \dagger$ & 1.256 \\
\hline DSGE1 & 1.120 & 1.460 & 1.451 & 1.342 & 0.780 & 1.252 & 1.407 & 1.348 \\
\hline
\end{tabular}

Notes: See notes to Table A.6. In Table A.7 forecasted series is the deviation of output from its long-run mean. 
Table A.8: CS Distributional Loss Measure for Various Models, Forecasted Series - Inflation

\begin{tabular}{|c|c|c|c|c|c|c|c|c|}
\hline & \multicolumn{4}{|c|}{ Estimation Period: 1983Q1:2009Q4 } & \multicolumn{4}{|c|}{ Estimation Period: 1960Q1:2009Q4 } \\
\hline \multicolumn{9}{|c|}{ A. Forecast Window: 1990Q1:1999Q4 } \\
\hline & $h=1$ & $h=3$ & $h=6$ & $h=12$ & $h=1$ & $h=3$ & $h=6$ & $h=12$ \\
\hline RW & 0.682 & 0.690 & 0.731 & 0.853 & 0.682 & 0.690 & 0.731 & 0.853 \\
\hline $\mathrm{AR}$ & 1.404 & 1.816 & 1.733 & 1.642 & 0.763 & 1.221 & 1.950 & 2.914 \\
\hline ARX & 1.403 & 1.816 & 1.638 & 1.477 & 0.765 & 1.284 & 2.202 & 3.448 \\
\hline VAR0 & $1.292 \dagger$ & 1.548 & 1.705 & 1.652 & 0.753 & 1.175 & 1.848 & 2.932 \\
\hline VAR1 & 1.315 & 1.582 & $1.230 \dagger$ & 3.969 & $0.714 \dagger$ & $0.920 \dagger$ & $1.504 \dagger$ & 2.623 \\
\hline DSGE0 & 1.670 & $1.011 \dagger$ & 1.319 & $1.103 \dagger$ & 3.014 & 2.237 & 1.669 & $2.219 \dagger$ \\
\hline DSGE1 & 2.356 & 2.356 & 1.430 & 1.264 & 1.496 & 1.011 & 2.192 & 2.638 \\
\hline \multicolumn{9}{|c|}{ B. Forecast Window: 2000Q1:2009Q4 } \\
\hline RW & 0.741 & 0.746 & 0.754 & 0.768 & 0.741 & 0.746 & 0.754 & 0.768 \\
\hline $\mathrm{AR}$ & 0.775 & 0.822 & 0.919 & 1.065 & 0.756 & 0.807 & 0.926 & 1.196 \\
\hline ARX & 0.781 & 0.825 & 0.941 & 1.033 & 0.756 & 0.805 & 0.932 & 1.188 \\
\hline VAR0 & $0.799 \dagger$ & 0.907 & 0.885 & 0.903 & $0.752 \dagger$ & 0.830 & 1.120 & 1.658 \\
\hline VAR1 & 0.840 & 0.893 & 0.871 & 0.892 & 0.753 & $0.818 \dagger$ & $1.034 \dagger$ & 1.447 \\
\hline DSGE0 & 0.954 & $0.781 \dagger$ & $0.762 \dagger$ & $0.814 \dagger$ & 1.666 & 1.491 & 1.237 & $1.246 \dagger$ \\
\hline DSGE1 & 0.861 & 1.280 & 2.000 & 0.893 & 1.312 & 2.052 & 1.670 & 1.812 \\
\hline \multicolumn{9}{|c|}{ C. Forecast Window: 1990Q1:2009Q4 } \\
\hline RW & 0.851 & 0.855 & 0.864 & 0.872 & 0.851 & 0.855 & 0.864 & 0.872 \\
\hline AR & 1.354 & 1.710 & 1.666 & 1.562 & 0.900 & 1.218 & 1.804 & 2.674 \\
\hline ARX & 1.354 & 1.716 & 1.572 & 1.447 & 0.903 & 1.253 & 1.959 & 3.027 \\
\hline VAR0 & 1.256 & 1.418 & 1.602 & 1.564 & 0.894 & 1.165 & 1.783 & 2.833 \\
\hline VAR1 & $1.249 \dagger$ & 1.444 & 1.872 & 3.849 & $0.867 \dagger$ & $1.023 \dagger$ & $1.522 \dagger$ & 2.551 \\
\hline DSGE0 & 1.797 & $1.157 \dagger$ & $1.168 \dagger$ & $1.084 \dagger$ & 3.014 & 2.093 & 1.943 & $1.498 \dagger$ \\
\hline DSGE1 & 5.095 & 4.889 & 1.389 & 1.364 & 1.904 & 1.322 & 2.483 & 2.560 \\
\hline
\end{tabular}

Notes: Table A.8 reports forecast accuracy results for inflation. Numerical entries are CS loss measure statistics described in section 2.4 and are based on fixed estimation and prediction construction schemes for deviations of inflation from its long-run mean, Boldface entries indicate the minimum CS loss measure among all models. Entries in italic show the minimum statistic between DSGE models. Entries tagged with $\dagger$ indicate the minimum statistic among DSGE and VAR models. Panels A, $\mathrm{B}$ and $\mathrm{C}$ indicate the start and the end of forecasting periods. The first column shows models for inflation forecasts. RW is the random walk model without drift. $\mathrm{AR}$ is a univariate autoregressive model. ARX is an autregressive model for inflation including money growth. VAR0, VAR1, DSGE0 and DSGE1 are described in section 2.3. VAR0 is the three-varibale vector autoregressive model withourt money growth. VAR1 included money growth to VAR0. DSGE0 is the New Keynesian model with the monetary policy described as Taylor-type interest rate rule. DSGE1 is the New Keynesian model with the monetary policy described as exogenous money growth equation. Colums show forecast horizons as 1, 3,6 and 12 quarter-ahead forecasts. 
Table A.9: CS Distributional Loss Measure for Various Models, Forecasted Series - Output

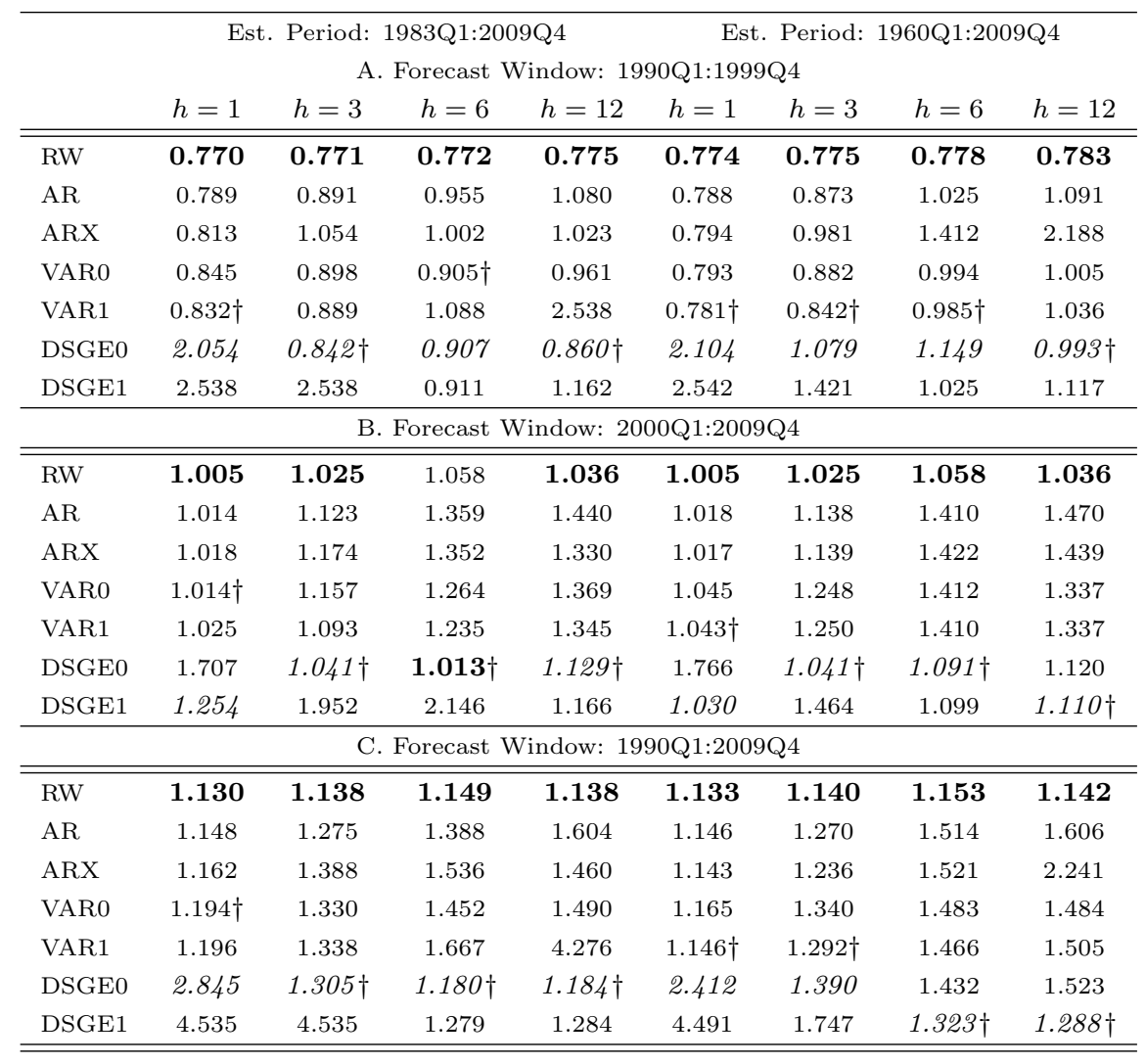

Notes: See notes to Table A.8. In Table A.9 forecasted series is the deviation of output from its long-run mean. 
Table A.10: CS Distributional Loss Measure, Simulated Series

\begin{tabular}{|c|c|c|c|c|}
\hline \multicolumn{5}{|c|}{ Panel A. 1983Q1 - 2009Q4 } \\
\hline & \multicolumn{2}{|c|}{ Output } & \multicolumn{2}{|c|}{ Inflation } \\
\hline & $S=20 T$ & $S=40 T$ & $S=20 T$ & $S=40 T$ \\
\hline RW & 5.734 & 5.739 & 6.202 & 6.202 \\
\hline AR & 1.218 & 1.218 & 1.014 & 1.014 \\
\hline ARX & 1.221 & 1.220 & 1.009 & 1.010 \\
\hline VAR0 & $1.225 \dagger$ & $1.220 \dagger$ & $1.019 \dagger$ & $1.011 \dagger$ \\
\hline VAR1 & 1.278 & 1.223 & 1.045 & 1.014 \\
\hline DSGE0 & 1.464 & 1.435 & 1.188 & 1.130 \\
\hline DSGE1 & 1.543 & 1.558 & 1.385 & 1.413 \\
\hline \multicolumn{5}{|c|}{ Panel B. 1960Q1 - 2009Q4 } \\
\hline RW & 8.010 & 7.991 & 5.043 & 5.035 \\
\hline AR & 1.432 & 1.433 & 1.377 & 1.370 \\
\hline ARX & 1.432 & 1.432 & 1.420 & 1.420 \\
\hline VAR0 & $1.432 \dagger$ & $1.432 \dagger$ & 1.371 & $1.377 \dagger$ \\
\hline VAR1 & 1.432 & 1.432 & 1.372 & 1.384 \\
\hline DSGE0 & 1.772 & 1.797 & 1.382 & 1.384 \\
\hline DSGE1 & 1.626 & 1.635 & 1.401 & 1.407 \\
\hline
\end{tabular}

Notes: Table A.10 reports simulation accuracy results for inflation. Numerical entries are CS loss measure statistics described in section 2.4. Boldface entries indicate the minimum CS loss measure among all models. Entries in italic show the minimum statistic between DSGE models. Entries tagged with $\dagger$ indicate the minimum statistic among DSGE and VAR models. Panels A and B indicate the sample periods for parameter estimation. Simulated series are deviations of inflation and output from their long-run mean, Rows show models for inflation forecasts. RW is the random walk model without drift. AR is a univariate autoregressive model. ARX is an autregressive model for inflation including money growth. VAR0, VAR1, DSGE0 and DSGE1 are described in section 2.3. VAR0 is the three-varibale vector autoregressive model withourt money growth. VAR1 included money growth to VAR0. DSGE0 is the New Keynesian model with the monetary policy described as Taylortype interest rate rule. DSGE1 is the New Keynesian model with the monetary policy described as exogenous money growth equation. $\mathrm{S}=20 \mathrm{~T}$ and $\mathrm{S}=40 \mathrm{~T}$ denote the length of the simulated sample where $\mathrm{T}$ indicates the historical sample size. 
Table A.11: Distributional Accuracy Test, Forecasted Series / Benchmark Model: Three-variable VAR model - Alternative Models: Fourvariable VAR and DSGE models

\begin{tabular}{|c|c|c|c|c|}
\hline \multirow[t]{2}{*}{$h, l$} & \multicolumn{2}{|c|}{ Estimation Period: 1983Q1 - 2009Q4 } & \multicolumn{2}{|c|}{ Estimation Period 1960Q1 - 2009Q4 } \\
\hline & Inflation & Output & Inflation & Output \\
\hline \multicolumn{5}{|c|}{ A. 1990Q1:1999Q4 } \\
\hline $1, l 1$ & -0.023 & 0.013 & 0.040 & 0.012 \\
\hline $1, l 2$ & -0.023 & 0.013 & 0.040 & 0.012 \\
\hline $3, l 1$ & 0.537 & 0.056 & $0.255^{* *}$ & 0.040 \\
\hline $3, l 2$ & 0.537 & 0.056 & $0.255^{* *}$ & 0.040 \\
\hline $6, l 1$ & $0.475^{* *}$ & -0.002 & $0.344^{* *}$ & 0.009 \\
\hline $6, l 2$ & $0.475^{* *}$ & -0.002 & $0.344^{* *}$ & 0.009 \\
\hline $12, l 1$ & 0.549 & 0.101 & $0.713^{* *}$ & 0.011 \\
\hline $12, l 2$ & 0.549 & 0.101 & $0.713^{* *}$ & 0.011 \\
\hline \multicolumn{5}{|c|}{ B. 2000Q1:2009Q4 } \\
\hline $1, l 1$ & -0.040 & -0.011 & -0.001 & 0.015 \\
\hline $1, l 2$ & -0.040 & -0.011 & -0.001 & 0.015 \\
\hline $3, l 1$ & 0.126 & 0.116 & 0.012 & 0.207 \\
\hline $3, l 2$ & 0.126 & 0.116 & 0.012 & 0.207 \\
\hline $6, l 1$ & 0.123 & 0.251 & 0.086 & $0.321 * *$ \\
\hline $6, l 2$ & 0.123 & 0.251 & 0.086 & $0.321 * *$ \\
\hline $12, l 1$ & 0.089 & $0.240 * *$ & $0.412^{* *}$ & $0.228 * *$ \\
\hline $12, l 2$ & 0.089 & $0.240^{* *}$ & $0.412^{*}$ & $0.228^{* *}$ \\
\hline \multicolumn{5}{|c|}{ C.1990Q1:2009Q4 } \\
\hline $1, l 1$ & 0.007 & -0.001 & 0.027 & 0.019 \\
\hline $1, l 2$ & 0.007 & -0.001 & 0.027 & 0.019 \\
\hline $3, l 1$ & 0.261 & 0.025 & 0.141 & 0.048 \\
\hline $3, l 2$ & 0.261 & 0.025 & 0.141 & 0.048 \\
\hline $6, l 1$ & $0.433^{* *}$ & $0.272^{*}$ & 0.261 & $0.161^{* *}$ \\
\hline $6, l 2$ & $0.433^{* *}$ & 0.272 & 0.261 & $0.161^{* *}$ \\
\hline $12, l 1$ & 0.480 & 0.306 & $1.335^{* *}$ & $0.195 * *$ \\
\hline $12, l 2$ & 0.480 & 0.306 & $1.335^{* *}$ & $0.195^{* *}$ \\
\hline
\end{tabular}

Notes: Table A.11 compares nonparametric marginal distribution of actual and out-of-sample forecasts of inflation and output. The benchmark model is the three-variable VAR model. Alternative models are four-variable VAR and DSGE models. Panels A through $\mathrm{C}$ belong to forecast periods. For each panel the first column indicates forecast horizon $\mathrm{h}$ and the block length $\mathrm{l}$ for bootstrap; were $\mathrm{h}=1,3,6,12$ quarters ahead forecasts and $11=2$ and $12=4$. Following columns show the test statistic. Results on columns two and three pertain to the insample estimation period starting in 1983Q1. Results on columns four and five pertain to the in-sample estimation period starting in 1983Q1. Rejections of the null hypothesis at $5 \%$ and $10 \%$ significance levels are denoted by $* *$ and $*$ respectively. Critical values are obtained from block bootstrap method assuming that parameter estimation error vanishes. Bootstrap distributions are obtained from 100 bootstrap replications. Test statistics are constructed using a grid of 100 values of $\mathrm{u}$, distributed uniformly across the historical data range. 
Table A.12: Distributional Accuracy Test, Forecasted Series / Benchmark Model: Three-variable VAR model - Alternative Models: Strawman models

\begin{tabular}{|c|c|c|c|c|}
\hline \multirow[t]{2}{*}{$h, l$} & \multicolumn{2}{|c|}{ Estimation Period: 1983Q1 - 2009Q4 } & \multicolumn{2}{|c|}{ Estimation Period 1960Q1 - 2009Q4 } \\
\hline & Inflation & Output & Inflation & Output \\
\hline \multicolumn{5}{|c|}{ A. 1990Q1:1999Q4 } \\
\hline $1, l 1$ & $0.610^{* *}$ & 0.075 & 0.072 & 0.018 \\
\hline $1, l 2$ & $0.610^{* *}$ & 0.075 & 0.072 & 0.018 \\
\hline $3, l 1$ & $0.857^{* *}$ & $0.127^{* *}$ & $0.485^{* *}$ & 0.107 \\
\hline $3, l 2$ & $0.857^{* *}$ & $0.127^{* *}$ & $0.485^{* *}$ & 0.107 \\
\hline $6, l 1$ & $0.974 * *$ & $0.134^{* *}$ & $1.117^{* *}$ & 0.216 \\
\hline $6, l 2$ & $0.974 * *$ & 0.134 & $1.117^{* *}$ & 0.216 \\
\hline $12, l 1$ & $0.799 * *$ & 0.186 & $2.079 * *$ & 0.222 \\
\hline $12, l 2$ & $0.799^{* *}$ & 0.186 & $2.079^{* *}$ & 0.222 \\
\hline \multicolumn{5}{|c|}{ B. 2000Q1:2009Q4 } \\
\hline $1, l 1$ & $0.058^{* *}$ & 0.009 & 0.011 & $0.040^{* *}$ \\
\hline $1, l 2$ & $0.058^{* *}$ & 0.009 & 0.011 & $0.040^{* *}$ \\
\hline $3, l 1$ & $0.161^{* *}$ & $0.132^{* *}$ & 0.084 & $0.223^{* *}$ \\
\hline $3, l 2$ & $0.161^{* *}$ & $0.132^{* *}$ & 0.084 & $0.223^{* *}$ \\
\hline $6, l 1$ & $0.131^{*}$ & $0.206^{* *}$ & $0.366^{* *}$ & $0.354^{* *}$ \\
\hline $6, l 2$ & 0.131 & $0.206^{* *}$ & $0.366^{* *}$ & $0.354^{* *}$ \\
\hline $12, l 1$ & 0.135 & $0.333^{* *}$ & $0.890^{* *}$ & $0.301 * *$ \\
\hline $12, l 2$ & 0.135 & $0.333^{* *}$ & $0.890^{* *}$ & $0.301^{* *}$ \\
\hline \multicolumn{5}{|c|}{ C.1990Q1:2009Q4 } \\
\hline $1, l 1$ & $0.405^{* *}$ & $0.064^{* *}$ & 0.043 & $0.032^{* *}$ \\
\hline $1, l 2$ & $0.405^{* *}$ & $0.064^{* *}$ & 0.043 & $0.032^{* *}$ \\
\hline $3, l 1$ & $0.564^{* *}$ & $0.192 * *$ & $0.310^{* *}$ & $0.200^{* *}$ \\
\hline $3, l 2$ & $0.564^{* *}$ & $0.192^{* *}$ & $0.310^{* *}$ & $0.200 * *$ \\
\hline $6, l 1$ & $0.738^{* *}$ & $0.303^{* *}$ & $0.919 * *$ & $0.330 * *$ \\
\hline $6, l 2$ & $0.738^{* *}$ & $0.303^{* *}$ & $0.919^{* *}$ & $0.330^{*}$ \\
\hline $12, l 1$ & $0.691 * *$ & $0.352^{* *}$ & $1.961 * *$ & 0.342 \\
\hline $12, l 2$ & $0.691^{* *}$ & $0.352^{*}$ & $1.961^{* *}$ & 0.342 \\
\hline
\end{tabular}

Notes: See notes to table A.11. Table A.12 reports results for strawman models set as alternative. 
Table A.13: Confidence Interval Test, Forecasted Series / Est. Period: 1983Q1 - 2009Q4 Benchmark Model: Three-variable VAR model - Alternative Models: Four-variable VAR and DSGE models

\begin{tabular}{|c|c|c|c|c|}
\hline \multirow[b]{2}{*}{$h, l$} & \multicolumn{2}{|c|}{0.5 standard deviation } & \multicolumn{2}{|c|}{1 standard deviation } \\
\hline & Inflation & Output & Inflation & Output \\
\hline \multicolumn{5}{|c|}{ A. 1990Q1:1999Q4 } \\
\hline $1, l 1$ & 0.000 & -0.016 & 0.020 & -0.095 \\
\hline $1, l 2$ & 0.000 & -0.016 & 0.020 & -0.095 \\
\hline $3, l 1$ & 1.075 & -0.059 & 0.000 & 0.553 \\
\hline $3, l 2$ & 1.075 & -0.059 & 0.000 & 0.553 \\
\hline $6, l 1$ & 1.348 & $1.127^{* *}$ & -0.712 & 0.652 \\
\hline $6, l 2$ & 1.348 & $1.127^{* *}$ & -0.712 & $0.652^{*}$ \\
\hline $12, l 1$ & 1.174 & $2.024^{* *}$ & -0.348 & 0.348 \\
\hline $12, l 2$ & 1.174 & $2.024^{* *}$ & -0.348 & 0.348 \\
\hline \multicolumn{5}{|c|}{ B. 2000Q1:2009Q4 } \\
\hline $1, l 1$ & $0.462^{* *}$ & 0.095 & $0.079 *$ & 0.000 \\
\hline $1, l 2$ & $0.462^{* *}$ & 0.095 & $0.079 * *$ & 0.000 \\
\hline $3, l 1$ & 0.771 & 0.854 & 0.237 & 0.178 \\
\hline $3, l 2$ & 0.771 & 0.854 & 0.237 & 0.178 \\
\hline $6, l 1$ & 0.771 & 1.411 & 0.142 & 0.506 \\
\hline $6, l 2$ & 0.771 & 1.411 & 0.142 & 0.506 \\
\hline $12, l 1$ & $2.467^{* *}$ & 1.277 & 0.332 & 0.000 \\
\hline $12, l 2$ & $2.467^{* *}$ & 1.277 & 0.332 & 0.000 \\
\hline \multicolumn{5}{|c|}{ C. 1990Q1:2009Q4 } \\
\hline $1, l 1$ & 0.050 & 0.000 & 0.000 & -0.061 \\
\hline $1, l 2$ & 0.050 & 0.000 & 0.000 & -0.061 \\
\hline $3, l 1$ & 0.447 & 0.231 & 0.063 & 0.402 \\
\hline $3, l 2$ & 0.447 & 0.231 & 0.063 & 0.402 \\
\hline $6, l 1$ & 1.212 & 0.839 & 0.286 & $1.027^{*}$ \\
\hline $6, l 2$ & 1.212 & 0.839 & 0.286 & 1.027 \\
\hline $12, l 1$ & 1.414 & $3.381^{* *}$ & 0.180 & 0.894 \\
\hline $12, l 2$ & 1.414 & $3.381^{* *}$ & 0.180 & 0.894 \\
\hline
\end{tabular}

Notes: Table A.13 compares non parametric marginal confidence interval of actual and out-of-sample forecasts of inflation and output. The benchmark model is the three-variable VAR model. Alternative models are fourvariable VAR and DSGE models. The in-sample parameter estimation period starts in 1983Q1. Panels A through $\mathrm{C}$ of each section belong to forecast periods. For each panel the first column indicates the forecast horizon $\mathrm{h}$ and the block length $\mathrm{l}$ for bootstrap; were $\mathrm{h}=1,3,6,12$ quarters ahead and $11=2$ and $12=4$. Entries on columns 2 and 3 pertain to the analysis of 0.5 standard deviation from the mean of actual series. Columns 4 and 5 reports frindings for the analysis of 1 standard deviation from the mean of the actual series. Rejections of the null hypothesis at $5 \%$ and $10 \%$ significance levels are denoted by ${ }^{* *}$ and $*$ respectively. Critical values are obtained from block bootstrap method assuming that parameter estimation error vanishes. Bootstrap distributions are obtained from 100 bootstrap replications. 
Table A.14: Confidence Interval Test, Forecasted Series / Est. Period: 1960Q1 - 2009Q4 Benchmark Model: Three-variable VAR model - Alternative Models: Four-variable VAR and DSGE models

\begin{tabular}{|c|c|c|c|c|}
\hline \multirow[b]{2}{*}{$h, l$} & \multicolumn{2}{|c|}{0.5 standard deviation } & \multicolumn{2}{|c|}{1 standard deviation } \\
\hline & Inflation & Output & Inflation & Output \\
\hline \multicolumn{5}{|c|}{ A. 1990Q1:1999Q4 } \\
\hline $1, l 1$ & -0.111 & $0.036^{* *}$ & 0.020 & 0.004 \\
\hline $1, l 2$ & -0.111 & $0.036^{*}$ & 0.020 & 0.004 \\
\hline $3, l 1$ & 0.000 & -0.225 & -0.004 & $0.075^{*}$ \\
\hline $3, l 2$ & 0.000 & -0.225 & -0.004 & $0.075 * *$ \\
\hline $6, l 1$ & $0.462^{* *}$ & $0.455^{* *}$ & $1.957^{* *}$ & 0.000 \\
\hline $6, l 2$ & $0.462^{* *}$ & $0.455^{* *}$ & $1.957^{* *}$ & 0.000 \\
\hline $12, l 1$ & $0.601 * *$ & 0.221 & $1.522^{* *}$ & 0.000 \\
\hline $12, l 2$ & $0.601^{* *}$ & 0.221 & $1.522^{* *}$ & 0.000 \\
\hline \multicolumn{5}{|c|}{ B. 2000Q1:2009Q4 } \\
\hline $1, l 1$ & 0.000 & 0.036 & -0.032 & 0.000 \\
\hline $1, l 2$ & 0.000 & 0.036 & -0.032 & 0.000 \\
\hline $3, l 1$ & 0.000 & 0.190 & -0.020 & 0.000 \\
\hline $3, l 2$ & 0.000 & 0.190 & -0.020 & 0.000 \\
\hline $6, l 1$ & 0.000 & 0.395 & -0.020 & 0.225 \\
\hline $6, l 2$ & 0.000 & 0.395 & -0.020 & 0.225 \\
\hline $12, l 1$ & 0.320 & 1.138 & $1.079^{* *}$ & 0.000 \\
\hline $12, l 2$ & 0.320 & 1.138 & $1.079^{*}$ & 0.000 \\
\hline \multicolumn{5}{|c|}{ C. 1990Q1:2009Q4 } \\
\hline $1, l 1$ & -0.089 & -0.045 & -0.101 & -0.028 \\
\hline $1, l 2$ & -0.089 & -0.045 & -0.101 & -0.028 \\
\hline $3, l 1$ & -0.045 & 0.061 & 0.029 & 0.155 \\
\hline $3, l 2$ & -0.045 & 0.061 & 0.029 & 0.155 \\
\hline $6, l 1$ & $0.890^{* *}$ & 0.089 & 0.470 & 0.569 \\
\hline $6, l 2$ & $0.890^{* *}$ & 0.089 & 0.470 & 0.569 \\
\hline $12, l 1$ & $0.742^{* *}$ & 0.743 & $2.415^{* *}$ & 0.537 \\
\hline $12, l 2$ & $0.742^{* *}$ & 0.743 & $2.415^{* *}$ & 0.537 \\
\hline
\end{tabular}

Notes: See notes to table A.13. Table A.14 shows results obtained from the in-sample estimation period in 1960Q1. 
Table A.15: Confidence Interval Test, Forecasted Series / Est. Period: 1983Q1 - 2009Q4 - Benchmark Model: Three-variable VAR model - Alternative Models: Strawman Models

\begin{tabular}{|c|c|c|c|c|}
\hline \multirow[b]{2}{*}{$h, l$} & \multicolumn{2}{|c|}{0.5 standard deviation } & \multicolumn{2}{|c|}{1 standard deviation } \\
\hline & Inflation & Output & Inflation & Output \\
\hline \multicolumn{5}{|c|}{ A. 1990Q1:1999Q4 } \\
\hline $1, l 1$ & 0.771 & 0.000 & 0.036 & $0.099^{* *}$ \\
\hline $1, l 2$ & 0.771 & 0.000 & 0.036 & $0.099^{*}$ \\
\hline $3, l 1$ & $1.739^{*}$ & 0.004 & 0.000 & $0.569 * *$ \\
\hline $3, l 2$ & 1.739 & 0.004 & 0.000 & $0.569^{*}$ \\
\hline $6, l 1$ & 1.739 & 1.142 & 0.028 & $0.668^{* *}$ \\
\hline $6, l 2$ & 1.739 & 1.142 & 0.028 & $0.668^{*}$ \\
\hline $12, l 1$ & 1.743 & $2.261^{* *}$ & 0.257 & $0.668^{* *}$ \\
\hline $12, l 2$ & 1.743 & $2.261^{* *}$ & 0.257 & $0.668^{*}$ \\
\hline \multicolumn{5}{|c|}{ B. 2000Q1:2009Q4 } \\
\hline $1, l 1$ & $0.478 * *$ & 0.099 & $0.138^{* *}$ & 0.000 \\
\hline $1, l 2$ & $0.478 * *$ & 0.099 & $0.138^{* *}$ & 0.000 \\
\hline $3, l 1$ & $0.771 * *$ & 0.889 & $0.217 * *$ & $0.320 * *$ \\
\hline $3, l 2$ & $0.771^{* *}$ & 0.889 & $0.217^{* *}$ & 0.320 \\
\hline $6, l 1$ & $0.759^{*}$ & 1.423 & $0.332^{* *}$ & $0.565^{* *}$ \\
\hline $6, l 2$ & $0.759^{* *}$ & 1.423 & $0.332^{*}$ & $0.565 * *$ \\
\hline $12, l 1$ & $2.467^{* *}$ & 1.138 & $0.332^{*}$ & $0.470^{*}$ \\
\hline $12, l 2$ & $2.467^{* *}$ & 1.138 & $0.332^{*}$ & $0.470^{*}$ \\
\hline \multicolumn{5}{|c|}{ C. 1990Q1:2009Q4 } \\
\hline $1, l 1$ & 0.049 & 0.001 & $0.558^{*}$ & 0.138 \\
\hline $1, l 2$ & 0.049 & 0.001 & $0.558 * *$ & 0.138 \\
\hline $3, l 1$ & 0.799 & 0.236 & $0.734^{* *}$ & 0.402 \\
\hline $3, l 2$ & 0.799 & 0.236 & $0.734^{* *}$ & 0.402 \\
\hline $6, l 1$ & 1.610 & 0.872 & $0.727^{* *}$ & $1.094 * *$ \\
\hline $6, l 2$ & 1.610 & 0.872 & $0.727^{* *}$ & $1.094^{* *}$ \\
\hline $12, l 1$ & 1.614 & $3.459^{* *}$ & $0.717^{* *}$ & $1.073^{* *}$ \\
\hline $12, l 2$ & 1.614 & $3.459^{* *}$ & $0.717^{* *}$ & $1.073^{* *}$ \\
\hline
\end{tabular}

Notes: See notes for table A.13. Table A.15 reports results for strawman models set as alternative. 
Table A.16: Confidence Interval Test, Forecasted Series / Est. Period: 1960Q1 - 2009Q4 - Benchmark Model: Three-variable VAR model - Alternative Models: Strawman Models

\begin{tabular}{|c|c|c|c|c|}
\hline \multirow[b]{2}{*}{$h, l$} & \multicolumn{2}{|c|}{0.5 standard deviation } & \multicolumn{2}{|c|}{1 standard deviation } \\
\hline & Inflation & Output & Inflation & Output \\
\hline \multicolumn{5}{|c|}{ A. 1990Q1:1999Q4 } \\
\hline $1, l 1$ & 0.138 & 0.099 & 0.036 & 0.004 \\
\hline $1, l 2$ & 0.138 & $0.099 * *$ & 0.036 & 0.004 \\
\hline $3, l 1$ & 0.190 & 0.253 & -0.004 & 0.395 \\
\hline $3, l 2$ & 0.190 & 0.253 & -0.004 & 0.395 \\
\hline $6, l 1$ & $1.739 * *$ & 0.775 & $2.241^{* *}$ & $0.569^{* *}$ \\
\hline $6, l 2$ & $1.739 * *$ & 0.775 & $2.241^{* *}$ & $0.569^{*}$ \\
\hline $12, l 1$ & $1.743^{* *}$ & 0.304 & $3.735^{* *}$ & 0.565 \\
\hline $12, l 2$ & $1.743^{* *}$ & 0.304 & $3.735^{* *}$ & 0.565 \\
\hline \multicolumn{5}{|c|}{ B. 2000Q1:2009Q4 } \\
\hline $1, l 1$ & 0.004 & 0.099 & 0.000 & 0.000 \\
\hline $1, l 2$ & 0.004 & 0.099 & 0.000 & 0.000 \\
\hline $3, l 1$ & 0.012 & 0.194 & 0.000 & 0.253 \\
\hline $3, l 2$ & 0.012 & 0.194 & 0.000 & 0.253 \\
\hline $6, l 1$ & 0.083 & 0.391 & 0.158 & $0.474^{*}$ \\
\hline $6, l 2$ & 0.083 & 0.391 & 0.158 & 0.474 \\
\hline $12, l 1$ & $0.874^{* *}$ & 1.000 & $2.055^{* *}$ & 0.470 \\
\hline $12, l 2$ & $0.874^{* *}$ & 1.000 & $2.055^{* *}$ & 0.470 \\
\hline \multicolumn{5}{|c|}{ C. 1990Q1:2009Q4 } \\
\hline $1, l 1$ & 0.049 & 0.068 & 0.011 & 0.021 \\
\hline $1, l 2$ & 0.049 & 0.068 & 0.011 & 0.021 \\
\hline $3, l 1$ & 0.000 & 0.201 & 0.029 & 0.558 \\
\hline $3, l 2$ & 0.000 & 0.201 & 0.029 & 0.558 \\
\hline $6, l 1$ & $1.337^{* *}$ & 0.140 & 0.861 & $0.804^{* *}$ \\
\hline $6, l 2$ & $1.337^{* *}$ & 0.140 & 0.861 & $0.804^{*}$ \\
\hline $12, l 1$ & $1.614^{* *}$ & 0.922 & $4.518^{* *}$ & $1.073^{* *}$ \\
\hline $12, l 2$ & $1.614^{* *}$ & 0.922 & $4.518^{* *}$ & $1.073^{* *}$ \\
\hline
\end{tabular}

Notes: See notes for table A.13. Table A.16 reports results for strawman models set as alternative and insample estimation period starting in 1960Q1. 
Table A.17: Distributional Accuracy Test, Simulated Series / Benchmark Model: Three-variable VAR model - Alternative Models: Four-variable VAR and DSGE models

\begin{tabular}{ccccc}
\hline & \multicolumn{2}{c}{ Inflation } & \multicolumn{2}{c}{ Output } \\
$S, l$ & $Z^{*}$ & $Z^{* *}$ & $Z^{*}$ & $Z^{* *}$ \\
\hline \multicolumn{5}{c}{ A. 1983Q3: 2009:Q4 } \\
\hline$S 1, l 1$ & -0.026 & -0.026 & -0.054 & -0.054 \\
$S 1, l 2$ & -0.026 & -0.026 & -0.054 & -0.054 \\
$S 2, l 1$ & -0.003 & -0.003 & -0.003 & -0.003 \\
$S 2, l 2$ & -0.003 & -0.003 & -0.003 & -0.003 \\
\hline \multicolumn{5}{c}{ B. 1960Q1:2009:Q4 } \\
\hline \hline$S 1, l 1$ & -0.002 & -0.002 & 0.000 & 0.000 \\
$S 1, l 2$ & -0.002 & -0.002 & 0.000 & 0.000 \\
$S 2, l 1$ & -0.006 & -0.006 & 0.000 & 0.000 \\
$S 2, l 2$ & -0.006 & -0.006 & 0.000 & 0.000 \\
\hline \hline
\end{tabular}

Notes: Table A.17 reports results of distributional accuracy test described in section 2.4. The benchmark model is the three-variable VAR model. Alternative models are four-variable VAR and DSGE models. The table compares nonparametric marginal distribution of actual and simulated inflation and output. Parameter estimation periods in panels A and B run from 1983Q1 to 2009Q4 and from 1960Q1 to 2009Q4 respectively. For each estimation period the first column indicates the simulaiton size and the block length 1 for bootstrap; were $\mathrm{S} 1=20 \mathrm{~T}$ and $\mathrm{S} 2=40 \mathrm{~T}, \mathrm{~T}$ is the sample size, and $11=2$ and $12=4$. Entries on columns 2 and 4 pertain to the analysis assuming that the simulation error vanishes. Columns 3 and 5 report frindings for the analysis assuming that there is simulation error. Rejections of the null hypothesis at $5 \%$ and $10 \%$ significance levels are denoted by ** and $*$ respectively. Critical values obtained from block bootstrap method assuming that parameter estimation error vanishes. Bootstrap distributions are obtained from 100 bootstrap replications. 
Table A.18: Distributional Accuracy Test, Simulated Series / Benchmark Model: Threevariable VAR model - Alternative Models: Strawman models

\begin{tabular}{ccccc}
\hline & \multicolumn{2}{c}{ Inflation } & \multicolumn{2}{c}{ Output } \\
$S, l$ & $Z^{*}$ & $Z^{* *}$ & $Z^{*}$ & $Z^{* *}$ \\
\hline \multicolumn{5}{c}{ A. 1983Q3:2009Q4 } \\
\hline \hline$S 1, l 1$ & $0.010^{* *}$ & $0.010^{* *}$ & $0.006^{* *}$ & $0.006^{* *}$ \\
$S 1, l 2$ & $0.010^{* *}$ & $0.010^{* *}$ & $0.006^{* *}$ & $0.006^{* *}$ \\
$S 2, l 1$ & $0.001^{* *}$ & $0.001^{* *}$ & $0.002^{* *}$ & $0.002^{* *}$ \\
$S 2, l 2$ & $0.001^{* *}$ & $0.001^{* *}$ & $0.002^{* *}$ & $0.002^{* *}$ \\
\hline \multicolumn{6}{c}{ B. 1960Q1:2009Q4 } \\
\hline \hline$S 1, l 1$ & $-0.365^{* *}$ & $-0.365^{* *}$ & $-0.173^{* *}$ & $-0.173^{* *}$ \\
$S 1, l 2$ & $-0.365^{* *}$ & $-0.365^{* *}$ & $-0.173^{* *}$ & $-0.173^{* *}$ \\
$S 2, l 1$ & $-0.359^{* *}$ & $-0.359^{* *}$ & $-0.163^{* *}$ & $-0.163^{* *}$ \\
$S 2, l 2$ & $-0.359^{* *}$ & $-0.359^{* *}$ & $-0.163^{* *}$ & $-0.163^{* *}$ \\
\hline \hline
\end{tabular}

Notes: See notes to table A.17. Table A.18 reports results for strawman models set as alternative. 
Table A.19: Confidence Interval Test, Simulated Inflation / Benchmark Model: Three-variable VAR model - Alternative Models: Four-variable VAR and DSGE models

\begin{tabular}{|c|c|c|c|c|}
\hline \multirow[b]{2}{*}{$S, l$} & \multicolumn{2}{|c|}{0.5 standard deviation } & \multicolumn{2}{|c|}{1 standard deviation } \\
\hline & $V^{*}$ & $V^{* *}$ & $V^{*}$ & $V^{* *}$ \\
\hline \multicolumn{5}{|c|}{ A. 1983Q3:2009Q4 } \\
\hline$S 1, l 1$ & -0.010 & -0.010 & -0.015 & -0.015 \\
\hline$S 1, l 2$ & -0.010 & -0.010 & -0.015 & -0.015 \\
\hline$S 2, l 1$ & -0.011 & -0.011 & -0.023 & -0.023 \\
\hline$S 2, l 2$ & -0.011 & -0.011 & -0.023 & -0.023 \\
\hline \multicolumn{5}{|c|}{ B. 1960Q1:2009Q4 } \\
\hline$S 1, l 1$ & 0.015 & 0.015 & -0.004 & -0.004 \\
\hline$S 1, l 2$ & 0.015 & 0.015 & -0.004 & -0.004 \\
\hline$S 2, l 1$ & 0.009 & 0.009 & $0.018^{* *}$ & $0.018^{*}$ \\
\hline$S 2, l 2$ & 0.009 & 0.009 & $0.018^{*}$ & $0.018^{*}$ \\
\hline
\end{tabular}

Notes: In Table A.19 nonparametric marginal confidence interval of actual inflation is compared to that of simulated inflation. The benchmark model is the three-variable VAR model. Alternative models are fourvariable VAR and DSGE models. The table analyzes 0.5 and 1 standard deviation distances around the mean of the actual inflation series. Panels A and B indicate the in-sample estimation periods. The first column in indicates the simulaiton size and the block length 1 for bootstrap; were $\mathrm{S} 1=20 \mathrm{~T}$ and $\mathrm{S} 2=40 \mathrm{~T}, \mathrm{~T}$ is the sample size, and $11=2$ and $12=4$. Entries on columns 2 and 4 pertain to the analysis assuming that the simulation error vanishes. Columns 3 and 5 report findings assuming simulation error. Rejections of the null hypothesis at $5 \%$ and $10 \%$ significance levels are denoted by $* *$ and $*$ respectively. Critical values obtained from block bootstrap method assuming that parameter estimation error vanishes. Bootstrap distributions are obtained from 100 bootstrap replications. 
Table A.20: Confidence Interval Test, Simulated Output / Benchmark Model: Three-variable VAR model - Alternative Models: Four-variable VAR and DSGE models

\begin{tabular}{|c|c|c|c|c|}
\hline \multirow[b]{2}{*}{$S, l$} & \multicolumn{2}{|c|}{0.5 standard deviation } & \multicolumn{2}{|c|}{1 standard deviation } \\
\hline & $V^{*}$ & $V^{* *}$ & $V^{*}$ & $V^{* *}$ \\
\hline \multicolumn{5}{|c|}{ A. 1983Q3:2009Q4 } \\
\hline$S 1, l 1$ & -0.007 & -0.007 & -0.014 & -0.014 \\
\hline$S 1, l 2$ & -0.007 & -0.007 & -0.014 & -0.014 \\
\hline$S 2, l 1$ & 0.008 & 0.008 & -0.002 & -0.002 \\
\hline$S 2, l 2$ & 0.008 & 0.008 & -0.002 & -0.002 \\
\hline \multicolumn{5}{|c|}{ B. 1960Q1:2009Q4 } \\
\hline$S 1, l 1$ & 0.001 & 0.001 & 0.006 & 0.006 \\
\hline$S 1, l 2$ & 0.001 & 0.001 & 0.006 & 0.006 \\
\hline$S 2, l 1$ & 0.000 & 0.000 & 0.003 & 0.003 \\
\hline$S 2, l 2$ & 0.000 & 0.000 & 0.003 & 0.003 \\
\hline
\end{tabular}

Notes: See notes to table A.19. Results on table A.20 pertain to simulated output series.

Table A.21: Confidence Interval Test, Simulated Inflation / Benchmark Model: Three-variable VAR model - Alternative Models: Strawman Models

\begin{tabular}{|c|c|c|c|c|}
\hline \multirow[b]{2}{*}{$h, l$} & \multicolumn{2}{|c|}{0.5 standard deviation } & \multicolumn{2}{|c|}{1 standard deviation } \\
\hline & $V^{*}$ & $V^{* *}$ & $V^{*}$ & $V^{* *}$ \\
\hline \multicolumn{5}{|c|}{ A. 1983Q3:2009Q4 } \\
\hline$S 1, l 1$ & $0.000^{* *}$ & $0.000^{* *}$ & $0.022^{* *}$ & $0.022^{* *}$ \\
\hline$S 1, l 2$ & $0.000 * *$ & $0.000^{* *}$ & $0.022^{* *}$ & $0.022^{* *}$ \\
\hline$S 2, l 1$ & $-0.010^{* *}$ & $-0.010 * *$ & $-0.015^{* *}$ & $-0.015^{* *}$ \\
\hline$S 2, l 2$ & $-0.010^{* *}$ & $-0.010 * *$ & $-0.015^{* *}$ & $-0.015^{* *}$ \\
\hline \multicolumn{5}{|c|}{ B. 1960Q1:2009Q4 } \\
\hline$S 1, l 1$ & -0.474 & -0.474 & $-2.410^{*}$ & $-2.410^{* *}$ \\
\hline$S 1, l 2$ & -0.474 & -0.474 & $-2.410^{* *}$ & $-2.410^{*}$ \\
\hline$S 2, l 1$ & $-0.476^{*}$ & $-0.476^{*}$ & $-2.398^{* *}$ & $-2.398^{* *}$ \\
\hline$S 2, l 2$ & $-0.476^{*}$ & $-0.476^{*}$ & $-2.398^{* *}$ & $-2.398^{* *}$ \\
\hline
\end{tabular}

Notes: See notes to table A.19. Table A.21 reports results for strawman models set as alternative. 
Table A.22: Confidence Interval Test, Simulated Output / Benchmark Model: Three-variable VAR model - Alternative Models: Strawman models

\begin{tabular}{|c|c|c|c|c|}
\hline \multirow[b]{2}{*}{$h, l$} & \multicolumn{2}{|c|}{0.5 standard deviation } & \multicolumn{2}{|c|}{1 standard deviation } \\
\hline & $V^{*}$ & $V^{* *}$ & $V^{*}$ & $V^{* *}$ \\
\hline \multicolumn{5}{|c|}{ A. 1983Q3: 2009Q4 } \\
\hline$S 1, l 1$ & $0.048 * *$ & $0.048^{* *}$ & $0.020^{* *}$ & $0.020 * *$ \\
\hline$S 1, l 2$ & $0.048^{* *}$ & $0.048^{* *}$ & $0.020^{* *}$ & $0.020^{* *}$ \\
\hline$S 2, l 1$ & $0.028^{* *}$ & $0.028^{* *}$ & $0.010^{* *}$ & $0.010^{* *}$ \\
\hline$S 2, l 2$ & $0.028 * *$ & $0.028^{* *}$ & $0.010^{* *}$ & $0.010^{* *}$ \\
\hline \multicolumn{5}{|c|}{ B. 1960Q1:2009Q4 } \\
\hline$S 1, l 1$ & -2.039 & -2.039 & $-0.718^{* *}$ & $-0.718^{* *}$ \\
\hline$S 1, l 2$ & -2.039 & -2.039 & $-0.718^{* *}$ & $-0.718^{* *}$ \\
\hline$S 2, l 1$ & -2.039 & -2.039 & $-0.706^{* *}$ & $-0.706^{* *}$ \\
\hline$S 2, l 2$ & -2.039 & -2.039 & $-0.706^{* *}$ & $-0.706^{* *}$ \\
\hline
\end{tabular}

Notes: See notes to table A.19. Table A.22 reports results for simulated output series where strawman models are set as alternative. 
Table A.23: Predictive Accuray Test, Forecasted Series / Benchmark Model: Three-variable VAR model - Alternative Models: Four-variable VAR and DSGE models

\begin{tabular}{|c|c|c|c|c|}
\hline \multirow[b]{2}{*}{$h, l$} & \multicolumn{2}{|c|}{ Estimation Period: 1983Q1 - 2009Q4 } & \multicolumn{2}{|c|}{ Estimation Period 1960Q1 - 2009Q4 } \\
\hline & Inflation & Output & Inflation & Output \\
\hline \multicolumn{5}{|c|}{ A. 1990Q1:1999Q4 } \\
\hline $1, l 1$ & -0.018 & -0.030 & 0.023 & 0.126 \\
\hline $1, l 2$ & -0.018 & -0.030 & $0.023^{*}$ & 0.126 \\
\hline $3, l 1$ & -0.024 & 0.127 & 0.112 & 0.590 \\
\hline $3, l 2$ & -0.024 & 0.127 & 0.112 & 0.590 \\
\hline $6, l 1$ & -1.026 & -5.290 & 0.259 & 0.295 \\
\hline $6, l 2$ & -1.026 & -5.290 & 0.259 & 0.295 \\
\hline $12, l 1$ & -1.901 & -14.534 & $0.334^{* *}$ & -0.501 \\
\hline $12, l 2$ & -1.901 & -14.534 & $0.334^{*}$ & -0.501 \\
\hline \multicolumn{5}{|c|}{ B. $2000 \mathrm{Q} 1: 2009 \mathrm{Q} 4$} \\
\hline $1, l 1$ & -0.081 & -0.479 & 0.010 & -0.301 \\
\hline $1, l 2$ & -0.081 & -0.479 & 0.010 & -0.301 \\
\hline $3, l 1$ & -0.030 & -0.278 & -0.040 & -0.287 \\
\hline $3, l 2$ & -0.030 & -0.278 & -0.040 & -0.287 \\
\hline $6, l 1$ & -0.006 & -0.107 & 0.109 & 0.379 \\
\hline $6, l 2$ & -0.006 & -0.107 & 0.109 & 0.379 \\
\hline $12, l 1$ & -0.016 & -0.255 & $0.268^{*}$ & 0.233 \\
\hline $12, l 2$ & -0.016 & -0.255 & 0.268 & 0.233 \\
\hline \multicolumn{5}{|c|}{ C.1990Q1:2009Q4 } \\
\hline $1, l 1$ & -0.010 & -0.041 & 0.027 & 0.011 \\
\hline $1, l 2$ & -0.010 & -0.041 & $0.027^{* *}$ & 0.011 \\
\hline $3, l 1$ & -0.022 & 0.341 & 0.086 & 0.617 \\
\hline $3, l 2$ & -0.022 & 0.341 & 0.086 & 0.617 \\
\hline $6, l 1$ & -0.807 & -15.028 & 0.313 & 0.665 \\
\hline $6, l 2$ & -0.807 & -15.028 & 0.313 & 0.665 \\
\hline $12, l 1$ & -1.824 & -25.999 & $0.460^{* *}$ & -0.343 \\
\hline $12, l 2$ & -1.824 & -25.999 & $0.460 * *$ & -0.343 \\
\hline
\end{tabular}

Notes: Table A.23 reports results of White test described in section 2.4. The benchmark model is the three-variable VAR model. Alternative models are fourvariable VAR and DSGE models. Panels A through $\mathrm{C}$ belong to forecast periods. For each panel the first column indicates forecast horizon $\mathrm{h}$ and the block length $\mathrm{l}$ for bootstrap; were $\mathrm{h}=1,3,6,12$ quarters ahead forecasts and $11=2$ and $12=4$. Following columns show the test statistic. Results on columns two and three pertain to the in-sample estimation period starting in 1983Q1. Results on columns four and five pertain to the in-sample estimation period starting in 1960Q1. Rejections of the null hypothesis at $5 \%$ and $10 \%$ significance levels are denoted by ** and * respectively. Critical values are obtained from block bootstrap method assuming that parameter estimation error vanishes. Bootstrap distributions are obtained from 100 bootstrap replications. 
Table A.24: Predictive Accuray Test, Forecasted Series / Benchmark Model: Three-variable VAR model - Alternative Models: Strwaman models

\begin{tabular}{|c|c|c|c|c|}
\hline \multirow[b]{2}{*}{$h, l$} & \multicolumn{2}{|c|}{ Estimation Period: 1983Q1 - 2009Q4 } & \multicolumn{2}{|c|}{ Estimation Period 1960Q1 - 2009Q4 } \\
\hline & Inflation & Output & Inflation & Output \\
\hline \multicolumn{5}{|c|}{ A. 1990Q1:1999Q4 } \\
\hline $1, l 1$ & $0.237 * *$ & $1.680^{* *}$ & 0.003 & $0.087 * *$ \\
\hline $1, l 2$ & $0.237 * *$ & $1.680 * *$ & 0.003 & 0.087 \\
\hline $3, l 1$ & $0.339^{* *}$ & $3.403^{* *}$ & 0.192 & 0.613 \\
\hline $3, l 2$ & $0.339 * *$ & $3.403^{* *}$ & $0.192^{* *}$ & 0.613 \\
\hline $6, l 1$ & $0.319^{* *}$ & $2.144^{* *}$ & $0.672^{* *}$ & 1.046 \\
\hline $6, l 2$ & $0.319^{* *}$ & $2.144^{* *}$ & $0.672^{* *}$ & 1.046 \\
\hline $12, l 1$ & $0.081^{* *}$ & 0.256 & $1.555^{* *}$ & 0.188 \\
\hline $12, l 2$ & $0.081 * *$ & 0.256 & $1.555^{* *}$ & 0.188 \\
\hline \multicolumn{5}{|c|}{ B. 2000Q1:2009Q4 } \\
\hline $1, l 1$ & -0.052 & 0.367 & $0.054^{*}$ & 1.144 \\
\hline $1, l 2$ & -0.052 & 0.367 & 0.054 & $1.144^{* *}$ \\
\hline $3, l 1$ & $0.079^{*}$ & $0.726^{*}$ & 0.189 & $4.581^{* *}$ \\
\hline $3, l 2$ & 0.079 & $0.726^{* *}$ & $0.189^{*}$ & $4.581 * *$ \\
\hline $6, l 1$ & $0.207^{* *}$ & $1.963^{*}$ & $0.666^{* *}$ & $3.791^{*}$ \\
\hline $6, l 2$ & $0.207^{* *}$ & $1.963^{* *}$ & $0.666^{* *}$ & 3.791 \\
\hline $12, l 1$ & 0.071 & $4.595^{* *}$ & $0.898 * *$ & -0.635 \\
\hline $12, l 2$ & 0.071 & $4.595^{* *}$ & $0.898^{* *}$ & -0.635 \\
\hline \multicolumn{5}{|c|}{ C.1990Q1:2009Q4 } \\
\hline $1, l 1$ & $0.095 * *$ & $1.990 * *$ & -0.032 & 0.924 \\
\hline $1, l 2$ & $0.095 * *$ & $1.990^{* *}$ & -0.032 & $0.924 * *$ \\
\hline $3, l 1$ & $0.118^{* *}$ & $3.747 * *$ & 0.222 & $4.080^{* *}$ \\
\hline $3, l 2$ & $0.118^{* *}$ & $3.747^{* *}$ & 0.222 & $4.080^{* *}$ \\
\hline $6, l 1$ & $0.278^{* *}$ & $2.762^{* *}$ & $1.179^{* *}$ & 4.019 \\
\hline $6, l 2$ & $0.278^{* *}$ & $2.762^{* *}$ & $1.179^{* *}$ & 4.019 \\
\hline $12, l 1$ & $0.065^{* *}$ & $1.448^{* *}$ & $2.185^{* *}$ & -0.165 \\
\hline $12, l 2$ & $0.065^{* *}$ & $1.448^{* *}$ & $2.185^{* *}$ & -0.165 \\
\hline
\end{tabular}

Notes: See notes to table A.23. Table A.24 shows results from the test where strawman models are set as alternative. 


\section{Appendix B}

\section{Tables of Chapter 3}

Table B.1: The Weighing Scheme

\begin{tabular}{|c|c|c|c|c|c|c|}
\hline & \multicolumn{2}{|c|}{ Index I } & \multicolumn{2}{|c|}{ Index II } & \multicolumn{2}{|c|}{ Index III } \\
\hline & A & $\mathrm{B}$ & A & $\mathrm{B}$ & A & $\mathrm{B}$ \\
\hline Exchange rate focus & & & $25.00 \%$ & $30.00 \% *$ & & \\
\hline Regime desc. as exch. rate targ.? & $6.25 \%$ & $7.50 \% *$ & & & $2.50 \%$ & $2.92 \% *$ \\
\hline Degree to which the exchange rate is fixed? & $6.25 \%$ & $7.50 \% *$ & & & $2.50 \%$ & $2.92 \% *$ \\
\hline Rank of objectives? & $6.25 \%$ & $7.50 \% *$ & & & $2.50 \%$ & $2.92 \% *$ \\
\hline Exchange rate prevails in policy conflicts? & $6.25 \%$ & $7.50 \% *$ & & & $2.50 \%$ & $2.92 \% *$ \\
\hline Money focus & & & $25.00 \%$ & $15.00 \%$ & & \\
\hline Regime described as money targeting? & $6.25 \%$ & $3.75 \%$ & & & $2.50 \%$ & $1.25 \%$ \\
\hline Specific target range published now? & $6.25 \%$ & $3.75 \%$ & & & $2.50 \%$ & $1.25 \%$ \\
\hline Rank of objectives? & $6.25 \%$ & $3.75 \%$ & & & $2.50 \%$ & $1.25 \%$ \\
\hline Money objective prevails in policy conflicts? & $6.25 \%$ & $3.75 \%$ & & & $2.50 \%$ & $1.25 \%$ \\
\hline Inflation focus & $25.00 \%$ & $40.00 \% *$ & $25.00 \%$ & $40.00 \% *$ & $10.00 \%$ & $35.00 \% *$ \\
\hline Discretion & $25.00 \%$ & $15.00 \%$ & $25.00 \%$ & $15.00 \%$ & $10.00 \%$ & $5.00 \%$ \\
\hline Central bank instrument independence & & & & & $10.00 \%$ & $5.00 \%$ \\
\hline Central bank financing of government deficit & & & & & $10.00 \%$ & $5.00 \%$ \\
\hline Accountability of central bank to government* & & & & & $10.00 \%$ & $5.00 \%$ \\
\hline Policy explanations & & & & & $10.00 \%$ & $5.00 \%$ \\
\hline Anal. of inflation expectations & & & & & $10.00 \%$ & $11.67 \% *$ \\
\hline Anal. using models and forecasts & & & & & $10.00 \%$ & $11.67 \% *$ \\
\hline
\end{tabular}

Notes: * denotes indicators grouped under $70 \%$ weight. 


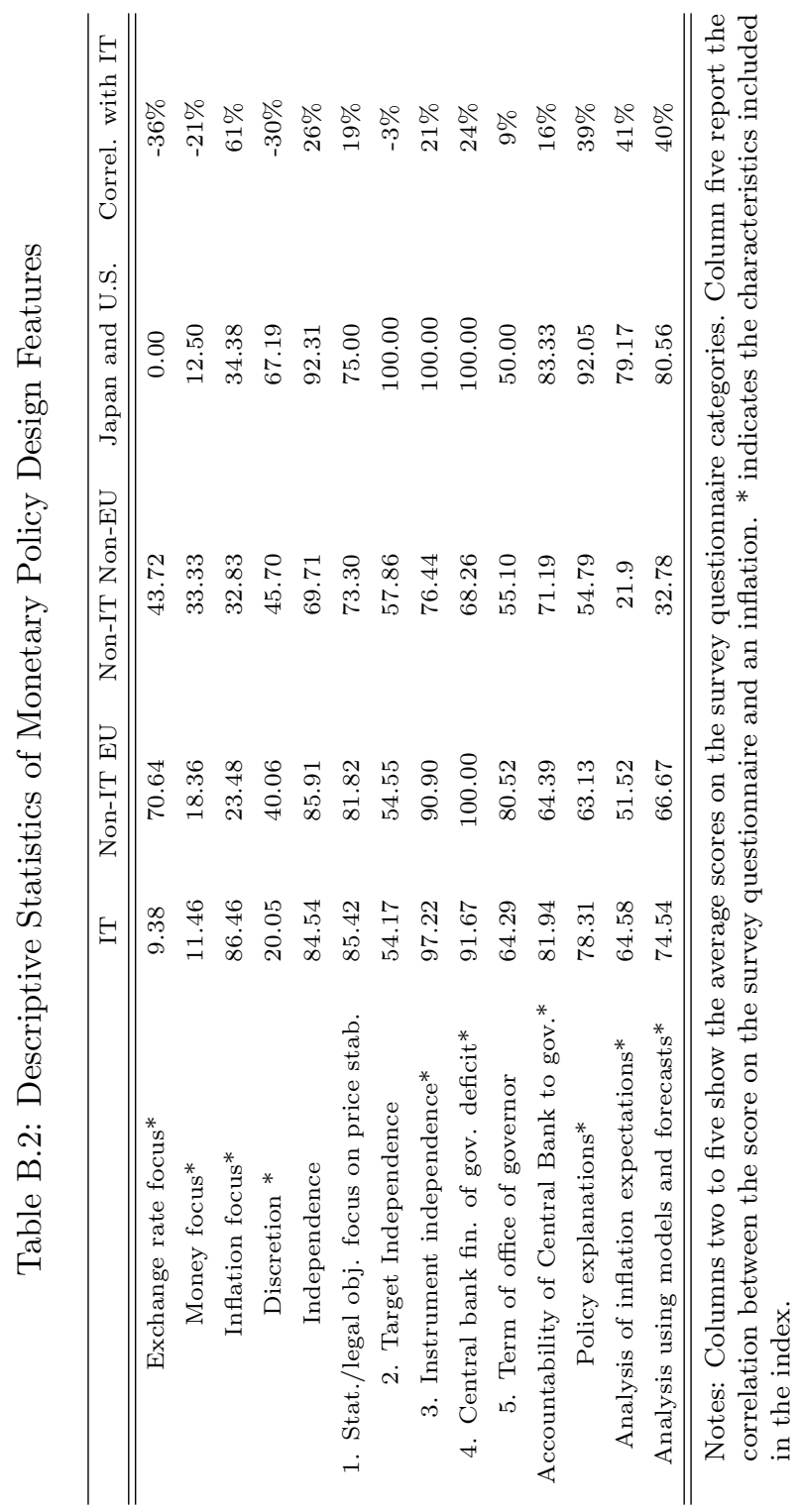


Table B.3: Monetary Policy Design Indices - Correlation Coefficients (\%)

\begin{tabular}{lccccccc}
\hline & IA & IB & IIA & IIB & IIIA & IIIB & IV \\
\hline \hline Index IA & 1.00 & & & & & & \\
Index IB & 0.90 & 1.00 & & & & & \\
Index IIA & 0.99 & 0.90 & 1.00 & & & & \\
Index IIB & 0.89 & 1.00 & 0.89 & 1.00 & & & \\
Index IIIA & 0.71 & 0.64 & 0.73 & 0.64 & 1.00 & & \\
Index IIIB & 0.80 & 0.89 & 0.81 & 0.90 & 0.87 & 1.00 & \\
Index IV & 0.81 & 0.75 & 0.83 & 0.76 & 0.82 & 0.82 & 1.00 \\
\hline \hline
\end{tabular}

Table B.4: Average Index Value by Group of Countries

\begin{tabular}{lccccccc}
\hline & IA & IB & IIA & IIB & IIIA & IIIB & IV \\
\hline \hline IT countries & 79.58 & 83.33 & 82.29 & 86.05 & 80.18 & 80.95 & 66.03 \\
Japan & 60.00 & 63.18 & 60.00 & 63.18 & 76.84 & 66.57 & 79.54 \\
U.S. & 23.75 & 34.52 & 23.75 & 34.52 & 68.69 & 53.14 & 70.19 \\
Non-IT EU & 19.31 & 19.13 & 19.31 & 19.13 & 52.29 & 36.53 & 3.32 \\
Non-IT OECD & 18.87 & 20.52 & 18.87 & 20.52 & 46.88 & 33.37 & 2.35 \\
Other & 24.29 & 31.08 & 25.44 & 31.76 & 37.43 & 30.74 & 3.50 \\
Other excl. outliers & 21.39 & 27.68 & 22.37 & 28.22 & 36.73 & 28.72 & 2.71 \\
\hline \hline
\end{tabular}

Notes: The group of non-IT OECD adds Hungary, Iceland, Norway, Slovak Republic, Switzerland and Turkey to the OECD countries and excludes Japan and U.S. to analyze their central banks. Outliers are Albania, Armenia, Ecuador, Jamaica and Sierra Leon.

Table B.5: Inflation Targeting Index Scores

\begin{tabular}{lccccccc}
\hline & IA & IB & IIA & IIB & IIIA & IIIB & IV \\
\hline \hline Albania & 72.5 & 84.1 & 72.5 & 84.1 & 39.8 & 54.6 & 4.6 \\
Argentina & 20.0 & 6.3 & 20.0 & 6.3 & 37.0 & 8.7 & 0.0 \\
Armenia & 77.5 & 88.7 & 77.5 & 88.7 & 56.3 & 66.0 & 27.0 \\
Austria* & 25.0 & 11.3 & 25.0 & 11.3 & 36.9 & 17.2 & 0.0 \\
Australia & 97.5 & 96.7 & 97.5 & 96.7 & 80.6 & 82.9 & 87.3 \\
Bahamas & 25.0 & 11.3 & 25.0 & 11.3 & 26.9 & 6.5 & 0.0 \\
Bahrain & 25.0 & 13.0 & 25.0 & 13.0 & 21.3 & 6.2 & 0.0 \\
Bangladesh & 10.0 & 29.7 & 10.0 & 29.7 & 26.6 & 28.8 & 0.0 \\
Barbados & 20.0 & 6.3 & 20.0 & 6.3 & 18.0 & 0.0 & 0.0 \\
Belgium* & 22.5 & 8.8 & 22.5 & 8.8 & 49.3 & 24.2 & 0.0 \\
Belize & 14.2 & 18.3 & 21.7 & 18.3 & 14.4 & 11.5 & 0.0 \\
\hline & & & & & Continued on next page \\
\hline
\end{tabular}


Table B.5 - continued from previous page

\begin{tabular}{|c|c|c|c|c|c|c|c|}
\hline & IA & IB & IIA & IIB & IIIA & IIIB & IV \\
\hline Bosnia H. & 20.0 & 6.3 & 20.0 & 6.3 & 37.9 & 9.1 & 0.0 \\
\hline Botswana & 40.0 & 49.8 & 52.5 & 59.8 & 47.7 & 52.8 & 3.2 \\
\hline Bulgaria & 20.0 & 6.3 & 20.0 & 6.3 & 44.0 & 14.7 & 0.0 \\
\hline Canada & 86.3 & 87.7 & 88.8 & 90.2 & 92.2 & 90.5 & 95.1 \\
\hline Chile & 71.3 & 75.1 & 78.8 & 82.6 & 63.0 & 67.0 & 8.6 \\
\hline China & 11.3 & 27.4 & 11.3 & 27.4 & 55.5 & 48.3 & 15.7 \\
\hline Croatia & 46.3 & 57.1 & 53.8 & 57.1 & 43.7 & 46.2 & 1.0 \\
\hline Cyprus & 2.5 & 13.4 & 2.5 & 13.4 & 22.6 & 11.2 & 0.0 \\
\hline Cz. Republic & 95.0 & 94.1 & 97.5 & 96.7 & 84.7 & 84.6 & 80.1 \\
\hline Denmark* & 22.5 & 8.8 & 22.5 & 8.8 & 53.3 & 24.9 & 0.2 \\
\hline Ecuador & 42.5 & 55.2 & 42.5 & 55.2 & 61.1 & 58.4 & 28.9 \\
\hline Eastern Car. & 22.5 & 8.8 & 22.5 & 8.8 & 26.5 & 6.3 & 0.0 \\
\hline Egypt & 25.0 & 41.0 & 25.0 & 41.0 & 38.3 & 36.8 & 1.0 \\
\hline Estonia & 20.0 & 6.3 & 20.0 & 6.3 & 57.6 & 27.3 & 0.5 \\
\hline Fiji & 26.3 & 29.9 & 28.8 & 32.4 & 27.4 & 21.3 & 0.0 \\
\hline Finland* & 31.3 & 38.3 & 31.3 & 38.3 & 63.5 & 55.9 & 14.0 \\
\hline France* & 0.5 & 18.1 & 0.5 & 18.1 & 46.6 & 40.8 & 1.5 \\
\hline Georgia & 35.0 & 47.7 & 35.0 & 47.7 & 45.3 & 42.3 & 4.2 \\
\hline Germany* & 16.3 & 28.2 & 16.3 & 28.2 & 44.4 & 35.4 & 1.2 \\
\hline Ghana & 23.8 & 34.5 & 23.8 & 34.5 & 17.6 & 15.3 & 0.0 \\
\hline Greece* & 10.0 & 10.9 & 10.0 & 10.9 & 41.5 & 30.5 & 0.0 \\
\hline Guyana & 13.8 & 27.8 & 13.8 & 27.8 & 19.0 & 17.2 & 0.0 \\
\hline Hong Kong & 20.0 & 6.3 & 20.0 & 6.3 & 43.6 & 14.1 & 0.0 \\
\hline Hungary & 23.8 & 18.2 & 23.8 & 18.2 & 24.4 & 15.5 & 0.0 \\
\hline Iceland* & 23.8 & 19.5 & 23.8 & 19.5 & 41.4 & 25.0 & 0.6 \\
\hline India & 25.0 & 42.3 & 25.0 & 42.3 & 38.6 & 34.7 & 2.3 \\
\hline Indonesia & 26.3 & 45.0 & 26.3 & 45.0 & 53.5 & 55.5 & 26.9 \\
\hline Ireland & 23.8 & 19.5 & 23.8 & 19.5 & 56.1 & 34.8 & 2.5 \\
\hline Israel & 82.5 & 84.5 & 87.5 & 89.5 & 78.0 & 78.7 & 66.4 \\
\hline Italy* & 2.5 & 22.2 & 2.5 & 22.2 & 58.0 & 54.6 & 9.9 \\
\hline
\end{tabular}


Table B.5 - continued from previous page

\begin{tabular}{|c|c|c|c|c|c|c|c|}
\hline & IA & IB & IIA & IIB & IIIA & IIIB & IV \\
\hline Jamaica & 48.8 & 65.1 & 48.8 & 65.1 & 29.5 & 48.2 & 0.7 \\
\hline Japan & 60.0 & 63.2 & 60.0 & 63.2 & 76.8 & 66.6 & 79.5 \\
\hline Jordan & 7.5 & 11.7 & 7.5 & 11.7 & 36.7 & 22.5 & 0.1 \\
\hline Kazakhstan & 13.8 & 32.8 & 13.8 & 32.8 & 48.5 & 47.5 & 5.8 \\
\hline Kenya & 21.3 & 39.1 & 21.3 & 39.1 & 25.4 & 27.7 & 0.2 \\
\hline Korea & 28.8 & 50.4 & 28.8 & 50.4 & 51.9 & 54.9 & 18.3 \\
\hline Kuwait & 12.5 & 7.5 & 12.5 & 7.5 & 34.2 & 14.2 & 0.0 \\
\hline Kyrgyzstan & 31.3 & 52.1 & 31.3 & 52.1 & 55.4 & 59.6 & 12.5 \\
\hline Latvia & 20.0 & 6.3 & 20.0 & 6.3 & 40.2 & 11.1 & 0.0 \\
\hline Lebanon & 27.5 & 33.9 & 30.0 & 33.9 & 30.6 & 37.4 & 0.0 \\
\hline Lithuania & 20.0 & 6.3 & 20.0 & 6.3 & 55.4 & 25.5 & 0.2 \\
\hline Macedonia & 25.0 & 18.4 & 25.0 & 18.4 & 38.3 & 20.2 & 0.0 \\
\hline Malaysia & 32.5 & 39.7 & 40.0 & 47.3 & 54.2 & 44.1 & 4.9 \\
\hline Malta & 5.0 & 0.0 & 5.0 & 0.0 & 48.5 & 22.9 & 0.2 \\
\hline Mauritius & 10.0 & 24.7 & 10.0 & 24.7 & 19.5 & 18.3 & 0.0 \\
\hline Mexico & 92.5 & 91.6 & 97.5 & 96.7 & 84.7 & 86.7 & 80.1 \\
\hline Moldova & 16.3 & 33.3 & 16.3 & 33.3 & 39.1 & 35.8 & 1.3 \\
\hline Mongolia & 36.3 & 54.2 & 36.3 & 54.2 & 49.3 & 57.2 & 4.8 \\
\hline Mozambique & 27.5 & 45.2 & 27.5 & 45.2 & 32.2 & 35.9 & 0.6 \\
\hline Namibia & 25.0 & 13.0 & 25.0 & 13.0 & 25.0 & 9.8 & 0.0 \\
\hline Netherlands* & 25.0 & 11.3 & 25.0 & 11.3 & 65.1 & 35.9 & 3.0 \\
\hline Nigeria & 21.3 & 34.1 & 21.3 & 34.1 & 19.5 & 18.9 & 0.1 \\
\hline Norway & 20.0 & 12.6 & 20.0 & 12.6 & 47.5 & 24.5 & 0.8 \\
\hline New Zealand & 97.5 & 96.7 & 97.5 & 96.7 & 98.4 & 96.7 & 98.8 \\
\hline Peru & 28.8 & 45.4 & 28.8 & 45.4 & 54.3 & 50.1 & 11.0 \\
\hline Poland & 80.0 & 82.8 & 85.0 & 87.9 & 78.9 & 82.7 & 51.5 \\
\hline Portugal* & 21.3 & 14.0 & 21.3 & 14.0 & 61.0 & 35.8 & 4.2 \\
\hline Romania & 12.5 & 30.1 & 12.5 & 30.1 & 35.0 & 31.5 & 0.5 \\
\hline Russia & 11.3 & 27.4 & 11.3 & 27.4 & 52.2 & 45.8 & 7.4 \\
\hline S. Africa & 22.5 & 36.8 & 22.5 & 36.8 & 49.6 & 42.0 & 7.3 \\
\hline
\end{tabular}


Table B.5 - continued from previous page

\begin{tabular}{|c|c|c|c|c|c|c|c|}
\hline & IA & IB & IIA & IIB & IIIA & IIIB & IV \\
\hline Sierra Leon & 42.5 & 52.7 & 57.5 & 64.0 & 39.8 & 39.6 & 0.5 \\
\hline Singapore & 23.8 & 23.2 & 23.8 & 23.2 & 42.3 & 28.9 & 0.1 \\
\hline Slovak Rep. & 10.5 & 32.3 & 10.5 & 32.3 & 33.9 & 35.8 & 0.3 \\
\hline Slovenia & 17.5 & 31.0 & 17.5 & 31.0 & 44.2 & 33.0 & 1.7 \\
\hline Spain* & 31.3 & 38.3 & 31.3 & 38.3 & 51.9 & 48.3 & 3.3 \\
\hline Sri Lanka & 20.0 & 31.4 & 30.0 & 37.7 & 25.3 & 21.1 & 0.2 \\
\hline Sweden & 95.0 & 95.0 & 100.0 & 100.0 & 95.5 & 96.5 & 95.8 \\
\hline Switzerland & 12.5 & 25.1 & 12.5 & 25.1 & 42.3 & 32.0 & 0.9 \\
\hline Taiwan & 11.3 & 32.4 & 11.3 & 32.4 & 50.3 & 46.4 & 5.7 \\
\hline Tanzania & 13.8 & 27.8 & 13.8 & 27.8 & 25.5 & 19.7 & 0.2 \\
\hline Thailand & 37.5 & 44.4 & 42.5 & 48.1 & 54.6 & 43.9 & 7.3 \\
\hline Tonga & 0.0 & 13.0 & 0.0 & 13.0 & 0.0 & 2.6 & 0.0 \\
\hline Turkey & 17.5 & 32.2 & 17.5 & 32.2 & 26.9 & 29.5 & 0.0 \\
\hline Turkmenistan & 32.5 & 48.5 & 32.5 & 48.5 & 26.0 & 40.5 & 0.6 \\
\hline Uganda & 37.5 & 58.2 & 37.5 & 58.2 & 51.6 & 54.4 & 19.9 \\
\hline U. K. & 100.0 & 100.0 & 100.0 & 100.0 & 100.0 & 100.0 & 99.3 \\
\hline Ukraine & 23.8 & 42.1 & 23.8 & 42.1 & 49.2 & 52.7 & 14.4 \\
\hline Uruguay & 25.0 & 19.7 & 25.0 & 19.7 & 31.6 & 20.0 & 0.0 \\
\hline U.S.A. & 23.8 & 34.5 & 23.8 & 34.5 & 68.7 & 53.1 & 70.2 \\
\hline Vietnam & 20.0 & 33.9 & 20.0 & 33.9 & 30.9 & 32.9 & 1.0 \\
\hline W. African St. & 25.0 & 22.2 & 25.0 & 22.2 & 23.2 & 17.6 & 0.0 \\
\hline Zambia & 20.0 & 41.4 & 20.0 & 41.4 & 23.8 & 33.5 & 0.0 \\
\hline
\end{tabular}

Notes: Numbers in bold are scores higher than 60 for non-IT countries.

Numbers in italic indicate the scores of IT countries. * denotes non-IT EU

member as of 1999 . 


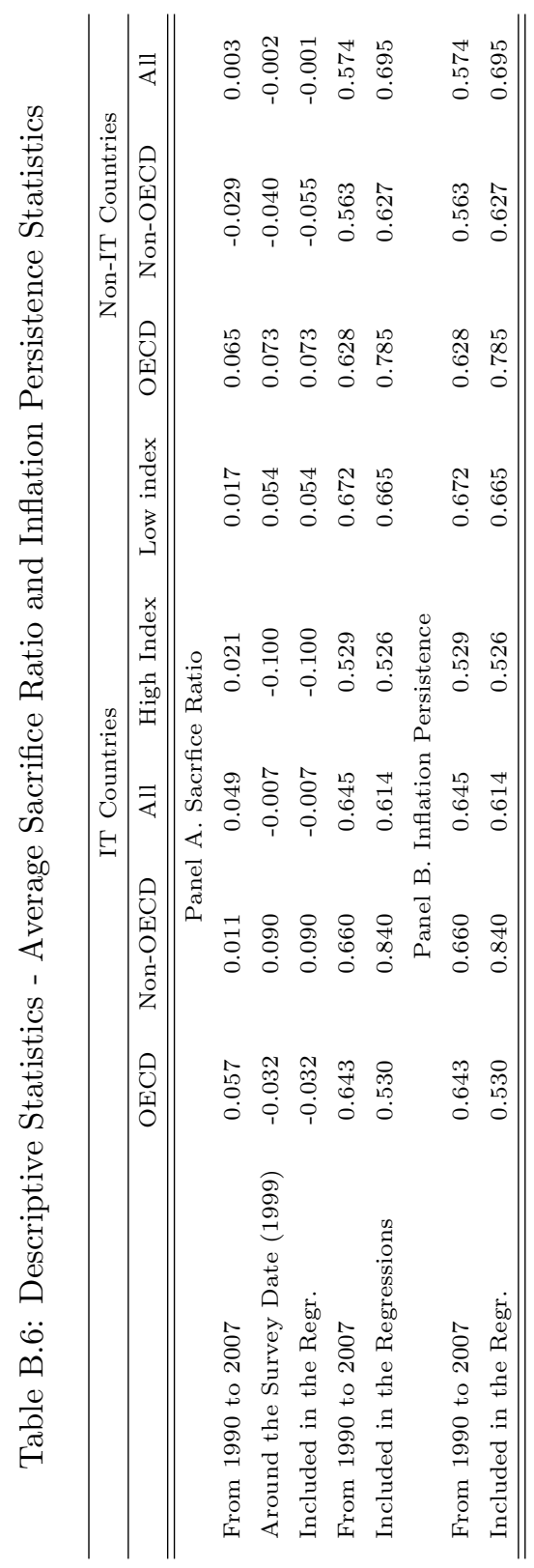


Table B.7: Sacrifice Ratio Statistics by Groups

\begin{tabular}{|c|c|c|c|c|c|c|}
\hline & \multicolumn{3}{|c|}{ OECD Countries } & \multicolumn{3}{|c|}{ All Sample } \\
\hline & IIIA & IIIB & IV & IIIA & IIIB & IV \\
\hline \multicolumn{7}{|c|}{ Panel A. Average Sacrfice Ratio } \\
\hline Group 1 & 0.00 & 0.00 & -0.02 & -0.06 & -0.07 & -0.06 \\
\hline Group 2 & 0.10 & 0.12 & 0.12 & 0.07 & 0.01 & -0.02 \\
\hline Group 3 & 0.12 & 0.11 & 0.12 & -0.04 & 0.03 & 0.02 \\
\hline Group 4 & -0.06 & -0.06 & -0.06 & -0.02 & -0.04 & 0.00 \\
\hline \multicolumn{7}{|c|}{ Panel A. Corr. with Sacrfice Ratio } \\
\hline All Countries & -0.23 & -0.24 & -0.31 & -0.02 & -0.01 & -0.01 \\
\hline Group $1,2,3$ & 0.39 & 0.45 & 0.22 & 0.05 & 0.16 & 0.05 \\
\hline Group 2, 3, 4 & -0.51 & -0.53 & -0.51 & -0.09 & -0.11 & -0.06 \\
\hline
\end{tabular}

Notes: Group 1 consists of countries with the lowest index value, group 4 includes those countries with the highest index value.

Table B.8: Inflation Persistence Statistics by Groups

\begin{tabular}{|c|c|c|c|c|c|c|}
\hline & \multicolumn{3}{|c|}{ OECD Countries } & \multicolumn{3}{|c|}{ All Sample } \\
\hline & IIIA & IIIB & IV & IIIA & IIIB & IV \\
\hline \multicolumn{7}{|c|}{ Panel A. Average Sacrfice Ratio } \\
\hline Group 1 & 0.96 & 0.86 & 0.92 & 0.58 & 0.65 & 0.69 \\
\hline Group 2 & 0.76 & 0.77 & 0.80 & 0.83 & 0.71 & 0.70 \\
\hline Group 3 & 0.60 & 0.67 & 0.59 & 0.69 & 0.74 & 0.71 \\
\hline Group 4 & 0.53 & 0.53 & 0.53 & 0.60 & 0.61 & 0.61 \\
\hline \multicolumn{7}{|c|}{ Panel A. Corr. with Sacrfice Ratio } \\
\hline All Countries & -0.64 & -0.57 & -0.46 & -0.11 & -0.12 & -0.21 \\
\hline Group $1,2,3$ & -0.58 & -0.42 & -0.15 & 0.22 & 0.18 & 0.01 \\
\hline Group 2, 3, 4 & -0.45 & -0.49 & -0.35 & -0.41 & -0.26 & -0.25 \\
\hline
\end{tabular}

Notes: Group 1 consists of countries with the lowest index value, group 4 includes those countries with the highest index value.

Table B.9: Estimates for the Impact of Inflation Targeting Indexes on Sacrifice Ratio

\begin{tabular}{lccccccccc}
\hline \multicolumn{1}{c}{} & \multicolumn{9}{c}{ OECD } \\
\multicolumn{1}{c}{ Panel A. Index III-A } \\
\hline \hline Constant & \multicolumn{1}{c}{ FULL SAMPLE } \\
& $0.273^{*}$ & $0.354^{*}$ & 0.155 & $0.278^{*}$ & -0.036 & 0.059 & 0.041 & -0.036 \\
& $(4.377)$ & $(3.754)$ & $(0.863)$ & $(4.374)$ & $(-0.415)$ & $(0.573)$ & $(0.318)$ & $(-0.410)$ \\
Initial Inflation & -0.366 & $-0.493^{*}$ & -0.228 & -0.422 & 0.086 & -0.008 & 0.010 & 0.084 \\
& $(-1.390)$ & $(-1.823)$ & $(-0.678)$ & $(-1.515)$ & $(0.258)$ & $(-0.026)$ & $(0.028)$ & $(0.245)$ \\
Velocity & $-2.538^{*}$ & $-2.744^{*}$ & $-2.353^{*}$ & $-2.556^{*}$ & -0.677 & -0.736 & -0.714 & -0.675 \\
& $(-3.857)$ & $(-4.215)$ & $(-3.315)$ & $(-3.833)$ & $(-0.994)$ & $(-1.091)$ & $(-1.040)$ & $(-0.979)$ \\
\hline
\end{tabular}


Table B.9 - continued from previous page

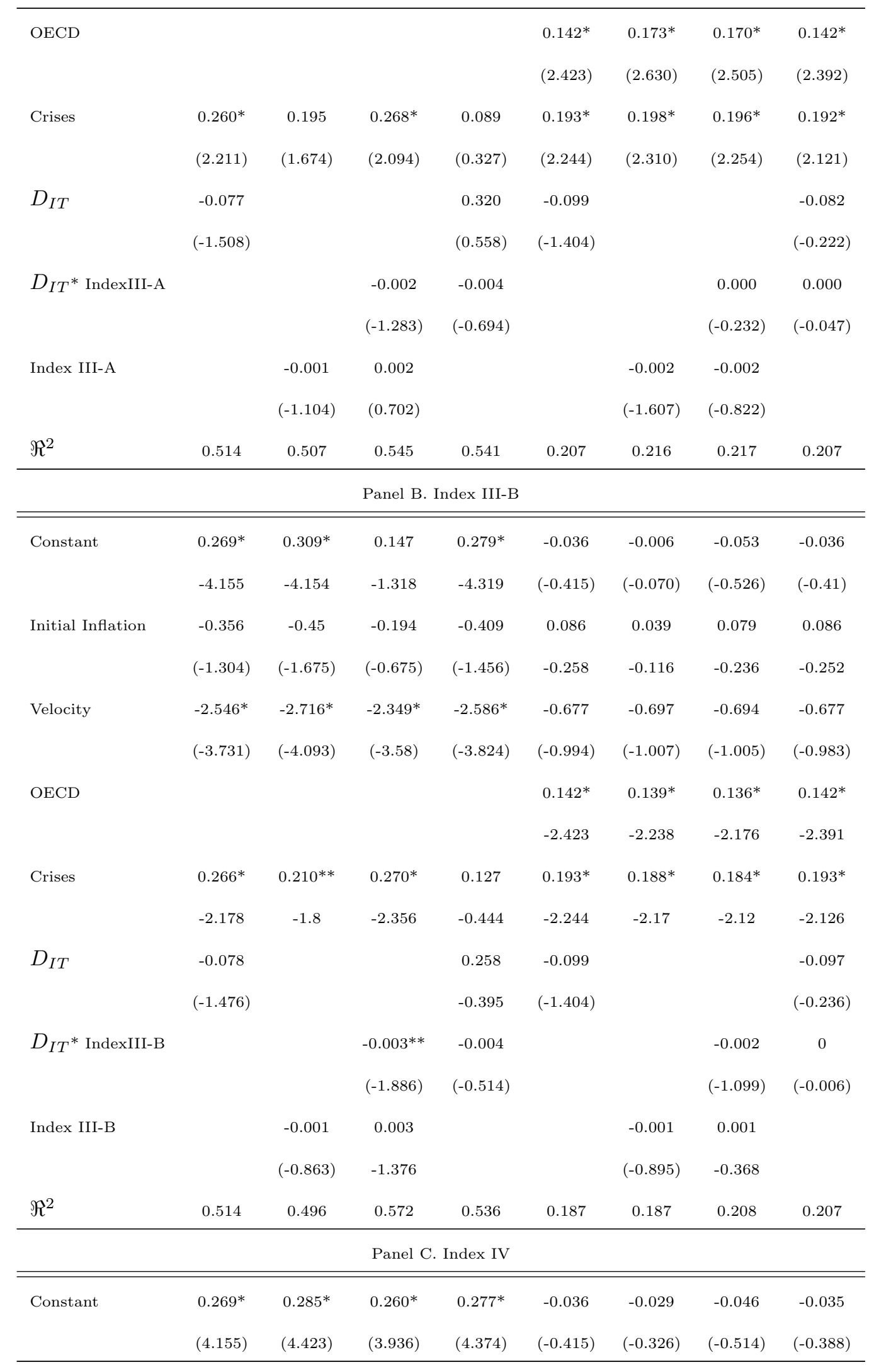

Continued on next page 
Table B.9 - continued from previous page

\begin{tabular}{|c|c|c|c|c|c|c|c|c|}
\hline \multirow[t]{2}{*}{ Initial Inflation } & -0.356 & -0.433 & -0.341 & -0.453 & 0.086 & 0.016 & 0.082 & 0.104 \\
\hline & $(-1.304)$ & $(-1.624)$ & $(-1.259)$ & $(-1.557)$ & $(0.258)$ & $(0.049)$ & $(0.241)$ & $(0.303)$ \\
\hline \multirow[t]{2}{*}{ Velocity } & $-2.546^{*}$ & $-2.661^{*}$ & $-2.488^{*}$ & $-2.504^{*}$ & -0.677 & -0.717 & -0.652 & -0.708 \\
\hline & $(-3.731)$ & $(-3.999)$ & $(-3.730)$ & $(-3.754)$ & $(-0.994)$ & $(-1.030)$ & $(-0.939)$ & $(-1.018)$ \\
\hline \multirow[t]{2}{*}{ OECD } & & & & & $0.142^{*}$ & $0.131^{*}$ & $0.130^{*}$ & $0.139^{*}$ \\
\hline & & & & & $(2.423)$ & $(2.115)$ & $(2.123)$ & $(2.314)$ \\
\hline \multirow[t]{2}{*}{ Crises } & $0.266^{*}$ & 0.198 & $0.204^{* *}$ & -0.070 & $0.193^{*}$ & $0.181^{*}$ & $0.185^{*}$ & $0.198^{*}$ \\
\hline & $(2.178)$ & $(1.702)$ & $(1.783)$ & $(-0.151)$ & $(2.244)$ & $(2.078)$ & $(2.132)$ & $(2.235)$ \\
\hline \multirow[t]{2}{*}{$D_{I T}$} & -0.078 & & & 0.334 & -0.099 & & & -0.144 \\
\hline & $(-1.476)$ & & & $(0.600)$ & $(-1.404)$ & & & $(-0.869)$ \\
\hline \multirow[t]{2}{*}{$D_{I T^{*}}$ IndexIV } & & & -0.002 & -0.005 & & & -0.002 & 0.001 \\
\hline & & & $(-1.318)$ & $(-0.741)$ & & & $(-1.233)$ & $(0.298)$ \\
\hline \multirow[t]{2}{*}{ Index IV } & & -0.001 & 0.001 & & & -0.001 & 0.001 & \\
\hline & & $(-1.040)$ & $(0.659)$ & & & $(-0.609)$ & $(0.795)$ & \\
\hline$\Re^{2}$ & 0.514 & 0.504 & 0.544 & 0.542 & 0.187 & 0.180 & 0.206 & 0.208 \\
\hline
\end{tabular}

Notes: t-statistics in parentheses

Table B.10: Estimates for the Impact of Inflation Targeting Indexes on Inflation Persistence

\begin{tabular}{|c|c|c|c|c|c|c|c|c|}
\hline & \multicolumn{5}{|c|}{ OECD } & \multicolumn{3}{|c|}{ FULL SAMPLE } \\
\hline \multicolumn{9}{|c|}{ Panel A. Index III-A } \\
\hline \multirow[t]{2}{*}{ Constant } & 0.785 & 1.159 & 1.223 & 0.785 & 0.785 & 0.371 & 0.720 & 0.657 \\
\hline & $(15.812)$ & $(9.898)$ & $(7.031)$ & $(15.483)$ & $(6.406)$ & $(1.409)$ & $(0.625)$ & -14.711 \\
\hline \multirow[t]{2}{*}{ OECD } & & & & & -0.100 & -0.118 & -0.075 & 0.103 \\
\hline & & & & & $(-0.484)$ & $(-0.66)$ & $(-0.266)$ & -1.55 \\
\hline \multirow[t]{2}{*}{$D_{I T}$} & -0.255 & & & -0.305 & 0.668 & & & 0.309 \\
\hline & $(-2.852)$ & & & $(-0.66)$ & $(0.879)$ & & & -0.741 \\
\hline \multirow[t]{2}{*}{$D_{I T}{ }^{*}$ IndexIII-A } & & & 0.001 & 0.001 & & & 0.010 & -0.006 \\
\hline & & & $(0.505)$ & $(0.109)$ & & & $(0.32)$ & $(-1.135)$ \\
\hline \multirow[t]{2}{*}{ Index III-A } & & -0.007 & -0.009 & & & 0.007 & -0.003 & \\
\hline & & $(-4.072)$ & $(-2.628)$ & & & $(1.092)$ & $(-0.092)$ & \\
\hline R2 & 0.514 & 0.409 & 0.415 & 0.254 & 0.056 & 0.051 & 0.057 & 0.1 \\
\hline
\end{tabular}


Table B.10 - continued from previous page

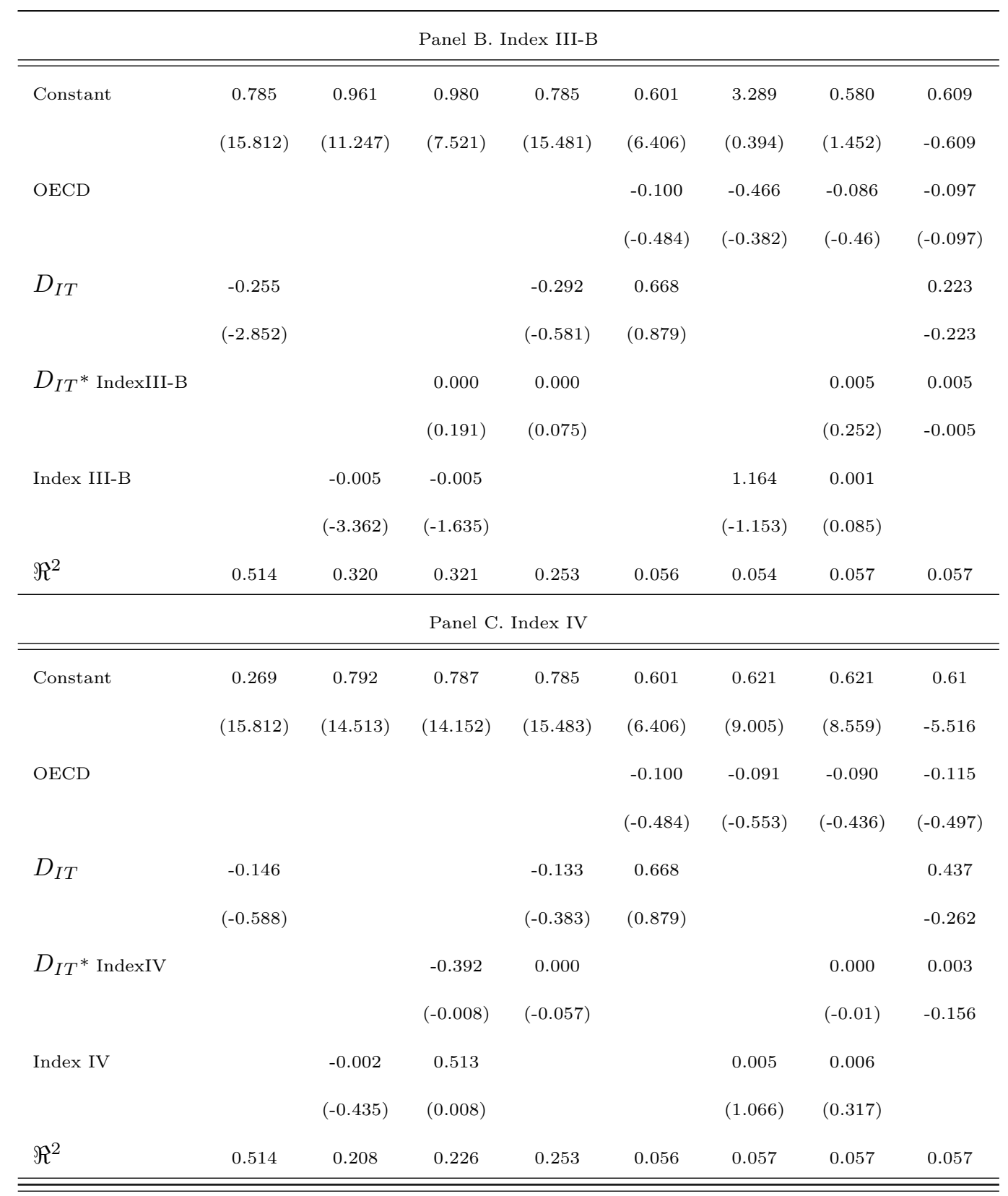

Notes: t-statistics in parentheses

Table B.11: Estimates for the Impact of Inflation Targeting Indexes on Sacrifice Ratio by Groups

\begin{tabular}{lllll}
\hline \multicolumn{4}{c}{ OECD } & \multicolumn{2}{c}{ FULL SAMPLE } \\
& Panel A. Index III-A & \\
\hline \hline Constant & $0.461^{*}$ & 0.151 & 0.057 & -0.004 \\
& $(4.360)$ & $(1.704)$ & $(0.376)$ & $(-0.040)$ \\
\hline
\end{tabular}

Continued on next page 
Table B.11 - continued from previous page

\begin{tabular}{|c|c|c|c|c|}
\hline \multirow[t]{2}{*}{ Initial Inflation } & 0.153 & -0.125 & $0.197^{*}$ & -0.051 \\
\hline & $(1.347)$ & $(-0.401)$ & $(2.102)$ & $(-0.147)$ \\
\hline \multirow[t]{2}{*}{ Velocity } & -0.557 & $-2.320^{*}$ & $0.159^{*}$ & -0.681 \\
\hline & $(-1.484)$ & $(-3.332)$ & $(2.086)$ & $(-0.973)$ \\
\hline \multirow[t]{2}{*}{ OECD } & & & -0.062 & $0.148^{*}$ \\
\hline & & & $(-0.154)$ & $(2.159)$ \\
\hline \multirow[t]{2}{*}{ Crises } & $-2.654^{*}$ & 0.173 & -1.116 & $0.193^{*}$ \\
\hline & $(-3.604)$ & $(1.402)$ & $(-1.344)$ & $(2.002)$ \\
\hline \multirow[t]{2}{*}{$D_{g 1}$} & & 0.025 & & \\
\hline & & $(0.379)$ & & \\
\hline \multirow[t]{2}{*}{$D_{g 2}$} & & 0.096 & & 0.000 \\
\hline & & $(1.461)$ & & $(0.003)$ \\
\hline \multirow[t]{2}{*}{$D_{g 3}$} & & $0.136^{*}$ & & -0.083 \\
\hline & & $(1.982)$ & & $(-0.981)$ \\
\hline \multirow[t]{2}{*}{$D_{g 4}$} & & & & -0.086 \\
\hline & & & & $(-0.937)$ \\
\hline \multirow{2}{*}{ Indexhigh } & $-0.003^{* *}$ & & -0.002 & \\
\hline & $(-1.808)$ & & $(-0.858)$ & \\
\hline \multirow[t]{2}{*}{$\Re^{2}$} & 0.608 & 0.567 & 0.258 & 0.210 \\
\hline & Panel I & Index II & & \\
\hline \multirow[t]{2}{*}{ Constant } & $0.356^{*}$ & $0.163^{* *}$ & 0.011 & -0.024 \\
\hline & $(4.036)$ & $(1.879)$ & $(0.093)$ & $(-0.238)$ \\
\hline \multirow[t]{2}{*}{ Initial Inflation } & 0.167 & -0.140 & $0.225^{*}$ & 0.044 \\
\hline & $(1.381)$ & $(-0.465)$ & $(2.443)$ & $(0.131)$ \\
\hline \multirow[t]{2}{*}{ Velocity } & -0.460 & $-2.432 *$ & $0.166^{*}$ & -0.815 \\
\hline & $(-1.176)$ & $(-3.563)$ & $(2.386)$ & $(-1.149)$ \\
\hline \multirow[t]{2}{*}{ OECD } & & & -0.052 & $0.133^{*}$ \\
\hline & & & $(-0.131)$ & $(2.107)$ \\
\hline \multirow[t]{2}{*}{ Crises } & $-2.018^{*}$ & 0.130 & -0.942 & $0.183^{*}$ \\
\hline & $(-2.454)$ & $(1.050)$ & $(-1.058)$ & $(2.063)$ \\
\hline \multirow[t]{2}{*}{$D_{g 1}$} & & 0.025 & & \\
\hline & & $(0.402)$ & & \\
\hline
\end{tabular}

Continued on next page 
Table B.11 - continued from previous page

\begin{tabular}{|c|c|c|c|c|}
\hline \multirow[t]{2}{*}{$D_{g 2}$} & \multicolumn{3}{|c|}{0.105} & -0.016 \\
\hline & \multicolumn{3}{|c|}{$(1.566)$} & $(-0.193)$ \\
\hline \multirow[t]{2}{*}{$D_{g 3}$} & \multicolumn{3}{|c|}{0.140} & 0.035 \\
\hline & \multicolumn{3}{|c|}{$(2.035)$} & $(0.447)$ \\
\hline \multirow[t]{2}{*}{$D_{g 4}$} & & & & -0.064 \\
\hline & & & & $(-0.751)$ \\
\hline \multirow[t]{2}{*}{ Indexhigh } & $-0.002^{*}$ & & -0.001 & \\
\hline & $(-1.831)$ & & $(-0.841)$ & \\
\hline \multirow[t]{2}{*}{$\Re^{2}$} & 0.509 & 0.576 & 0.238 & 0.203 \\
\hline & \multicolumn{3}{|c|}{ Panel C. Index IV } & \\
\hline \multirow[t]{2}{*}{ Constant } & $0.317^{*}$ & $0.158^{* *}$ & -0.043 & -0.033 \\
\hline & $(4.573)$ & $(1.824)$ & $(-0.376)$ & $(-0.332)$ \\
\hline \multirow[t]{2}{*}{ Initial Inflation } & 0.168 & -0.137 & $0.213^{*}$ & 0.024 \\
\hline & $(1.483)$ & $(-0.45)$ & $(2.285)$ & $(0.070)$ \\
\hline \multirow[t]{2}{*}{ Velocity } & -0.587 & $-2.390 *$ & $0.164^{*}$ & -0.769 \\
\hline & $(-1.514)$ & $(-3.497)$ & $(2.242)$ & $(-1.061)$ \\
\hline \multirow[t]{2}{*}{ OECD } & & & -0.021 & $0.114^{* *}$ \\
\hline & & & $(-0.051)$ & $(1.768)$ \\
\hline \multirow[t]{2}{*}{ Crises } & $-2.514^{*}$ & 0.143 & -0.683 & $0.182^{* *}$ \\
\hline & $(-3.366)$ & $(1.133)$ & $(-0.812)$ & $(1.978)$ \\
\hline \multirow[t]{2}{*}{$D_{g 1}$} & & 0.025 & & \\
\hline & & $(0.411)$ & & \\
\hline \multirow[t]{2}{*}{$D_{g 2}$} & & $0.117^{*}$ & & 0.009 \\
\hline & & $(1.768)$ & & $(0.119)$ \\
\hline \multirow[t]{2}{*}{$D_{g 3}$} & & $0.127^{*}$ & & 0.009 \\
\hline & & $(1.808)$ & & $(0.113)$ \\
\hline \multirow[t]{2}{*}{$D_{g 4}$} & & & & 0.004 \\
\hline & & & & $(0.052)$ \\
\hline \multirow[t]{2}{*}{ Indexhigh } & -0.001 & & -0.001 & \\
\hline & $(-1.573)$ & & $(-0.838)$ & \\
\hline$\Re^{2}$ & 0.588 & 0.571 & 0.257 & 0.174 \\
\hline
\end{tabular}


Table B.12: Estimates for the Impact of Inflation Targeting Indexes on Inflation Persistence by Groups

\begin{tabular}{|c|c|c|c|c|}
\hline \multirow{3}{*}{$\begin{array}{l} \\
\text { Constant }\end{array}$} & \multicolumn{2}{|c|}{ OECD } & \multicolumn{2}{|c|}{ FULL SAMPLE } \\
\hline & \multicolumn{3}{|c|}{ Panel A. Index III-A } & \\
\hline & 0.958 & 0.535 & 0.052 & 0.578 \\
\hline & $(6.031)$ & (7.663) & $(0.495)$ & (9.438) \\
\hline \multirow[t]{2}{*}{ OECD } & & & 0.130 & 0.050 \\
\hline & & & $(1.885)$ & $(0.690)$ \\
\hline \multirow[t]{2}{*}{ Dg1 } & & 0.423 & & \\
\hline & & $(4.121)$ & & \\
\hline \multirow[t]{2}{*}{ Dg2 } & & 0.221 & & 0.229 \\
\hline & & $(2.240)$ & & $(2.479)$ \\
\hline \multirow[t]{2}{*}{ Dg3 } & & 0.062 & & 0.090 \\
\hline & & $(0.606)$ & & (1.003) \\
\hline \multirow[t]{2}{*}{ Dg4 } & & & & -0.016 \\
\hline & & & & $(-0.155)$ \\
\hline \multirow[t]{2}{*}{ IndexHigh } & -0.005 & & -0.002 & \\
\hline & $(-2.126)$ & & $(-1.228)$ & \\
\hline \multirow[t]{2}{*}{$\mathrm{R} 2$} & 0.201 & 0.473 & 0.094 & 0.187 \\
\hline & \multicolumn{3}{|c|}{ Panel B. Index III-B } & \\
\hline \multirow[t]{2}{*}{ Constant } & 0.933 & 0.535 & 0.001 & 0.638 \\
\hline & $(7.629)$ & $(6.702)$ & $(0.019)$ & $(9.650)$ \\
\hline \multirow[t]{2}{*}{ OECD } & & & 0.143 & 0.078 \\
\hline & & & $(2.256)$ & $(1.086)$ \\
\hline \multirow[t]{2}{*}{ Dg1 } & & 0.353 & & \\
\hline & & $(3.124)$ & & \\
\hline \multirow[t]{2}{*}{ Dg2 } & & 0.193 & & 0.032 \\
\hline & & (1.643) & & $(0.331)$ \\
\hline \multirow[t]{2}{*}{ Dg3 } & & 0.139 & & 0.061 \\
\hline & & $(1.186)$ & & $(0.654)$ \\
\hline \multirow[t]{2}{*}{$\operatorname{Dg} 4$} & & & & -0.089 \\
\hline & & & & $(-0.868)$ \\
\hline
\end{tabular}


Table B.12 - continued from previous page

\begin{tabular}{|c|c|c|c|c|}
\hline \multirow[t]{2}{*}{ IndexHigh } & -0.004 & & -0.002 & \multirow[b]{3}{*}{0.071} \\
\hline & $(-2.41)$ & & $(-1.275)$ & \\
\hline \multirow[t]{2}{*}{ R2 } & 0.244 & & 0.131 & \\
\hline & \multicolumn{3}{|c|}{ Panel C. Index IV } & \\
\hline \multirow[t]{2}{*}{ Constant } & 0.716 & 0.535 & -0.058 & 0.671 \\
\hline & (11.086) & $(7.206)$ & $(-1.228)$ & $(9.949)$ \\
\hline \multirow[t]{2}{*}{ OECD } & & & 0.147 & 0.092 \\
\hline & & & $(2.216)$ & (1.297) \\
\hline \multirow[t]{2}{*}{$D_{g 1}$} & & 0.353 & & \\
\hline & & (3.359) & & \\
\hline \multirow[t]{2}{*}{$D_{g 2}$} & & 0.275 & & -0.011 \\
\hline & & $(2.514)$ & & $(-0.114)$ \\
\hline \multirow[t]{2}{*}{$D_{g 3}$} & & 0.058 & & -0.010 \\
\hline & & $(0.528)$ & & $(-0.105)$ \\
\hline \multirow[t]{2}{*}{$D_{g 4}$} & & & & -0.133 \\
\hline & & & & $(-1.326)$ \\
\hline \multirow[t]{2}{*}{ Indexhigh } & -0.002 & & -0.001 & \\
\hline & $(-1.576)$ & & $(-1.204)$ & \\
\hline$\Re^{2}$ & 0.121 & 0.404 & 0.120 & 0.063 \\
\hline
\end{tabular}

Notes: t-statistics in parentheses

Table B.13: Estimates for the Impact of Individual Policy Design Characteristics

\begin{tabular}{lcccc}
\hline & \multicolumn{2}{c}{ Sacrifice Ratio } & \multicolumn{2}{c}{ Inflation Persistence } \\
Constant & 0.170 & 0.287 & $1.397^{*}$ & 0.161 \\
& $(0.363)$ & $(0.939)$ & $(2.802)$ & $(0.508)$ \\
Initial Inflation & -0.409 & -0.410 & & \\
& $(-0.822)$ & $(-1.033)$ & & \\
Velocity & $-2.085^{*}$ & $-1.258^{* * *}$ & \\
& $(-2.380)$ & $(-1.665)$ & & \\
OECD & & $0.252^{*}$ & & $(1.102)$ \\
\hline & & $(3.000)$ & Continued on next page
\end{tabular}


Table B.13 - continued from previous page

\begin{tabular}{|c|c|c|c|c|}
\hline \multirow[t]{2}{*}{ Crises } & 0.085 & $0.202^{* *}$ & & \\
\hline & $(0.389)$ & $(1.962)$ & & \\
\hline \multirow[t]{2}{*}{ Exchange rate focus } & 0.002 & -0.001 & -0.002 & 0.002 \\
\hline & $(0.936)$ & $(-0.324)$ & $(-0.813)$ & $(1.216)$ \\
\hline \multirow[t]{2}{*}{ Money focus } & 0.000 & -0.000 & -0.001 & $0.002^{* * *}$ \\
\hline & $(0.031)$ & $(-0.303)$ & $(-0.215)$ & $(1.362)$ \\
\hline \multirow[t]{2}{*}{ Inflation focus } & 0.000 & -0.000 & -0.002 & 0.002 \\
\hline & $(0.217)$ & $(-0.239)$ & $(-0.699)$ & $(0.858)$ \\
\hline \multirow[t]{2}{*}{ Discretion } & $0.002^{* * *}$ & 0.001 & $0.003^{* * *}$ & $0.002^{* * *}$ \\
\hline & $(1.759)$ & $(0.775)$ & $(1.494)$ & $(1.615)$ \\
\hline \multirow[t]{2}{*}{ Instrument independence } & 0.000 & 0.0002 & -0.003 & -0.001 \\
\hline & $(0.144)$ & $(0.187)$ & $(-0.963)$ & $(-0.839)$ \\
\hline \multirow[t]{2}{*}{ Central Bank finan. of govern. deficit } & -0.003 & $-0.004^{*}$ & 0.003 & $0.003^{* * *}$ \\
\hline & $(-1.021)$ & $(-2.127)$ & $(0.886)$ & $(1.392)$ \\
\hline \multirow[t]{2}{*}{ Accountability } & -0.001 & -0.001 & $0.000 * * *$ & 0.002 \\
\hline & $(-0.761)$ & $(-0.501)$ & $(0.164)$ & $(1.166)$ \\
\hline \multirow[t]{2}{*}{ Policy Explanations } & 0.003 & 0.001 & $-0.006^{* * *}$ & 0 \\
\hline & $(1.145)$ & $(0.618)$ & $(-1.675)$ & $(-0.047)$ \\
\hline \multirow[t]{2}{*}{ Analysis of Inflation Expectations } & 0.001 & -0.001 & -0.002 & $0.000 * * *$ \\
\hline & $(0.559)$ & $(-0.369)$ & $(-0.771)$ & $(-1.318)$ \\
\hline \multirow[t]{2}{*}{ Analysis using models and forecasts } & -0.000 & -0.001 & -0.002 & 0 \\
\hline & $(-0.352)$ & $(-0.603)$ & $(-0.846)$ & $(0.068)$ \\
\hline$\Re^{2}$ & 0.705 & 0.359 & 0.618 & 0.177 \\
\hline
\end{tabular}

Notes: t-statistics in parentheses 
Table B.14: Estimates for the Impact of the Change in Policy Design

\begin{tabular}{lcc}
\hline & \multicolumn{2}{c}{ Sacrifice Ratio } \\
\hline & OECD & Full Sample \\
\hline \hline Initial Inflation & -0.112 & 0.169 \\
& $(-0.087)$ & $(0.255)$ \\
Velocity & $-2.966^{*}$ & -0.973 \\
& $(-2.339)$ & $(-1.322)$ \\
Crises & $0.746^{*}$ & 0.133 \\
& $(2.352)$ & $(1.114)$ \\
$D_{I T} * I_{\text {change }}$ & 0.003 & 0.000 \\
$\Re^{2}$ & $(0.853)$ & $0.075)$ \\
\hline \hline
\end{tabular}

Notes: t-statistics in parentheses

Table B.15: Factor Loadings

\begin{tabular}{lcccc}
\hline & Factor 1 & Factor 2 & Factor 3 & Factor 4 \\
\hline \hline Exchange rate focus & & & & \\
Regime described as exchange rate targeting? & 0.816 & -0.412 & 0.031 & 0.177 \\
Degree to which the exchange rate is fixed ? & 0.749 & -0.368 & -0.212 & 0.021 \\
Rank of objectives? & 0.747 & -0.375 & -0.082 & -0.052 \\
Degree to which exchange rate prevails in policy conflicts? & 0.885 & -0.309 & 0.012 & 0.109 \\
Money focus & & & & \\
Regime described as money targeting? & -0.075 & 0.915 & -0.021 & -0.012 \\
Specific target/monitoring range published now? & -0.266 & 0.604 & -0.038 & -0.189 \\
Rank of objectives? & -0.188 & 0.842 & -0.152 & -0.001 \\
Degree to which money objective prevails in policy conflicts? & -0.172 & 0.893 & -0.103 & -0.132 \\
Inflation focus & -0.868 & -0.143 & 0.093 & 0.032 \\
Discretion & -0.410 & 0.264 & -0.158 & -0.613 \\
Central bank instrument independence & -0.023 & 0.128 & 0.675 & -0.168 \\
Central bank financing of government deficit & 0.182 & -0.122 & 0.793 & 0.189 \\
Accountability of central bank to government & -0.108 & -0.033 & 0.076 & 0.857 \\
Policy explanations & -0.305 & -0.160 & 0.684 & 0.130 \\
Analysis of inflation expectations & -0.476 & -0.183 & 0.528 & 0.147 \\
Analysis using models and forecasts & -0.068 & -0.089 & 0.805 & 0.095 \\
\hline \hline
\end{tabular}

Notes: The table displays orthogonally transformed factor loadings.

Table B.16: Discrete Choice Model on Underlying Factors

\begin{tabular}{lccccc}
\hline & Constant & Factor 1 & Factor 2 & Factor 3 & Factor 4 \\
\hline \hline Coefficients & -2.272 & $-1.273^{*}$ & -0.170 & $1.018^{*}$ & 0.516 \\
Standard error & 0.549 & 0.508 & 0.294 & 0.407 & 0.373 \\
Pseudo $\Re^{2}: 0.617$ & & \multicolumn{2}{c}{ Score Test: 0.052} & \multicolumn{2}{c}{ N: 93 } \\
\hline \hline
\end{tabular}

Notes: Dependent variable in the discrete choice model is the inflation targeting dummy. * indicates rejection at $5 \%$ significance level. The test statistic for the null hypothesis of homogeneity is distributed as a chi-square with 4 degrees of freedom. The test is not rejected against the critical value of 9.48 at $5 \%$ significance level. 


\section{Appendix $\mathrm{C}$}

\section{Figures of Chapter 2}

Figure C.1: Impulse Response to Unanticipated Monetary Policy Shock
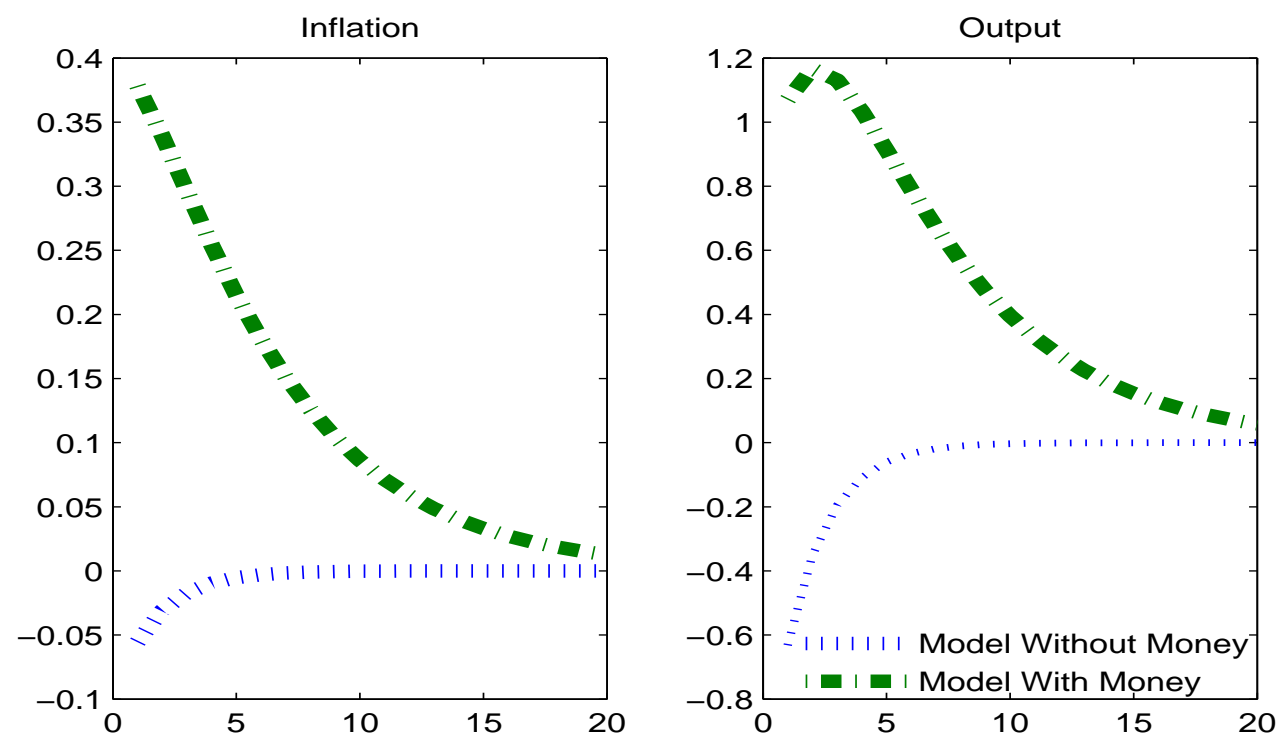

Notes: Figure C.1 shows responses (X100) of inflation and output to a monetary policy shock. The shock results in a 25 basis point increase in nominal interest rate. $\mathrm{X}$-axis corresponds to quarters. The unit of measurement on the $\mathrm{y}$-axis is percentsage points. 
Figure C.2: Impulse Response to Unanticipated Technology Shock
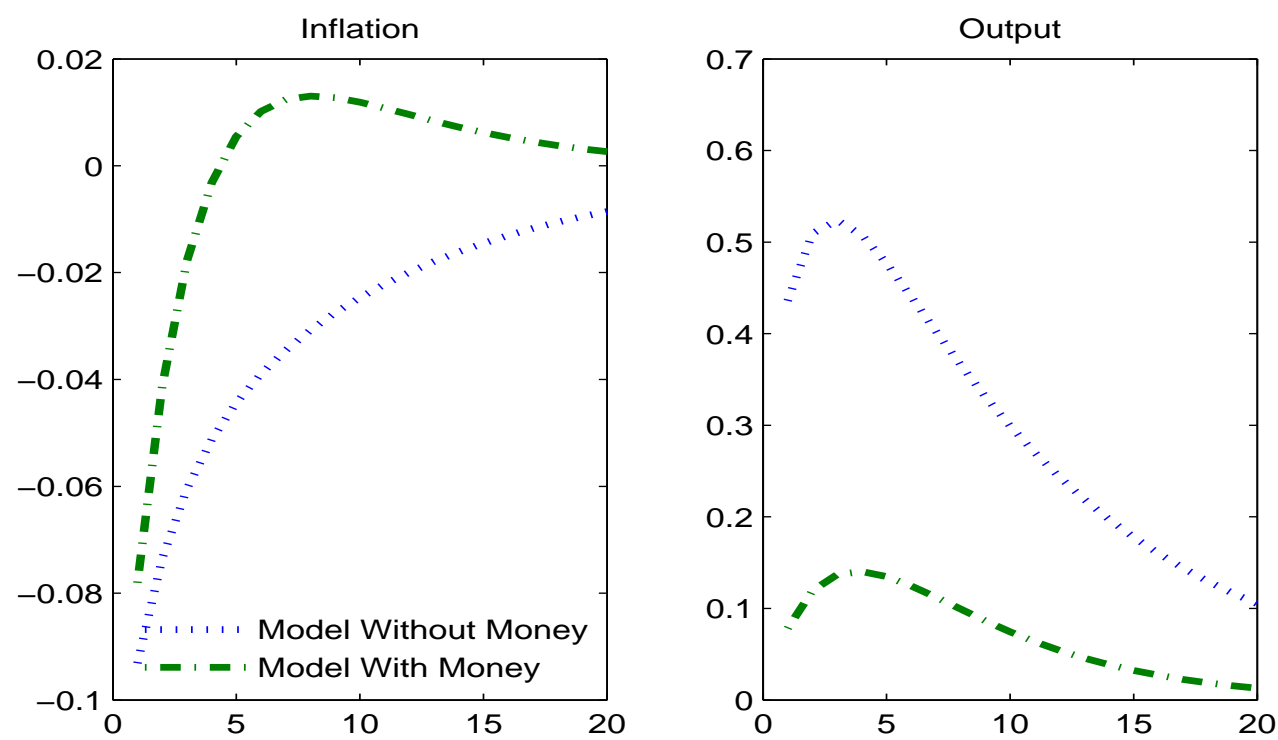

Notes: Figure C.2 shows responses (X100) of inflation and output to a favorable technology shock. The size of the shock is an $0.97 \mathrm{pp}$ increase in the level of technology. $\mathrm{X}$-axis corresponds to quarters.

The unit of measurement on the y-axis is percentsage points. 
Figure C.3: Historical and Forecasted Empirical Densities of Inflation Estimation Period: 1983Q1:2009Q4 - Forecasting period 1990Q1:1999Q4

(a)
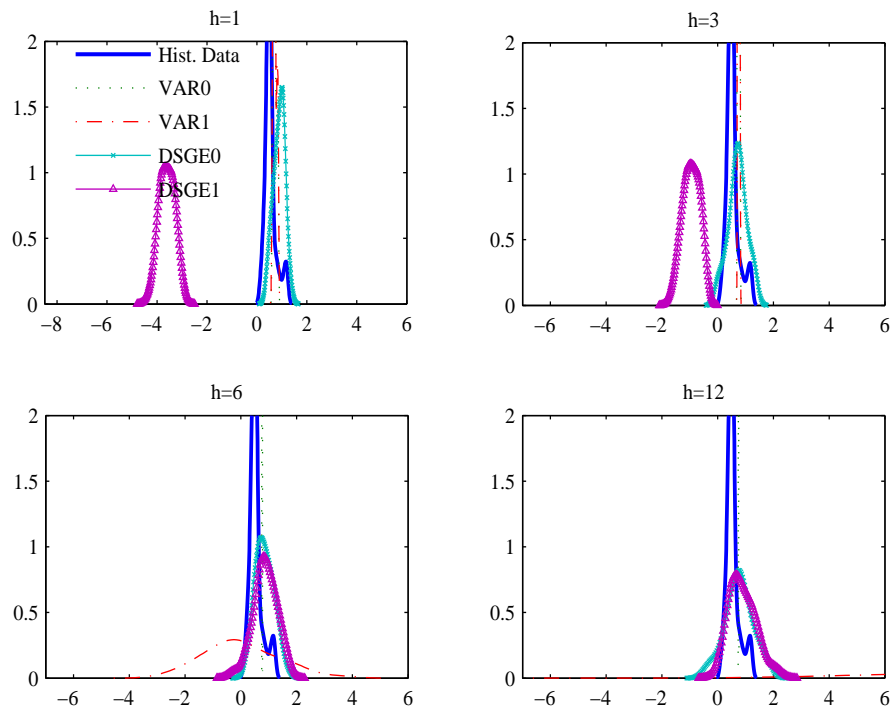

(b)
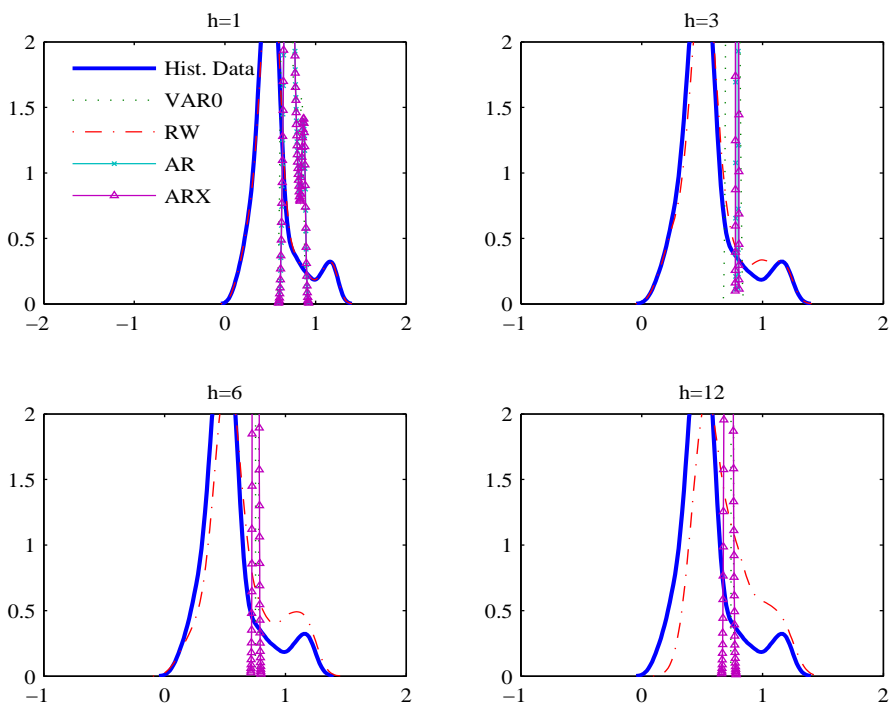

Notes: Figure C.3 displays empirical predictive density plots for inflation forecasts. RW is the random walk model without drift. AR is a univariate autoregressive model. ARX is an autregressive model for inflation including money growth. VAR0, VAR1, DSGE0 and DSGE1 are described in section 2.3. VAR0 is the three-variable vector autoregressive model without money growth. VAR1 includes money growth to VAR0. DSGE0 is the New Keynesian model with the monetary policy described as Taylor-type interest rate rule. DSGE1 is the New Keynesian model with the monetary policy described as exogenous money growth equation. 
Figure C.4: Historical and Forecasted Empirical Densities of Inflation Estimation Period: 1983Q1:2009Q4 - Forecasting period 2000Q1:2009Q4

(a)
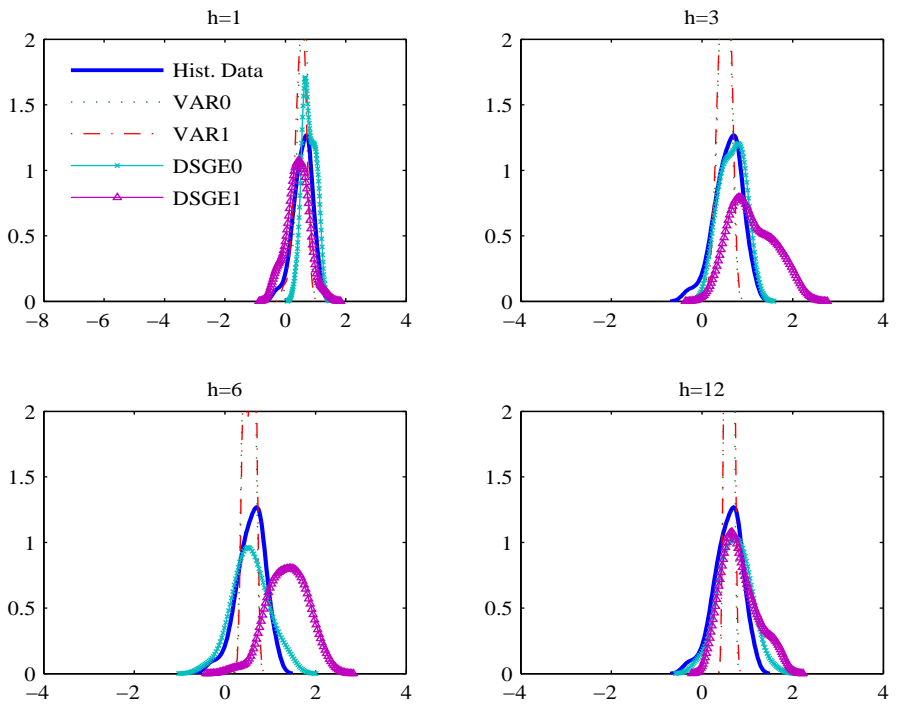

(b)
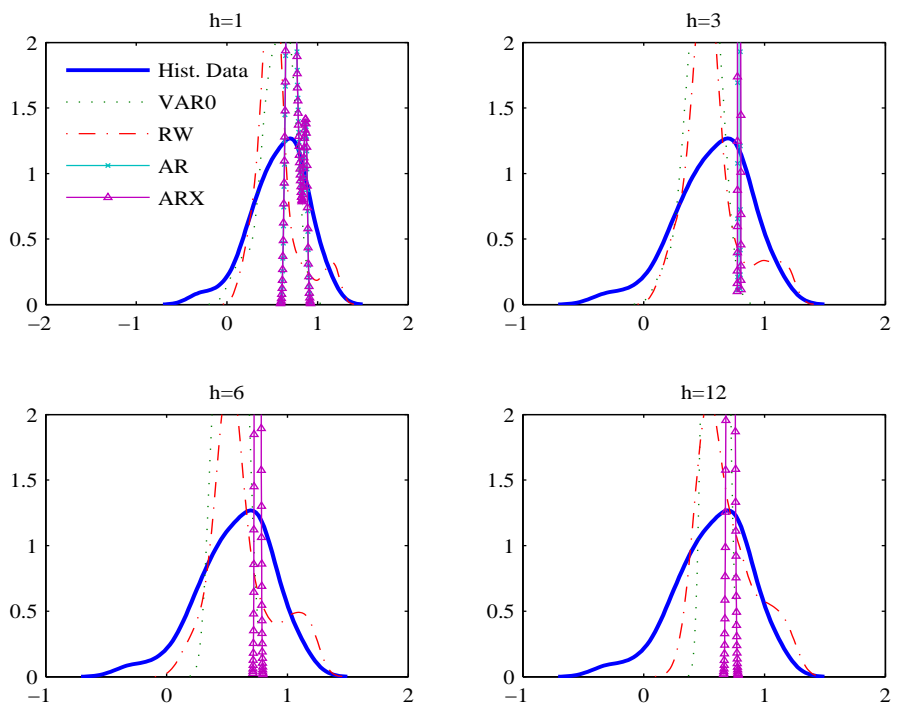

Notes: See notes to table C.3 
Figure C.5: Historical and Forecasted Empirical Densities of Inflation Estimation Period: 1983Q1:2009Q4 - Forecasting period 1990Q1:2009Q4

(a)
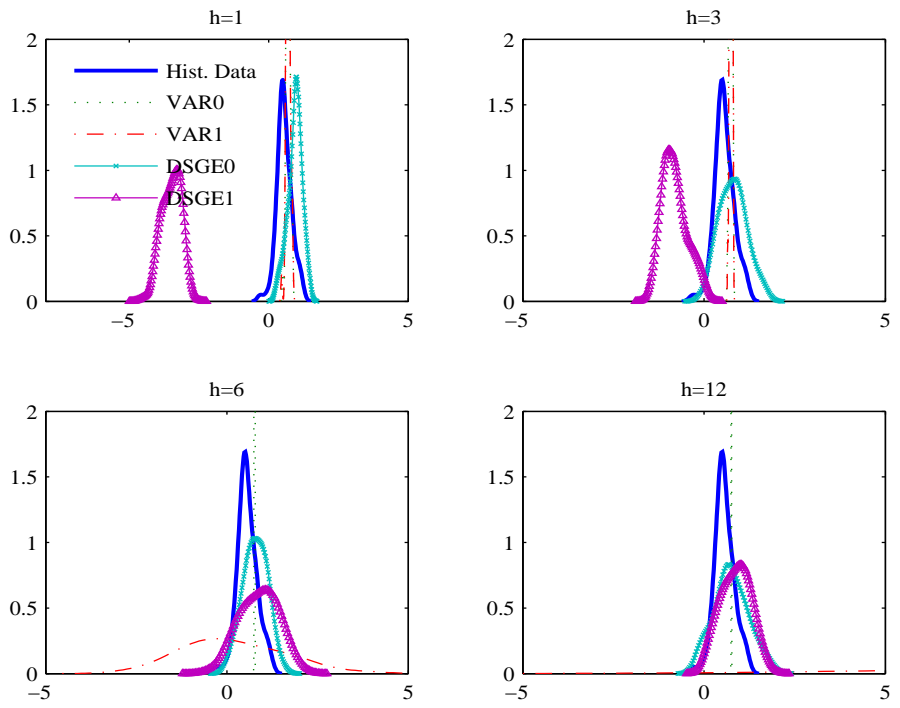

(b)
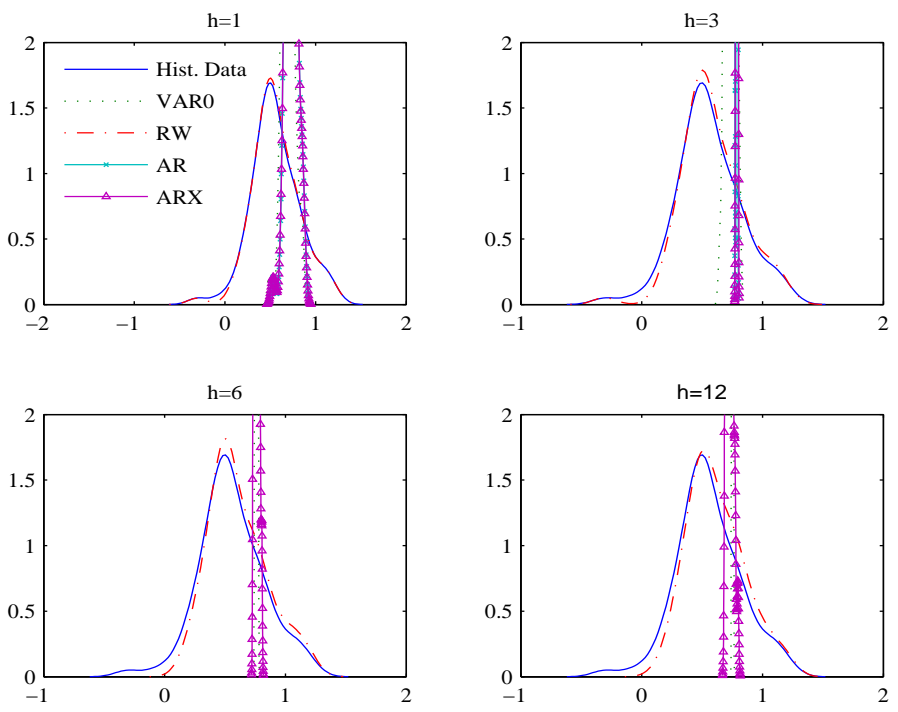

Notes: See notes to table C.3 
Figure C.6: Historical and Forecasted Empirical Densities of Inflation Estimation Period: 1960Q1:2009Q4 - Forecasting period 1990Q1:1999Q4

(a)
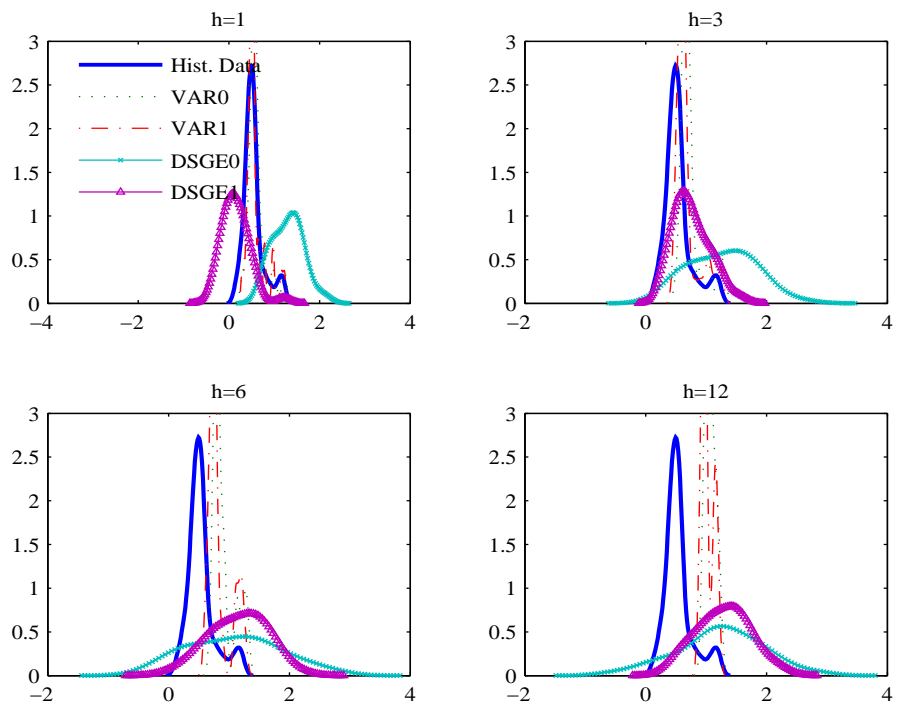

(b)
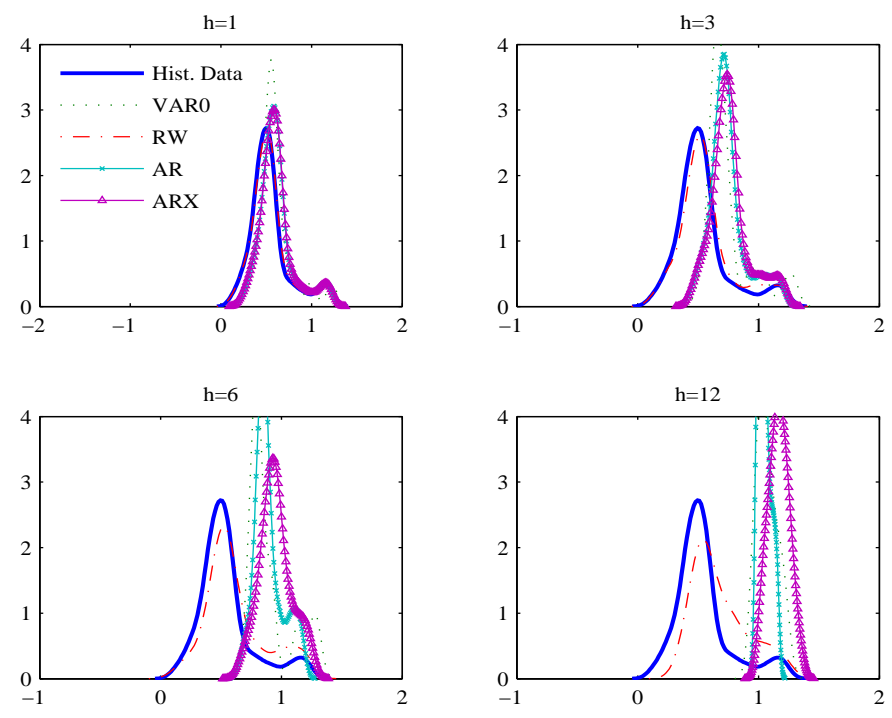

Notes: See notes to table C.3 
Figure C.7: Historical and Forecasted Empirical Densities of Inflation Estimation Period: 1960Q1:2009Q4 - Forecasting period 2000Q1:2009Q4

(a)
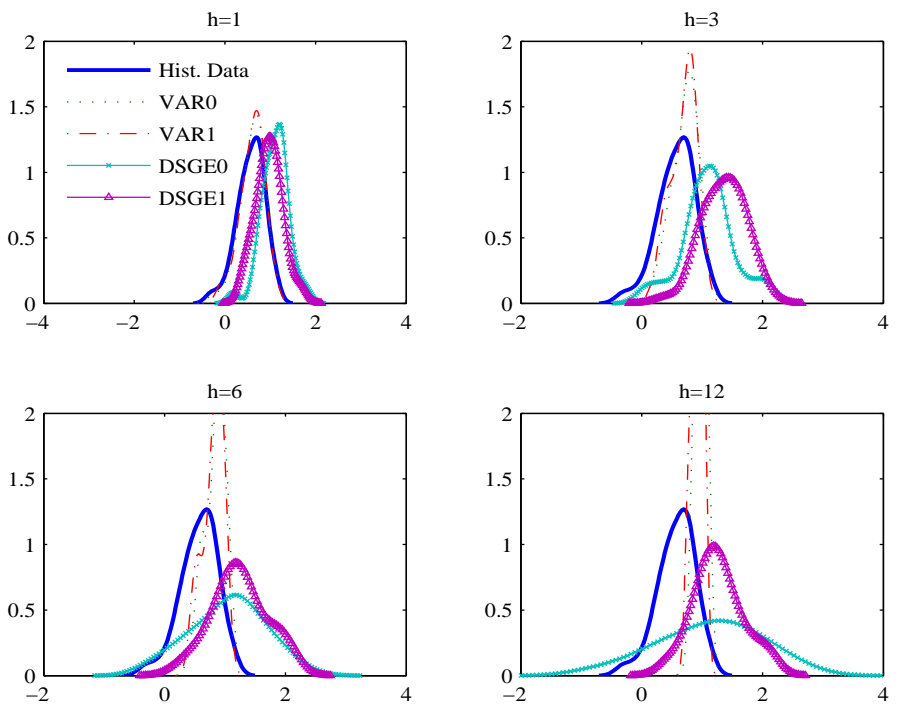

(b)
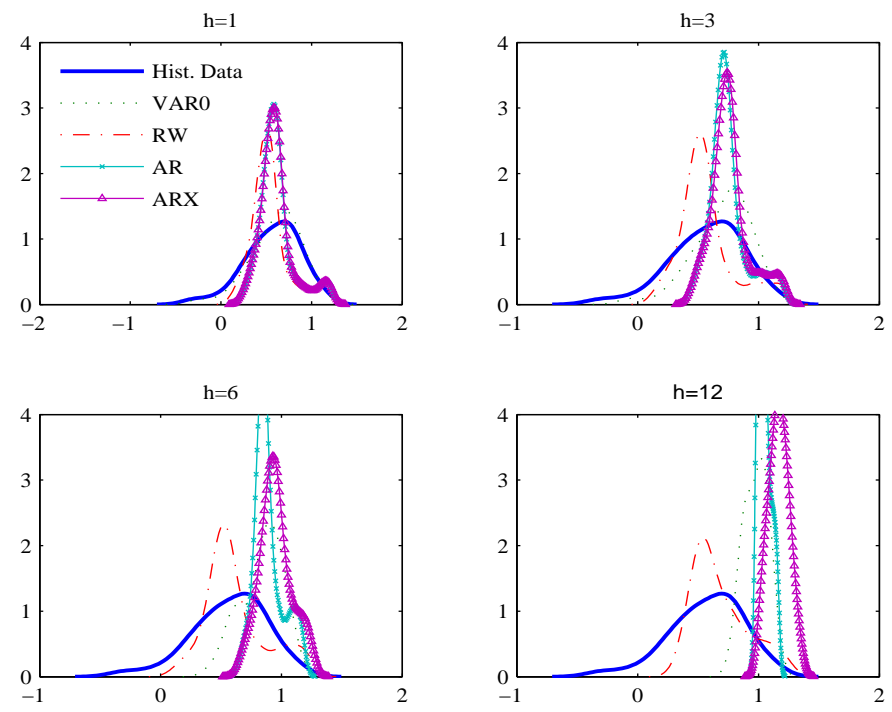

Notes: See notes to table C.3 
Figure C.8: Historical and Forecasted Empirical Densities of Inflation Estimation Period: 1960Q1:2009Q4 - Forecasting period 1990Q1:2009Q4

(a)
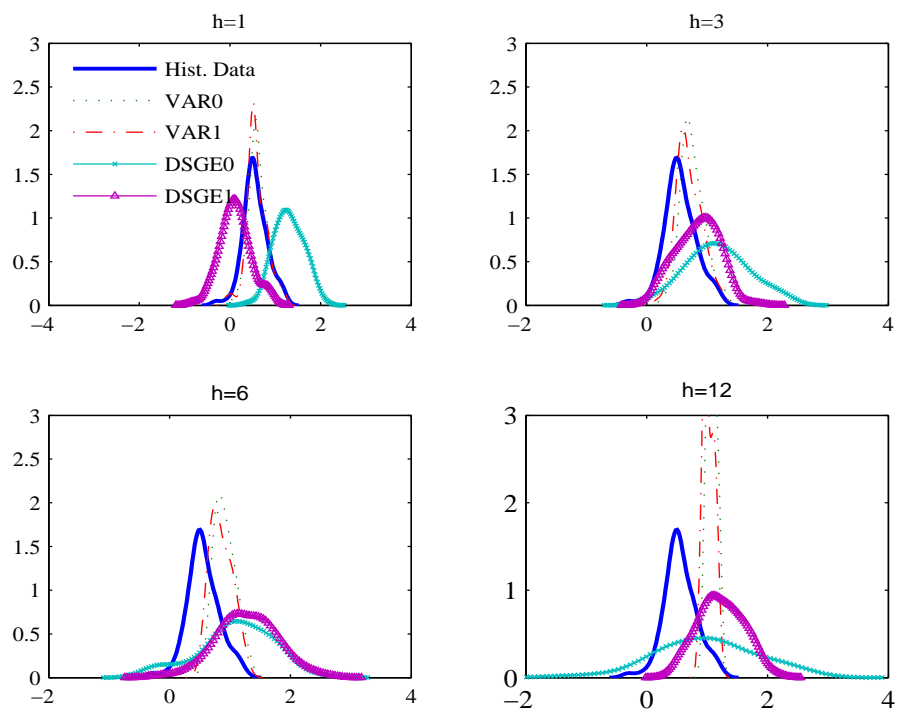

(b)
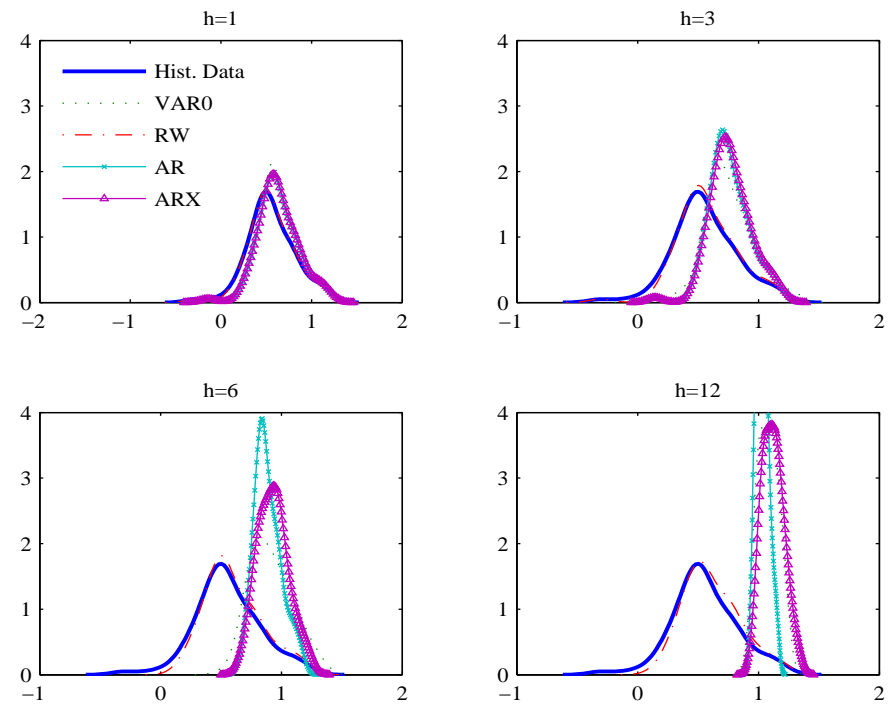

Notes: See notes to table C.3 
Figure C.9: Historical and Forecasted Empirical Densities of Output Estimation Period: 1983Q1:2009Q4 - Forecasting period 1990Q1:1999Q4

(a)
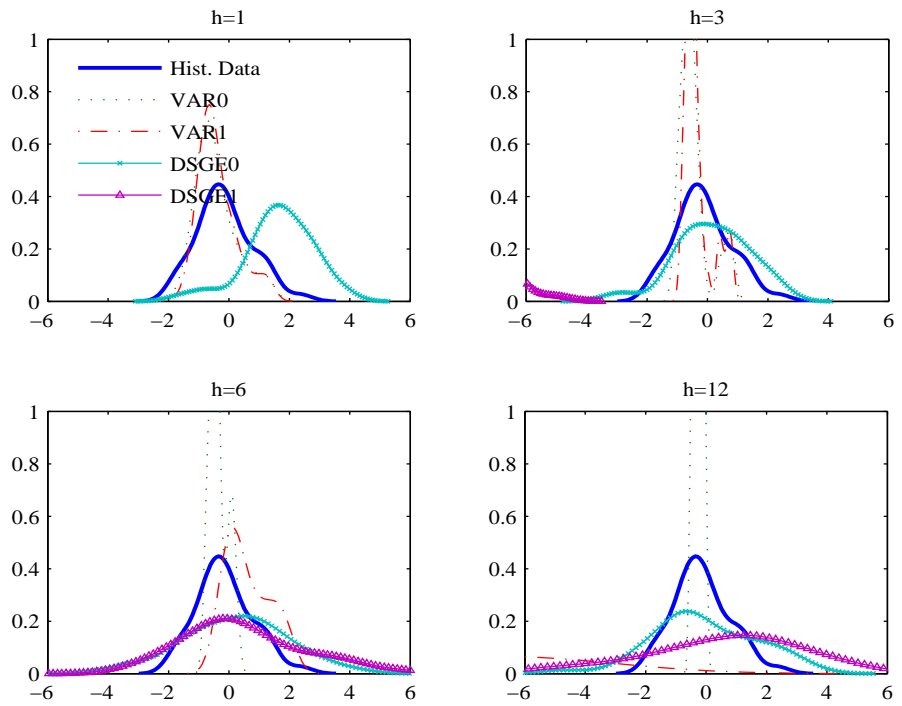

(b)
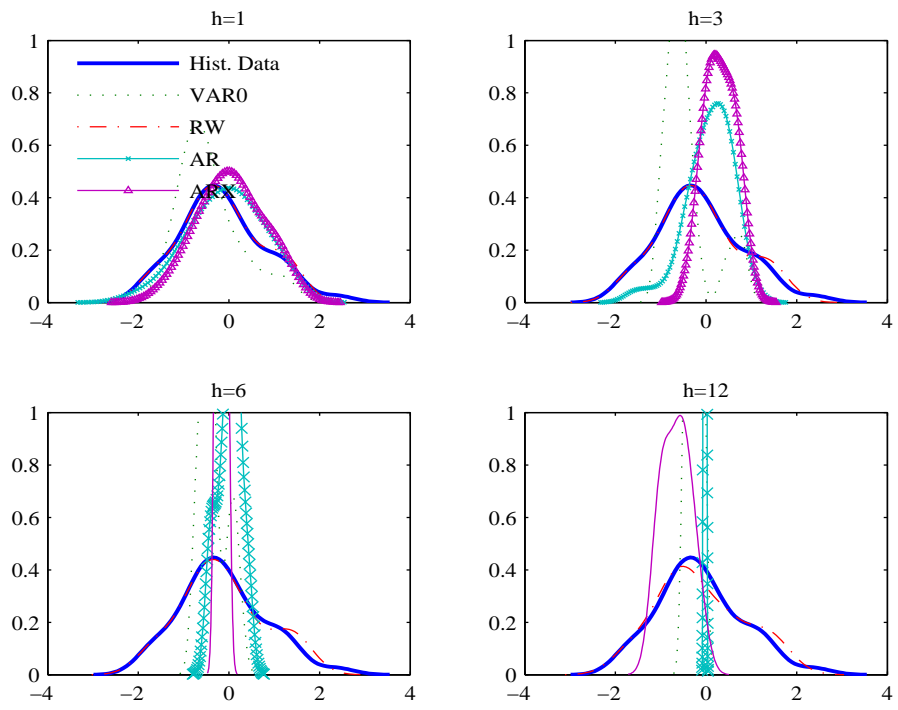

Notes: See notes to table C.3 
Figure C.10: Historical and Forecasted Empirical Densities of Output Estimation Period: 1983Q1:2009Q4 - Forecasting period 2000Q1:2009Q4

(a)
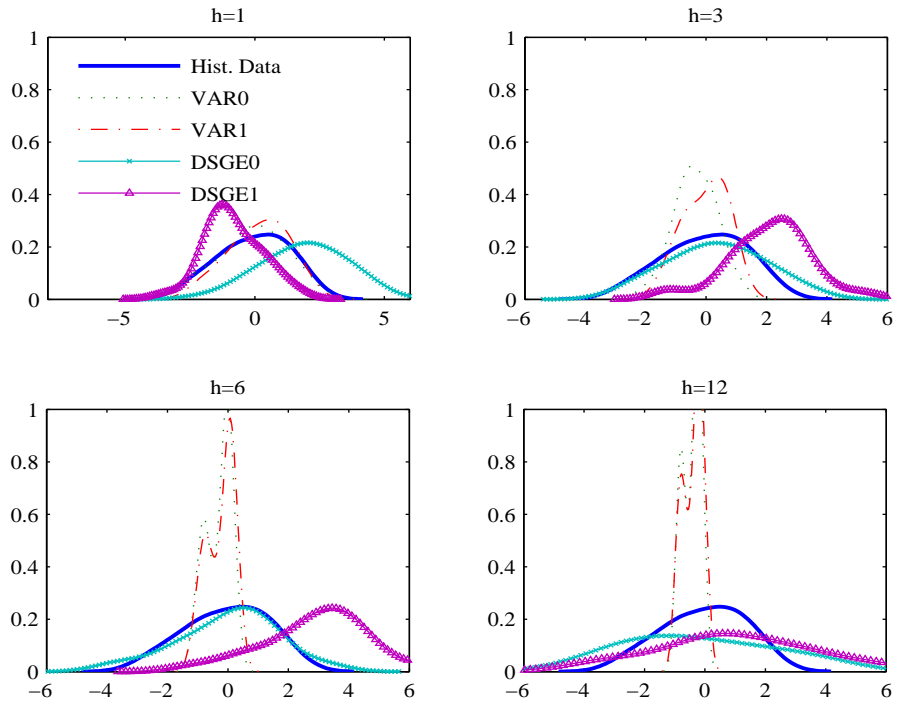

(b)
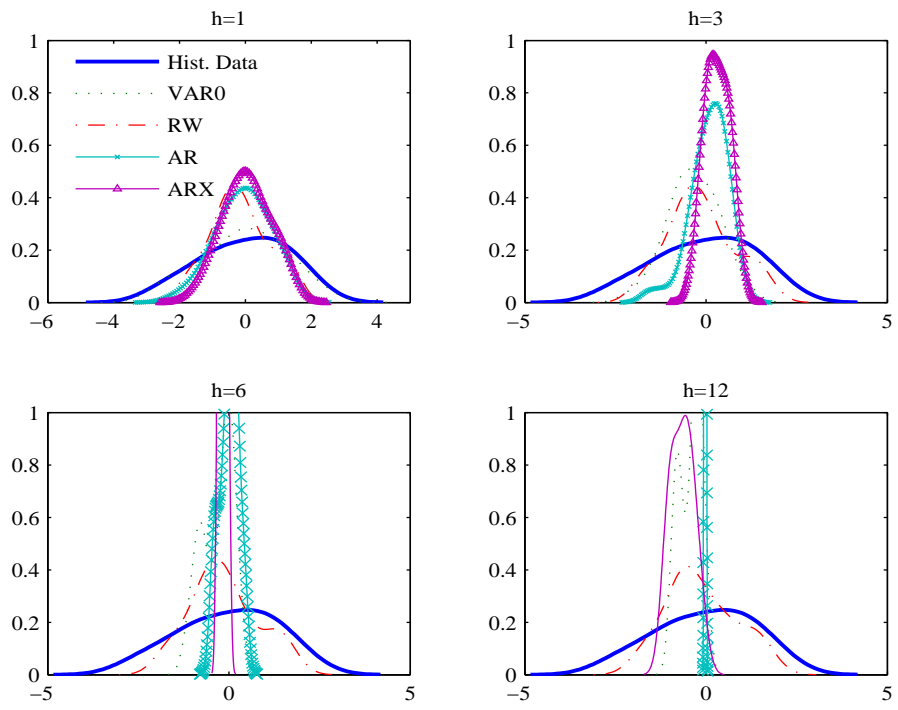

Notes: See notes to table C.3 
Figure C.11: Historical and Forecasted Empirical Densities of Output Estimation Period: 1983Q1:2009Q4 - Forecasting period 1990Q1:2009Q4

(a)
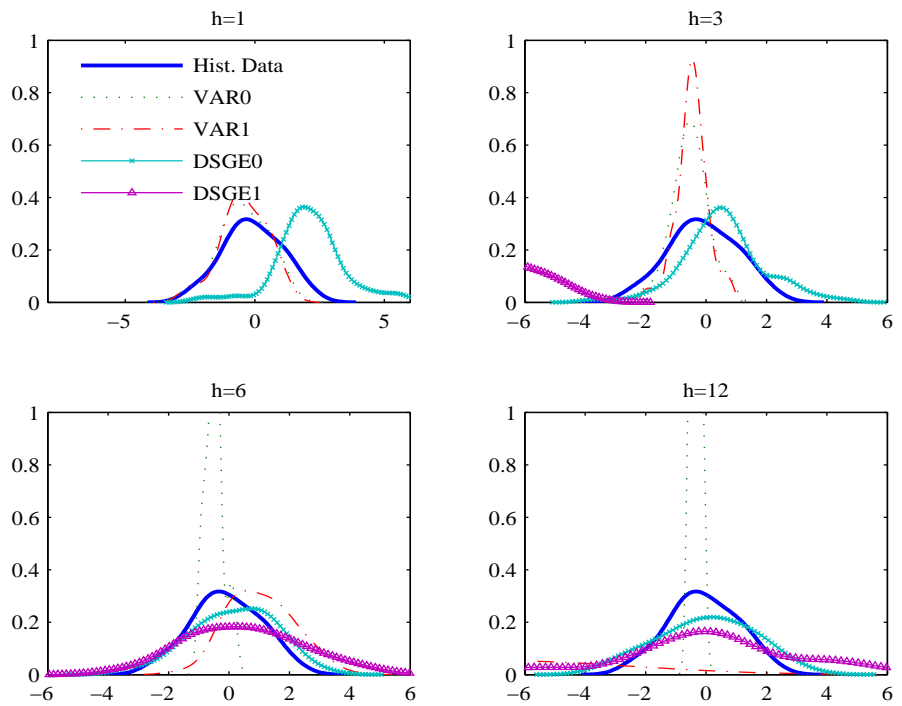

(b)
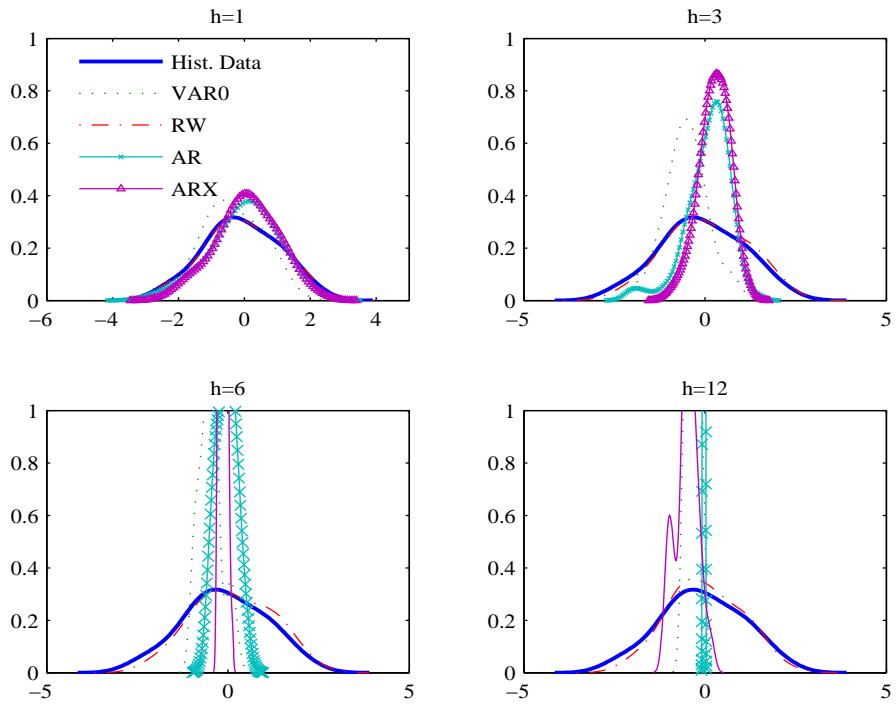

Notes: See notes to table C.3 
Figure C.12: Historical and Forecasted Empirical Densities of Output Estimation Period: 1960Q1:2009Q4 - Forecasting period 1990Q1:1999Q4

(a)
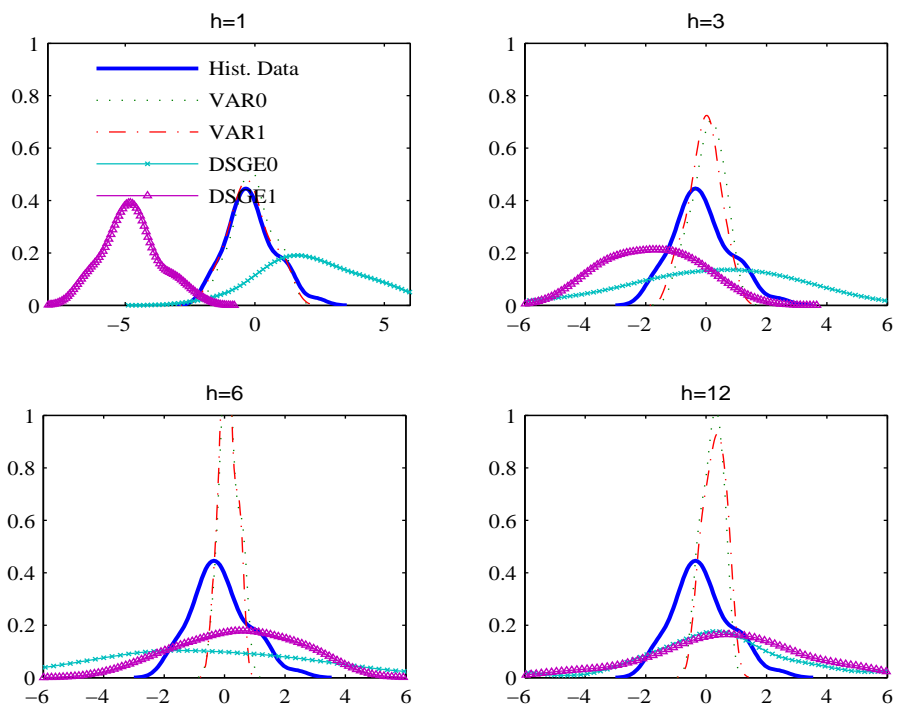

(b)
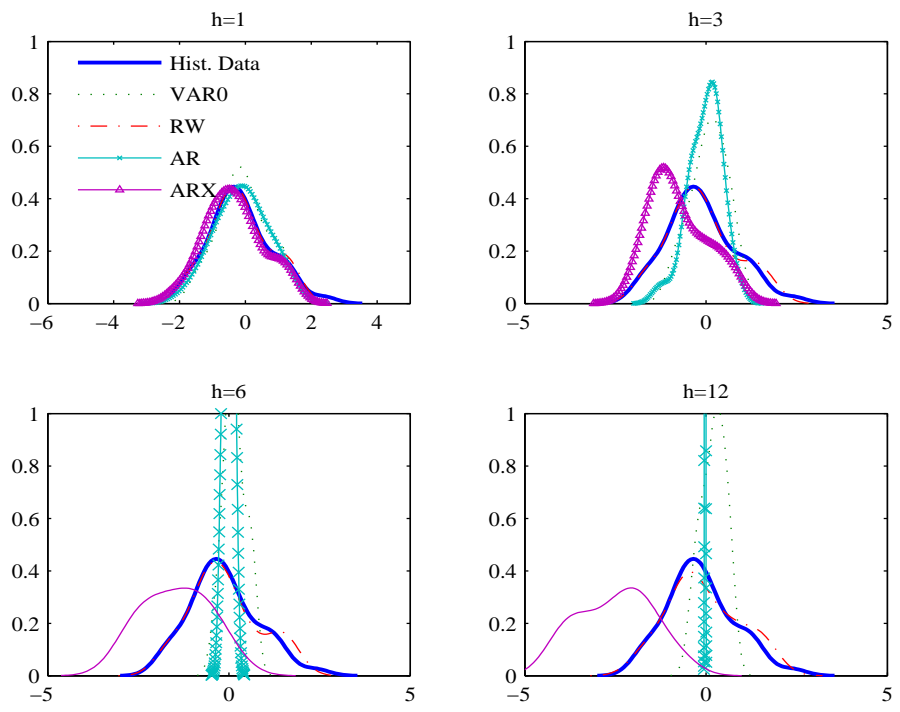

Notes: See notes to table C.3 
Figure C.13: Historical and Forecasted Empirical Densities of Output Estimation Period: 1960Q1:2009Q4 - Forecasting period 2000Q1:2009Q4

(a)
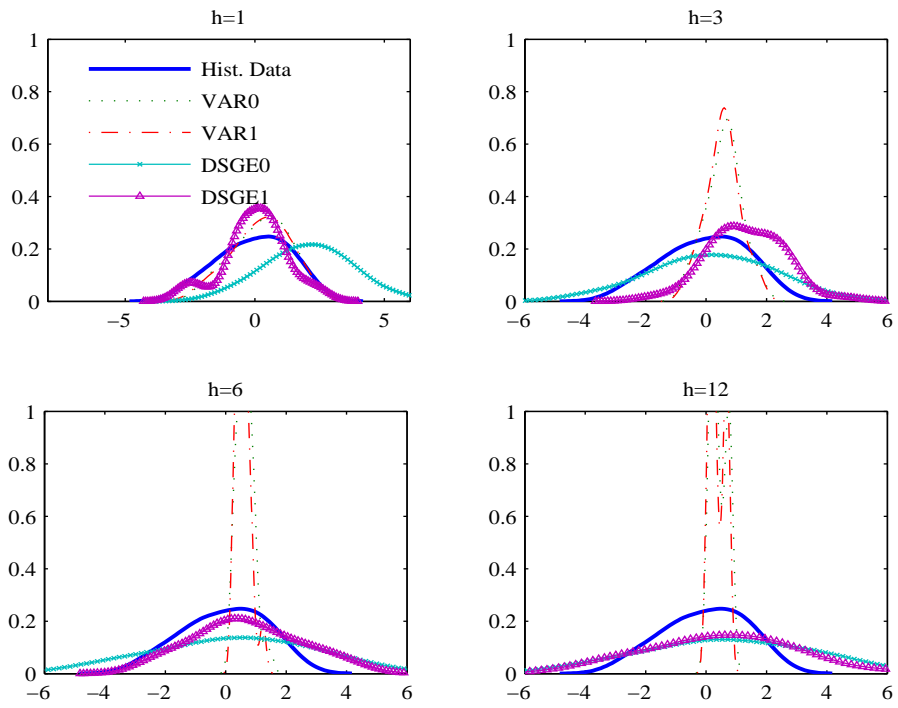

(b)
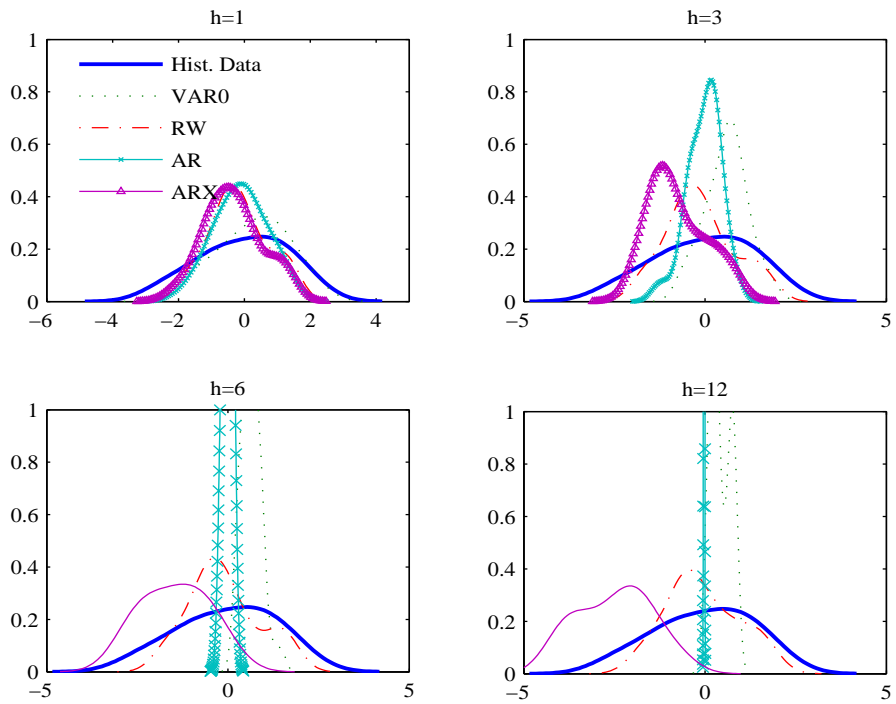

Notes: See notes to table C.3 
Figure C.14: Historical and Forecasted Empirical Densities of Output Estimation Period: 1960Q1:2009Q4 - Forecasting period 1990Q1:2009Q4

(a)
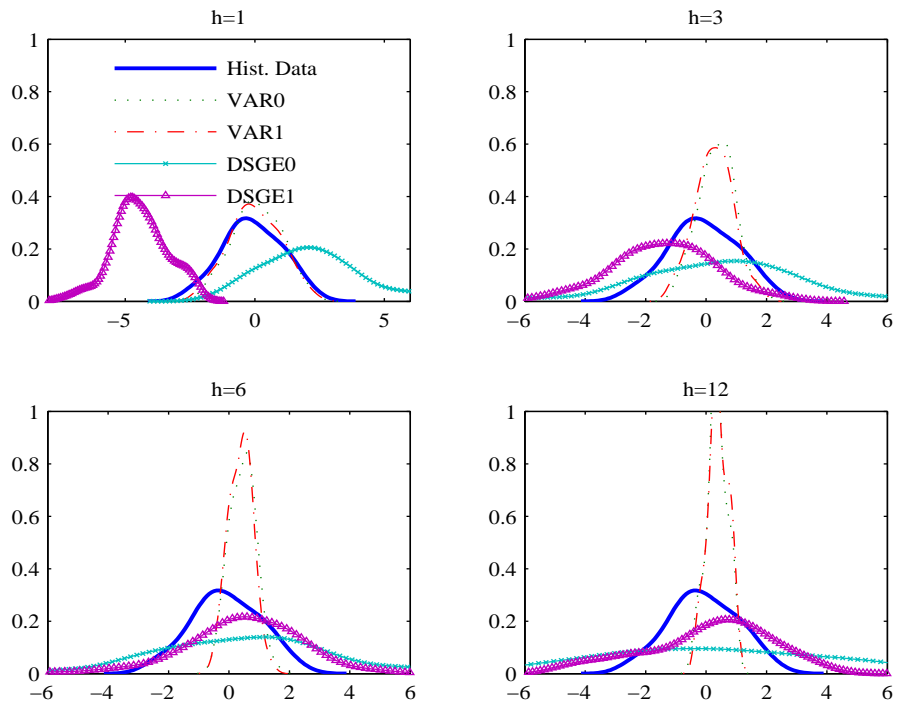

(b)
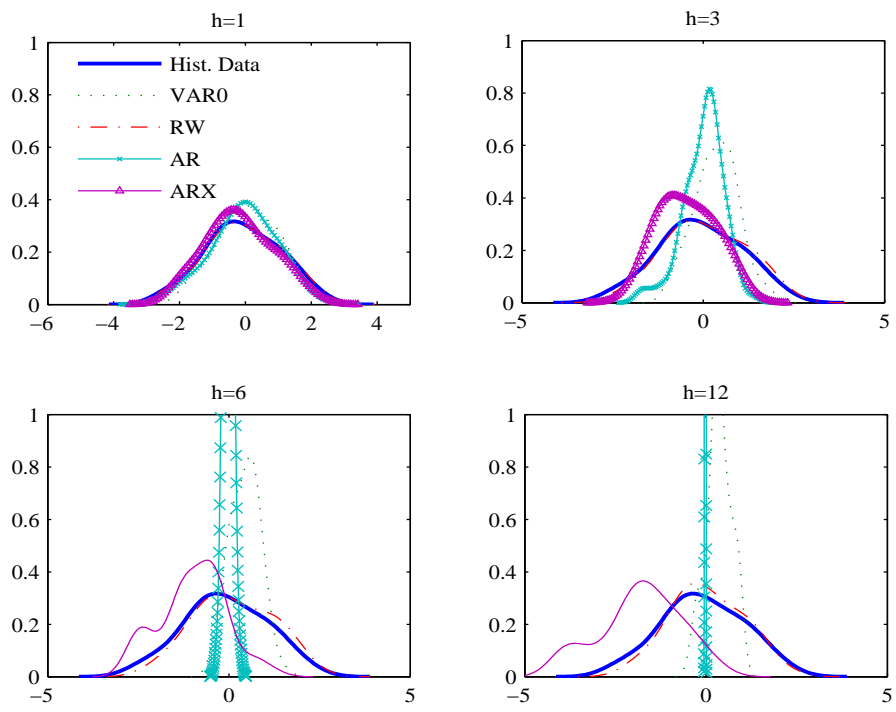

Notes: See notes to table C.3 
Figure C.15: Historical and Simulated Empirical Densities of Inflation and Output

(a)
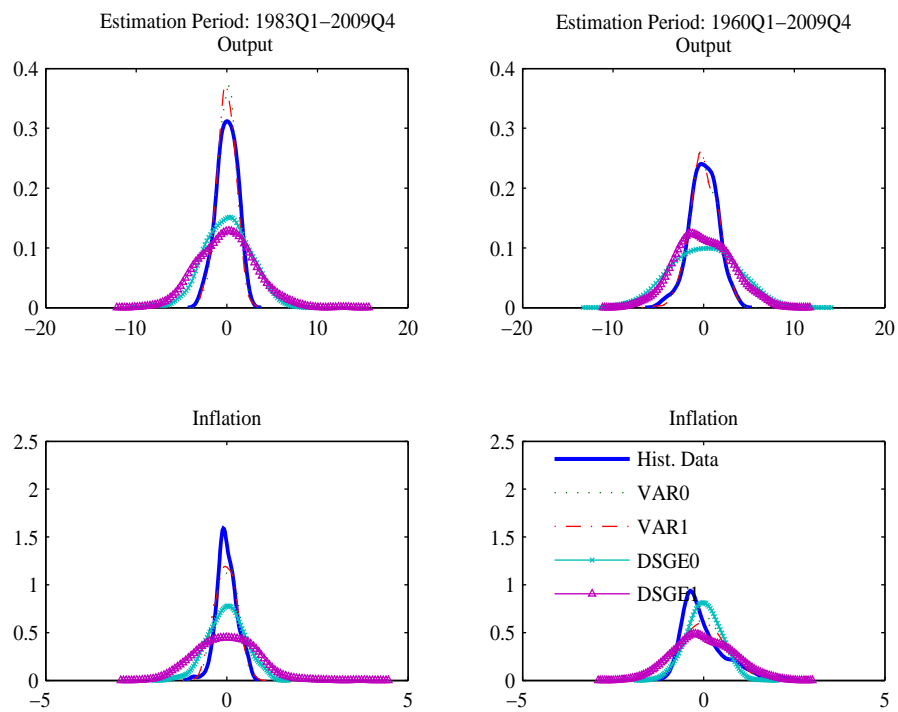

(b)
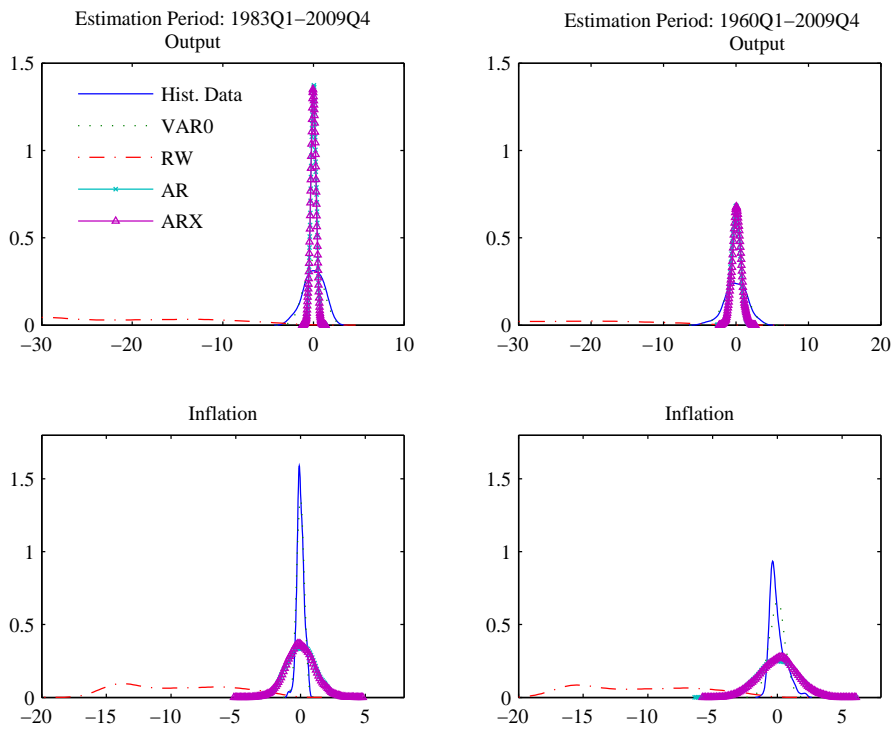

Notes: Figure C.15 displays empirical density plots for inflation and output simulations. RW is the random walk model without drift. $\mathrm{AR}$ is a univariate autoregressive model. ARX is an autregressive model for inflation including money growth. VAR0, VAR1, DSGE0 and DSGE1 are described in section 2.3. VAR0 is the three-variable vector autoregressive model without money growth. VAR1 includes money growth to VAR0. DSGE0 is the New Keynesian model with the monetary policy described as Taylor-type interest rate rule. DSGE1 is the New Keynesian model with the monetary policy described as exogenous money growth equation. 
Appendix D

Figures of Chapter 3 
Figure D.1: Monetary Policy Characteristics Inflation Targeting Countries

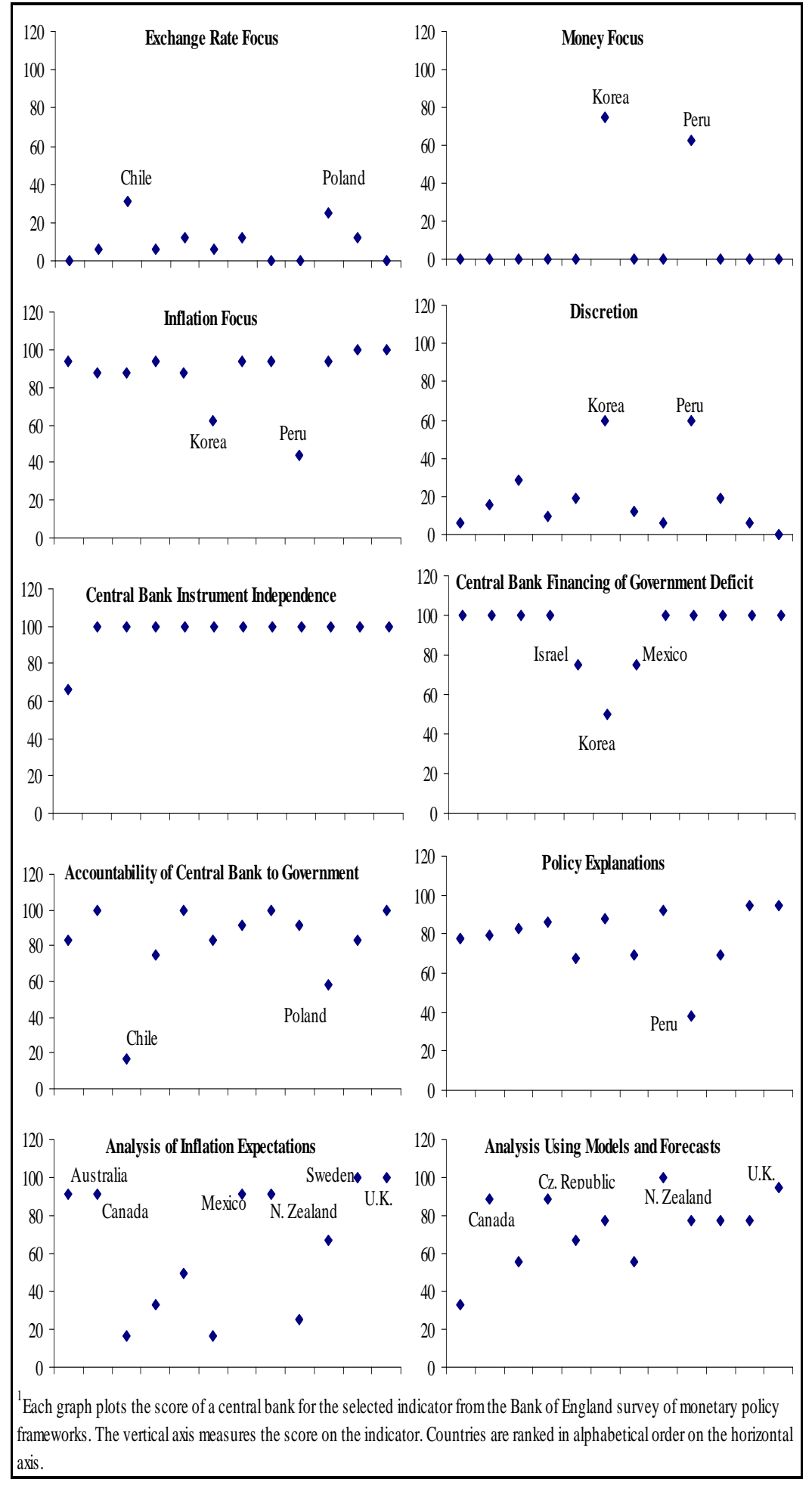


Figure D.2: Monetary Policy Characteristics Non-Inflation Targeting Countries

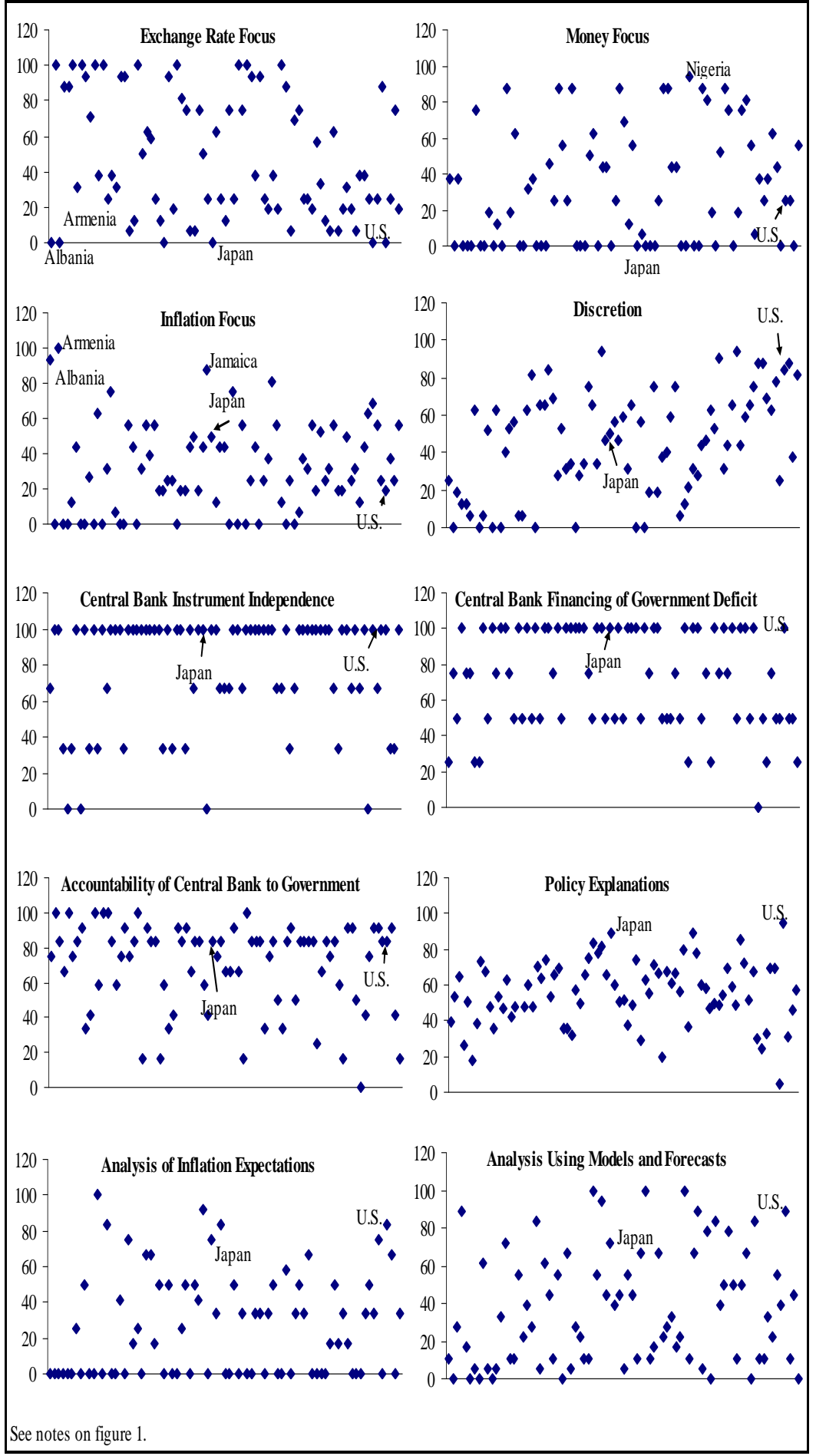


Figure D.3: Path of the Proxy for Monetary Policy Design
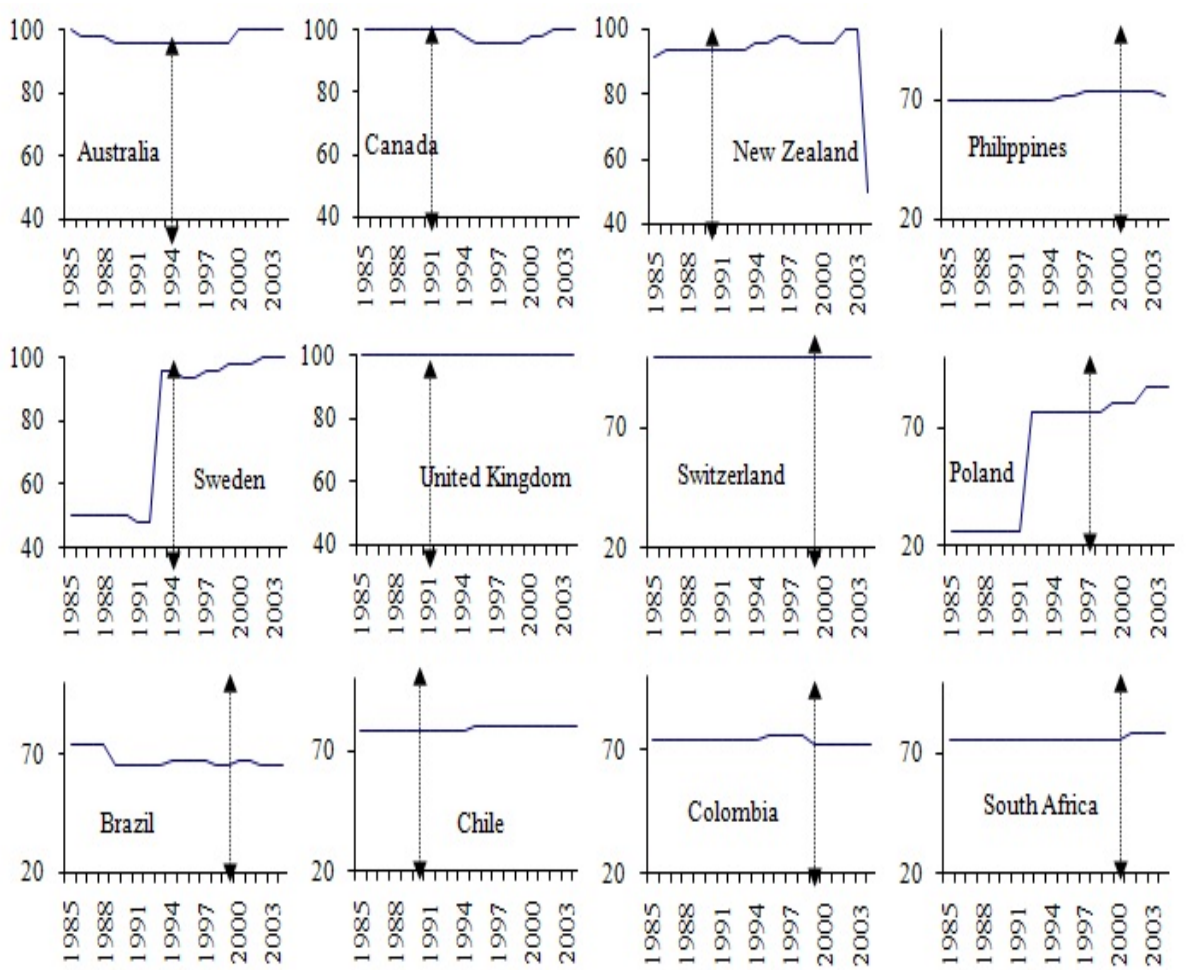

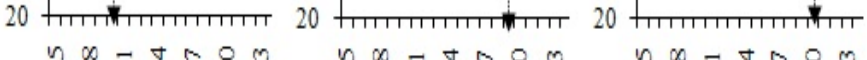

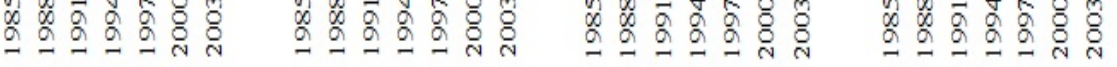
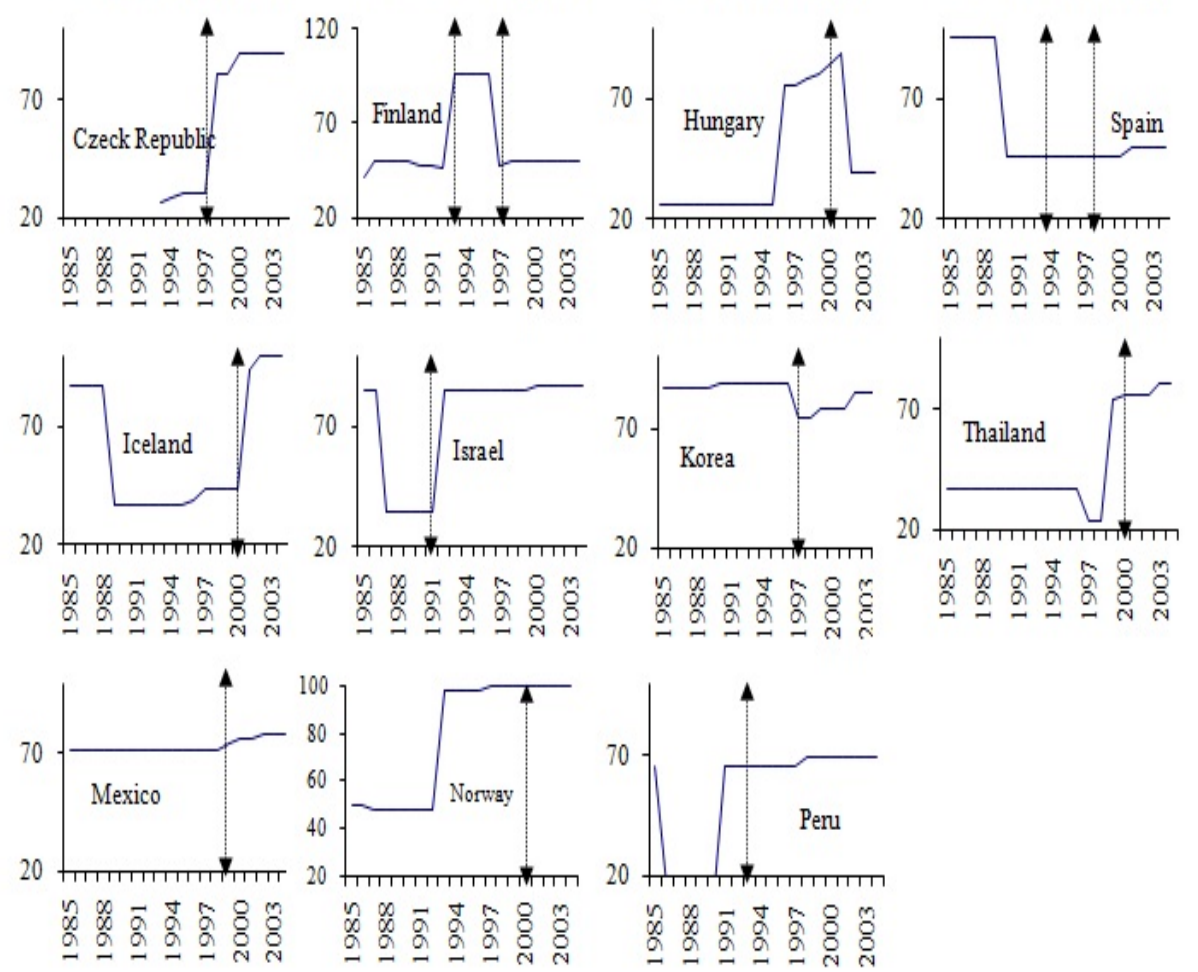
Figure D.4: Sacrifice Ratio and Inflation Persistence Statistics

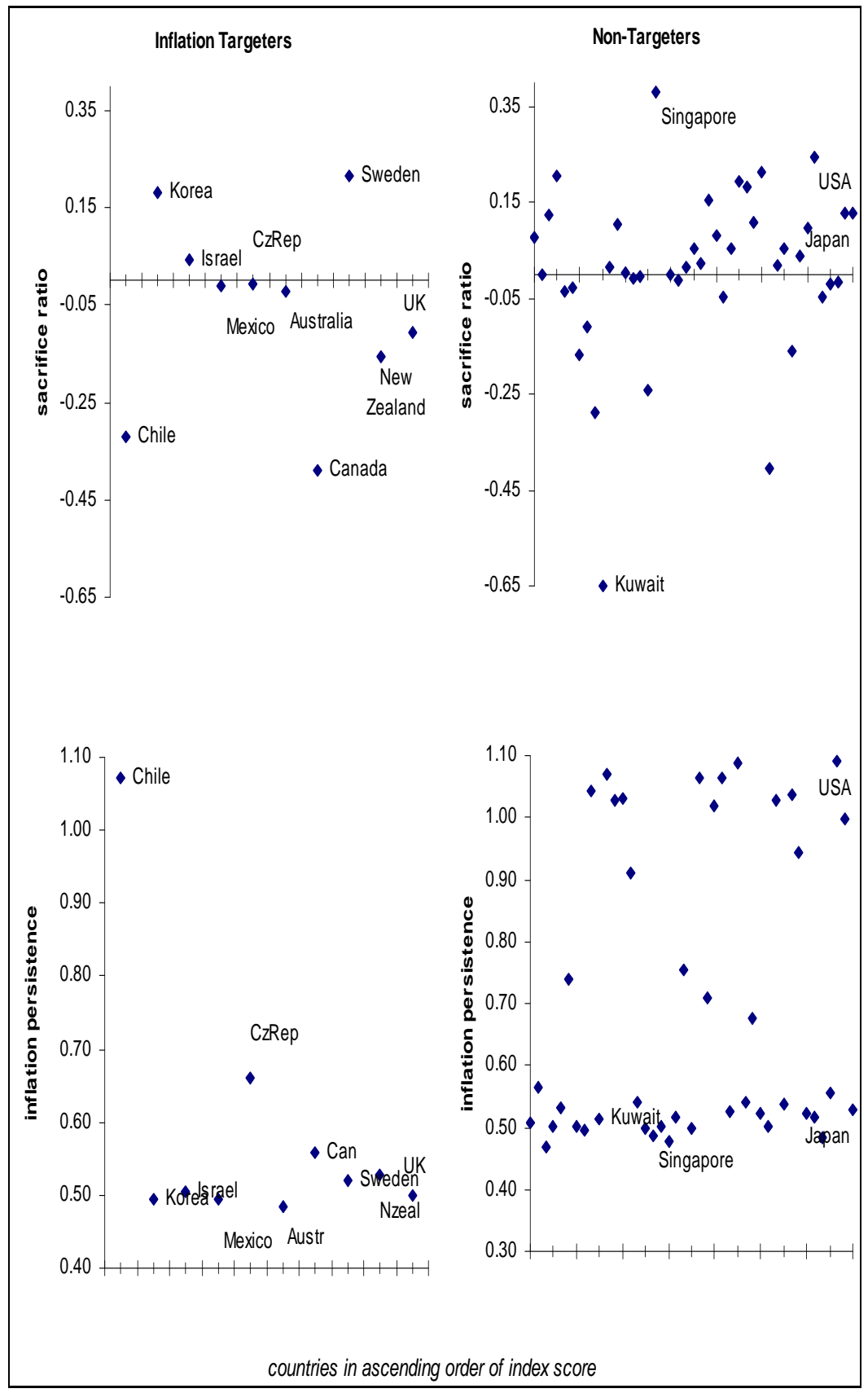


Figure D.5: $95 \%$ confidence interval for $\beta_{1,4}$

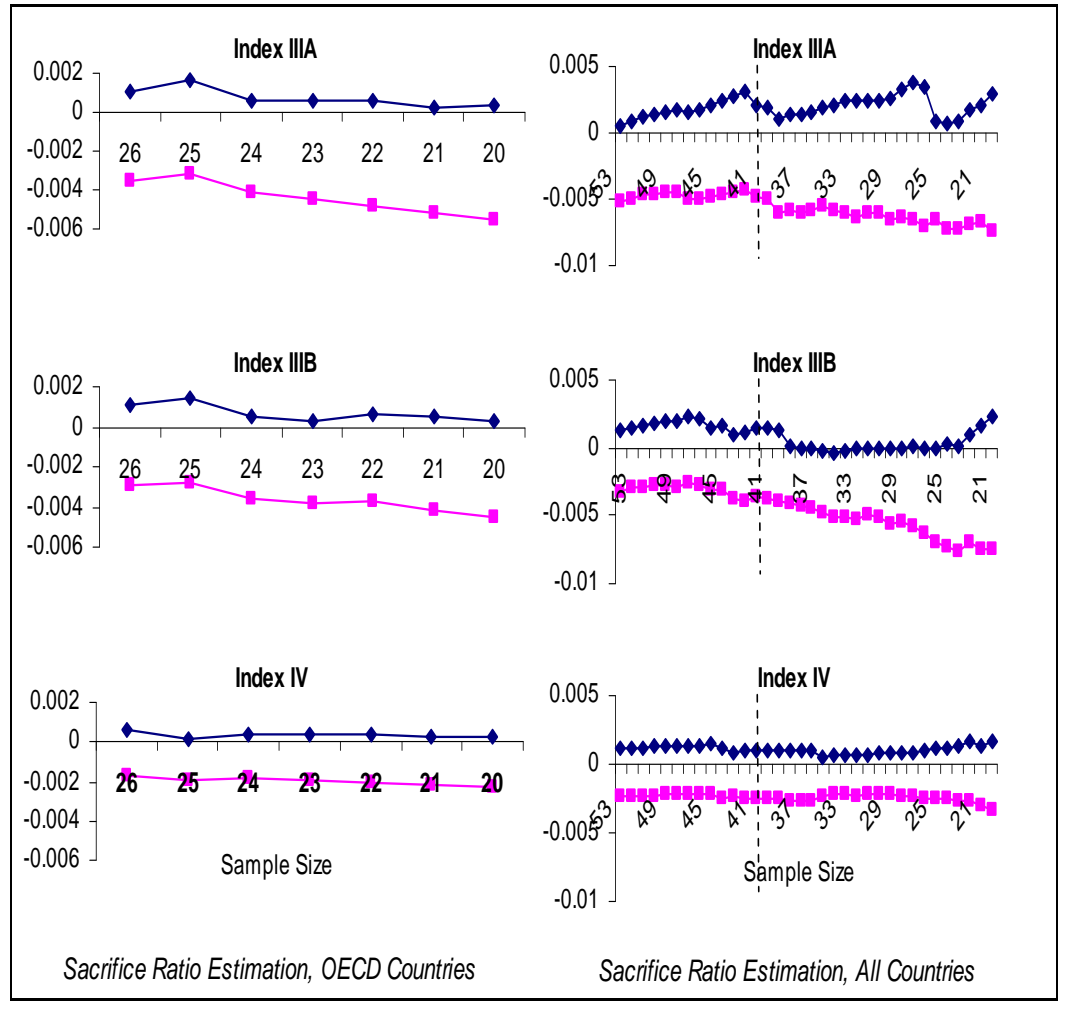


Figure D.6: 95\% confidence interval for $\alpha_{1,4}$

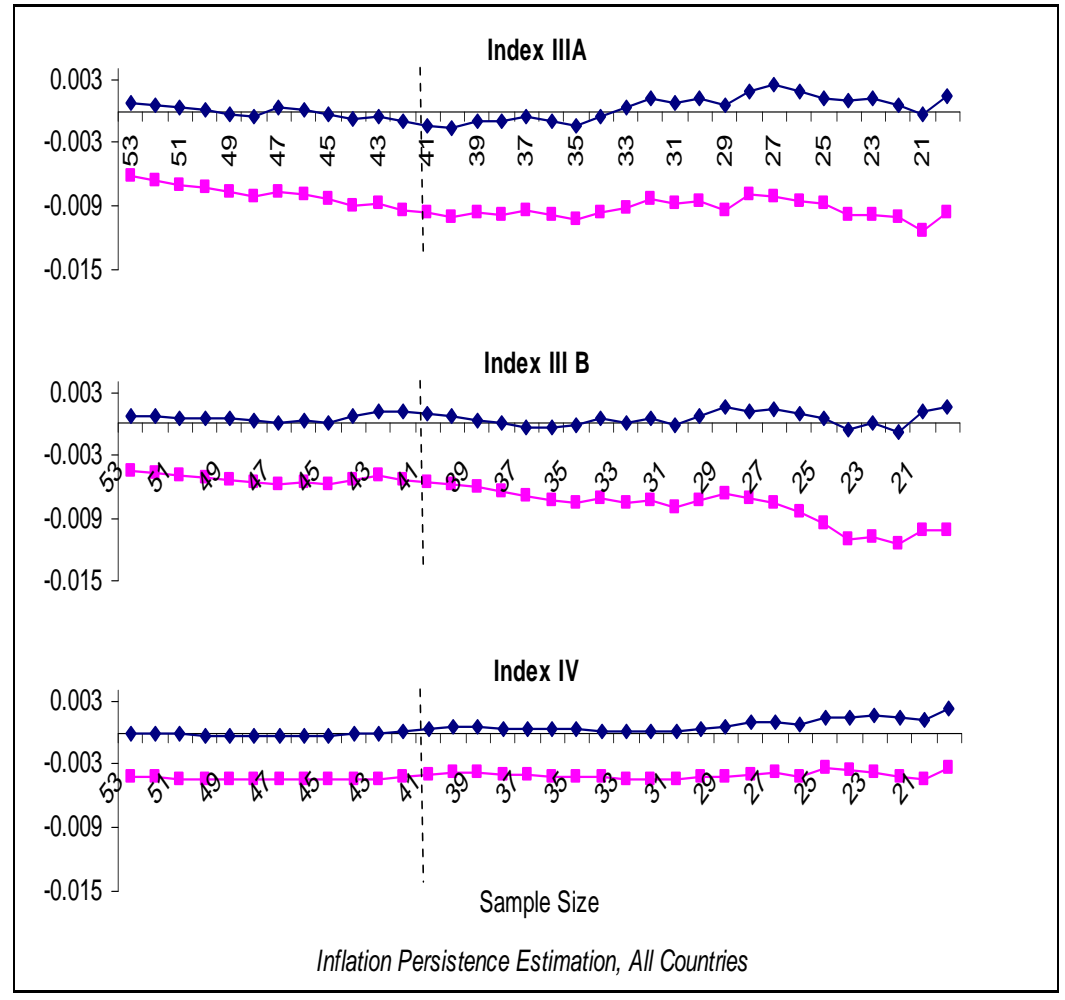




\section{Bibliography}

P. R. Agenor. Monetary policy under flexible exchange rates: An introduction to inflation targeting, 2001. Central Bank of Chile, Working Paper, No.124.

J. D. Amato and S. Gerlach. Inflation targeting in emerging market and transition economies: Lessons after a decade, 2002. CEPR Discussion Paper.

J. D. Amato and N. R. Swanson. The real-time predictive content of money for output, 2001. Working Paper No.96.

J. Andres, J. D. Lopez-Salido, and J. Valle. Money in an estimated business cycle model of the euro area. The Economic Journal, 116(116):457-477, 2006.

J. Andres, J. D. Lopez-Salido, and E. Nelson. Money and the natural rate of interest: Structural estimates for the united states and the euro area. Journal of Economic Dynamics and Control, $33(33): 758-776,2008$.

D. W. K. Andrews and C. Hong-Yuan. Approximately median-unbiased estimation of autoregressive models. Journal of Business and Economic Statistics, 12:187-204, 1994.

K. Assenmacher-Wesche and S. Gerlach. Money at low frequencies. Journal of the European Economic Association, 5(5):534-542, 2007.

L. Ball. What determines the sacrifice ratio?, pages 155-182. Monetary Policy. University of Chicago University Press, Chicago, 1993.

L. Ball, N., and Sheridan. Does inflation targeting matter, 2003. NBER Working Paper, No.9577.

E. Baltensperger and P. Kugler. Central bank independence and sacrifice ratios: Some further considerations. Open Economies Review, 11:111-125, 2000.

L. Benati. Investigating inflation persistence across monetary regimes, 2002. Manuscript, Bank of England.

B. S. Bernanke. Alternative explanations of the money-income correlation. Carnegie-Rochester Conference Series on Public Policy, 25(25):49-99, 1986.

B. S. Bernanke, T. Laubach, F. S. Mishkin, and A. Posen. Inflation Targeting: Lessons from the International Experience. Princeton University Press, Princeton, PA, 1999.

J. M. Binner, P. Tino, J. Tepper, R. Anderson, B. Jones, and G. Kendall. Does money matter in inflation forecasting? Physica A, (389):4793-4808, 2010.

A. S. Blinder, E. R. Canetti, D. Lebow, and J. B. Rudd. Asking About Prices: A New Approach to Understand Price Stickeness. New York: Russell Sage Foundation, 1998.

M. Bruno and J. Sachs. Economics of Worldwide Stagflation. Harvard University Press, Cambridge, Massachusetts, 1985.

G. A. Calvo. Staggered prices in a utility maximizing model. Journal of Monetary Economics, $12(12): 383-398,1983$.

A. Carare and M. Stone. Inflation targeting regimes. European Economic Review, (50):1297$1315,2006$.

E. Castelnuevo. Money and output in a new keynesian framework: Further evidence for the u.s., 2008. Manuscript, University of Padua. 
R. Chang. Financial crises and political crises. Journal of Monetary Economics, 54(8):24092420, 2007.

L. J. Christiano and L. Ljungqvist. Money does granger-cause output in bivariate money-output relation. Journal of Monetary Economics, (22):217-235, 1988.

R. Clarida, J. Gali, and M. Gertler. The science of monetary policy: A new keynesian perspective. Journal of Economic Literature, 37(4):1661-1707, 1999.

E. V. Clifton, L. Hyginus, and C. H. Wong. Inflation targeting and the unemployment-inflation trade-off. IMF Working Paper No.166.

V. Corbo, M. O. Landerretche, and K. Schmidt-Hebbel. Inflation targeting in latin america, 2001. Central Bank of Chile, Working Paper No.105.

V. Corbo, M. O. Landerretche, and K. Schmidt-Hebbel. Inflation Targeting: Design, Performance, Challenge. Central Bank of Chile: Santiago, Chile, 2002.

V. Corradi and N. R. Swanson. A test for comparing multiple misspecified conditional interval model. Econometric Theory, 21(21):991-1016, 2005.

V. Corradi and N. R. Swanson. Predictive density and conditional confidence interval accuracy. Journal of Econometrics, 135(135):187-228, 2006a.

V. Corradi and N. R. Swanson. Predictive density evaluation, 2006b.

V. Corradi and N. R. Swanson. Evaluation of dynamic stochastic general equilibrium models based on distributional comparison of simulated and historical data. Journal of Econometrics, 136(136):699-723, 2007a.

C. Cotarelli and C. Giannini. Credibility without rules: Monetary frameworks in the postbretton woods era, 1997. IMF Occasional Paper, No.154.

C. Crowe and E. E. Meade. Central bank independence and transparency: Evolution and effectiveness. IMF Working Paper, No.119.

J. P. Daniels, F. Nourzad, and D. D. Vanhoose. Openness, central bank independence and the sacrifice ratio. Journal of Money, Credit, and Banking, 37(2).

S. Edwards. The relationship between exchange rates and inflation targeting revisited, 2006. Central Bank of Chile, Working Paper No.409.

M. Eichenbaum and K. J. Singleton. Do equilibrium real business cycle theories explain postwar u.s. business cycle?, 1986. NBER Macroeconomics Annual.

A. Estrella and F. S. Mishkin. Is there a role for monetary aggregates in the conduct of monetary policy? Journal of Monetary Economics, (40):279-304, 1997.

G. Favara and P. Giordani. Reconsidering the role of money for output, prices and interest rates, 2002. Economics and Finance Working Paper No.514.

B. M. Feldstein and J. H. Stock. The Use of Monetary Aggregates to Target Nominal GDP, pages 7-70. Monetary Policy. University of Chicago Press, Chicago IL, 1993. NBER Working Paper.

P. H. Franses and H. Hans. The effects of additive outliers on tests for unit roots and cointegration. Journal of Business and Economic Statistics, 12:471-478, 1994.

B. M. Friedman and K. N. Kuttner. Money, income, prices and interest rates. American Economic Review, (82):474-492, 1992. 
M. D. J. Fry, L. Mahadeva, S. Roger, and G. Sterne. Monetary Frameworks in a Global Context. Bank of England, Routledge, London, 2000.

J. C. Fuhrer and G. R. Moore. Monetary policy trade-os and the correlation between nominal interest rates and real output. American Economic Review, (85):219-239, 1995.

G. Gadzinski and F. Orlandi. Inflation persistence in the european union, the euro area and the united states, 2004. European Central Bank working paper, No. 414.

J. Gali. New perspectives on monetary policy, inflation and business cycle, 2002. NBER Working Paper No.8767.

J. Gali. Monetary Policy, Inflation, and the Business Cycle:An Introduction to the New Keynesian Framework. Princeton University Press, Princeton, PA, 2008.

J. Gali and M. Gertler. Inflation dynamics: A structural econometric analysis. Journal of Monetary Economics, (44):195-222, 1999.

C. Gunter, A. Levin, and V. Wielanda. Data uncertainty and the role of money as an information variable for monetary policy. European Eco- nomic Review, (49):975-1006, 2005.

R. W. Hafer and A. M. Kutan. More evidence on the money-output relationship. Economic Inquiry, (35):48-54, 1997.

J. D. Hamilton. Time Series Analysis. Princeton University Press, Princeton, PA, 1994.

B. E. Hansen. The grid bootstrap and the autoregressive model. The Review of Economics and Statistics, 81:594-607, 1999.

D. Hauner, J. Jonas, and M. S. Kumar. Policy credibility and sovereign credit: The case of the new eu member states, 2007. IMF Working Paper No.1.

R. Hodrick and E. Prescott. Post-war us business cycles: An empirical investigation. Journal of Money, Credit and Banking, 29, 1997.

B. Hoffman. Do monetary indicators lead euro area inflation. Journal of International Money and Finance, (28):1165-1181, 2009.

M. Hutchinson and C. Walsh. The output inflation trade-off and central bank reform: Evidence from new zealand. Economic Journal, pages 703-725, 1988.

P. N. Ireland. Money's role in monetary business cycle. Journal of Money Credit and Banking, (36):969-983, 2004.

P. N. Ireland. Endogenous money or sticky prices. 2003, (50):1623-1648, Journal of Monetary Economics.

R. A. Johnson and D. W. Wichern. Applied Multivariate Statistical Analysis. Prentice Hall, New Jersey, 1992.

R. G. King, C. I. Plosser, J. H. Stock, and H. M. Watson. Stochastic trends and economic fluctuations. American Economic Review, (81):819-840, 1991.

K. N. Kuttner. Does inflation targeting work in emerging markets?, 2005. IMF World Economic Outlook, Chapter 4.

K. N. Kuttner and A. S. Posen. Beyond bipolar: A three-dimensional assessment of monetary frameworks. International Journal of Finance and Economics, 6(4):369-387, 2001.

F. Kydland and E. Prescott. Rules rather than discretion: The inconsistency of optimal plans. Journal of Political Economy, 83:473-491, 1977. 
E. M. Leeper and J. E. Roush. Putting 'm' back in monetary policy, 2003. Board of Governors of the Federal Reserve System International Finance Discussion Papers No.761.

E. M. Leeper and T. Zha. Assessing simple rules: A view from a complete macro model, 2000. FRB of Atlanta Working Paper No.19.

L. Leiderman and L. E. O. Svensson. Inflation Targets. CEPR, London, 1995. Chapter 1.

A. T. Levin, F. M. Natalucci, and J. M. Piger. The macroeconomic effects of inflation targeting, 2004. Federal Reserve Bank of St. Louis Review 86(4).

R. B. Litterman and L. Weiss. Money, real interest rates and output: A reinterpretation of postwar u.s. data. Econometrica, (53):129-156, 1985.

A. Maddison. Historical series for the world economy: 1-2003 ad, 2007. www.ggdc.net/maddison/.

N. G. Mankiw and L. H. Summers. Money demand and the effects of fiscal policies. Journal of Money, Credit and Banking, (18):415-429, 1986.

C. R. Marques. Inflation persistence: Facts or artefacts, 2004. European Central Bank working paper, no.371.

P. Masson, M. A. Savastano, and S. Sharma. The scope for inflation targeting in developing economies, 1997. IMF Working Paper, No.130.

B. T. Mc.Callum and E. Nelson. An optimizing is-lm specification for monetary policy and business cycle analysis. Journal of Money Credit and Banking, (31):296-316, 1999.

A. H. Meltzer. The transmission process, 1999. mimeo, Carnegie Mellon University.

F. S. Mishkin. Inflation targeting for emerging market economies. American Economic Review, (90):105-109, 2000.

F. S. Mishkin and K. Schmidt-Hebbel. Does inflation targeting make a difference?, 2006. Central Bank of Chile, Working Paper No.404.

E. Nelson. Direct effects of base money on aggregate demand: Theory and evidence. Journal of Monetary Economics, (49):687-708, 2002.

G. O'Reilly and K. Whelan. Has euro area inflation persistence changed over time? The Review of Economics and Statistics, 87(4):709-720, 2004.

D. Polotis and J. Romano. The stationary bootsrap. Journal of American Statistical Association, (89):1303-1313, 1994.

A. Posen. Central bank independence and disinflationary credibility: A missing link, 1998. Oxford Economic Review, No.50.

S. Reynard. Money and the great disinflation, 2009. Swiss National Bank Working Paper No.2006-7.

J. J. Rotemberg and M. Woodford. An optimization-based econometric framework for the evaluation of monetary policy: Expanded version, 1998. NBER Working Paper No.233.

G. D. Rudebusch and L. E. O. Svensson. European monetary targeting: Lessons from u.s. data. European Economic Review, (46):417-442, 2002.

T. J. Sargent. The Ends of Four Big Inflations. Inflation: Causes and Effects. University of Chicago Press, Chicago, 1999. 
P. L. Siklos. Inflation-target design: Changing inflation performance and persistence in industrial countries, 1991. Federal Reserve Bank of St. Louis Review, No.81.

C. A. Sims. Comparison of interwar and postwar cycles: Monetarism reconsidered. American Economic Review, (70):250-257, 1980.

C. A. Sims. Solving linear rational expectations models. Journal of Computational Economics, (20):1-20, 2001.

F. Smets and R. Wouters. An estimated dynamic stochastic general equilibrium model of the euro area. Journal of the European Eco- nomic Association, (5):1123-1175, 2003.

J. H. Stock. Confidence intervals for the largest autoregressive root in u.s. macroeconomic time series. Journal of Monetary Economics, 28(3):435-459, 1991.

J. H. Stock and M. W. Watson. Interpreting the evidence on money-income causality. Journal of Econometrics, (40):161-181, 1989.

J. H. Stock and M. W. Watson. A simple estimator of cointegrating vectors in higher order integrated systems. Econometrica, (61):783-820, 1993.

J. H. Stock and M. W. Watson. Forecasting inflation. Journal of Monetary Economics, (44): 293-335, 1999.

L. E. O. Svensson. Inflation forecast targeting: Implementing and monitoring inflation targets. European Economic Review, (41):1111-1146, 1997a.

L. E. O. Svensson. Optimal inflation targets, 'conservative' central banks, and linear inflation contracts. American Economic Review, pages 98-114, 2001.

L. EO Svensson. Inflation targeting: Some extensions. Scandinavian Journal of Economics, (101):337-361, 1999.

L. O. E. Svensson. Inflation forecast targeting: Implementing and monitoring inflation targets. European Economic Review, (41):1111-1146, 1997b.

N. R. Swanson. Money and output viewed through a rolling window. Journal of Monetary Economics, (41):445-473, 1998.

E. M. Truman. Inflation Targeting in the World Economy. Peterson Institute, Washington D.C., 2003.

H. White. A reality check for data snooping. Econometrica, (68):1097-1126, 2000.

M. Woodford. Inflation targeting and optimal monetary policy, 2003a. Federal Reserve Bank of St. Louis Review.

M. Woodford. Interest and Prices: Foundations of a Theory of Monetary Policy. Princeton University Press, 2003b.

T. Wu. Does inflation targeting reduce inflation? an analysis for the oecd industrial countries. Banco Central de Brazil, Working Paper No.83. 


\section{Vita}

\section{Demet Tunali}

2004-2012 Ph. D. in Economics, Rutgers University, USA

2002-2004 Assistant Economist, Global Securities Research Department, Turkey

2001-2002 M. Sc. in Economics, Katholieke Universiteit Leuven, Belgium

1996-2001 B. A. in Economics, Bogazici University, Turkey

2005-2009 Teaching Assistant, Department of Economics, Rutgers University

2006-2008 Part-time lecturer, Department of Economics, Rutgers University

2004-2005 Graduate School Fellowship, Rutgers University 